$$
\angle A-S U B--94-183
$$

\title{
Corrosion and Failure Processes in High-Level Waste Tanks
}

by

Rao K. Mahidhara

Thomas S. Elleman

K. Linga Murty

North Carolina State University

Raleigh NC 27695-7909

Report prepared for

Los Alamos National Laboratory

Contract No. 9-XQ-Y3122-1

November 20, 1992

DISTRIBUTION OF THIS DOCUMENT IS UNLIMTED

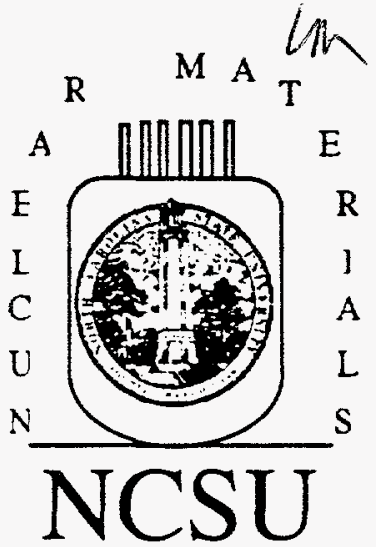




\section{DISCLAIMER}

This report was prepared as an account of work sponsored by an agency of the United States Government. Neither the United States Government nor any agency thereof, nor any of their employees, make any warranty, express or implied, or assumes any legal liability or responsibility for the accuracy, completeness, or usefulness of any information, apparatus, product, or process disclosed, or represents that its use would not infringe privately owned rights. Reference herein to any specific commercial product, process, or service by trade name, trademark, manufacturer, or otherwise does not necessarily constitute or imply its endorsement, recommendation, or favoring by the United States Government or any agency thereof. The views and opinions of authors expressed herein do not necessarily state or reflect those of the United States Government or any agency thereof. 


\section{DISCLAMMER}

Portions of this document may be illegible in electronic image products. Images are produced from the best available original document. 


\begin{abstract}
A large amount of radioactive waste has been stored safely at the Savannah River and Hanford sites over the past 46 years. The aim of this report is to review the experimental corrosion studies at Savannah River and Hanford with the intention of identifying the types and rates of corrosion encountered and indicate how these data contribute to tank failure predictions. The compositions of the High-Level Wastes, mild steels used in the construction of the waste tanks and degradation-modes particularly stress corrosion cracking and pitting are discussed. Current concerns at the Hanford Site are highlighted.
\end{abstract}




\section{Contents}

1 INTRODUCTION 1

2 BACKGROUND 1

2.1 Radioactive Wastes .................. 1

2.2 Chemical Composition of High Level Radioactive Wastes 3

2.3 Waste storage tanks ................... 4

3 TANK FAILURE PROCESSES 6

4 FAILURE MODELS

5 CORROSION STUDIES

5.1 Work at Savannah River Site . . . . . . . . . . . 12

5.1.1 Stress Corrosion Cracking .............. 13

5.1.2 Pitting Corrosion .................. 21

5.2 Work at Hanford Site ................. 21

5.2.1 Stress Corrosion Cracking .............. 21

5.2.2 Pitting Corrosion .................... 22

5.2.3 Modeling Work. .................. 24

6 CURRENT CONCERNS AT HANFORD SITE 26

7 SUMMARY AND CONCLUSIONS 28

8 REFERENCES $\quad 29$ 


\section{List of Figures}

1 Typical Single Shell Storage Tank [9]. . . . . . . . . . . 5

2 Typical Double Shell Storage Tank [9]. . . . . . . . . . 6

3 Schematic of Processes that Cause Stress Corrosion Cracking. 14

4 Intergranular Cracking Associated with Nitrate SCC in A 285-B Steel. . . . . . . . . . . . . . . . . . . 16

5 Crack in A 285-B Steel Tank at Savannah River Plant. . . . . 17

6 Effects of nitrite concentration and potential on the reduction in area to fracture C-Mn mild steel specimens in boiling $8 M$ $\mathrm{KMnO}_{3}$ solution by slow strain rate testing [45]. . . . . . 


\section{List of Tables}

1 Typical Double Shell Slurry Composition Range [2] . . . . 3

2 Compositions of the Mild Steels Used For Construction Of Tank (in $\%) \ldots \ldots \ldots \ldots \ldots \ldots \ldots \ldots$ 


\section{INTRODUCTION}

The Hanford Site in south-central Washington State has been a major U.S Governmental facility for the research, development and production of nuclear weapons since the 1940s [1]. Construction of the Hanford facility began in 1943 under the direction of the US Army Corps of Engineers. Today, its nuclear material production mission is drawing to a close, and the major mission is waste management and environmental restoration.

This paper describes one area of waste management: the storage of radioactive waste in underground tanks. Large underground storage tanks have been the central waste management facilities at the Hanford Site. The liquid radioactive wastes resulting from chemically processing nuclear reactor spent fuel to recover the plutonium and uranium have been neutralized and sent to these tanks for the past 46 years. Liquid wastes from other processes, laboratories, and reactor decontamination solutions have also been sent to the tanks. Also, the wastes have been concentrated, selected radioisotopes removed, and the different waste types intermingled.

This large volume of multiple waste types, much of it is stored in old facilities, poses a challenging waste management issue to the nuclear industry. Those involved have been particularly conscious of the possible hazards associated with the radioactive materials. Extremely high standards of protection of individuals have been instituted. The management of radioactive waste, which for the first 20 years or so of the nuclear age was regarded as a matter of good housekeeping, has now broadened almost into a discipline in its own right, embracing subjects as diverse as radiation biology, corrosion, chemical engineering, and computer modeling. In addition to the Hanford Site the wastes have also been stored in the form of liquids, solids or sludges at the Savannah River Plant (SRP) at Aiken, South Carolina, and at the Idaho Chemical Processing Plant (ICPP) at Idaho Falls, Idaho in low carbon steel and stainless steel tanks, respectively. However, both the Savannah River and Hanford Sites together, hold the majority of the wastes.

\section{BACKGROUND}

\section{$2.1 \quad$ Radioactive Wastes}

Hanford Defense Waste is a complex chemical system [2]. The high-level waste has been accumulated over a 40 year period as the principal waste material 
resulting from production of plutonium for the defense program. While the waste contains large amounts of radioactive material, the bulk of the waste consists of nonradioactive chemicals that were used in the separation of the nuclear material. The wastes were generated in the following sequence of operations.

Fuel elements, consisting of metallic uranium in corrosion-resistant jackets, were irradiated in water-cooled, graphite-moderated production reactors. The irradiated fuel elements after discharge were stored under water for several months to allow short-lived fission products, particularly I-131, to decay to suitable levels before processing. The spent fuel was then transported in shielded containers from the reactor areas to the 200-Area reprocessing plants where the jackets were removed with sodium hydroxide, and the irradiated uranium and other components were dissolved in nitric acid. By an initial separation of plutonium and uranium from the bulk of the fission products, a nitric acid solution of the fission products were obtained; this solution was combined with other fission-product streams from the further purification of the plutonium and uranium. The combined fission-product solution was partially stripped of nitric acid and neutralized with sodium hydroxide or sodium carbonate. The resulting slurry of alkaline liquor and precipitated hydroxides and carbonates was transferred to the 200-Area waste tank farm storage.

The high level wastes have been produced by a number of different chemical separation processes. The original war-time plant used the bismuth phosphate process, which separated only the plutonium (as a co-precipitate with bismuth phosphate), and the alkaline high-level wastes contained all of the uranium as well as the fission products.

Near the end of World War II, an improved method of separating and purifying plutonium and uranium from irradiated reactor fuel was developed by the Metallurgical Laboratory of the Manhattan Project. This process, known as the Redox Process, made use of the counter-current extraction with the aliphatic ketone combined with control of the oxidation states of plutonium to effect the separation of plutonium and uranium from the fission products and the subsequent separation of the two elements from each other. The Redox process began production at Hanford in 1951 and continued in operation until mid-1967 [2].

A principal disadvantage of the Redox process [2] was the volatile and inflammable nature of the ketone solvent. When additional chemical reprocessing capacity was needed in the mid-1950s, the Redox process was replaced by another solvent extraction method which used a high-boiling, high flash-point solvent, and which produced substantially lower volume of waste. Known as 
the Purex Process, this method is now used world-wide in fuel reprocessing plants. Purex operations began at Hanford in 1955 and continued until 1972, when the plant was placed on standby to await build-up of a backlog of spent fuel from the nuclear reactor [3].

\subsection{Chemical Composition of High Level Radioactive Wastes}

High-level wastes from the various separation processes have been mixed, and therefore the composition is not uniform from tank to tank. Nitrate is the major anion, but nitrite from hydrolysis of nitrate is a major component after aging and evaporation. The relative amount of hydroxide in solution has increased because of the difficulty of crystallizing $\mathrm{NaOH}$ [4-6]. In general, high-level wastes consist of sodium salts such as nitrate, nitrite, carbonate, aluminate, and small amounts of the hydrous oxides of iron and manganese [7]. These salts are distributed between an aqueous supernatant liquid and a solid, ill-defined precipitate or sludge. The High-Level Wastes from the recovery of plutonium and uranium are primarily alkaline nitrate solutions that contain many radioactive and non-radioactive components. An approximate average overall composition of the sodium salts is given in Table 1 [2].

Table 1: Typical Double Shell Slurry Composition Range [2]

$$
\begin{array}{lr}
\text { ANION/ } & \text { COMPOSITION } \\
\text { COMPOUND } & \text { Range (MOLARITY) }
\end{array}
$$

$\begin{array}{lr}\mathrm{OH}^{-} & 0.5-10.0 \\ \mathrm{NO}_{3}^{-} & 1.0-8.0 \\ \mathrm{NO}_{2}^{-} & 0.2-10.0 \\ \mathrm{AlO}_{2}^{-} & 0.0-5.0 \\ \mathrm{CO}_{3}^{-} & 0.2-0.25 \\ \mathrm{PO}_{4}^{3-} & 0.0-2.0 \\ \mathrm{EDTA} / \mathrm{HEDTA} & 0.0-1.0 \\ \mathrm{Citrate} & 0.0-0.6 \\ \mathrm{SO}_{4}^{2-} & 0.05\end{array}$

In addition, the high-level wastes contain fission-product radionuclides and actinide elements, such as uranium, plutonium and neptunium. Small quantities of organic matter, (for example entrained extraction solvent) which are primar- 
ily long-chained hydrocarbons have occasionally been part of liquid wastes. In the presence of intense radiation from high-level wastes, such organic matter is rapidly and completely destroyed by radiolysis to give largely carbon-dioxide which combines with sodium hydroxide of the wastes and water. Thus the organic content of the aged high-level wastes is reduced below detectable limits sometimes.

\subsection{Waste storage tanks}

The Hanford high-level radioactive waste, after neutralization with aqueous sodium hydroxide, is stored in underground storage tanks constructed of reinforced concrete containing a mild steel liner. This decision was based in part on results of laboratory corrosion studies conducted by the Clinton Laboratory [8].

Hanford Site tanks are of two types called single-shell tanks (Figure 1) and double-shell tanks (Figure 2). They are located in clusters called tank farms [9-12]. Single-shell tanks, 149 in number, range in size from a 210-cubic-meter to a 3,800-cubic-meter capacity and were constructed between 1943 and 1964 . The tanks are constructed of reinforced concrete with a carbon steel liner and a soil overburden of 2.4 meters. The tanks are equipped with monitoring instrumentation for waste level and temperature. Sixty-six tanks have leaked an estimated 2,800 cubic meters of liquid. In the mid-1970s, commitment was made to deactivate the 149 tanks and store the high-level liquid waste in double-shell tanks. The goal was met in November 1980. Various evaporative techniques have been used since 1950 to reduce the volume of the liquid waste and to ultimately allow storage in the double-shell storage tanks which currently store 140,000 cubic meters of sludge (which consists of solids of hydrous metal oxides precipitated from the neutralization of acid waste), saltcake (which consists of various salts formed from evaporation of water in the tanks), and liquids (which exist as supernatant and interstitial liquid). The radionuclide content is approximately 160 million curies, mostly cesium-137 and strontium-90.

Twenty-eight double-shell tanks, ranging from a 3,800- to a 4,300-cubic-meter capacity, were constructed between 1968 and 1986. These tanks are tankwithin-a-tank. The primary (inner) tank is constructed of carbon steel that was heated to relieve the weld stresses after construction. The primary tank is located within a reinforced concrete and a steel lined outer tank with a 76centimeter-wide annular space between them. The high-heat tanks are cooled by allowing the wastes to boil, condensing the steam, and returning the con- 


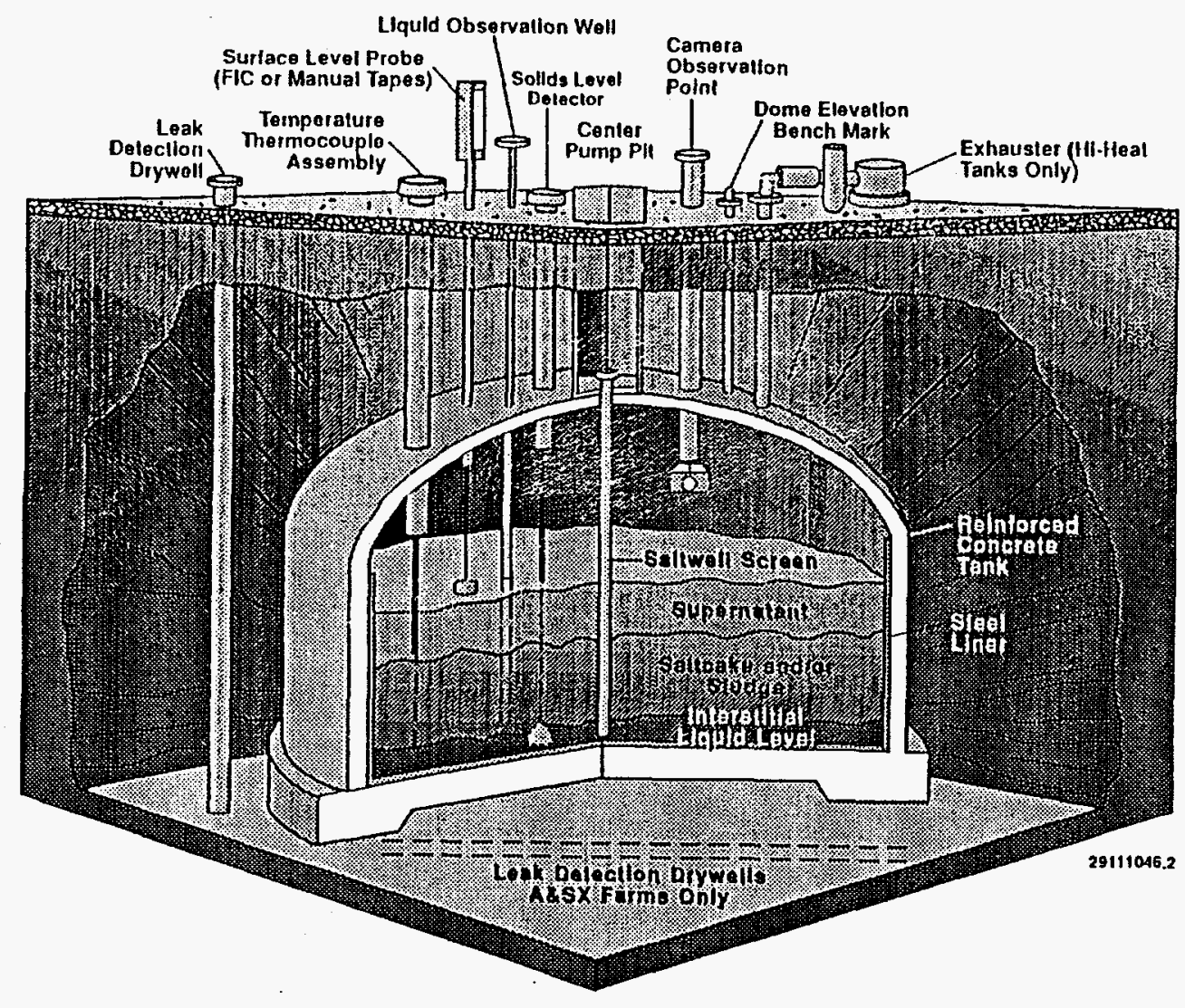

Figure 1: Typical Single Shell Storage Tank [9].

densate to the tanks. Tanks with less heat are cooled by the air flow through the tank annulus between the primary and secondary tanks and through the primary tank vapor space. The tanks are equipped with automatic monitoring systems. Pumpable interstitial liquid and supernatant wastes have been removed from single-shell tanks and transferred to double-shell tanks. The double-shell tanks were placed into service beginning in 1971. The sides and bottom of all the tanks are lined with mild steel plate welded to form a seamless inner steel container which acts as a leak-tight barrier protecting the concrete from attack by caustic wastes. None of the double shell tanks at Hanford have leaked. There are currently more than 7,600 cubic meters of waste containing 110 million curies stored in these tanks. 


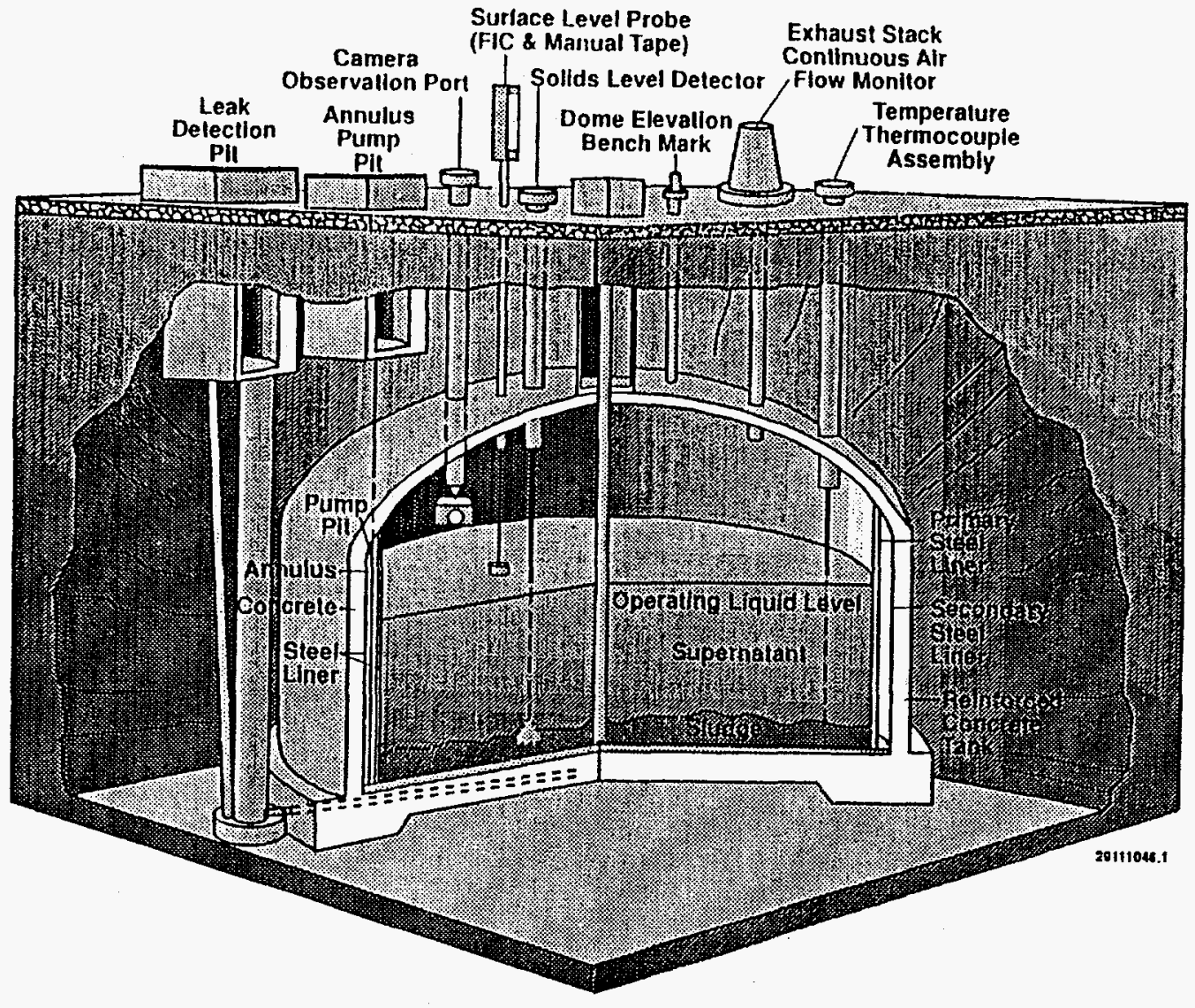

Figure 2: Typical Double Shell Storage Tank [9].

\section{TANK FAILURE PROCESSES}

Based upon analysis of liquid level history, test well radiation profiles and soil sampling and analyses, Tank 241-BX-102 has been confirmed as the first case of a leaking tank in Hanford Site. The most probable explanation of the Tank $102-\mathrm{BX}$ is as follows [13]:

1. The concrete shell of Tank 102-BX was breached on its southeast edge near the tank footing, approximately 40 feet below grade.

2. The carbon steel liner failed approximately two feet from the tank bottom. Pit corrosion caused by a static tank liquid level for more than five years is thought to be the cause of liner failure. 
The Tank 102-BX leaked approximately 70,000 gallon of waste into the ground, amounting to a loss of no more than $51 \mathrm{KCi}$ of $\mathrm{Cs}^{137}$.

At Savannah River Plant, waste that is evolving appreciable fission product heat is stored in water-cooled carbon steel tanks. Four of these tanks are known to have leaked [14]. The leaks were seen to occur near, but usually not on, the welds and the leaks tended to seal themselves due to accumulation of salts. Examination of several leaking sites using remote equipment and of samples taken from tank wall showed many cracks. These cracks were presumed [14] to have arisen from chemical action of waste on steel under the influence of stress resulting from welding. It was also certain [14] that cracks resulted from stress cracking, and this was probably the cause of the leaks in the other tanks. So far, 9 out of 16 Single-Shell Tanks have leaked at the Savannah River Plant [15].

At Hanford, leaks from 20 High-Level Waste tanks had been detected through 1976 [2], releasing altogether about 1,700 cubic meters (450,000 gallons) of High-Level Wastes to the ground. About half of the total volume of leakage was from three of the oldest tanks; one of these (Tank 106-T, in 1973) experienced the largest leak, about 435 cubic meters (115,000 gallons) [16].

In addition to 20 confirming leaking tanks, another 14 have been removed from service because their integrity was suspect. Reasons for suspecting tank integrity have included:

1. Excessive pitting or corrosion of the carbon steel liner, as determined by photographic inspection.

2. Anomalies in fluid-level measurements which might indicate leakage but which could not be confirmed as such.

3. Experience records with other tanks of the same age and type of use, from which a maximum dependable life has been estimated.

The minimum volume of leakage that can be detected at present varies with tank design, type of waste stored, and length of service. It is also anticipated [2] that with the establishment of improved detection systems and increased frequency of monitoring, large undetected leaks are most unlikely in the future under normal operations. So far, 66 out of 149 Single-Shell Tanks have leaked an estimated 2,800 cubic meters $(738,000$ gallons) at the Hanford Site $[17,18]$ and possibly much more according to a 1991 report by the Government Accounting Office [19]. About 157 million curies of radioactive material remains in the Single-Shell Tanks, and about 111 million curies in the Double-Shell Tanks [20]. 
As a result of some premature failures at Hanford and Savannah River, it became apparent that stress corrosion cracking (SCC) was the most likely cause for failure. At both facilities conditions are favorable for this type of failure; namely, residual stress in the weld areas, nitrate ion in the waste solution, and elevated temperatures.

The bulk of the subsequent experimental effort has been directed toward investigating the conditions for SCC. At the Hanford Site, Maness [21] and Moore [22] demonstrated using simulated (non-radioactive) solutions that the sodium nitrate concentrations found in high-level liquid waste (5-8N, where $\mathrm{N}$ denotes normality of the solution) are sufficient to cause stress corrosion cracking in the mild steel liners at the temperatures $(>100 \mathrm{C}$ ) the waste was stored originally. For specimens stressed to levels approaching $100 \%$ of yield or precracked, cracking zones could be identified. They $[21,22]$ showed that sodium hydroxide, sodium nitrite, and sodium sulfate will inhibit nitrate cracking. Under certain conditions sodium hydroxide will cause stress corrosion cracking in a manner analogous to nitrate cracking. This work is discussed in greater detail on page 20.

The corrosion studies were extended to include the corrosive effect of simulated salt cake including long-term immersion tests [23-34]. Initial results have suggested that the rate or severity of corrosion might be different from that encountered with liquid wastes, but failure modes are same. These earlier studies have been confirmed in another study [35] which also demonstrated that general corrosion is not the problem in liquid waste tanks although, vapors attacked the samples and gave rise to severe pitting corrosion. this has been confirmed by laboratory studies conducted on SAE 1010 and 1020 specimens at $\mathrm{pH}>10$ and temperatures $\geq 100 \mathrm{C}(220 \mathrm{~F})[23-29]$ and In situ tank studies [31] on specimens of SAE 1020 carbon steel after exposure to sludge layer. Furthermore, it has also been found that the average pit depth and maximum pit depth increased by atleast a factor of two. Similar studies have not been reported in the more common steels like A 285-B, A 516-70 and A 537 Class I steels used for the construction of the waste tank liner and warrants further investigation.

It has also been confirmed $[21,22]$ that weldment areas are subject to cracking by nitrate ion $\left(\mathrm{NO}_{3}^{-}\right)$and the propensity of cracking can be reduced by annealing or cathodic protection $[36,37]$.

The important conclusion that nitrate ion was the cause of the stress corrosion cracking in the waste storage tanks, particularly at the weldment areas, was confirmed by subsequent work carried out at Savannah River Site $[15,38]$ using simulated solutions. Such cracks have been observed in the SRP waste 
tanks [8]. Characteristic temperature and electrochemical potential ranges have been identified for both nitrate and caustic cracking in synthetic solutions by Ondrejcin ans his coworkers [6, 7, 41-43]. These are respectively, -0.30 to $+1.10 V_{S C E}$ and -0.90 to $-1.04 V_{S C E}$ in nitrate and caustic solutions. The electrochemical potential of the tanks and the temperature of the solution indicate the probable cause of SCC of the tanks is the nitrate ion $[3,6,7,39$ 47]. Some of the nitrate ion may produce nitrite ions by radiolysis of nitrate ion, and may influence the stress corrosion cracking. Laboratory studies at Savannah River Site also confirmed the earlier studies of Maness [21] and Moore [22]. The susceptibility of SCC depends on various parameters of the system:

1. The strength of the steel.

2. The magnitude of the stress.

3. The temperature.

4. The composition of the environment.

The waste management programs at SRP were designed to specify, design, construct, and operate the waste storage tanks in such a way as to minimize the probability of SCC [42]. Nitrate stress corrosion cracking was believed to occur by a film rupture mechanism that decreases with increasing strength of the material; therefore, recently fabricated tanks were constructed from stronger steels (i.e. A 516-70 and A 537 Class I) than was used for the tanks that have developed cracks (i.e. A 285-B), and future tanks may be made from even stronger steel if tests show the stronger steel is more resistant to SCC. Statistically designed series of experiments known as the Plackett-Burman series, were performed to evaluate which independent variables were most important in causing nitrate SCC $[6,7]$. Seven independent variables: temperature and six anionic concentrations, were considered. This approach required 12 experiments rather than 128 for a two-level $2^{n}$ factorial design. Therefore, as a screening design, the Plackett-Burman has the advantage that a small number of experiments are required to investigate a large number of independent variables. Four dependent variables, ultimate tensile strength (UTS) and three measures of ductility, were chosen as values that might be affected by the independent variables based on stress-strain curve.

The Plackett-Burman data showed that temperature and $\mathrm{NO}_{3}^{-}$stood out above all interactions and experimental error in affecting ductility parameters $[6,7]$. Metallographic examination of the cracked specimen showed that 
the failures were intergranular stress corrosion cracks that would be typical of nitrate stress corrosion cracking.

Electrochemical control of a straining specimen $[6,7]$ causes crack initiation at locations where it would occur without control and also to accelerate the process. Initiation of mild steel cracking by nitrate solutions is believed to involve carbon in steel [48] present either in solid solution or as iron carbide $\left(\mathrm{Fe}_{3} \mathrm{C}\right)$ which acts as an efficient cathode. This cathodic action stimulates anodic dissolution very close to the cathode, forming micropit or trench defects, the precursor of a crack. Nitrate, which takes part in the cathodic reaction, is reduced more easily as the solution becomes more acidic. Anodic dissolution of grain boundaries has been simulated by electrochemical control if an anodic current flows through a specimen defined by polarization curves. It has also been demonstrated $[6,7]$ that mild steel in some SRP waste exhibits activepassive transition i.e. small potential differences can cause relatively high current flows.

Welded structures may contain high stress levels due to nonequilibrium cooling during welding. The cracks observed in the waste tanks were typically perpendicular to the welds and were in the heat-affected zone. This observation indicated that the welding residual stresses were responsible for cracking $[15,49,51]$ of low carbon steels. Tanks built after 1966 were stress-relieved to minimize one of the strongest driving forces for SCC.

SCC is a thermally activated process; therefore, the lower the temperature, the less rapid is the SCC growth. Temperatures $<70 \mathrm{C}$ have been recommended [ 6 , $7,41,43,44]$. The temperature of High-Level Waste tanks can be controlled by cooling coils to remove heat produced by radioactive decay.

The composition of the environment is the last parameter that can be varied to influence the susceptibility of the system to nitrate SCC. A maximum nitrate concentration of $5.5 \mathrm{M}$ is specified to limit the aggressiveness of the supernate. The presence of $\mathrm{NO}_{2}^{-}$and $\mathrm{OH}^{-}$ions has been reported to inhibit nitrate SCC [50] because they acted synergistically. The concentrations of $\mathrm{NO}_{2}^{-}$and $\mathrm{OH}^{-}$, is maintained at specific minimum levels depending on the $\mathrm{NO}_{3}^{-}$concentrations. It has been demonstrated [44] using slow strain-rate tensile test $[6,7]$ and fracture mechanics approach $[44,47]$, that $0.75 \mathrm{M} \mathrm{NO}_{2}^{-}$and $0.3 \mathrm{M} \mathrm{OH} \mathrm{H}^{-}$in $5 \mathrm{M} \mathrm{NaNO}{ }_{3}$ can inhibit SCC. Knowledge of the influence of $\mathrm{NO}_{2}^{-}$and $\mathrm{OH}^{-}$ concentrations on nitrate cracking of mild steel provides a basis for controlling the waste composition to minimize the tendency for SCC.

Furthermore, recent studies at Savannah Research Laboratory have raised concern over localized corrosion of carbon steel processing tanks by precipitate slurries, which are washed to reduce the concentration of soluble salts in the 
slurry. Since the $\mathrm{pH}$ of the washed precipitate is lower than that of waste typically stored at SRP, pitting corrosion was a strong possibility. Coupon tests in simulant washed precipitate slurries indicated that an inhibitor would be required to protect the tanks from pitting. Pitting was observed at and above the water line and occasionally below the waterline on the coupons. A corrosion mechanism related to the hydroxide depletion by $\mathrm{CO}_{2}$ absorption in the wetted film on the steel above the waterline was proposed $[52,53]$. Analytical evidence indicated that the tetraphenylborate (TPB) formed a weak passive film on the steel below the waterline but did not form a film on the surface of the metal above the waterline. It was subsequently observed [54-56] that, whereas $\mathrm{NO}_{3}^{-}, \mathrm{SO}_{4}^{2-}, \mathrm{Cl}^{-}$, and $\mathrm{F}^{-}$were aggressive anions, $\mathrm{NO}_{2}^{-}$is the only effective inhibitor to prevent pitting of the A 537 carbon steel container.

\section{FAILURE MODELS}

A first attempt at predicting the corrosion rate of A 516-70 and A 537 was made at Hanford Site by Devine and his co-workers by conducting weight-loss and U-bend corrosion tests in a double shell slurry (DSS) composition range and in other compositions with temperature up to tank design temperature, $350 \mathrm{~F}$ (177 C) [57]. The experimental data for alloy A 516-70 and A-537 were statistically analyzed. The protection of Fe from corrosion in the waste solution was considered to be due to the production of a protective $\mathrm{Fe}_{3} \mathrm{O}_{4}$ film. The experimental data were fitted to a 300 parameter polynomial model for each alloy which defined corrosion rate as a function of exposure time, temperature, and the concentrations of the nine anions in a chemical solution. The model included an intercept and 299 predictors each multiplied by a coefficient. The intercept and the 299 coefficients were unknown parameters in the model. Stepwise regression analysis was performed to obtain a subset of predictors for each alloy tested. The models were used to predict corrosion rate for each alloy with reasonable accuracy. Overall, the corrosion rates for the conditions tested after one year were below the design limit of 1 mpy. The model was later extended to predict the corrosion rate in other waste types [58-60]. Because of the low corrosion rate observed, very little modeling work has been done to predict the corrosion rate, and hence the life of the High-Level Waste tanks in the absence of stress corrosion cracking. This work is discussed further on page pages 21 and 23.

The corrosion studies measured only bulk thinning of the specimens and did not provide insight into failure by other processes such as stress corrosion cracking and hydrogen embrittlement. The results therefore provide only an upper limit for the corrosion rate. 


\section{CORROSION STUDIES}

High-level waste tanks both at Savannah River Site at Aiken, SC and Hanford Site at Hanford, WA had developed leaks at the walls of the primary vessel of tanks designed and built before 1960. Nitrate stress corrosion cracking was believed to be the cause of the leaks in the walls. Consequently, all tanks built since 1968 have been of double-wall construction with improved design and materials at both the facilities. The tanks were also heat-treated prior to construction to relieve stresses. Four distinct forms of corrosion attack may be observed in systems such as the waste tanks:

- General corrosion - the surface is attacked uniformly resulting in a gradual thinning of the structure.

- Pitting - the surface is attacked at very localized site forming relatively deep pits or crevices. Pitting may cause very rapid penetration of the structure.

- Beachline-attack - the metal is attacked more rapidly at the liquid-air (vapor) interface.

- Stress corrosion cracking (SCC) - under the influence of an imposed stress and a slightly corrosive environment, the metal cracks at an imposed load much lower than its normal tensile strength.

The tank leaks had spurred extensive studies in the area of corrosion, particularly stress corrosion cracking at Savannah River Laboratory, on the mild steels used in the tank construction. In this connection mild steels such as ASTM A 285, A 516-70 and A 570 class I have been considered important structural materials. The composition of the mild steels are shown in Table II. The table shows that, in these steels the levels of alloying elements is low, i.e. less than 5\%. Additionally, the carbon content in these steels is also low, i.e. less than $0.22 \%$. These steels were extensively studied from a corrosion standpoint in order to provide a technical basis for guiding waste management operations to protect the integrity of tanks used to store radioactive wastes, to identify causes of materials deficiencies that were experienced at Savannah River Plant and suggest modifications in the construction of the tanks to increase the integrity of the tanks and provide a more secure containment.

\subsection{Work at Savannah River Site}

Laboratory studies to those at Hanford have been performed at Savannah 
Table 2: Compositions of the Mild Steels Used For Construction Of Tank (in $\%)$

$$
\begin{array}{lllllllll}
\text { C } & \mathrm{Cr} & \mathrm{Cu} & \mathrm{Mn} & \mathrm{Mo} & \mathrm{Ni} & \mathrm{P} & \mathrm{S} & \mathrm{Si}
\end{array}
$$

ASTM A 537 Class I

$\begin{array}{llllllllll}\text { Heat 1 } & 0.15 & 0.15 & 0.20 & 1.26 & <0.01 & 0.20 & 0.026 & 0.007 & 0.43 \\ \text { Heat 2 } & 0.15 & 0.19 & 0.26 & 1.20 & 0.04 & 0.13 & 0.008 & 0.008 & 0.25\end{array}$

ASTM A 516-70

$\begin{array}{llllllllll}\text { Heat 1 } & 0.13 & 0.03 & 0.10 & 0.89 & <0.01 & 0.05 & 0.009 & 0.020 & 0.26\end{array}$

ASTM A 285

$\begin{array}{lllllllll}\text { B } & 0.22 & 0.3 & 0.4 & 0.9 & 0.12 & 0.40 & 0.035 & 0.04\end{array}$

River Site using non-radioactive synthetic waste solutions based on analyses of actual wastes. These synthetic waste solutions were prepared to correspond to samples taken either from the waste stored in the tank farm or from fresh waste in the process buildings.

The electrochemical behavior of synthetic wastes is found to be equivalent to that of actual wastes so that laboratory studies with synthetic solutions could be expected to give results that were meaningful to plant operations. From a number of corrosion studies that have been performed at Savannah River Laboratory, significant general corrosion would not be expected in the waste tanks. Evidence has been in the form of inspections (both wall thickness measurements and direct observation) and experiments using in-tank coupons. However, there have been several cases of stress corrosion cracking as the cause of leaks of several underground storage tanks [12-15]. Pitting, and possibly beachline attack, had caused leaks in about $10 \%$ of the cooling coils installed in some of these tanks [39]. These corrosion mechanisms have been studied in the laboratory in an effort to select better materials of construction for new tanks and to control operating conditions to prevent additional failures.

\subsubsection{Stress Corrosion Cracking}

Stress corrosion cracking has been the most serious threat to the integrity of 


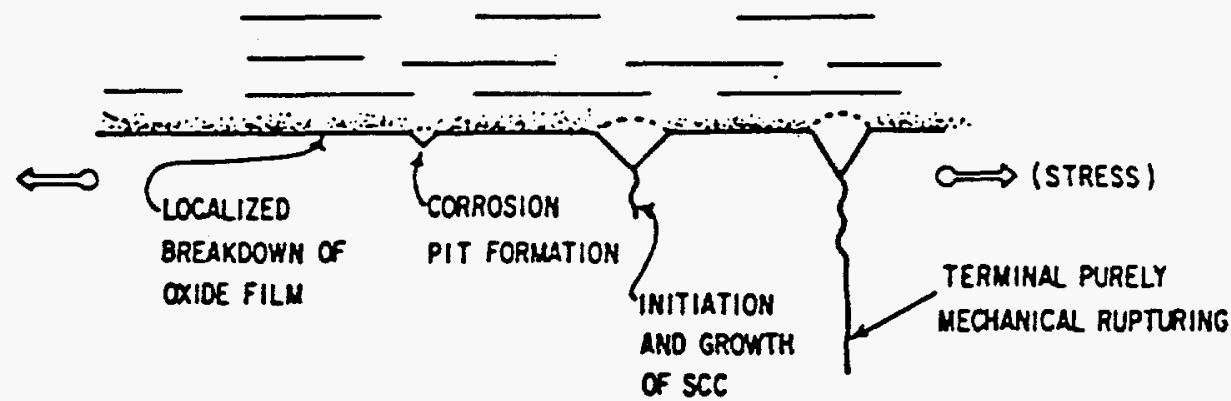

Figure 3: Schematic of Processes that Cause Stress Corrosion Cracking.

the mild steel (a generic name for a class of steels that contains less than about $0.3 \%$ carbon) liner in the High-Level Waste tanks. Stress corrosion cracking (SCC) in mild steel occurs due to the combined action of corrosion and stress. Neither significant corrosion nor stress alone would cause structural failure but together they can. Figure 3 schematically shows the processes involved. Mild steels are susceptible to SCC in nitrate solutions as well as in caustic solutions and several other environments [61]. The precise mechanism of this form of failure is not agreed upon, but it is no doubt related to the fact that in a crevice or a crack the chemistry of the system can be very different from that in the bulk solution. The most generally accepted mechanism is that the stress maintains a crevice in which the solution is agressive towards the metal. The chemistry at the crack tip has been shown to be significantly different by measurements of the $\mathrm{pH}$ (an indication of the concentration of the hydrogen ions or the relative concentration of acid). Laboratory measurements have shown that the $\mathrm{pH}$ in the crack tip region to be about 3 (acid) while the bulk solution was near neutral, a $\mathrm{pH}$ of 7 [62]. A solution with a $\mathrm{pH}$ of 3 readily corrodes mild steel. The carbon steel that is the main structural material in tanks used for storing wastes from nuclear fuel reprocessing at the Savannah River Plant (SRP) was susceptible to stress corrosion cracking (SCC) in nitrate 
and hydroxide solutions and stress corrosion cracks have been observed in the tanks $[6,7,15,38,40-44]$. SCC has been observed in single-shell as well as in the primary steel shells of the older double-shell waste tanks. The primary carbon steel shells of 9 of 16 older, non-stress relieved, double-shell tanks at SRP have leaked due to stress corrosion cracking. Both the single-shell tanks and inner wall of double-shell tanks were constructed of ASTM A-285 B steel mostly without adequate stress relief treatment of the welded or stressed material [12-15, 40-44].

A characteristic of this type of cracking is that it is intergranular. That is, the grain boundaries of the metal are preferentially attacked. Figure 4 shows the path of a nitrate SCC in A 285-B steel [44] compared with the crack found in the sample from one of the tanks at SRP (Figure 5). This evidence, along with the electrochemical behavior of steel, is suggestive that cracking in waste tanks was caused by nitrate stress corrosion [7]. Stress corrosion work at the Naval Research Laboratory (NRL) suggested that in a number of high-strength steels the tip of the crack became acidic [63] and that a $\mathrm{pH}$ value of 3.5 was controlled by the hydrolysis of the ferrous ion i.e. ferrous ion becoming ferrous hydroxide was controlling according to the reaction [62]:

$$
\mathrm{Fe}^{2+}+\mathrm{HOH} \longrightarrow \mathrm{Fe}(\mathrm{OH})^{+}+\mathrm{H}^{+}
$$

Parkins and Usher [64] have shown that in nitrate solutions, the severity of cracking increases according to the cation series $\mathrm{Na}^{+}<\mathrm{Ca}^{2+}<\mathrm{NH}_{4}^{+}$. This series is also one of increasing acidity. The increase causes the open circuit potential of steels in these solutions to become more anodic. A consequence of the open circuit potential of the steel becoming more anodic is that at a corrosion site either the current density at the anode increased or the cathodic reactions were accelerated [14].

Corrosion, the precursor to cracking, occurs normally under the control of cathodic reactions in aqueous solutions [65] and is relatively unaffected by minor changes in the steel composition. The corrosion rate is influenced by the reduction kinetics and diffusion of reactants to cathodic sites. Nitrate is more easily reduced, as the solution becomes more acidic. In a variety of nitrate solutions, cracking has been most rapid in the most acidic solutions because: 1) they produced the largest anodic open circuit potential, and 2) cathodic reactions were simulated more. As a result, corrosion was accelerated and micropits or intergranular trenches form faster.

On the basis of electrochemical theory, the best approach to reduce cracking has been to inhibit the cathodic reaction. This reaction could be inhibited by increasing the concentrations of either the $\mathrm{NO}_{2}^{-}$or $\mathrm{OH}^{-}$or preferentially both. Solutions containing low concentrations of either nitrite or hydroxide 


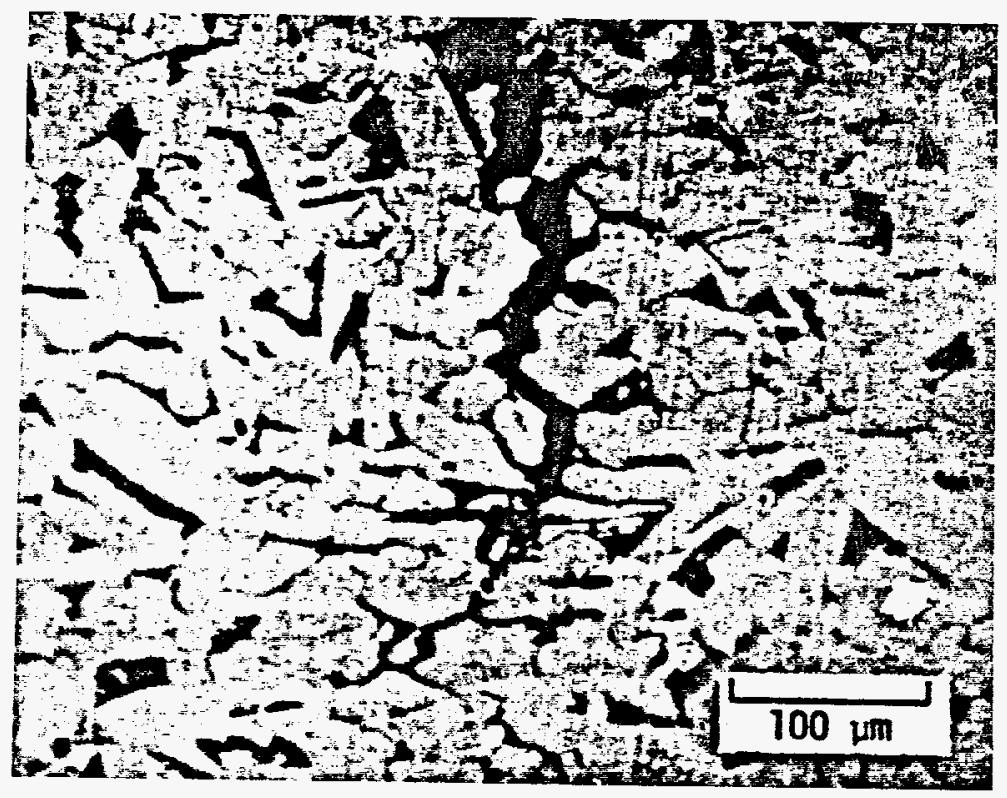

Figure 4: Intergranular Cracking Associated with Nitrate SCC in A 285-B Steel. 




Figure 5: Crack in A 285-B Steel Tank at Savannah River Plant. 
alone caused as much crack growth as concentrated nitrate solutions. However, as the nitrite concentrations are increased, the extent of crack growth decreased and the threshold stress intensity increased. These results at Savannah Research Laboratory on synthetic waste solutions strongly suggest that both nitrite and hydroxyl ions, when present in sufficient amounts, act as inhibitors of nitrate stress corrosion crack propagation. Synergistic effects have also been noted in that the combined concentration of nitrite and hydroxyl ions required to inhibit cracking was less when both are present than when they were added individually $[6,7,40-44]$.

An accepted theory of crack initiation in mild steel by nitrate solutions involves carbon in the steel [48]. Carbon is present in solid solution or as $\mathrm{Fe}_{3} \mathrm{C}$ in the grain boundaries; it acts as an efficient cathode with the adjacent metal surface forming the anode of the electrochemical cell. This arrangement enhances anodic dissolution very close to the cathode leading to a micropit or trench, the precursor of a crack. Anodic dissolution of the grain boundaries also has been simulated by electrochemical control if an anodic current flows through a specimen. Current flows that one expected from metals in solution have been defined by anodic polarization curves. Polarization studies have shown that in certain solutions where the metal shows an active-passive transition, such as mild steel in SRP wastes, relatively large increases in current flows was caused by small increase in potential. The cause for such potential differences is attributed to precipitates, second phases, or elements in solid solution, such as carbon [43]. These localized potential differences result in the localized attack required to initiate stress corrosion cracking.

Stress corrosion cracks in waste tanks have been predominantly associated with welds. Cracks have been found to initiate at right angles to the weld bead, propagate a short distance into the base metal, and then stop. The largest crack observed in a waste tank was $15.2 \mathrm{~cm}$ (6 in.) long [43]. On the basis of experimental work $[6,7]$ and other supporting laboratory [48] and industrial [66] experience on the role of residual stresses, some of the waste tanks at SRP have been heat-treated after fabrication to relieve stresses. Any long-range reaction stresses would also been relieved. This heat treatment has been a significant advance in minimizing the probability of stress corrosion cracks in waste tanks.

It has also been demonstrated that the probability of crack initiation is affected by the temperature of the waste [43,44]. Based upon an electrochemically controlled slow strain rate tensile test data it has been found that temperature and $\mathrm{NO}_{3}^{-}$concentration more strongly affect the measured ductility. An evaluation of tensile data in air has shown that the limit of uniform elongation for ASTM A 285-B mild steel was about 13\%; this is the point of maximum 
load and the point at which stresses in a tensile specimen change from biaxial to triaxial. Triaxial stresses are generally considered to be more effective in crack initiation of polycrystalline materials. Finally, the limit of $13 \%$ limit is consistent with results of tests using a fracture mechanics approach to evaluate crack growth [45]. At $75 \mathrm{C}$ a low elongation to fracture has been reported [41]. Corrosion of mild steel has been observed to be maximum at $80 \mathrm{C}$ and it decreased at both lower and higher temperatures $[45,67]$.

It was suggested that the higher temperatures decreased $\mathrm{O}_{2}$ solubility reduced the corrosion rate, while at lower temperatures the corrosion rate also decreased because of the decreased reaction rates. Smialowski and Ostrowska [68] contend that $\mathrm{O}_{2}$ is of great importance in assisting the nitrate cracking mechanism, although Herzog and Portevin [23] claimed it was without effect. The differences in interpretation could be due to temperature and its effect on $\mathrm{O}_{2}$ solubility. Ondrejcin [9] however recommended on the basis of his experimental data that at a temperature of $70 \mathrm{C}$ when there are enough $\mathrm{NO}_{2}^{-}$ and $\mathrm{OH}^{-}$ions in the solution as inhibitors, nitrate stress cracking of ASTM A 285-B steel will not occur [41]. The maximum temperature of $70 \mathrm{C}$ is the lowest value that can normally be maintained in the tanks during storage of fresh wastes because of their relatively high heat generation. Low temperatures are generally desirable because they reduce corrosion reaction rates. After evaporation the wastes are returned from the evaporator at nearly the boiling point. Because the concentrations of $\mathrm{OH}^{-}$and $\mathrm{NO}_{2}^{-}$are then quite high, no corrosion damage should result as a result of the higher temperatures $[43,44]$. These results are similar to those obtained by Parkins [45] and is summarised in Figure 6.

Parkins [45] found that the severe cracking that is promoted by $8 \mathrm{M} \mathrm{KNO} \mathrm{N}_{3}$ can be inhibited by the open-circuit potential by the presence of only 2 or $3 \mathrm{~kg} / \mathrm{m}^{3}$ $(0.04 M)$. However, if the potential is raised above open-circuit value, cracking returns at potentials that increase as the concentration of $\mathrm{NaNO}_{2}$ is increased as is apparent in Figure 6 which shows the results from slow strain-rate tests involving solutions of different nitrite concentrations and various controlled potentials. The figure shows two plateaus, one at about $66 \% \mathrm{RA}$ and the other at about $20 \% \mathrm{RA}$, corresponding to ductile failure and severe stress corrosion fracture, respectively. It also is apparent that the ductile-fracture plateau extends to more positive potentials the higher the concentration, with cracking only obtained at $800 \mathrm{~kg} / \mathrm{m}^{3}(11.59 \mathrm{M}) \mathrm{NaNO}_{2}$ when the system was subjected to a potential above $\left(-0.4 V_{S C E}\right)$. Furthermore, in nitrite-free solutions Parkins [45] noticed a black film of $\mathrm{Fe}_{3} \mathrm{O}_{4}$ which formed over the exposed surfaces of the mild steel, but in solutions containing nitrite and for potentials at which cracking occurred, the surfaces remained unchanged, with a thin transparent film of $\mathrm{Fe}_{2} \mathrm{O}_{3}$, except for small discrete black spots from which the stress 


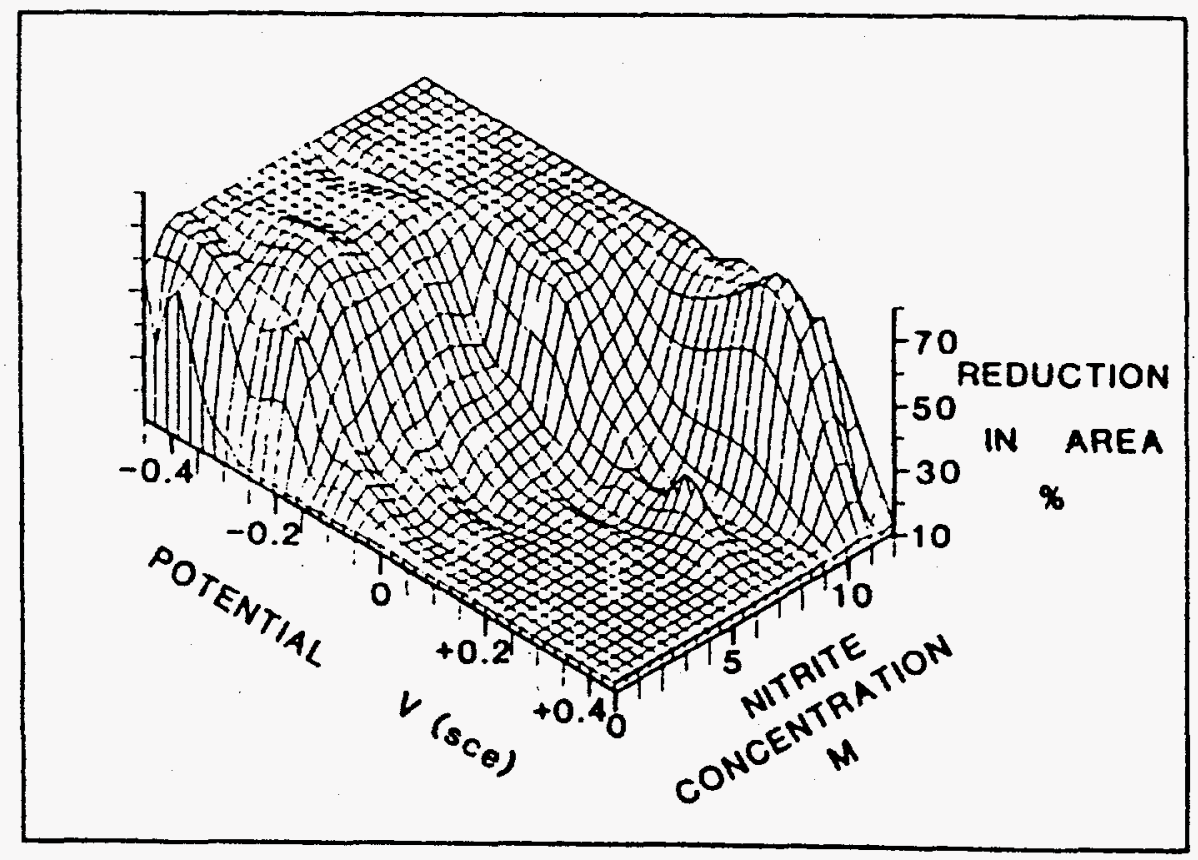

Figure 6: Effects of nitrite concentration and potential on the reduction in area to fracture C-Mn mild steel specimens in boiling $8 \mathrm{M} \mathrm{KMnO}_{3}$ solution by slow strain rate testing [45].

corrosion cracks propagated, the surfaces of which were covered with a film of $\mathrm{Fe}_{3} \mathrm{O}_{4}$. The implication is that the environmental conditions were locally changed from those of bulk environment to circumstances in which cracking occurred, which is suggested by the different corrosion products present on the fracture and outer surfaces of the specimens. This further implies that pitting occurs at defects in the film and the potentials at which cracking is initiated in the nitrite-containing solutions should correspond to the pitting potentials for the various nitrite concentrations.

Interestingly, it has been confirmed that under identical test conditions using elongation tension tests, the resistance to cracking increased in the order $A$ 285-B, A 516-70, and A 537 Class I [6, 7, 43, 44]. Especially, the last two types have finer microstructure and smaller amount of ferrite along with improved fracture toughness compared to A 285-B steel and were specified for new tank construction beginning in 1976. Later tanks were built of the more stress corrosion resistant A 516-70. Tanks are now being built of A 516-70 normalized or A 537 Class I. These last two alloys were chosen to improve mechanical performance and are equivalent to A $516-70$ (rolled) in stress corrosion 
resistance.

\subsubsection{Pitting Corrosion}

The first instance of failure from pitting corrosion in high-level radioactive storage tanks occurred at Savannah Research Plant in 1965 [39]. The cooling coils of the high-level waste tanks fabricated from ASTM Grades A 53 and A 106 mild steels had undergone corrosion damage by pitting. No leakage of the radioactive waste occurred. Since then pitting corrosion has not been recognized as an important failure mechanism of the waste tanks at SRP. Recently, pitting of ASTM A 537 carbon steel has been reported [52-56]. Using laboratory and in-tank demonstration tests, it has been shown that pitting corrosion above waterline occurred because the $\mathrm{pH}$ of the washed precipitate was reduced. The reasons for corrosion were:

1) hydroxide was consumed by reaction with carbon dioxide in the air producing a lowered $\mathrm{pH}$ (the carbon dioxide in the air was used to purge the tanks), and

2) radiolysis of tetraphenylborate (TPB) ion gave species which were predominantly acidic (TPB precipitated the radioactive cesium and nonradioactive potassium).

The washed precipitates then became dilute in nitrite corrosion inhibitors. The concentrations of the species sulfate, chloride, and nitrate in combination with organic species made it difficult for low-nitrite levels to passivate carbon steel in contact with washed waste precipitate $[54,55]$.

\subsection{Work at Hanford Site}

\subsubsection{Stress Corrosion Cracking}

To substantiate that nitrate ion is the cause of the stress corrosion cracking being observed in the waste tanks as was discussed on page 12, Maness [21] had carried out a series of laboratory-and pilot- scale tests to evaluate the effects of sodium nitrate and/or ammonium nitrate on the cracking propensity of mild steel specimens. Several important and far-reaching conclusions were made in his report:

- It was shown that different results can be obtained depending on the choice of specimen size, configuration and stress mode. 
- These tests confirm that the weldment areas are subject to cracking by nitrate ion.

- Cracking can be prevented by annealing or by cathodic protection.

These results were confirmed by a subsequent work carried out by Moore [22] and at Savannah River [6, 7, 40-47]. Laboratory-scale experiments have been conducted with C-ring specimens (American Society for Testing and Materials A-106) and with notched and stressed (bent-beam) specimens (ASTM A 20157 Grade B, A 201-B, and A 283-59 Grade C at two carbon levels). It has been found that:

- ASTM A 201-57T Grade B, appears to offer the greatest resistance to crack initiation (of the metals tested).

- cracking susceptibility in mild steel is inversely proportional to the carbon content (in the range of 0.04 to $0.25 \mathrm{wt} \%$ ).

- cathodic protection can guard against cracking of susceptible steels.

- susceptibility of mild steels to SCC is increased by plastic deformation, spherodizing heat treatments, and the presence of ammonium ion in nitrate solution.

The work of both Maness [21] and Moore [22] amply demonstrated that a sodium nitrate solution will cause stress corrosion cracking of stressed mild steel at elevated temperature. The three variables are interdependent; but at a temperature near $100 \mathrm{C}$ and a stress of 50 to $100 \%$ of yield, the concentration of nitrate ion which will cause cracking was found to be 6 to $8 \mathrm{~N}$. Increasing concentrations of nitrate ion reduced the time-to-failure in ASTM A-106, Grade $B$ mild steel and the propensity to stress corrosion cracking increased. In the $\mathrm{pH}$ range 11 to 13 , iron became increasingly passive and it was this surface passivity that advantageously retarded crack growth rate. Consequently, $2 \%$ $\mathrm{NaOH}$ had been used to inhibit SCC in nitrate solutions. It appeared that at intermediate levels of $\mathrm{NaOH}, \mathrm{SCC}$ by nitrate can be retarded. Also, it was found that the propensity to cracking is greatly lessened by an incremental decrease in temperature.

\subsubsection{Pitting Corrosion}

The early reports [29-35] using SAE 1010 and 1020 steel confirmed that at $\mathrm{pH}$ $>10$ and temperatures at $100 \mathrm{C}(220 \mathrm{~F})$ there was little general corrosion. 
However, extensive pitting corrosion has been observed on that portion of the mild steel coupon exposed to the vapors ( 1.8 mils after 24 hours). The effects of $\mathrm{pH}$ has also been investigated. It was concluded that there were no ill effects in lowering the $\mathrm{pH}$ from 9 to 7 ; at $\mathrm{pH} 6$ extensive pitting corrosion of the metal exposed to the vapors had occurred. However, solutions at $\mathrm{pH}$ 12 and 13 contained solids which caused nonuniform heat distribution and higher sludge temperatures ( $>100 \mathrm{C}$ or $200 \mathrm{~F}$ ) led to higher corrosion values [28]. Additional laboratory testing [29] over a six-week period of time at a temperature of $121 \mathrm{C}(250 \mathrm{C})$ and $\mathrm{pH} 13$ resulted in a general corrosion rate of 0.6 mpy for a sample of SAE 1010 steel.

In this study pitting was also observed around the stressed area of the coupon. A pitting rate of $4.8 \mathrm{mpy}$ was reported with the rate decreasing with time. The maximum pit depth observed in this and a subsequent report [30] was 3.8 mils after 10 months. The rates of general corrosion at that time were considered reasonable for the storage of caustic liquid in mild steel containers. In most of the laboratory tests using simulated waste the effect of $\mathrm{pH}$ had received the most attention. The Clinton Laboratory report [9] indicated that the waste solution could be adequately stored at $\mathrm{pH} 10$. However the important concern at that time was that by lowering the $\mathrm{pH}$ to 7 to 9 , the total volume of stored waste would be less and therefore more economical [9]. The other environmental factors were pseudo-invariant and therefore not variables to be studied. The rate or nature of corrosion as a function of one of the constituents (studies on which were being pursued by researchers at Savannah River) has not been considered as important as the total effect of the waste on the steel liner.

In situ tank studies on the rate of corrosion of mild steel coupons have been conducted [31,32]. These studies along with earlier studies [30] at $121 \mathrm{C}(250$ F) on SAE 1020 carbon steel confirmed the bulk of the laboratory studies on general and pitting corrosion of mild steel immersed in the waste solution. A similar study has been conducted on tanks containing Bismuth Phosphate Process Waste [33, 34]. The results confirmed that general corrosion was not the problem in liquid waste. However, the vapors in one of the tanks severely attacked the mild steel liner resulting in pitting corrosion. Again, in another study [35] specimens made of A-283 mild steel were exposed to simulated boiling alkaline high-level waste solutions (both fluoride-bearing and fluoridefree). Pitting attack was observed on that part of the specimen exposed to the vapor phase. There was no evidence of general corrosion at the vapor-liquid interface or in the alkaline solution on these mild steel specimens.

Corrosion studies have also been conducted at the Hanford Site on several mild steels. However, there have been no reports on corrosion of important 
mild steels like ASTM A 285-B, A 517-70 normalized and 570 Grade I from Hanford Site. Corrosion evaluation of these mild steels for application as tank construction materials was pursued vigorously at Savannah River Site. In this effort, the contributions of Ondrejcin $[6,7,40,43,44]$ and Donovan $[42,44-46]$ have been invaluable. Because of the leaks in single-shell tanks at the Savannah River and Hanford Sites due to nitrate stress corrosion cracking of the ASTM A 285-B mild steel liners, all steel tanks built since 1968 were of double-wall construction with improved design and construction. Metallurgical research, particularly at Savannah River Site $[6,7,15,38]$, had shown that the tank wall cracking could be eliminated by :

(a) using an improved steel alloy such as ASTM A 516-70 or A 570 Grade I for liners.

(b) reducing stress concentrations during construction.

(c) heat treating the inner tank at $590 \mathrm{C}(1100 \mathrm{~F})$ followed by controlled slow cooling to relieved stresses in and adjacent to the welded joints.

(d) controlling caustic/nitrate ratio in the high level wastes.

(e) cathodic protection $[36,37]$.

At Hanford Site, 28 double-shell underground storage tanks were constructed. The double-shell design provided one more barrier to the environment than the original single-shell design. In the mid-1970s, commitment was made to deactivate the 149 single-shell tanks and store the high level waste in double-shell tanks. The goal was met in November 1980. Using crystallizer-evaporators the wastes from the single-shell tanks were being concentrated to reduce the volume of the liquid waste and to ultimately allow storage in the 29 doubleshell tanks. The product of this process was a thick concentrated slurry to minimize the storage volume which was dubbed double-shell slurry(DSS), consisting of a solution high in $\mathrm{NaOH}, \mathrm{NaNO}_{3}, \mathrm{NaNO}_{2}, \mathrm{NaAlO}_{2}$, dissolved organic complexants [EDTA (ethylene diamine tetra acetic acid), HEDTA (hydroxy ethylethylene diamine triacetic acid), NTA (nitrilo triacetic acid), HOA$\mathrm{cOH}$ (glycolic acid), etc.)], and other salts (sulfates and phosphates). Other wastes resulting from current processes were similarly concentrated, and the aqueous portions stored in double-shell tanks.

\subsubsection{Modeling Work}

Although a modest amount of corrosion work has been done since mid-1940s when waste storage began, the changes in the processes and waste types have 
outpaced the development of new data pertinent to the new double shell tanks. As a consequence, Pacific Northwest Laboratory (PNL) began a development of corrosion data on a broad base of waste compositions in 1980. Devine and his co-workers [57-60] developed corrosion data on tank construction materials such as ASTM A 537 carbon steel (used in double-shell tanks) and A 516 carbon steel (used in earlier single-shell tanks) in an expanded double-shell slurry (DSS) composition range and in other waste compositions with temperatures up to the tank design temperature, $350 \mathrm{~F}(177 \mathrm{C})$ at which corrosion rates were not to exceed one mil per year.

The available data were selected from the literature. The literature included data from the Savannah River and Hanford experiments which were found inadequate to describe the behavior of the waste proposed for storage in the new tanks. Therefore, additional corrosion rate data have been generated through experiments using weight loss (to determine the corrosion rate) and U-bend specimens (to determine the fracture behavior). The corrosion data were neccessary to allow safe operation of the waste tanks in a wide range of simulated waste fluids with a tank design temperature up to $350 \mathrm{~F}(177 \mathrm{C})$. Initially corrosion work was carried out on double shell slurry (DSS) waste, at temperatures at or below $100 \mathrm{C}$. The mechanism of the protection of $\mathrm{Fe}$ was considered to be due to the production of a protective $\mathrm{Fe}_{3} \mathrm{O}_{4}$ film. The corrosion data were analyzed and have been used to generate prediction equations. Both linear and non-linear equations were used to produce prediction equations for interpolating, within the bounds of existing chemistries and temperatures, the expected corrosion behavior of the storage tanks to new combinations of storage conditions.

A 300 parameters polynomial model for each alloy which expresses corrosion rate as a function of exposure time in hours, temperature in degree centigrade, and the levels of the nine anions in a chemical solution was initially developed. The experiment was designed so that the data would accommodate fitting the 300 parameter model which includes the intercept and 299 terms which are the 299 predictors, multiplied by a coefficient. The intercept and the 299 coefficients are unknown parameters in the model. These are estimated by fitting the model to the experimental data. Statistical tests on the estimates were then performed to decide which of the unknown coefficients are not zero.

Stepwise regression analysis was then used to select an adequate subset of predictors in each model corresponding to each alloy type. The models were statistical in nature with no attempt to describe the physical interaction [58, 59].

As discussed in page 11, predictor equations have been developed for A 537 
(which has 55 predictors in the model and $R^{2}=0.89$ where $R^{2}$ is the percent of the variability in the observed corrosion rates accounted for the fitted model) and A 517-70 which has 74 predictors in the model and $R^{2}=0.87$ in a range of synthetic DSS waste compositions expected to be stored in the double-shell tanks. Both linear and non-linear equations were used to produce predictor expressions. These equations have been used to predict the corrosion rate as a function of temperature, alloy and time within the ranges of experiment.

The predicted corrosion rates in mils per year (mpy) obtained for each alloy type (0.350 mpy for A-537 and $0.359 \mathrm{mpy}$ ) in the DSS environment is in reasonable agreement with the mean experimental value $(0.360$ mpy for $A-537$ and $0.359 \mathrm{mpy}$ for A-516). It was concluded that the DSS specified in the environmental impact statement (EIS) could be put into the new tanks made of A-537 mild steel provided the temperatures were kept close to or below the proposed operating values $(100 \mathrm{C})$ because that was the primary operating range. However, it was not possible to conclude from the prediction equation whether the presence or absence of a component was significant.

Later on these models were extended to model,to simulate Double Shell Slurry waste and Future PUREX waste at temperatures between 40 and $180 \mathrm{C}$ as well as Hanford Facilities waste at temperatures of 25 and $50 \mathrm{C}$.

A fourth comprehensive model has also been developed using the combined corrosion data collected for each of the above waste types $[59,60]$. It was found that the corrosion rates were well below the design limit of $1 \mathrm{mpy}(0.001$ inch/yr) and usually less than $0.5 \mathrm{mpy}$. Excessive corrosion rates ( $>1 \mathrm{mpy}$ ) were only found in dilute waste compositions or in concentrated caustic compositions at temperatures above $140 \mathrm{C}$. Localized and stress corrosion cracking were only observed under similar conditions. Indeed, though U-bend tests are considered to be a severe test [70], less SCC was observed than expected from the previous work $[6,7,47]$. Normal operating conditions for the wastes tested [60] do not lead to significant corrosion rates.

\section{CURRENT CONCERNS AT HANFORD SITE}

Although none of the double-shell tanks at the Hanford Site have leaked since they were put to active service in 1980 , there have been other concerns. In 1977 , the first crystallizer-evaporator was tested with radioactive waste and the product was pumped to tank 241-SY-101, commonly known as tank 101SY, for storage. Shortly after transferring approximately 250,000 gallons of 
double-shell slurry to tank 101-SY, the waste volume began to increase $[17,71-$ 73]. Later that year, complex concentrate was added to the tank to dilute the waste and quench the slurry growth. Three more waste additions were made between 1977 and 1980. During that time period, a crust developed on the top of the liquid waste and has grown in thickness, further complicating an already difficult-to-interpret situation. In March 1981, the first growth and collapse cycle was observed. These cycles have continued more or less regularly since that time. Preliminary chemical analyses indicated that the gases that evolved during the waste volume collapse consisted of $\mathrm{H}_{2}$ and $\mathrm{N}_{2} \mathrm{O}$, with (perhaps) some $\mathrm{NH}_{3}$ from degradation of the organics in the waste. Furthermore, the presence of the gases creates the possibility of a hydrogen burn. The resulting pressure from a hydrogen burn event could cause structural damage to the tank if sufficient gas burn occurred. There is still no evidence that combustion has occurred in any of the 177 waste tanks during the past 46-year-operation, yet the potential, however low, appears to exist. Because of the potential for explosion and attendant release of hazardous materials into the environment, Westinghouse Hanford Company and the U.S. Department of Energy realized the need to know about chemical and physical processes occurring in the tank that lead to the generation of gases and their episodic release.

Processing facilities at the Hanford Site have produced various radioactive liquid and slurry wastes that are stored in 149 underground single-shell tanks. More than twenty-four of these tanks may contain ferrocyanide in quantities sufficient to present a potential for exothermic or explosive reactions between ferrocyanide precipitates, and nitrate and nitrite compounds. Ferrocyanide was used in the 1950 s to remove cesium- 137 from the liquid waste $[17,71,74$, 75].

For a runaway exothermic reaction to occur in the waste, a sufficient amount and concentration of reactant material and a minimum reaction temperature must exist. Single-shell tanks are inactive (i.e., wastes are no longer added to the tanks), and the heat generation rates continue to decrease as a result of radioactive decay. Based upon these factors and tank thermal modeling, no significant temperature rise is expected. The highest temperature currently measured in any ferrocyanide tank is approximately $56 \mathrm{C}(132 \mathrm{~F})$. This is considerably lower than the lowest exothermic reaction temperature of 220 $\mathrm{C}(430 \mathrm{~F})$ and explosive temperature of $280 \mathrm{C}(540 \mathrm{~F})$ respectively, for an oxidant mixture of $47.5 \mathrm{~mol} \%$ sodium nitrate, $47.5 \mathrm{~mol} \%$ sodium nitrite, and 5 mol\% EDTA (ethylene diamine tetra acetic acid) measured in the laboratory [76]. 


\section{SUMMARY AND CONCLUSIONS}

1. High-Level Wastes (HLWs) have been originally stored at Hanford and Savannah River Sites in Single-Shell Tanks (SSTs) with an inner carbon steel liner. Sixty-six out of 149 SSTs have leaked so far and have been deactivated from service.

2. Tank leakage spurred laboratory research activities at the Hanford and Savannah River Sites. These studies have connected the leaks to $\mathrm{NO}_{3}^{-}$ Stress Corrosion Cracking of the liner which is made of coarse-grained A-285 carbon steel unrelieved of welding stresses. Failure occurs most frequently at tank wall temperatures greater than $100 \mathrm{C}$ in the presence of a tank solution maintained at low $\mathrm{pH}$ or acidic state.

4. Laboratory studies at Hanford and Savannah River Sites have provided recommendations to avoid the nitrate stress corrosion cracking. These recommendations are:

- Remove welding stresses by annealing to homogenize microstructure.

- Maintain tank wall temperature $\leq 60 \mathrm{C}$.

- Maintain tank solution at a high $\mathrm{pH}$ (10-12) using hydroxide.

- Introduce inhibitor $\sim \mathrm{NO}_{2}^{-}$.

- Improve metallurgical design. Fine-grained, low fracture-toughness A-516 or A-537 alloys are preferable to coarse-grained, high fracturetoughness A-285 carbon steel.

Under these conditions, thermodynamically stable $\mathrm{Fe}_{3} \mathrm{O}_{4}$ is formed which provides protection of the carbon steel liner. More literature work needs to be done to understand the mechanism of $\mathrm{NO}_{3}^{-} \mathrm{SCC}$ in detail.

5. The mechanism relative to the role of $\mathrm{NO}_{2}^{-}$in controlling overall corrosion of mild steel is not explained by the Hanford and SRL work. A later report that reviews the general corrosion literature discusses $\mathrm{NO}_{2}^{-}$ passivation mechanisms.

6. A multiparameter study has been carried out at SRL to define the chemical envelope that produces passivation of tank alloys and a resulting reduction in the probability of failure by SCC. This study has provided the basis for the chemical control of wastes in the SRL tanks.

7. Modeling work to predict bulk corrosion-rate and hence, the life of the tanks by general corrosion is extremely limited, i.e. due to Devine and his 
co-workers at Hanford Site. The model is the first attempt at modeling the corrosion of mild steel in a variety of synthetic waste solutions. The predicted corrosion rates are less than one mil per year. The model does not incorporate other important modes of corrosion which are precursor to SCC, hydrogen embrittlement as a consequence of cathodic reactions and/or hydrogen evolution, and irradiation effects, all of which could accelerate the SCC synergistically in environments such as the HighLevel Waste tank solution.

8. Because of intense radiation fields, very little has been done in the direct observation of direct corrosion of tank walls.

9. No direct evidence for pitting corrosion in tank walls has been observed. Pitting corrosion in cooling coils has been observed, apparently resulting from the dissolution of $\mathrm{CO}_{2}$ from the air and a resulting low $\mathrm{pH}$ in the region of the coils.

10. Sudden gas release or "burping" from reactions involving ferrocyanide has been observed in one of the SST tank 241-SY-101. Additionally, in a recent workshop [71] it was emphasized that the SSTs have not been monitored on several grounds viz. $\mathrm{pH}$, temperature, ferrocyanide content etc in many of the SSTs and is an issue of concern.

11. A synergistic approach to rate - modeling and life - prediction of the High-Level Waste tank is lacking and is important. This was also emphasized at recent Workshop on High-Level Waste Tank Structural Integrity [71], held at Hanford, WA.

\section{REFERENCES}

1. J. L. Waite, Tank Wastes Discharged Directly to the Soil at the Hanford Site., Report, Westinghouse Hanford Company, Richland, WA (1991).

2. Panel on Hanford Wastes, Committee on Radioactive Waste Management, National Research Council, Radioactive Wastes at the Hanford Reservation, A Technical Review, National Academy of Sciences, Washington, D. C. (1978).

3. R. S. Ondrejcin, Chemical Composition of Supernates stored in SRP High Level Waste Tanks, Report, DP-1347 (1974).

4. W. P. Dornsife, Classification of Radioactive Materials and Wastes, in Management of Radioactive Materials and Wastes: Issues and Progress, 
Eds. S. K. Majumder and E. W. Miller, Pennsylvania Academy of Sciences, Phillipsburg, NJ page 1 (1985).

5. Office of Nuclear Regulatory Research, Radioactive Waste Management Research Program Plan for High-Level Waste - 1987, Report, NUREG1245, U.S. Regulatory Commission, Washington, D.C. (1987)

6. R. S. Ondrejcin, Prevention of Stress-Corrosion Cracking in Nuclear Waste Storage Tanks, Report, DP-MS-83-18, Savannah Research Laboratory, E. I. DuPont de Nemours and Co., Aiken, SC (1983).

7. R. S. Ondrejcin, Prevention of Stress Corrosion Cracking in Nuclear Waste Storage Tanks, Report, DP-MS-83-79 (1984).

8. W. L. Poe, Leakage from Waste Tanks 16, Amount, Fate and Impact, USAEC Report, DP-1358, Savannah Research Laboratory, E. I. DuPont de Nemours and Co., Aiken, SC (1974).

9. Progress Report, Separation Development Division, Metallurgical report, CN-1316, Clinton Laboratories, March 10, 1944.

10. M. R. Morton and M. A. Mihalic, Underground Storage Tank Complaince Activities at the Hanford Site, Report, DE90-017235, Westinghouse Hanford Company, Richland, WA (1990).

11. B. M. Hanlon, Tank Farm Surveillance and waste Status Summary Report for February 1992, Report, WHC-EP-0182-47, Westinghouse Hanford Company, Richland, WA (1992).

12. R. M. Girder, Storage of Liquid Radioactive Wastes at the Savannah River Plant, Report, DP-3207, E. I. DuPont de Nemours \& Co., Savannah River Laboratory, Aiken SC (1969).

13. J. C. Womack and D. J. Larkin, Investigation and Evaluation of 102 BX Tank Leak, Report, ARH-2035, Atlantic Richfied Hanford Company, Richland, WA (1971).

14. R. M. Girder, Leaks in Radioactive Waste Tanks, Report, DP-990, E. I. DuPont de Nemours \& Co., Savannah River Labortory, Aiken, SC (1965).

15. M. L. Holzworth, R. M. Girder, and L. P. Costas, How to Prevent Stress Corrosion Cracking of Radioactive waste Storage Tanks, Materials Protection, volume 7, page 26 (1968). 
16. A. G. Fremling, R. L. Ferguson, J. H. Straub, and R. B. Smith, Report on the Investigation of the 106T Tank Leak at the Hanford Reservation, USAEC Report, TID-26431, Washington, D.C.: Richland Operations Office, Atomic Energy Commission.

17. D. D. Wodrich, Radioactive Waste Storage Tanks at the Hanford Site, Report, WHC-SA-0937-FP, Westinghouse Hanford Company, Richland, WA (1990).

18. B. G. Levi, Physics Today, Volume 45, page 17 (1992).

19. Govt. Accounting Office, Nuclear Waste: Hanford Single-Shell Tank Leaks Greater than Estimated, Report, GAO/RCED-91-177, Washington, D.C. (1991).

20. Office of Technology Assessment, US Congress, Long-Lived Legacy: Managing High-Level and Transuranic waste at the DOE Nuclear Weapons Complex,Report, OTA-BP-0-83, US Govt. Printing Office, Washington, D.C. (May 1991).

21. R. F. Maness, Stress Corrosion cracking of Mild Steel In Nitrate Solutions, Report, HW-78168, General Electric Company (1968).

22. E. L. Moore, Stress corrosion Cracking of A 515 Grade Carbon Steel, Report, ARH-1290, Atlantic Richfield Hanford Company, Richland, WA (1971).

23. W. W. Koenig, Corrosion rates of Mild Steel and Stainless Steel, Report, HW-14923, General Electric Company (1948).

24. W. W. Koenig and K. L. Sanberg, Corrosion of Redox Waste Storage Tank Construction Material, Report, HW-18595, General Electric Company WA (1950).

25. K. L. Sanbon, A Study of the Effect of $p H$ on First Cycle Bismuth Phosphate Waste on the Corrosion of mild steel, Report, HW-26202, General Electric Company (1952).

26. N. D. Groves, Technical Activities Report - Corrosion and Welding Effect of Lowering the $p H$ in TPB Waste Solutions, Report, HW-29183, General Electric Company (1958).

27. E. C. Pitzer, Corrosion Test SAE 1010 Mild Steel in Synthetic Waste Solution, Report, HW-24136, General Electric Company (1952). 
28. R. E. Olson, Corrosion Tests SAE 1010 Mild Steel in Synthetic Neutralized Redox Wastes, Report, HW-26201, General Electric Company (1954).

29. N. Endow and K. Sanborg, Laboratory Study of the Corrosion of SAE 1010 Steel in Simulated Neutralized Purex Process Waste Solutions, Report, HW-32734, General Electric Company (1954).

30. G. R. Mallet, Corrosion Test of Mild Steel in Redox Waste Tank (SAE 1020), Report, HW-33552, General Electric Company (1954).

31. N. Endow and K. Sanborn, Field Corrosion Test SAE 1020 Carbon Steel in Redox Process Waste Solution Tank 104, 241-S, Report, HW-32755, General Electric Company (1954).

32. N. Endow, Field Corrosion Tests SAE 1020 Steel in Bismuth Waste Storage Tanks, Report, HW-30641, General Electric Company (1954).

33. N. D. Groves, M. C. Fraser and, W. L. Walker, Field Corrosion Tests in Redox and Purex Underground Storage Tanks, Report, HW-37642, General Electric Company (1955).

34. K. L. Sanborn and W. R. Smith, Examination of Removable Tube Bundles for Redox, Report, HW-32642, General Electric Company (1954).

35. R. E. Isaacson an R. E. Tomlinson, ed., Atlantic Richfield Hanford Semiannual Report, Process Development, Nov.1, 1970 through April 31, 1971, Report, ARH-1968B, Atlantic Richfield Hanford Company (1972).

36. H. H. Hopkins, Jr, ed., Atlantic Richfield Hanford Company Semiannual Report, Research and Development, Report, ARH-2656B, Atlantic Richfield Hanford Company (1972-1973).

37. E. L. Alpen, Pacific Northwest Laboratories Monthly Activities Report, February 1974, Report, BNWL-1819, Battelle Pacific Northwest Laboratory, March (1974).

38. L. P. Costas, M. L. Holzworth, and W. C. Rion, Stress Corrosion Cracking of Carbon steel in Simulated Waste Solutions, Report, DP-1023, E. I. DuPont de Nemours and Co., Savannah River Laboratory, Aiken, SC (1966).

39. R. S. Ondrejcin, Investigation of Cooling Coil Corrosion in Radioactive Waste Storage Tanks, Report, DP-1425, E. I. DuPont de Nemours \& Co., Savannah River Laboratory, Aiken, SC (1965). 
40. R. S. Ondrejcin, Chemical Composition of Supernates Stored in SRP High Level Waste Tanks, Report, DP-1347, E. I. DuPont de Nemours \& Co., Savannah River Laboratory, Aiken, SC (1974).

41. R. S. Ondrejcin, Prediction of Stress Corrosion of Carbon Steel by Nuclear Process Liquid Wastes, Report, DP-1478, E. I. DuPont de Nemours \& Co., Savannah Research Laboratory, Aiken, SC (1978).

42. R. S. Ondrejcin, Stress Corrosion Cracking Test with Slow Strain Rate and Constant Current, ASTM STP 665, American Society for Testing and Materials,page 203 (1979).

43. R. S. Ondrejcin, S. P. Rideout and, J. A. Donovan, Control of Stress Corrosion Cracking in Storage Tanks Containing Radioactive Waste, Nuclear Technology, volume 44, page 247 (1979).

44. J. A. Donovan, Inhibition of Nitrate Stress Corrosion Cracking of Mild Steel in Nuclear Process Wastes, Report, DP-MS-75-10, E. I. DuPont de Nemours \& Co., Savannah Research Laboratory, Aiken, SC (1975).

45. R. N. Parkins, Materials Characterization, volume 26, page 303 (1991).

46. J. A. Donovan, Trans. American Nuclear Soc., volume 21, page 266 (1975).

47. J. A. Donovan, Materials Aspects of SRP Waste Storage - Corrosion and Mechanical Failure, Report, DP-1476, E. I. DuPont de Nemours \& Co., Savannah River Laboratory, Aiken, SC (1977).

48. R. N. Parkins, Stress Corrosion Cracking of Low Carbon Steels, in Proceedings of Conference of Fundamental Aspects of Stress Corrosion Cracking, September 11-15, 1967 at Ohio State University, Columbus, OH, NACE, Houston, TX page 361 (1969).

49. L. A. James, Short-term Stress Corrosion Cracking Tests for Cast A27 Steel and A36 Steel Weldments in Simulated Hanford Groundwater, Report, HEDL-7566, Hanford Engineering Developmental Laboratory, Richland, WA (1986).

50. N. Rothwell and M. E. D. Turner, Materials Performance, Volume 29, page 55 (1990).

51. H. R. Baker and C. R. Singleterry, Corrosion, Volume 28, page 385 (1972).

52. S. B. Oblath and J. W. Congdon, Inhibiting Localized Corrosion During Storage of Dilute Wastes, Waste Management '87, Tuscon, AZ (1987). 
53. S. B. Oblath and J.W.Congdon, Inhibiting Localised Corrosion During Storage Of Dilute SRP Wastes, Report, DP-MS-86-139 (1988)

54. J. W. Congdon, Materials Performance, Volume 27, page 34 (1988).

55. J. W. Congdon, Inhibition of Nuclear Waste Solutions Containing Multiple Aggressive Anions, Report, DP-MS-87-85 (1987).

56. D.F.Bickford, J. W. Congdon and, S. B. Oblath, Corrosion of Radioactive Waste Tanks Containing Washed Sludge And Precipitate, Materials Performance, volume 27, page 16 (1988).

57. J. R. Devine, W. M. Bowen, S. A. McPartland, R. P. Elmore and, D. W. Engel, Double-Shell-Slurry Low-Temperature Corrosion Tests, Report, PNL-427, Pacific Northwest Laboratory, Richland, WA (1983).

58. J. R. Devine and W. M. Bowen, Corrosion of Carbon Steel in Oxidizing Caustic Solutions, Report, PNL-SA-11667, Pacific Northwest Laboratory, Richland, WA (1983).

59. D. B. Mackey and J. R. Devine, User's Guide for Waste Tank Corrosion Data Model Code, Report, PNL-5766, Pacific Nortwest Laboratory, Richland, WA (1986).

60. J. R. Devine, W. M. Bowen, D. B. Mackey, D. J. Bates and, K. H. Pool, Prediction Equations for Corrosion Rates of A 537 and a 516 Steels in Double Shell Slurry, Future Pyrex and, Hanford Facilities Wastes, Report, PNL-5488, Pacific Northwest Laboratory, Richland WA (1985).

61. R. N. Parkins, The Stress Corrosion Cracking of Low Strength Ferritic Steels, The Theory of Stress Corrosion Cracking in Alloys, ed. NATO, Brussels (1971).

62. G. Sandoz, C. T. Fuyii, and B. F. Brown, Solution Chemistry within Stress Corrosion Cracks in Alloy Steels, Corrosion Science, Volume 10, page 839 (1970).

63. T. P. Hoar and J. R. Galvele, Anodic Behavior of Mild Steel During Yielding In Nitrate Solutions, Corrosion Science, volume 10, Page 211 (1970).

64. R. N. Parkins and R. Usher, The Effect of Nitrate solutions In Producing Stress Corrosion Cracking in Mild Steel, in First International Congress on Metallic Corrosion, Butterworths, London page 289 (1962). 
65. R. A. Legault, S. Mori and, H. P. Lockie, An Electrochemical Statistical Study of the Efect of Chemical Environment on the Corrosion Behavior of Mild Steel, Corrosion, volume 6, page 12 (1970).

66. M. G. Fontana and N. D. Green, Corrosion Engineering, page 106, McGraw-Hill Book Company, New York, NY (1967).

67. H. H. Uhlig, Corrosion and Corrosion Control, 2nd Edition, John Wiley \& Sons, New York, NY (1971).

68. M. Smialowski and T. Ostrowska, Mechanism of Intercrystalline Corrosion of Mild Steel by Ammonium Nitrate, Corro. et. Anticorr., volume 5 , page 76 (1957).

69. E. Herzog and M. Portevin, Sur La Corrosion Fi Ssurate D'anciers Doux A Faibles Teneurs En Additions Dars Les Nitrates, Metaux et Corrosion, volume 24, page 40 (1949).

70. W. H. Ailor, Handbook of Corrosion Testing, John Wiley \& Sons, New York, NY, page 250 (1971).

71. Workshop on High-Level Waste Tank Systems Structural Integrity, Richland, WA, February 19-20, 1992.

72. D. M. Strachan and L. G. Morgan, Minute of the Tank Waste Science Panel Meeting June 26-27, 1990, Report, PNL-7660, Pacific Northwest Laboratory, Richland, WA (1991).

73. D. A. Reynolds, D. D. Siemer, D. M. Strachan, and R. W. Wallace, Survey of Avialable Information on Gas Generation in Tank 241-SY. 101, Report, PNL-7520, Pacific Northwest laboratory, Richland, WA (1991).

74. G. L. Borsheim and N. W. Kirch, Summary of Single-Shell Tank Waste Stability, Report, WHC-EP-0347, Westinghouse Hanford Company, Richland, WA (1991).

75. R. J. Cash and J. Thurman, Action Plan for Response to abnormal Conditions in Hanford Site Radioactive Waste Tanks Containing Ferrocyanide, Report, WHC-EP-0407, Westinghouse Hanford Company, Richland, WA (1991).

76. L. L. Burger and R. D. Scheele, The Reactivity of Cesium Nickel Ferrocyanide Towards Nitrate and Nitrite Salts, Report, PNL-7550, Pacific Northwest Laboratory, Richland, WA (1990). 


\section{Chemical and Metallurgical Effects \\ in \\ High Level Waste Tanks}

Final Report

to

Los Alamos National Laboratory

(Subcontract 9-XQ2-Y3122-1)

by

K. Linga Murty

Thomas S. Elleman

Charles W. Mayo

Department of Nuclear Engineering

North Carolina State University

Raleigh, NC 27695 


\title{
Chemical and Metallurgical Effects \\ in \\ High Level Waste Tanks
}

\begin{abstract}
Summary
The original proposal included investigations on 3 different aspects : 1. Catalytic and LET Effects on the Radiolytic Production of Hydrogen; 2. Instrumentation Techniques for Remote Determination of Activity Distributions, Flow and Hydrogen Release in High Level Waste Tanks; and 3. Survey of Corrosion and Embrittlement Effects in Carbon Steels. After several iterations, it was decided that NCSU perform only the task 3 on the detailed survey of corrosion and embrittlement effects in carbon steels appropriate for radioactive waste tank walls. Three reports were generated on the related aspects (by Rao K. Mahidhara, Thomas S. Elleman and K. Linga Murty) : 1. Corrosion Failure Processes in Low Carbon Steels; 2. Corrosion and Failure Processes in High-Level Waste Tanks; and 3. Failure Predictions/Rate Models in Low Carbon Steels. These 3 reports are included here as Appendixes and no further work is planned under this subcontract.
\end{abstract}

A proposal was submitted in 1992 to extend the grant to include some experimental aspects, a copy of which is included in the following pages. No decision was made on the proposed extension and thus a new contract needs to be issued for this work. 


\title{
Chemical and Metallurgical Effects in High Level Waste Tanks
}

\author{
Proposal \\ (Supplement and Continuation to 1992-93) \\ to \\ Los Alamos National Laboratory \\ attention of Dr. Harold Sullivan \\ Proposed Budget \\ 2-year total : \$229,270. \\ (FY93: \$109,651.00 FY94: \$119,619.00) \\ by \\ K. Linga Murty \\ Thomas S. Elleman \\ Department of Nuclear Engineering \\ North Carolina State University \\ Raleigh, NC 27695
}

\begin{abstract}
Summary
This work will be to support the Los Alamos National Laboratory's High Level Waste Tank effort in the corrosion and related failure of the tank steels. A review will be made of the waste inventory and the expected radiation doses from which the radiation damage of the steels in terms of dpa and its effect on fracture characteristics will be assessed. Experimental work is proposed on the SCC susceptibility of the representative steels to the chemical environment relevant to waste tanks. The superimposed radiation effects constitute an extension of the proposed investigation.
\end{abstract}




\section{Proposed Research}

\section{Introduction}

Discussions with scientists and engineers at Los Alamos National Laboratory have revealed that various safety concerns exist related to the long-term storage of highlevel liquid wastes in carbon steel tanks. A program at Los Alamos is designed to address the relevant safety issues and to develop bounding conditions for the severity of potential accidents. A part of this effort relates to the determination of the composition of the liquids and sludges in the tanks while a parallel effort is directed towards an analysis of the potential energy releases that could be produced by chemical reaction of tank decomposition products.

During the initial phase of the NCSU project which started in the mid-92, three reviews were made:1-3 Corrosion and Failure in High Level Radioactive Waste Tanks, Failure Processes in Low Carbon Steels, and Corrosion Models of Tank Materials which pointed out some aspects related to corrosion that need further investigations. Recent discussions with LANL personnel lead to this supplemental proposal which involves (1) analytical investigation of low flux effects on radioactive tank materials, and (2) an experimental study on stress corrosion cracking (SCC) of typical steel(s) used for the waste tanks.

Single-walled or double-walled carbon steel tanks have been used for a long time for the storage of radioactive waste solutions and there is considerable information on the integrity of these containers. Details on the failure processes, corrosion mechanisms and models may be found in the reviews made during FY' 92 and it was clear that hydrogen embrittlement and $\mathrm{SCC}$ due to $\mathrm{OH}^{-}, \mathrm{NO}_{3}^{-}, \mathrm{NO}_{2}^{-}, \mathrm{Cl}^{-}$and other ions could lead to tank failures. Transportation of atomic hydrogen (tritium) into the steels and in particular the enhanced diffusion to the crack front with the resulting influence on the fracture behaviors are being studied at NCSU by the Pls under a research grant funded by DOE starting Sep. $92 .{ }^{4}$ In the current proposed research, we plan to investigate the $\mathrm{SCC}$ effects due to the hydroxyl, nitrite, nitrate and other relevant ions.

Similarly, corrosion effects and mechanisms can be influenced by the radiation field. The fact that some tanks have been found to leak supports the existence of corrosion processes that are sufficient to affect tank integrity. While the expected radioactive dose rates of the stored waste are low, recent investigations on LWR support steels 
revealed enhanced embrittlement which brings out the significance of the damage due to low flux radiations. 5,6 It is thus important to characterize the low dose rate effect on the radiation embrittlement (decrease in the shelf energy) of the steels.

\section{Low Dose Effects on Embrittlement of Tank Materials (steels)}

There exist a large number of radioactive species in the stored waste which emit $\gamma$ rays of varied energies. These $\gamma$ rays generate low energy neutrons at flux rates which are relatively low compared to pressure vessels in LWRs. However, recent work on HIFAR materials at Oak Ridge clearly revealed far higher rates of embrittlement than those predicted from extrapolation of the high flux data. 6 it is now believed that neutrons at much lower energies, even down to thermal, give raise to atomic displacements high enough to result in changes in macroscopic properties of ferritic steels. ${ }^{7}$ The main reason for this seems to lie in the fact that at these low dose rates, while the total number of atomic displacements created is relatively low, the fraction annihilated during irradiation is much lower resulting in enough freely moving defects (FMDs).

It is proposed to survey the literature and collect information on the known and predicted radioactive inventory from which the energies and dose rates of the emitted radiations $(\gamma, n$, etc) will be estimated. It should be pointed out that back-of-theenvelope type calculations do indicate very low atomic displacements. We estimate that the total fluence due to neutrons generated from $(\gamma, n)$ reactions to be about $3 \times 10^{13} \mathrm{n} / \mathrm{cm}^{2}$. In addition, one might expect atomic displacements due to $y$-rays which seems to result in atomic displacements of about $3 \times 10^{-11}$ dpa which is about 6 times lower than that expected from $(\gamma, n)$ reactions. Notwithstanding such low estimates made by rough calculations, it might be of significance to take up a detailed systematic evaluation of the damage from the known and predicted radioactive inventory.

A major objective of the task here is to estimate the dpa expected to be accumulated during the design life time of the radioactive waste tanks. Since the goal is to evaluate the embrittlement of the steels, first a review will be made of the dose rate effects on the decrease in the shelf energy (and on increase in the RTNDT) which might need judicious extrapolation to the values corresponding to the radioactive waste tanks. Since these changes due to radiation exposure are sensitive to the composition and the condition (base vs weld vs HAZ) of the ferritic steels, a search will be made of the steels relevant to the radioactive waste tanks. 


\section{Experimental Study (SCC)}

Mild steels such as A516 Grade 70 and A285 Grade B are commonly used as waste tank materials and are known to be susceptible to stress corrosion cracking in appropriate chemical solutions. While some studies were made on A285 steel to establish the relative aggressiveness of waste solutions and to fix the corrosion limits on compositions, work on A516 steel is very limited. ${ }^{1-3,8,9}$ It is important to obtain this type of information so that the stored waste solutions may be modified to minimize or eliminate the corrosion problem. A systematic study on A516 steel is thus warranted.

We propose here an experimental investigation of the stress corrosion susceptibility of A516 Grade 70 steel to simulated waste solutions. A laboratory test will be developed to characterize the effective threshold stress intensity for SCC using 3-point bend tests on specimens of Charpy geometry (Fig.1). Similar geometry is being studied in our DOE research grant on hydrogen embrittlement. 4 In addition, this is the kind of geometry used in our other programs (since 1982) such as (1) the radiation embrittlement of PV steels, 10,11 and (2) ferritic steels at low doses with application to reactor (LWR) supports. 5,6 Moreover, this geometry is suitable both for multi-specimen post exposure as well as single-specimen in situ crack growth experiments. Initially, we plan to work on the first type, the results of which are expected to provide the direction on the slow strain-rate single specimen tests with in situ crack growth studies which might be taken up at later times.

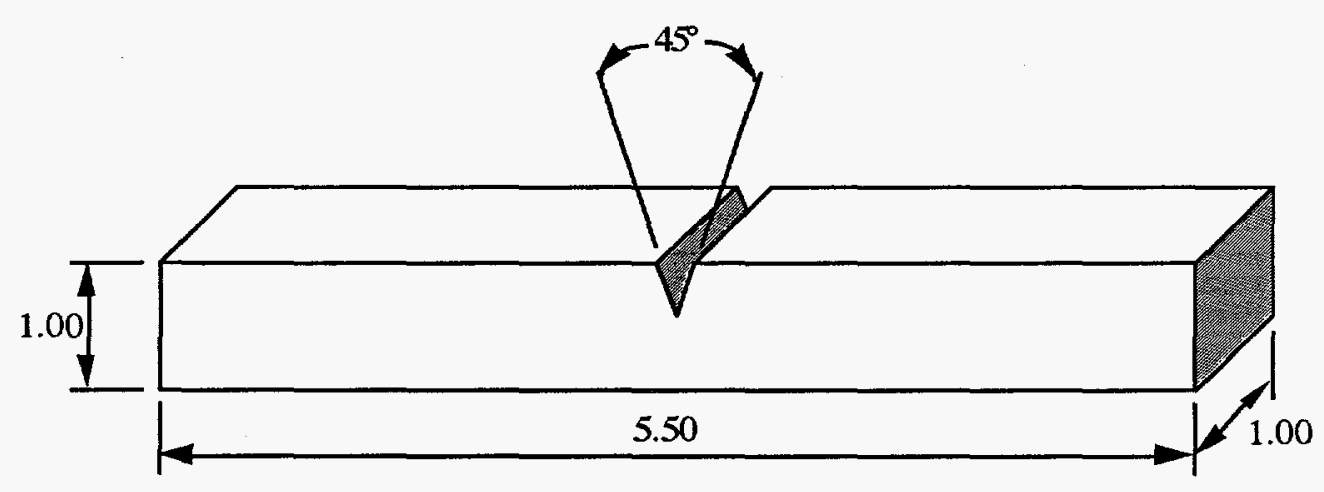

Fig. 1. 3-point bend specimen geometry (dimensions in $\mathrm{cm}$ )

The goal is to expose a number of specimens loaded to different levels of stress intensity to solutions of various concentrations to examine the relative aggressiveness. We propose to load the specimens to various load or stress levels using a fixture such as shown in Fig. 2 where each specimen will be subject to 3-point bend using the 
compression jig (Fig.3) on the closed-loop Instron testing machine. A number of such stressed specimens will be exposed to the specific corrosive medium at varied temperatures and will be examined for crack extension following given exposure period (s). The exposed specimens will be mechanically ruptured in air under 3-point bend mode from which the crack growth will be determined using suitable metallography techniques. These results will enable an evaluation of the effective threshold stress intensity for stress corrosion cracking ( $\left.\mathrm{K}_{\mathrm{SCC}}\right)$. Tests will be performed at elevated temperatures both to accelerate the cracking susceptibility and also to characterize the temperature dependence. It is proposed that a minimum of 20 specimens will be tested.

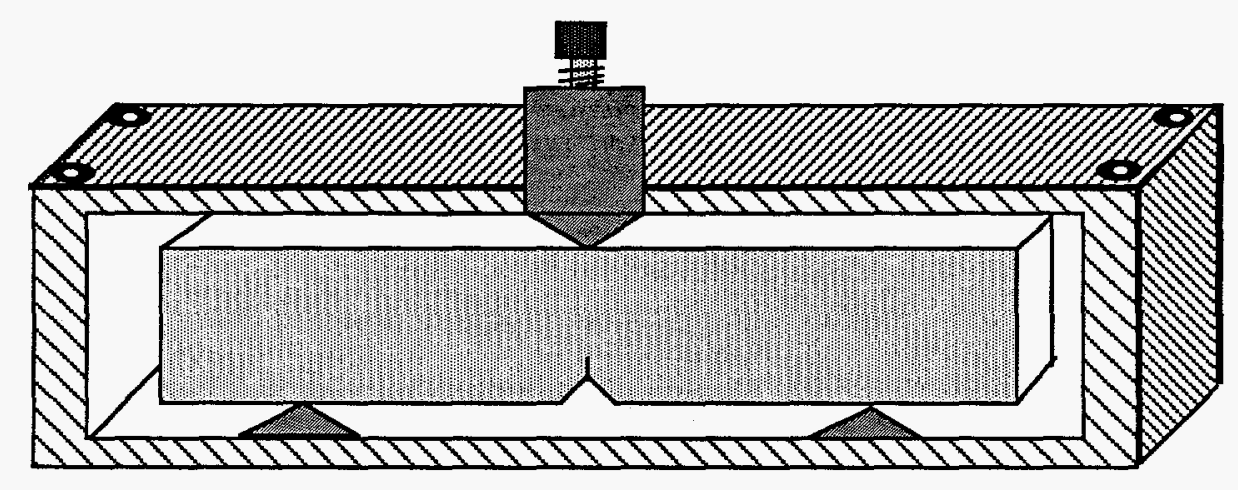

Fig.2. Loaded 3-point bend specimen (for gang set-up) 


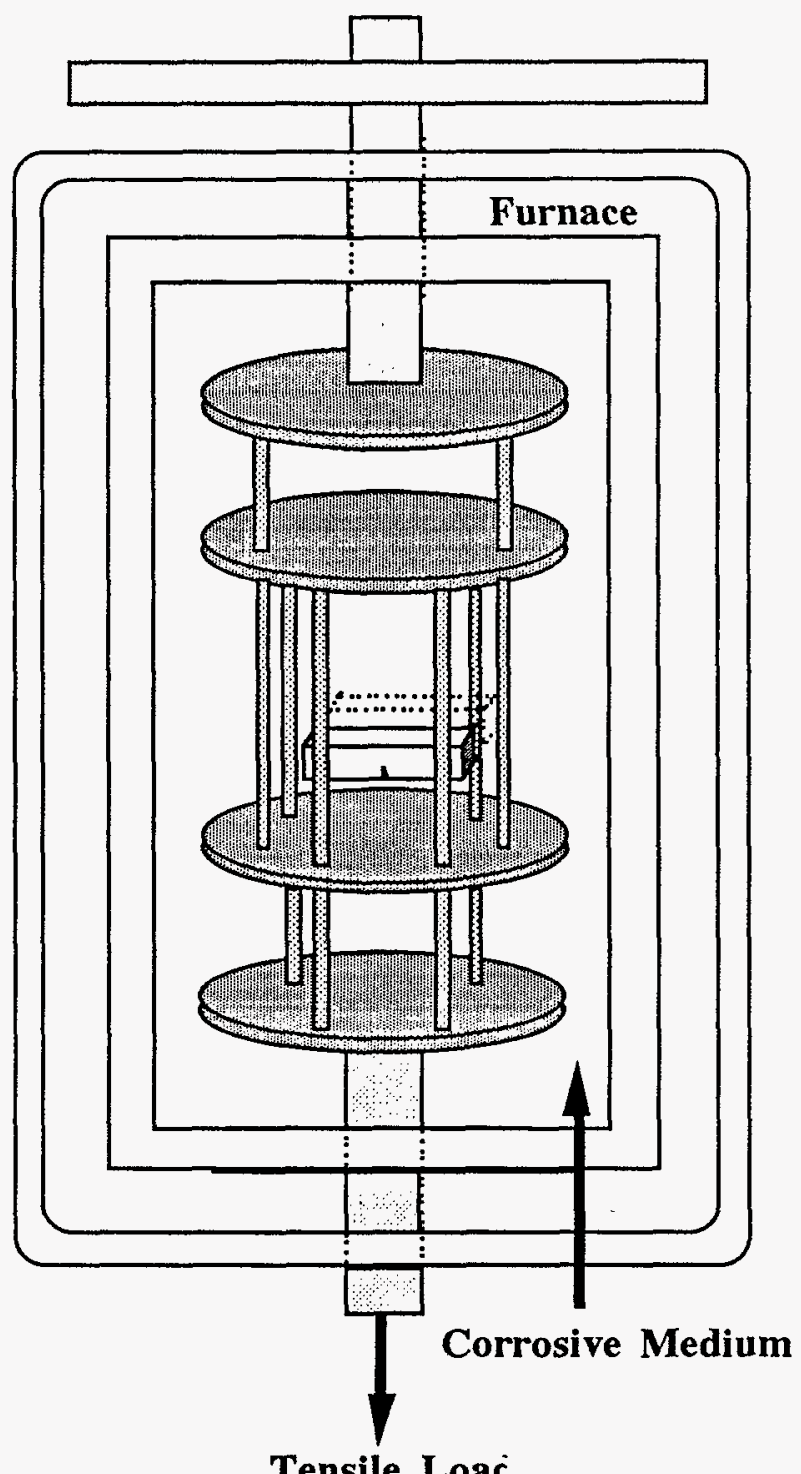

Fig.3. 3-point bend test specimen in compression jig

The corrosive solution will be varied to cover the compositions of $\mathrm{NaNO}_{3}, \mathrm{NaNO}_{2}$ and $\mathrm{NaOH}$ relevant to radioactive wastes that are of concern in the embrittlement of tank steels. While the temperatures are expected to be below $100^{\circ} \mathrm{C}$, we propose to cover a much higher temperature region to obtain the quantitative functional dependence of SCC susceptibility on the test temperature. These results will be useful in extrapolating to relevant temperatures for predicting the remnant life of these steels.

The second method involves single specimen testing under slow strain-rates along with in situ crack growth measurements; however, this type of testing is time 
consuming and material incentive although the results would be of significant value in crack growth predictions. This involves development and construction of some experimental equipment, and this aspect will be taken up during the later part of the project. Here again, we propose to use the 3-point bend Charpy-type specimens (Fig.1) along with the compression jig in Fig.3. The test specimen is subject to a constant displacement-rate $\left(\approx 10^{-4} \mathrm{~s}^{-1}\right)$ in a universal or specially made test machine under suitable atmosphere while the crack growth rate is monitored using methods such as potential drop. We propose here, instead, to characterize the SCC susceptibility of the candidate materials by investigating the effects of corrosive medium (accentuated by electrochemical action) on the bend characteristics such as the yield load, maximum load, displacements to maximum load and to fracture respectively (Fig.4). The load and the load-line displacements will be monitored using a load cell and an LVDT (Fig.4 left) and typical load-displacement curve is illustrated in the Fig. 4 - right. The energies to crack initiation $\left(E_{i}\right)$ and fracture $\left(E_{t}\right)$ will be obtained from these data. These various parameters will be characterized as a function of the environmental variables (ion concentrations and compositions, test temperature, etc.). Fractography will be performed on the tested specimens using SEM.

The strain-rate dependence of the SCC susceptibility is not considered to be of importance; however, this aspect will be considered if time permitting and if it is deemed to be of significance. The current density will be controlled to $\approx 0.2 \mathrm{~mA} / \mathrm{cm}^{2}$ with the specimen used as the anode. Testing will be made at varied temperatures covering the useful range from about 50 to $150^{\circ} \mathrm{C}$. The electrochemical slow strain rate 3-point bend tests are designed based on a method developed by Plackett and Burman. 12 In these tests, the independent variables are the temperature and the concentrations of different ions, and the dependent variables are the various mechanical properties of the steel. A minimum of 10 tests will be performed. 

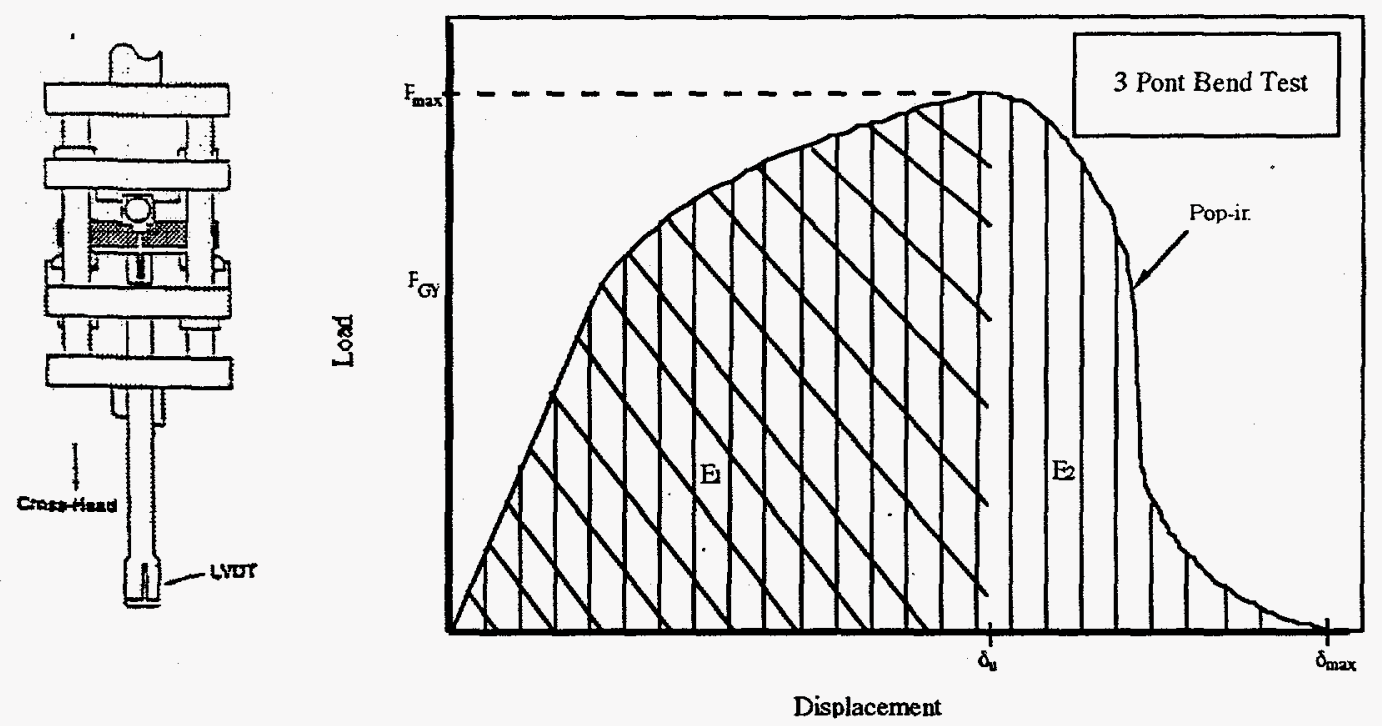

Fig.4.

3-point bend test jig (left) and typical load-displacement curve with relevant parameters (right)

\author{
Specimen : 3 -point bend (Charpy-type) \\ Variables \\ Temperatures : $50-150^{\circ} \mathrm{C}$

$$
\begin{aligned}
& \mathrm{NO}_{3}^{-}: 1.5-5.5 \mathrm{M} \\
& \mathrm{NO}_{2}^{-}: 0-3.5 \mathrm{M} \\
& \mathrm{OH}^{-}: 0-5.0 \mathrm{M}
\end{aligned}
$$ \\ Current density : $0.2-0.3 \mathrm{~mA} / \mathrm{cm}^{2}$
}

Superimposed radiation effects and work on other steels such as A285 Grade B will be considered in the future.

\title{
References
}

1. Rao K. Mahidhara, Thomas S. Elleman and K. Linga Murty, Corrosion Failure Processes in Low Carbon Steels, NCSU Report to LANL, Nov. 1992.

2. Rao K. Mahidhara, Thomas S. Elleman and K. Linga Murty, Corrosion and Failure in High Level Radioactive Waste Tanks, NCSU Report to LANL, Dec. 1992.

3. Rao K. Mahidhara, Thomas S. Elleman and K. Linga Murty, Corrosion Models in Tank Materials, NCSU Report to LANL, Dec. 1992.

4. Thomas S. Elleman and K. Linga Murty, A Study of Hydrogen Effects on Fracture Behavior of Radioactive Waste Tanks, DoE-ER Grant, 9/92-8/94. 
- 5. K. L. Murty et al., Fracture Behavior of A533B Class 1 Steels: Effects of DSA and Neutron Irradiation, 11th International Conference on Structural Mechanics in Reactor Technology (SMiRT-11), Tokyo, Aug. 22 (1991) paper F12/2.

6. K. L. Murty, Radiation Embrittlement of Ferritic Steels: Application to Reactor Supports, Research supported by the Electric Power Research Center at NCSU, 1/92-12/93.

7. G. Brauer et al., Microstructural aspects of neutron embrittlement of reactor pressure vessel steels - $A$ viewpoint from positron annihilation spectroscopy, Nucl. Eng. and Design (1993) and various papers in Proceedings of conference on Irradiation Effects in Metals (PM'91), Hungary, Trans Tech. Pub. (1991).

8. R. S. Ondrejcin, Prediction of Stress Corrosion of Carbon Steel by Nuclear Process Liquid Waste, DP-MS-76-61, International Conference of the ANS, Washington, Nov. 1976; also, see Ondrejcin, R. S., et al, Control of Stress Corrosion Cracking in Storage Tanks Containing Radioactive Waste, Nuclear Technology 44:297 (1979).

9. J. A. Donovan, Inhibition of Nitrate Stress Corrosion Cracking of Mild Steel in Nuclear Process Wastes, Trans. Am. Nucl. Soc., 21 266 (1975).

10. M. S. Wechsier and K. L. Murty, Impurity-Defect Interactions and Radiation Hardening and Embrittlement in BCC Metals, Met. Trans. 20A, (1989) pp.26372649.

11. Y. Jung, Effect of Dynamic Strain Aging on Fracture Characteristics of A533B Class1 Nuclear Pressure Vessel Steel, Ph. D. Thesis, North Carolina State University (1986).

12. R. L. Plackett and J. P. Burman, The Design of Optimum Multifactorial Experiments, Biometrika 33, 305 (1946); see also H. R. Baker and C. R. Singleterry, Inhibition of Stress Corrosion Cracking of AISI 4340 Steel in 10\% Potassium Nitrate Solution at $100^{\circ} \mathrm{C}$, Corrosion-Nace $\underline{28}, 385(1972)$.

\section{Personnel}

Prof. K. Linga (KL) Murty will be the principal investigator and Prof. Thomas S. Elleman will also be involved (low-dose effects) in the project. In addition, a post-doctoral research associate with relevant experience in fracture of steels and 2 graduate students will participate in the activities. Detailed resume of the principal investigator is attached in the appendix.

Dr. K. Linga Murty holds a Ph.D. degree in Materials Science and worked for a number of years at Babcock and Wilcox Co. and Westinghouse on a variety of nuclear metallurgical problems. His interests are in the deformation, creep, fatigue and fracture 
behavior of nuclear materials. He teaches the department courses on nuclear materials and conducts research on defect properties and mechanical properties of nuclear materials. He will have the primary responsibility of the project.

Dr. Thomas Elleman holds a Ph.D. in physical chemistry and has conducted research related to hydrogen transport in solids, radiation effects in materials and gas trapping effects in solids. At various times he has taught department courses in radiological safety, radiation effects on materials and introductory nuclear engineering. 
I. Low Dose Effects on Embrittlement
a. review of radioactive inventory
$1 / 93 \quad 8 / 93$
b. dose calculations
$4 / 93$
$11 / 93$
c. review of embrittlement of steels (A516, A285, etc)
$3 / 93 \quad 11 / 93$
d. correlations and report

II. SCC Experiments (A516 steel)

(1) Gang Specimens
a. Procure materials for testing
$1 / 93 \quad 3 / 93$
b. Procure furnace, SCC chamber
$1 / 93 \quad 4 / 93$
c. Prepare loaded gang specimens
$4 / 93$
$6 / 93$
d. Initiate corrosion testing
e. Analyze experimental results and make correlations
$8 / 93 \quad 6 / 94$

(2) Single Specimens
a. Design and get the assembly for electrochemical testing
$8 / 93 \quad 2 / 94$
b. Initiate 3-point bend tests in air and in corrosive medium
$1 / 94$
c. Analyze experimental results and make correlations
$6 / 94$

(3) a. Procure other steels (A285, ???)*

$6 / 94$

(*based on the experimental results on A516 and discussions with LANL personnel)

b. Superimposed radiation effects 


\section{Appendixes}

Reports

by

Rao K. Mahidhara, Thomas S. Elleman and K. Linga Murty

1. Corrosion Failure Processes in Low Carbon Steels

2. Corrosion and Failure Processes in High-Level Waste Tanks

3. Failure Predictions/Rate Models in Low Carbon Steels 


\title{
Corrosion Failure Processes in Low Carbon Steels
}

\author{
by \\ Rao K. Mahidhara \\ Thomas S. Elleman \\ K. Linga Murty \\ North Carolina State University \\ Raleigh NC 27695-7909
}

Report prepared for

Los Alamos National Laboratory

Contract No. 9-XQ-Y3122-1

November 25, 1992

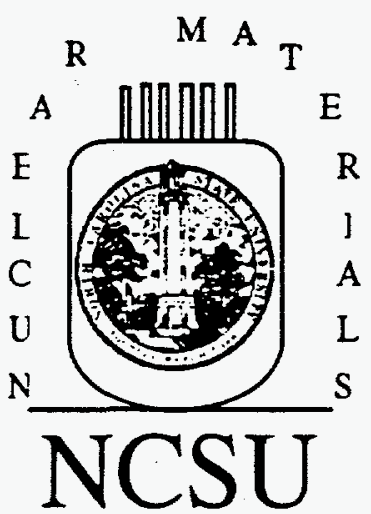




\begin{abstract}
Corrosion failure is an issue of concern for the low alloy carbon steel tanks that contain high level radioactive waste at the Hanford and Savannah River sites. The purpose of this report is to review the conditions and mechanisms of failure of low carbon steels. An earlier report summarized the work at the two sites related to tank corrosion while this report deals with a broader review of corrosion processes in carbon steels as obtained from the general literature. A background is provided on the high-level wastes and the tank construction materials. The mechanisms by which of carbon steels degrade, particularly pitting corrosion, hydrogen embrittlement and stress corrosion cracking are discussed. Passivation issues are also considered.
\end{abstract}




\section{Contents}

1 INTRODUCTION 1

2 BACKGROUND 1

2.1 Radioactive Wastes ...................... 1

2.2 Radioactive Waste Storage Tanks ........... 2

2.3 Carbon Steels ...................... 3

2.4 Radioactive Waste Composition ........... 5

3 FAILURE PROCESSES IN LOW CARBON STEELS

4 VAPOR-PHASE CORROSION 8

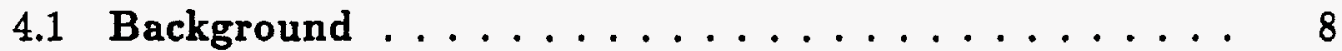

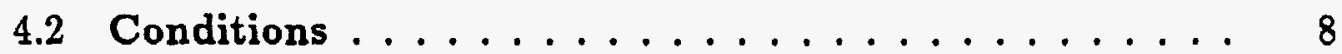

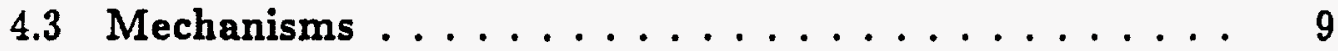

5 LIQUID-PHASE CORROSION 11

6 LIQUID-PHASE PITTING CORROSION 11

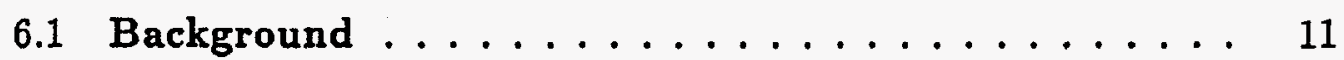

6.2 Conditions ........................... 13

7 INITIATION OF PITS

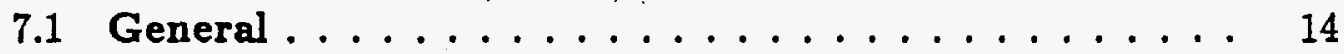

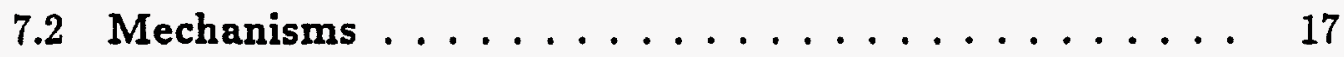

7.2.1 Theory of Competetive Ion Adsorption . . . . . . . 18

7.2.2 Anion Penetration and Migration Theories ....... 18 
7.2.3 Thermodynamic Theory of Pitting . . . . . . . . 19

7.2.4 The Mechano-Chemical Model ........... 19

7.2.5 Localized Acidification Theory . . . . . . . . . . . 20

7.2.6 Halide Nuclei Theory. . . . . . . . . . . . . 21

7.2.7 An Evaluation of Pit Initiation Mechanisms ........ 21

8 PROPAGATION OF PITS 24

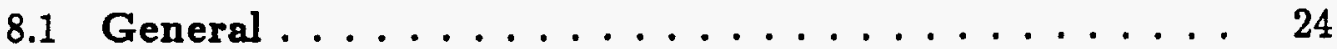

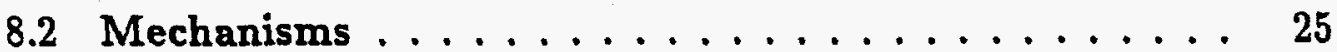

8.2.1 Pit Growth due to an Active Surface at the Base of the Pit and Chemically Inactive Walls ........... 25

8.2.2 Pit Growth due to an Active Surface at the Base of the Pit and Chemically Active Pit Wall .......... 27

8.2.3 Pit Growth Limited by Salt Film . . . . . . . . . . . . 28

8.2.4 An Evaluation of Pit Propagation Mechanisms . . . . . 29

9 STRESS CORROSION CRACKING 29

9.1 Conditions ..................... 30

9.2 Electrochemical Effects . . . . . . . . . . . 32

9.3 Mechanisms ................... 36

9.3.1 Film Rupture/ Slip Dissolution Mechanism . . . . . . 36

9.3.2 Intergranular Stress Corrosion Cracking: Grain Boundary Cleanliness lssues ................ 39

9.3.3 Hydrogen Embrittlement: General . . . . . . . . . . . 43

9.3.4 Hydrogen Embrittlement: Carbon Steels ........ 45

9.3.5 Surface Mobility .................. 50

9.3.6 Stress Sorption Mechanism ............. 51 


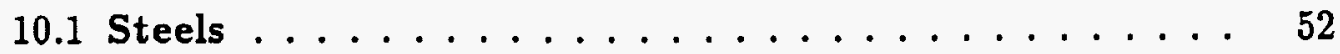

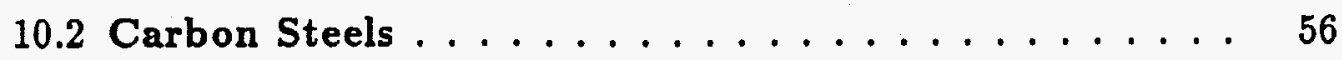

10.2.1 Corrosion Protection by Addition of Corrosion-retarding Substances (Inhibitors) . . . . . . . . . . . 58

10.2.2 Corrosion protection by electrochemical (cathodic and anodic) corrosion potential . . . . . . . . . . . . 62

11 RADIATION EFFECTS 63

11.1 Background $\ldots \ldots \ldots \ldots \ldots \ldots \ldots$

11.2 Carbon Steels . . . . . . . . . . . . . 64

12 SUMMARY AND CONCLUSIONS 66

13 REFERENCES 


\section{List of Figures}

1 Schematic determination of critical pitting potential, $E_{\text {pit }}$, from anodic polarization curve. .............

2 (a) The Pickering-Frankenthal model for propagation of a pit with an active metal base [81]. (b) The Galvele modification of the Pickering-Frankenthal model takes into account hydrolysis and suppression of the $\mathrm{pH}[71]$. Both models assume quasisteady-state conditions. ...............

3 Simultaneous tensile stress, susceptible metallurgical condition, and critical corrosive solution required for stress corrosion cracking. .......................

4 Schematic anodic polarization curve showing zones of susceptibility to stress corrosion cracking. . . . . . . . . . .

5 Anodic polarization curves on mild steel in boiling $8 \mathrm{~N} \mathrm{NaOH}$ and boiling $4 \mathrm{~N} \mathrm{NH}_{4} \mathrm{NO}_{3}$. ..............

6 Anodic polarization curves at different potential sweep rates for mild steel in $\mathrm{Na}_{2} \mathrm{CO}_{3}+\mathrm{NaHCO}_{3}$ at 90C [104]. . . . . . .

7 Schematic summary of proposed mechanisms of stress corrosion

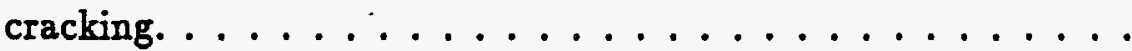

8 Schematic diagram showing potential ranges over which SCC of carbon steel occurs in various solutions [161] .........

9 Pourbiax diagram for iron superimposed on the diagram for chromium designated by dashed lines. Shaded area indicates stability of $\mathrm{Cr}_{2} \mathrm{O}_{3}$ [201]. .................

10 Potential-pH diagram for iron in sulfate solutions. Iron concentration $10^{-3}$ mole/liter, $25 \mathrm{C}$ [202]: (1) unprotected, corroding specimen; (2) cathodically protected specimen; (3) anodically protected specimen. . . . . . . . . . . . .

11 Effects of nitrite concentration and potential on the reduction in area to fracture C-Mn mild steel specimens in boiling $8 M$ $\mathrm{KMnO}_{3}$ solution by slow strain rate testing [97]. . . . . . 
12 Ranges of $\mathrm{pH}$ and potential for bulk solutions in which stress corrosion cracking of carbon steels and low alloy steels with low to medium strengths is normally observed $[206]$. . . . . . . 


\section{List of Tables}

1 Compositions of the Mild Steels Used For Construction Of Tanks (in \%) ................... 5

2 Typical Double Shell Slurry Composition Range . . . . . . 6 


\section{INTRODUCTION}

The Hanford Site in south-central Washington State has been a major U.S. Governmental facility for the research, development and storage of High Level Wastes. Large underground storage tanks have been the central storage facilities at the Hanford Site. The liquid radioactive wastes resulting from chemically processing nuclear reactor spent fuel from which the plutonium and uranium have been recovered, have been neutralized and placed in tanks for the past 46 years. Liquid wastes from other processes, laboratories, and reactor decontamination solutions have also been sent to the tanks. Also, the wastes have been concentrated, selected radioisotopes removed, and the different waste types intermingled. This large volume of multiple waste types, much of it stored in old facilities, poses a challenging waste management issue to the nuclear industry.

Extremely high standards of protection for individuals have been instituted. The management of radioactive waste, which for the first 20 years or so of the nuclear age was regarded as a matter of good housekeeping, has now broadened almost into a discipline in its own right, embracing subjects as diverse as radiation biology, corrosion, chemical engineering, and computer modeling. In addition to the Hanford Site, the defense wastes have also been stored in the form of liquids, solids or sludges at the Savannah River Plant (SRP) at Aiken, South Carolina, and at the Idaho Chemical Processing Plant (ICPP) at Idaho Falls, Idaho in low carbon steel and stainless steel tanks, respectively. Also, civilian wastes are stored at West Valley, New York.

\section{BACKGROUND}

\subsection{Radioactive Wastes}

Hanford Defense Waste is a complex chemical system. The high-level waste has been accumulated over a 46 year period as the principal waste material resulting from the production of plutonium for the defense program. While the waste contains large amounts of radioactive material, the bulk of the waste consists of nonradioactive chemicals that were used in the separation of the nuclear material. The original war-time plant used the bismuth phosphate process which separated only the plutonium (as a co-precipitate with bismuth phosphate) and the alkaline high-level wastes contained all of the uranium as well as the fission products. 
Near the end of World War II, an improved method of separating and purifying plutonium and uranium from irradiated reactor fuel was developed by the Metallurgical Laboratory of the Manhattan Project. This process, known as the Redox Process, made use of the counter-current extraction with an aliphatic ketone combined with control of the oxidation states of plutonium to effect the separation of plutonium and uranium from the fission products and the subsequent separation of the two elements from each other. The Redox process produced the first radioactive raffinate by liquid-liquid extraction separation. In addition to $\mathrm{HNO}_{3}$, Redox waste contained principally fission products and aluminium nitrate; dichromate ion was the minor but important component. The Redox waste was neutralized to a $\mathrm{pH}$ of 10-12 with caustic, and stored in mild steel tanks without special cooling. The Redox process began production at Hanford in 1951 and continued in operation until mid-1967.

A principal disadvantage of the Redox process was the volatile and inflammable nature of the methyl isobutyl ketone solvent. When additional chemical reprocessing capacity was needed in the mid-1950s, the Redox process was replaced by another solvent extraction method which used a high-boiling, high flashpoint solvent and which produced substantially lower volume of waste. Known as the Purex Process, aluminium as a salting agent was replaced by nitric acid in the process and this was made possible by the use of tributylphosphate (TBP) as an extractant. The high-level waste resulting from the process contained principally fission products, nitric acid and ferric sulfate. This method is now used world-wide in fuel reprocessing plants. Purex operations began at Hanford in 1955 and continued until 1972, when the plant was placed on standby to await build-up of a backlog of spent fuel from the nuclear reactor. Both the Redox and Purex waste types were neutralized at the Hanford and Savannah River Plant prior to storage.

Also, there was another important issue with respect to the High-Level Wastes. Ferrocyanide was used in the 1950 s to remove cesium-137 from the liquid waste. Approximately 140 tonnes of ferrocyanide was mixed with more than 100,000 cubic meters of waste which was then piped to waste storage tanks where the ferrocyanide precipitated. During the years, the liquid has been mostly removed from these tanks, but the ferrocyanide sludges, and nitrate salts remain [2].

\subsection{Radioactive Waste Storage Tanks}

The Hanford high-level radioactive waste was neutralized with aqueous sodium hydroxide, is stored in underground storage tanks constructed of reinforced concrete with a liner made of carbon steel. The liner decision was based 
in part on results of laboratory corrosion studies conducted by the Clinton Laboratory [1].

Hanford Site tanks are of two types called single-shell tanks and double-shell tanks. They are located in clusters called tank farms. Single-shell tanks, 149 in number, range in size from a 210 -cubic-meter to a 3,800-cubic-meter capacity and were constructed between 1943 and 1964. The tanks are constructed of reinforced concrete with a carbon steel liner and a soil overburden of 2.4 meters. The tanks are equipped with monitoring instrumentation for waste level and temperature. Sixty-six tanks have leaked an estimated 2,800 cubic meters of solution. In the mid-1970s, commitment was made to deactivate the 149 tanks and store the high level liquid waste in double-shell tanks. The goal was met in November 1980. Various evaporative techniques have been used since 1950 to reduce the volume of the liquid waste and to ultimately allow storage in the double-shell storage tanks which currently store 140,000 cubic meters of sludge (which consists of solids of hydrous metal oxides precipitated from the neutralization of acid waste), saltcake (which consists of various salts formed from evaporation of water in the tanks), and liquids (which exist as supernatant and interstitial liquid). The radionuclide content is approximately 160 million curies, mostly cesium-137 and strontium-90.

Twenty-eight double-shell tanks, ranging from a 3,800- to a 4,300-cubic-meter capacity, were constructed between 1968 and 1986. These tanks are tank within a tank. The primary (inner) tank is constructed of carbon steel that was heated to relieve the weld stresses after construction. The primary tank is located within a reinforced concrete and a steel-lined outer tank with a 76centimeter-wide annular space between them. The high-heat tanks are cooled by allowing the wastes to boil, condensing the steam, and returning the condensate to the tanks. Tanks with less heat are cooled by the air flow through the tank annulus between the primary and secondary tanks and through the primary tank vapor space. The tanks are equipped with automatic monitoring systems. The double-shell tanks were placed into service beginning in 1971 . The sides and bottom of all the tanks are lined with mild steel plate welded to form a seamless inner steel container, which acts as a leak-tight barrier protecting the concrete from attack by caustic wastes. No double-wall tanks at Hanford have leaked. There are currently more than 7,600 cubic meters of waste containing 110 million curies stored in these tanks.

\subsection{Carbon Steels}

The low carbon steel selected for construction of tanks, must perform well in the following categories: 
- Mechanical strength and toughness.

- Fabricability and cost.

- Metallurgical phase stability

- Resistance to:

- Hydrogen embrittlement and hydrogen-induced degradation.

- Uniform oxidation and dissolution.

- Pitting.

- Stress corrosion cracking (SCC).

- Radiation-enhanced degradation.

- Microbiologically induced degradation.

Federal law requires that the high-level radioactive waste containers provide "substantially complete containment" for a period of 300 to 1000 years, with a very slow, controlled release of radionuclides allowed for 10,000 years [2]. High-level waste tanks both at Savannah River Site at Aiken, SC and Hanford Site at Hanford, WA had developed leaks at the walls of the primary vessel of tanks designed and built before 1960 at Savannah River [3] and Hanford [4]. The importance of preventing accidental leaks of stored waste to the ground had resulted in various corrosion studies on mild steel at Hanford in neutralized waste which were compiled by Lini [5]. Lini [5] has concluded that stress corrosion cracking (SCC) was the most serious threat to the integrity of the mild steel liners.

Nitrate stress corrosion cracking in particular was believed to be the cause of the leaks in the walls. Several studies in the review by Lini [5] have thus led to the stress annealing of all new tanks built at Hanford and the Savannah River Plant. Additionally, all tanks built since 1968 have been of doublewall construction with improved design and materials at both facilities with possible use of cathodic protection.

From the data available in the literature, it was established that within the family of low carbon steels, annealed ASTM A 516-70 or A 537 Class I were far superior to the A 285 Grade B steel used for the early tanks [6, 7]. This was because the ductile-to-brittle transition temperature (DBTT) for the A 285 Grade B $(20 \mathrm{C})$ was considerably higher than the stress relieved A 516-70 $(-18 \mathrm{C})$ and $\mathrm{A} 537$ Class I (-45 C) [8]. Interestingly, based on elongationelectrochemical tension tests, it has been confirmed that under identical test condition, the resistance to cracking increased in the order A 285-B, A 516-70, 
and A 537 Class I [8]. Especially, the last two types have finer microstructure and smaller amounts of ferrite along with improved fracture toughness compared to A 285-B steel and were specified for new tank construction beginning in 1976. Later tanks were built of the more stress corrosion resistant A 516-70. Tanks are now being built of annealed A 516-70 or A 537 Class I. These last two alloys were chosen to improve mechanical performance and are equivalent to A 516-70 (rolled) in stress corrosion resistance. The compositions of the mild steels are shown in Table 1 . These steels have been extensively studied

Table 1: Compositions of the Mild Steels Used For Construction Of Tanks (in \%)

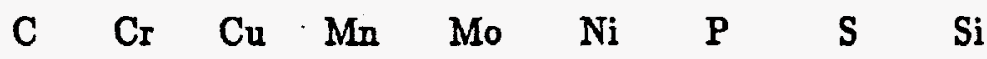

ASTM A 537 Class I

$\begin{array}{llllllllll}\text { Heat 1 } & 0.15 & 0.15 & 0.20 & 1.26 & <0.01 & 0.20 & 0.026 & 0.007 & 0.43 \\ \text { Heat 2 } & 0.15 & 0.19 & 0.26 & 1.20 & 0.04 & 0.13 & 0.008 & 0.008 & 0.25\end{array}$

$\underline{\text { ASTM A 516-70 }}$

Heat 1

$\begin{array}{lll}0.13 & 0.03 & 0.10\end{array}$

$0.89<0.01$

0.05

0.009

0.020

0.26

ASTM A 285

Grade B

0.22

0.3

0.4

$0.9 \quad 0.12$

$0.40 \quad 0.035$

0.04

from a corrosion standpoint in order to provide a technical basis for guiding radioactive wastes, to identify causes of materials deficiencies that were experienced at Savannah River Plant and suggest modifications in the construction of the tanks to increase the integrity of the tanks and provide a more secure containment both at Savannah River and Hanford Sites.

\subsection{Radioactive Waste Composition}

Both the high-level Redox as well as the Purex Wastes are essentially nitric acid wastes. High-level wastes from the various separation processes have been mixed, and therefore the composition is not uniform from tank to tank. These wastes are normally acidic containing essentially $\mathrm{HNO}_{3}$. These nitric acid 
wastes are neutralized prior to storage as liquid. In general high-level wastes in the storage tanks consist of sodium salts such as nitrate, nitrite, carbonate, aluminate, and small amounts of the hydrous oxides of iron and manganese. Approximately $90 \%$ of the waste is soluble salt, primarily sodium nitrate. The sodium nitrate results from neutralization of nitric acid processing solutions with sodium hydroxide. These salts are distributed between an aqueous supernatant liquid and a solid, ill-defined precipitate or sludge. The sludge which constitutes $10 \%$ of the waste is formed by the precipitation of iron, aluminium, transition metals, and transuranic hydroxides. An approximate average overall composition of the sodium salts [15] is given in Table 2.

Ferrocyanide was used in the mid-50s at the Hanford Site as part of a carrier precipitation process to remove cesium from radioactive waste supernates. The ferrocyanide was added as a solution of either the sodium $\left(\mathrm{Na}_{4} \mathrm{Fe}(\mathrm{CN})_{6} .10 \mathrm{H}_{2} \mathrm{O}\right)$ or potassium $\left(\mathrm{K}_{4} \mathrm{Fe}(\mathrm{CN})_{6} .3 \mathrm{H}_{2} \mathrm{O}\right)$ salt. The cesium was precipitated as cesium nickel ferrocyanide $\left(\mathrm{Cs}_{2} \mathrm{NiFe}(\mathrm{CN})_{6}\right)$ and settled to the bottom of some SSTs where it exists with other compounds in a layer of sludge. This complex is so strong that the salts are often considered nontoxic. However, when heated to a sufficiently high temperature, ferrocyanide compounds will undergo a rapid exothermic reaction with nitrate and nitrite salts [9]. Today the high

Table 2: Typical Double Shell Slurry Composition Range

$\begin{array}{lr}\text { ANION/ } & \text { COMPOSITION } \\ \text { COMPOUND } & \text { Range (MOLARITY) }\end{array}$

$\begin{array}{lr} & \\ \mathrm{OH}^{-} & 0.5-10.0 \\ \mathrm{NO}_{3}^{-} & 1.0-8.0 \\ \mathrm{NO}_{2}^{-} & 0.2-10.0 \\ \mathrm{AlO}_{2}^{-} & 0.0-5.0 \\ \mathrm{CO}_{3}^{-} & 0.2-0.25 \\ \mathrm{PO}_{4}^{3-} & 0.0-2.0 \\ \text { EDTA/HEDTA } & 0.0-1.0 \\ \text { Citrate } & 0.0-0.6 \\ \mathrm{SO}_{4}^{2-} & 0.05\end{array}$

level wastes are maintained at relatively high $\mathrm{pH}(10-12)$ by the addition of high levels of sodium hydroxide. Sodium nitrite is the major inhibitor used to reduce the occurrence of stress corrosion cracking (SCC). In addition, the highlevel wastes contain fission-product radionuclides and actinide elements, such as uranium, plutonium and neptunium. Small quantities of organic matter, 
for example entrained extraction solvents, which are primarily long-chained hydrocarbons have occasionally been part of liquid wastes. These extraction solvents are linked to operational mishaps. It has been suggested $[2,9]$ that, such organic matter is rapidly and completely destroyed by radiolysis to give largely carbon-dioxide in the presence of intense radiation from high-level wastes. The $\mathrm{CO}_{2}$ combines with sodium hydroxide in the wastes, and water to form carbonates.

Additionally, absorption of $\mathrm{CO}_{2}$ from air can convert $\mathrm{NaOH}$ to $\mathrm{Na}_{2} \mathrm{CO}_{3}[6$, 7]. Thus the organic content of the aged high-level wastes is reduced below detectable limits sometimes. Also, radiolytic conversion of nitrite to nitrate, separation of radionuclides into soluble and insoluble fractions, and decay of radionuclides can occur in a continuous manner $[6,7]$. Gamma radiolysis of salts can give rise to increasing levels of hydrogen ions and gaseous hydrogen thereby promoting the SCC of mild steels $[2,9]$.

Therefore, the composition of individual tanks varies widely, depending on the detailed history of their contents. A review has been published of the corrosion of metals and alloys in nitric acid and Purex waste covering the period 1947 through 1975 [10]. This review along with that of Lini [5] on corrosion of mild steel in neutralized waste are suggestive of the importance of pitting corrosion and stress corrosion cracking and nitrate and alkaline SCC in particular.

\section{FAILURE PROCESSES IN LOW CARBON STEELS}

Four distinct forms of liquid-phase corrosion attack may be expected in carbon steel systems such as the high-level waste tanks on the basis of literature:

- General corrosion - the surface is attacked uniformly resulting in a gradual thinning of the structure.

- Pitting - the surface is attacked at very localized sites forming relatively deep pits or crevices. Pitting may cause very rapid penetration of the structure.

- Beachline attack - the metal is attacked more rapidly at the liquid-air (vapor) interface.

- Stress corrosion cracking (SCC) - the metal cracks at an imposed load much lower than its normal tensile strength under the influence of an 
imposed stress and a slightly corrosive environment. This form of attack presents a particular problem because the metal cracks at an imposed load much lower than its normal tensile strength. Consequently, rate of propagation of stress corrosion cracks is so fast that it is not feasible to provide a corrosion allowance.

The review by Lini [5] is suggestive that vapor-phase corrosion is an important degradation mode in single-shell tanks [5] that are considered inactive. This is because it leads to pitting corrosion in these tanks. Consequently, this process may be of relevance at the liquid-air(vapor) interface of active doubleshell tanks also. Aqueous corrosion is important in the double-shell tanks. Promoters like $\mathrm{Cl}^{-}, \mathrm{NO}_{3}^{-}$etc., depolarizers like $\mathrm{O}_{2}, \mathrm{H}^{+}$etc. and inhibitors like $\mathrm{OH}^{-}, \mathrm{NO}_{2}^{-}$etc., play important roles in the localized corrosion (LC) and SCC of the candidate materials. Additionally, gamma radiolysis can generate hydrogen peroxide, various oxides of nitrogen, and may be influencial in contributing to container corrosion.

\section{VAPOR-PHASE CORROSION}

\subsection{Background}

When a metal is exposed at room or elevated temperatures to oxidizing gas (e.g., oxygen, or halogens) corrosion may occur in the absence of liquid electrolyte. This is sometimes called "dry" corrosion in the absence of a liquid electrolyte or "vapor-phase" corrosion in the presence of liquid. Under such a situation, a solid reaction-product film or scale (a scale is a thick film) forms on the metal surface through which the metal, the gas phase, or both must diffuse in order for the reaction to continue.

\subsection{Conditions}

Humidity is necessary for vapor phase corrosion. A thin layer of condensed water deposits on the surface to provide the electrolyte needed for electrochemical corrosion. Although necessary, humidity is not sufficient. Even in very humid environments, corrosion of uncontaminated surfaces is often relatively low in unpolluted atmospheres.

Pollutants increase vapor-phase corrosion by enhancing the electrolyte properties and stability of films that condense on the surface. The pollutants 
(nitrates, chlorides, oxygen species from organic degradation etc.) can provide films on the surface of the steel.

Temperature has a variable effect on corrosion. At ambient temperatures corrosion rates may be relatively low but the lower temperature may enhance the condensation of aqueous corrosion films to increase corrosion. Higher temperature may dry the surface and reduce corrosion.

Thus a combination of high humidity, higher temperature, and the presence of pollutants from the high-level nuclear wastes can influence corrosion behavior of the waste tanks.

\subsection{Mechanisms}

Generally, in the presence of dry or humid air, steel or iron forms a thin oxide film composed of an inner layer of magnetite, $\mathrm{Fe}_{3} \mathrm{O}_{4}\left(\mathrm{FeO}_{\mathrm{Fe}} \mathrm{O}_{3}\right)$, covered by an outer layer of $\mathrm{FeOOH}$ (rust). Some $\mathrm{Fe}$ in magnetite is in the ferrous (FeO) and the rest in the ferric $\left(\mathrm{Fe}_{2} \mathrm{O}_{3}\right)$ oxidation state. The outer $\mathrm{FeOOH}$ layer is penetrated by fissures, from which most of the water has evaporated, allowing complete oxidation of magnetite to hydrated $\mathrm{Fe}_{2} \mathrm{O}_{3}$ or $\mathrm{FeOOH}\left(\mathrm{Fe}_{2} \mathrm{O}_{3} \cdot \mathrm{H}_{2} \mathrm{O}=\right.$ $2 \mathrm{FeOOH}$ ). Pores in the magnetite are filled with condensed water and become plugged by insoluble oxide corrosion products.

The electrochemical mechanism involves anodic dissolution of iron,

$$
F e \longrightarrow F e^{2+}+2 e^{-}
$$

under the inner magnetite layer. Ferrous ions in the saturated, or nearsaturated, solution within the pores of the magnetite react with oxygen at the outer magnetite surfaces to form additional magnetite by

$$
3 \mathrm{Fe}^{2+}+2 \mathrm{OH}^{-}+\frac{1}{2} \mathrm{O}_{2} \longrightarrow \mathrm{Fe}_{3} \mathrm{O}_{4}+\mathrm{H}_{2} \mathrm{O}
$$

The cathodic reduction reaction is

$$
8 \mathrm{FeOOH}+\mathrm{Fe}^{2+}+2 e^{-} \longrightarrow 3 \mathrm{Fe}_{3} \mathrm{O}_{4}+4 \mathrm{H}_{2} \mathrm{O}
$$

in which ferric iron in $\mathrm{FeOOH}$ (rust) is reduced to ferrous iron in $\mathrm{Fe}_{3} \mathrm{O}_{4}$ (magnetite) at the interface between the two. Oxygen from the vapor-phase migrating through in the outer $\mathrm{FeOOH}$ layer, can then oxidize the magnetite to rust by

$$
3 \mathrm{Fe}_{3} \mathrm{O}_{4}+0.75 \mathrm{O}_{2}+4.5 \mathrm{H}_{2} \mathrm{O} \longrightarrow 9 \mathrm{FeOOH} \text {. }
$$


Should the anodic reaction become localized, anion enrichment may occur locally. Copious anodic production of positively charged $\mathrm{Fe}^{2+}$ attracts negative anions, e.g., $\mathrm{Cl}^{-}, \mathrm{NO}_{3}^{-}$, oxygen species from organic degradation etc. to sites like grain-boundaries and inclusions. Hydrolysis by

$$
\mathrm{Fe}^{2+}+2 \mathrm{H}_{2} \mathrm{O}+2 \mathrm{Cl}^{-} \longrightarrow \mathrm{Fe}(\mathrm{OH})_{2}+2 \mathrm{HCl}
$$

produces localized $\mathrm{pH}$ reductions at the sites resulting in pits.

Early reports [11-17] using SAE 1010 and 1020 steel confirmed that at $\mathrm{pH}>10$ and temperature of $100 \mathrm{C}(220 \mathrm{~F})$ there was little general corrosion. Extensive pitting corrosion was observed on that portion of the mild steel coupon exposed to the vapors ( 1.8 mils after 24 hours). The effects of $\mathrm{pH}$ were also investigated and it was concluded that there were no ill effects in lowering the $\mathrm{pH}$ from 9 to 7 . At $\mathrm{pH} 6$ there was extensive pitting corrosion of the metal exposed to the vapors.

Olson [16] reported a maximum rate of general corrosion of $48 \times 10^{-5}$ inches/month $(6 \mathrm{mils} / \mathrm{year})$ for a $1 \times 10^{3}$ - hour test at $100 \mathrm{C}$. The range observed was 0.3 to $48 \times 10^{-5} \mathrm{ipm}$. Furthermore, he observed no pitting corrosion and no evidence for accelerated corrosion at the liquid vapor interface. Olson concluded that at a uniform rate of corrosion of 6 mils/year, one-half the wall thickness of 0.38 inch steel tank would be removed in $\mathbf{3 0}$ years. Insitu studies in tanks containing Bismuth Phosphate Process Waste also confirmed pitting corrosion on mild steel samples exposed to vapors $[18,19]$. The deepest pit was 11 mils with an average of 6 mils. This corresponds to a rate of pitting of $18 \mathrm{mpy}$ (based on a 5,400 hour test). Unfortunately, these reports document several observation of pitting without adequate chemical analysis of the pits.

There continues to be a concern at Savannah Research Laboratory that the storage of washed potassium tetraphenyl borate may result in the pitting of carbon steel waste tanks at or near the interface of the air and liquid [20-22]. It has been suggested [23] that low inhibitor levels in combination with halides in the washed sludge and precipitate make coupon tests and tank operations sensitive to the effects of evaporation and condensation. For instance, if water evaporates, condenses and runs down the tank wall or test coupon, it will leave water low in $\mathrm{pH}$ and inhibitors at the surface of the water. Halides may migrate to the area more rapidly than the inhibitors, and a concentration cell may be set up which is favorable for pitting. Furthermore, pitting at and above the waterline and occasionally below the water on the coupons has been observed [24-26] when coupon tests in simulant washed precipitate slurries were conducted. A recent meeting at Hanford [27] reemphasized the potential importance of pitting corrosion. 


\section{LIQUID-PHASE CORROSION}

In the presence of liquid phase containing nitrate ions, nitrite ions, hydroxide ions, carbonate ions, oxygen and organic species, the rates of LC (localized corrosion) and SCC (stress corrosion cracking) are more likely to control tank life than rates of uniform oxidation or dissolution. Rates of uniform oxidation and dissolution are typically orders of magnitude less than the rates of pitting corrosion or stress corrosion cracking. This is probably why general corrosion has not been a threat to waste tank integrity.

\section{LIQUID-PHASE PITTING CORROSION}

\subsection{Background}

Penetration rates at local sites of corrosive attack are expected to be a far more serious threat to tank life than rates of uniform vapor and liquid phase corrosion [5]. Ionic and molecular species present in liquid environments (HLW waste and their vapors) can serve as promoters, depolarizers, or inhibitors of LC (localized corrosion) and SCC (stress corrosion cracking) in mild steel [29, 30 ].

Frequently, SCC initiates at pits. Pitting is a form of localized corrosion. Pitting forms from a failure of the passive film. For example, halides ions, (particularly $\mathrm{Cl}^{-}$) and carbonate ions can induce localized breakdown of passive films, thereby initiating pit formation. Such species are known as promoters, but $\mathrm{Br}^{-}, \mathrm{I}^{-}$, and in some solutions $\mathrm{SO}_{4}^{2-}$ have also been found to cause pits. Recent observations by Riechman [20-22] and Congdon [24-26] in High-Level Radioactive Waste tanks proves that $\mathrm{Cl}^{-}$is associated with pitting corrosion although possibilities of $\mathrm{Cl}^{-}$in earlier studies [11-17] cannot be discounted. Mechanistic and modeling work center around the notion that $\mathrm{Cl}^{-}$causes pitting corrosion. Thus both service and synthetic solutions for laboratory-scale tests must be sufficiently oxidizing to favor passivity.

Anodic dissolution at the bases of pits and at crack tips can be enhanced by a number of depolarizers, including $\mathrm{O}_{2}$ and $\mathrm{H}^{+}$. Additionally, $\mathrm{OH}^{-}$and $\mathrm{NO}_{2}^{-}$are considered inhibitors from the perspective of localized corrosion as suggested by the work of Ondrejcin [7]. High Level Waste tanks at Hanford have failed. These tanks have indicated more of interfacial pitting corrosion than was observed in laboratory experiments. At Savannah Research Labora- 
tory the first instance of pitting was also reported in 1965 [28]. The cooling coils of the High-Level Waste tanks from ASTM Grades A 53 and A 106 mild steels had undergone corrosion damage by pitting. Since then there have been several reports on pit corrosion [11-17, 20-22, 24-26]. These studies seem to indicate that pitting is an important degradation mode. However, no reports have been made thus far on the actual observation of pitting corrosion in High-Level Waste tanks.

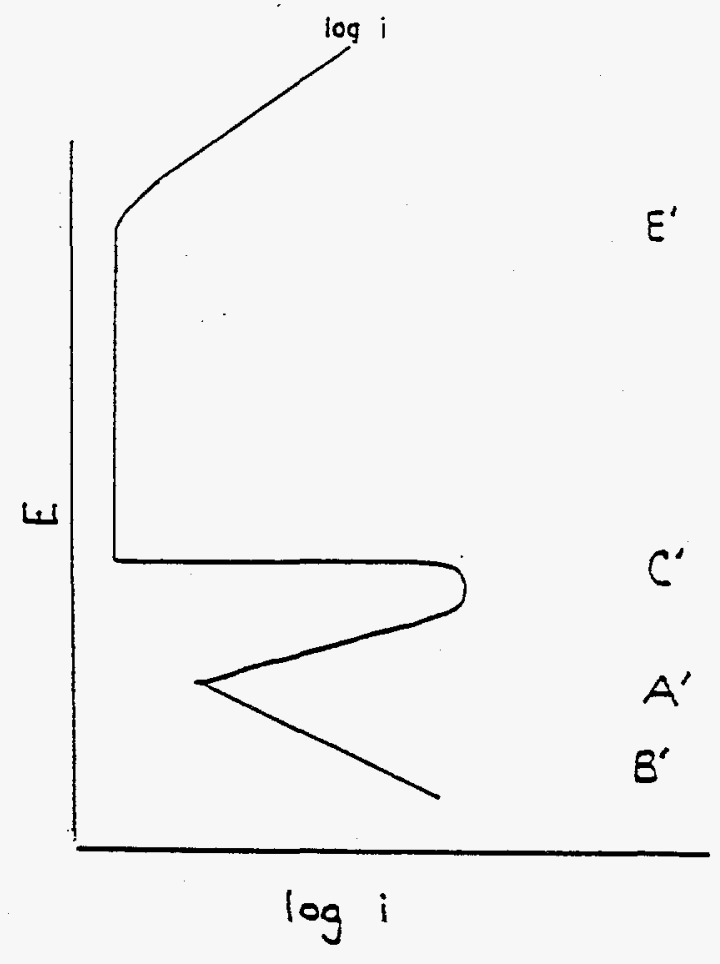

Figure 1: Schematic determination of critical pitting potential, $E_{p i t}$, from anodic polarization curve.

In most solutions more than one reaction will occur on the metal surface and each of these reactions will have different reversible potentials. Reversible potential is the potential on the polarization curve at which the rates of oxidation (dissolution or corrosion), i.e. anodic current, and reduction (plating) i.e. cathodic current, are equal and no net current flows across the interface as denoted by point $A^{\prime}$ in Figure 1. At B' the total cathodic current is greater than the anodic current. It is important to stress that at a point such as B' or $C^{\prime}$ one is measuring the total from all the possible reactions that are occurring. Thus, at B' metal will still be dissolving because this potential is above the reversible potential for the reaction. However, a cathodic reaction, for example hydrogen reduction, is also occurring and the cathodic current produced by 
this reaction is greater than that produced by metal dissolution.

Another important reaction is shown in Figure 1, which we now consider. It is clear that between points $A^{\prime}$ and $C^{\prime}$ the metal is rapidly dissolving and the anodic current is directly proportional to the applied potential. In this range of potential the metal is said to be in the active state. However, at point $\mathrm{C}^{\prime}$ a very unusual transition takes place. As the potential is swept to more positive values the anodic current decreases to very low values and may remain there with increasing voltage. In this state the metal is said to be passive. The current at which passivation begins is referred to as the critical passivation current, and the potential at which it occurs is called the passivation potential.

Passivity is a very desirable state for any metal in service because the corrosion rate is negligible. If a metal is held in the passive state for a long period of time, a thick oxide will build up on the surface. This oxide may be analyzed by techniques such as X-ray or electron diffraction and it is often tempting to assume that formation of this oxide causes passivation. Although the passive state can remain stable over a range of voltages, at sufficiently high potential the oxide of many metals will break down and the anodic current will increase again. This region is referred to as the transpassive range. In Figure 1 it begins at $E^{\prime}$. The potential corresponding to $E^{\prime}$ is called the critical pitting potential, $E_{\text {pit }}$.

\subsection{Conditions}

Generally, chloride ion is an essential ingredient to break down the passive film and initiate localized corrosion. The combination of a strong oxidizer to maintain passivity, an acid solution, and presence of chloride results in an aggressive environment for testing the resistance of steels toward pitting. Recently, Electron Microprobe Analysis results by Congdon [24-26] of pits in ASTM A 516-70 are suggestive of the presence of chlorides within the pits formed in the mild steel liner. Therefore, chlorides should be present in high-level wastes. Susceptibility to pitting increases with temperature in chloride solutions with a strong oxidizer. Dissolved oxygen is sufficient to passivate steels and induce pitting in the presence of chlorides although higher temperature may reduce pitting by decreasing solubility of dissolved oxygen.

Pitting refers to the especially aggressive action of specific anions in destroying passive film at potentials above the active range but below the transpassive range. This can occur at sites of inclusions, defects, cracks, etc. Pitting corrosion occurs when different points in the same metal are at different potentals. Potential differences may arise due to contact of different metals, inclusions or impurities, intermetallic compounds, strains, or any variance from uniform 
composition and structure. The potential of the steel is the driving force for pit initiation. Carbon steels in general contain considerable amount of inclusions, where the contact of the metal with the outside is restricted. This results in an oxygen concentrated cell.

The metal in contact with the inclusion becomes a localized anode and undergoes corrosion. The surrounding surfaces become the cathode. Once initiated, pits provide sheltered areas that prevent easy mass transport between the the pit interior and the exterior bulk solution. Hydrolysis of the corrosion product, sodium chloride salt within the pits, results in acidic solutions that destroy passivity locally and create an active corroding anode within the pit. The pit anode is supported by reduction of dissolved oxidizers on the surrounding cathode surfaces.

\section{INITIATION OF PITS}

\subsection{General}

It is very important to understand the dependence of pitting on various environmental conditions such as chloride concentration, $\mathrm{pH}$, and temperature. Modeling work by Aziz and Godard [31], May [32], Aziz [33], Green and Fontana [34], and Streicher [35] emphasize that pitting phenomena fall into two broad classes: initiation, which terminates after a certain time of initiation and propagation, a process controlled by the subsequent local corrosive environment. In many systems the onset of pitting has been associated with the critical potential. Phenomenologically, the critical potential for pit nucleation can be defined as the potential $E_{\text {pit }}$ at which the first pit is noticed, and above which severe pitting proceeds. It is also the measure of resistance to pitting corrosion. The presence of chloride in acidic solution generally increases potentiostatic or potentiodynamic anodic currents in all potentials, but the most significant feature is the dramatic increase in the current at the critical potential, $E_{p i t}$, as shown in Figure 1. The more noble is $E_{p i t}$, the more resistant is the alloy to pitting.

Good correlation has been demonstrated between $E_{\text {pit }}$ and the resistance of a series of $\mathrm{Fe}-\mathrm{Cr}$ alloys to pitting in long term exposures to seawater. As chromium content increases, $E_{\text {pit }}$ becomes more noble, and the alloys become more resistant to pitting. This value may vary greatly from sample to sample in a given alloy. The potential greatly decreases to more anodic values as the concentration of the aggressive anion increases. Pits also initiate above $E_{\text {pit }}$ when the potential (i.e., corrosion potential) is established chemically 
where $\tau_{0}$ is the minimum induction period, for $\Delta E=E-E_{p i t} \longrightarrow \infty$ where, $E$ is the applied potential and $E_{p i t}$ is the critical pitting potential. $\tau_{0}$ is obtained by plotting $\tau$, the induction period of pit nucleation, as a function of $1 / \Delta E$. At $1 / \Delta E=0$, the value of $\tau$ corresponds to the minimum induction period, $\tau_{0} . \tau_{0}$ does not depend on halide concentration but on its kind and is an order of magnitude higher for $I^{-}$than for the other halides. The slope $E_{0}=$ $\delta \log \tau / \delta(1 / \Delta E)$ diminishes with halide concentration and strongly depends on halide concentration. The validity of the model based on Equation 7 has been confirmed for iron and $\mathrm{Fe} 5 \% \mathrm{Cr}$ alloy.

The actual mechanism of pit initiation at $E_{p i t}$ is not well understood [41], although the following sequence of events [42] is supported by considerable experimental data.

As potential increases and approaches $E_{p i t}$, the concentration of $\mathrm{Cl}^{-}$increases at a passive iron or steel surface, as measured with $\mathrm{Cl}^{-}$microelectrodes [43]. This results in an electrostatic attraction between the positively charged surface and the negatively charged $\mathrm{Cl}^{-}$anion. Electron probe measurements have revealed the accumulation of relatively thick chloride salt "islands" on the surface of iron at potentials even below $E_{\text {pit }}$. Accumulation of $\mathrm{Cl}^{-}$makes $E_{p i t}$ more noble [44]. A high chloride, low- $\mathrm{pH}$ microenvironment may be developed beneath an island by the hydrolysis reaction, with cation corrosion products from the alloy represented by

$$
\mathrm{Fe}^{2+}+2 \mathrm{H}_{2} \mathrm{O}+2 \mathrm{Cl}^{-} \longrightarrow \mathrm{Fe}(\mathrm{OH})_{2}+2 \mathrm{HCl}
$$

$\mathrm{Fe}(\mathrm{OH})_{2}$ is a weak base and $\mathrm{HCl}$ a strong acid, leading to an expected low $\mathrm{pH}$. Other anions of strong acids, such as nitrate, will also hydrate to acid $\mathrm{pH}$, but chloride is far more mobile in solution and more aggressive in both acid and alkaline solutions during pitting corrosion. The acid hydrolysis is still more apparent during the propagation of pits.

In the absence of chloride, the passive film dissolves slowly, as ferric ions

$$
\mathrm{FeOOH}+\mathrm{H}_{2} \longrightarrow \mathrm{Fe}^{3+}+3 \mathrm{OH}^{-},
$$

where $\mathrm{FeOOH}$ represents the hydrated passive film, with iron in the ferric oxidation state. Chloride is proposed to catalyze the liberation of $F^{3+}$ by displacement of the outer layers of the passive film

$$
\begin{gathered}
\mathrm{FeOOH}+\mathrm{Cl}^{-} \longrightarrow \mathrm{FeOCl}+\mathrm{OH}^{-} \\
\mathrm{FeOCl}+\mathrm{H}_{2} \mathrm{O} \longrightarrow \mathrm{Fe}^{3+}+\mathrm{Cl}^{-}+2 \mathrm{OH}^{-}
\end{gathered}
$$

where $\mathrm{FeOCl}$ approximates the composition of the salt islands on the passive film and presumably dissociates to yield the enhanced $F e^{3+}$. Subsequent reactions (Equation 11), or others that are similar, thin or remove the passive film at preferred site until direct anodic dissolution to $F e^{2+}$ initiates a pit. 
At $E_{\text {pit }}$, sufficient chloride has concentrated in salt islands at the surface to start a new anodic reaction at the initiation sites. The increase in anodic current above $E_{\text {pit }}$ represents the polarization curve for the new anodic process of the pit environment.

Preferred sites for pit initiation in carbon steels are often related to sulfide inclusions. Mixed $(M n F e) S_{z}$ sulfides, have been most potent nucleants [45, 46]. The mechanism of nucleation at inclusions is uncertain. A microcrevice may be created by dissolution of the inclusion or the inclusion may be electrochemically active and corrode preferentially [42]. However, recent studies [47] have revealed that mineral sulfides are generally noble to passive steels. Therefore, in some cases at least, sulfides may create a microgalvanic couple which locally accelerates anodic dissolution of the nearby metal. Precipitation, segregation, cold work, and heat treatments can affect size and distribution of pits. Localized attack has been observed using transmission electron microscope in low alloy steel after it had undergone stress corrosion cracking in nitrate solution [48]. It was suggested that the highest reactivity occurred in high-angle boundaries where interstitial elements such as $\mathrm{C}$ and $\mathrm{N}$ are segregated in additiion to $\mathrm{P}$ although it has been cautioned that this observation is not a general one [49].

It has been reported [50] that pitting of carbon steels would not occur in a solution containing a higher concentration $(>7 \mathrm{mM}$ ) of chelating agent like EDTA (ethylenediamine tetraacetic acid). This is attributed to the adsorption of chelating agent onto the local anodic area. These actions of chelating agent do not lead to pit initiation but to the complete reduction of passive film followed by the uniform dissolution of iron. High-Level Wastes have EDTA in the concentration range of 0-1 $\mathrm{M}$ depending upon the extent of degradation of organics by radiation. There are other circumstances in which pitting or localized attack can occur but deep pits do not result. For example, pitting may occur at a potential where the metal is undergoing active corrosion or the point where the metal changes from active corrosion to the passive state [42, $51]$, and in these cases, general corrosion occurs and deep pits do not develop.

\subsection{Mechanisms}

The process of pit generation is regarded as a stochastic process [52], which proceeds to the next stage where local dissolution proceeds at the pits thus formed. Pit initiation models enable us to predict the effects of environment on quantities such as the critical potential and induction time $[53,54]$. 


\subsubsection{Theory of Competetive Ion Adsorption}

An early attempt to explain the mechanism of pitting was the theory of competitive ion adsorption, by Kolotyrkin $[55,56]$ and Uhlig [57, 58]. It assumes that pit formation is a result of a competitive adsorption of chloride ions and oxygen. According to this concept, pits develop at the sites where the oxygen adsorbed on the metal surface is replaced by $\mathrm{Cl}^{-}$. Kolotyrkin believes the density of the anodic current of metal dissolution to be unequal over the whole metal surface on account of surface inhomogenity. Metal dissolves more rapidly where chlorides are more strongly adsorbed. According to the theory, the breakdown potential is that minimal electrode potential at which aggressive anions are capable of replacing the passivating oxygen on the metal surface.

The adsorption theory however fails to account for all the facts observed, especially the occurrence of induction time, and is inadequate in the light of current views on the nature of passive films.

\subsubsection{Anion Penetration and Migration Theories}

Penetration and migration theories have enjoyed a wider acceptance. According to Rozenfeld $[59,60]$ in 1964 , at the sites of passive film where the metal-oxygen bonding is the weakest, oxygen may become replaced by chloride ions. Aggressive anions which interchange with oxygen penetrate into the passive film to result in a pit. In terms of this theory, the induction time may be defined as the time required for an aggressive anion to penetrate the passive film and reach the metal surface. The assumption is made that the first stage of this penetration process involves adsorption of aggressive ions on the surface of the passive film. Consequently, the critical potential of pit nucleation would be the potential at which these ions adsorb on the passivated metal surface.

Hoar and co-authors [61] in 1965, assume that the aggressive ions permeate the oxide film without any exchange under the influence of an electrostatic field across the film/solution interface. This would result in the formation of a "contaminated" path of a relatively high ionic conduction in the film, which would facilitate the flow of a high intensity current at certain spots, leading to localized corrosion.

In 1962 Pryor et. al. [62, 63] upheld the "contaminated film" concept, but they suggest that cationic vacancies arise, which reduce the ionic conduction and favor film breakdown.

McBee and Kruger [64] assumed in 1974 that anion vacancies were created 
during the migration of chloride ions. Namely, $\mathrm{Cl}^{-}$would exchange with $\mathrm{O}^{2-}$ and $\mathrm{OH}^{-}$. McBee and Kruger propose the following pattern (equation 12) for ionic exchange and migration:

$$
\mathrm{Cl}_{\text {sol. }}^{-}+\square \mathrm{O}^{2-}+2 \mathrm{OH}^{-}=\mathrm{Cl}_{\text {lattice }}^{-}+2 \square_{O B}^{-}+2 O \mathrm{H}_{\text {sol. }}^{-}
$$

where $\square$ symbolizes vacancies in the crystal lattice of the film.

\subsubsection{Thermodynamic Theory of Pitting}

Another interpretation of the pit nucleation process was put forward by Vetter $[65,66]$. He supposed that the oxide film on the metal surface remains in equilibrium with the thin chloride salt film, provided that films have the same chemical potential and that an equilibrium exists in both films between $\mathrm{M}^{2+}$ cations and electrons. Pitting is considered to start on the non-porous oxide containing salt nuclei. A tendency to form salt exists at potentials more positive than the critical potential for pit nucleation, whereas at more negative potentials the more stable form is the oxide.

\subsubsection{The Mechano-Chemical Model}

In a later study Vetter and Strehblow [67] assumed the pits to arise from mechanical breakdown of the passive film, accompanied by the formation of a non-porous salt or a chemisorptive film in the pit.

Yet another model for pit nucleation has been advanced by Hoar [68] in 1967. It is suggested that adsorption of aggressive anions on surface of the passive film lowers the surface tension at the solution interface and results in "peptization" of the film. If mutual repulsion of the adsorbed ions becomes strong enough, the passive film breaks and aggressive ions reach the uncovered metal surface.

The mechano-chemical concept of pit nucleation has been developed by Sato [69]. He assumes that the high intensity of electric field operating at the electrolyte-passive film-metal interfaces may cause the film to break, if the electrostrictive pressure set up in the film becomes higher than its compressive strength. The pressure can be calculated from Equation 13:

$$
p-p_{\bullet}=\epsilon(\epsilon-1) \frac{E^{2}}{8 \pi}-\frac{\gamma}{L}
$$

where $p$ is the electrostriction pressure in the film, $p_{0}$ is the atmospheric pressure, $\epsilon$ is the diectric constant of the film, $E$ is the electric field, $\gamma$ is the surface tension, and $L$ is the thickness of the passive film. The first term on the righthand side of the equation represents the electrostrictional effect, and the second the interfacial tension effect. Electrostriction pressures from 10 to 100 
$\mathrm{kg} / \mathrm{cm}^{2}$ are possible, which are sufficient for plastic deformation and rupture of the oxide film.

The value of the electrostrictive pressure depends, among other factors, on the surface tension of the film. As a result of adsorption, aggressive ions lower the surface tension of the oxide, thus increasing the electrostrictive pressure. The critical potential for pit nucleation for this model would be the potential above which the electrostrictive pressure exceeds the compressive strength of the film. Sato [69] claims that either a pit originates, or its growth is suppressed, depending upon the rate with which the film is recovered at the sit of breakdown. This model, however, can hardly be invoked to explain the induction time for pitting and the specific role played by the aggressive ions in this process.

Ambrose and Kruger [70] assumed that the aggressive ions, having penetrated to the metal surface, result in the formation of a local "pocket" at the metaloxide interface. This pocket is filled with corrosion products that have no protective properties (possibly gamma-FeOOH). The growth of these pockets sets up a localized concentration of stresses and results in the film breaking. The authors assume that the specific action of aggressive anions is to affect the rate of repassivation. In turn, the rate of repassivation process, the mechanical properties of the film and the adsorption of aggressive ions affect the critical passivation potential.

\subsubsection{Localized Acidification Theory}

Galvele [71-73] developed a pit model from 1976 to 1978 under the assumption that metal ions hydrolyze inside of the micropits already existing on the surface, and that corrosion products are transported by diffusion. Film breakdown is presumed to occur constantly even below the pitting potential. When a crack in the passive film is produced and the electrode potential is high enough, metal dissolution occurs followed by the hydrolysis.

The $\mathrm{pH}$ in the solution near the electrode will drop. For each metal and alloy, a critical acidification is neccessary to render repassivation impossible and sustain pit activity. It has been also suggested that the critical potential for pit nucleation is the minimum potential at which a local acidity of the electrolyte in contact with metal can be maintained. Calculations performed by these authors showed that this acidity probably occurred at a very early stage of pit nucleation. The deeper the pit, the greater the variations in the composition and $\mathrm{pH}$ of the pit solution. This view, however, is contradictory to the opinion of Vetter and Strehblow [67] and Vetter et al. [74] who argue that the initiation of pitting is related neither to $\mathrm{pH}$ changes nor to variations 
in potential or ionic concentration, as these variations are minute at the early stage of pitting.

\subsubsection{Halide Nuclei Theory}

Okada $[53,54]$ assumes that the pit initiation on a stainless steel begins with the formation of a hemispherical halide nucleus on a passive oxide film. If the nucleus is stable and grows continuously, it can eventually breach the protective oxide. After dissolution of the metal halide, the underlying metal is exposed and undergoes rapid corrosive attack. Okada has used two independent approaches to derive the same expressions for the critical potential $E_{\text {pit }}$, the induction time $\tau$, and the critical size for the stable halide nucleus, $r^{*}$. For thin passive films, the critical potential is a linear function of the logarithm of the halide ion concentration, $\ln \left[X^{-}\right]$:

$$
E_{\text {pit }}=\text { constant }-\frac{R T}{\xi F} \ln \left[X^{-}\right]
$$

where $R$ is the universal gas constant, $T$ is the absolute temperature, $\xi$ is a constant, $F$ is Faraday's constant. The relationship between the critical pitting potential and halide ion concentration is consistent with the experimental results of several research findings. The induction time, $\tau$, is the time required for the halide nuclei's radius to become larger than the critical size for stable nuclei, $r^{*}$,

$$
\ln \tau=\text { constant }-2 n \ln \left[X^{-}\right]-\frac{2 \xi F E}{R T}
$$

where $n$ is the valency of the metal ion. Note that equation 14 implies that the induction time increases exponentially as the chloride concentration decreases.

\subsubsection{An Evaluation of Pit Initiation Mechanisms}

Most of the theories of pitting assume that a critical potential exists below which this process does not occur. The question then is essentially one of why the aggressive anions break down the passive film. It has been suggested that the critical potential of pitting is that potential at which the aggressive anions can reversibly displace the passivating oxygen from the metal surface. There are several pieces of evidence to support this viewpoint. One is the induction time required to cause the oxide to breakdown once $\mathrm{Cl}^{-}$is added to a solution that has previously produced passivation. Another is the extreme localization of pitting since breakdown might be much easier on inhomogeneities than on smooth surfaces. According to Hoar and coworkers [68], rather than have oxygen displaced by $\mathrm{Cl}^{-}$, they suggest that $\mathrm{Cl}^{-}$penetrates the rather porous film under the influence of the field. Again this idea is consistent with the 
inhomogeneities being ideal sites for pit formation since the film may be more defective in these regions.

The general picture that has developed for the electrochemistry of the pitting process is as follows. The metal is polarized in the noble direction. Since most of the microstructural asperities (i.e. sulfides) that are sites for pitting are also semi-conductors they will be polarized as well. However, while the metal is still passive the film on the inhomogeneity breaks down and that region begins to corrode.

At all the microstructural asperities (sulphides) the passage of ions through the oxide film is rendered more facile, and the adsorption of various species from the surrounding medium is more pronounced than elsewhere; localized adsorption of aggressive anions on the surface of passivated metals is considered the first step of pitting. As the pit grows the solution in the pit will become rich in metal ions which will cause hydrolysis reactions and produce an acidic solution. The facilitated release of cations and the migration of anions to microdepressions existing at defective sites induce the formation of an aggressive environment resulting from hydrolysis. The acidic solution formed at these discrete points first locally attacks the oxide film, and next the metal itself. The pit will soon come into contact with the host metal. If the solution has become aggressive enough it will keep the metal from repassivating and the pit will grow.

Most theories advocate the interactions of halide ions with passive films on metal surfaces for formation of pits. Some are purely speculative, but many have been developed to explain certain experimental observations. However, none seem to be able to explain all the features of film breakdown satisfactorily. Models need to be developed that account for situations other than a uniform passive oxide layer i.e. nucleation at heterogeneties like inclusions, grain boundaries, dislocations etc. $[41,42,75,76]$. No model can quantitatively predict the formation and incubation time of pits. It is obvious from many of the models that pitting is dependent on the chloride concentration, $\mathrm{pH}$, and temperature and provide explicit expressions for incubation time. Studies on mild steels have demonstrated that the propensity of pitting is strongly dependent on these parameters [77]. All these pitting theories share the view that the adsorption of $\mathrm{Cl}^{-}$on the metal surface is the first stage; passive film are attacked, but individual investigators differ in their views as to the nature of these sites.

The following are some of the reasons which have been advanced for the occurrence of weak sites in the film:

- weak metal-oxygen bonding (Rozenfeld). 
- mechanical damage (Vetter, Videm).

- breakthrough due to a local reduction of the surface tension at the filmelectrolyte interface as a result of $\mathrm{Cl}^{-}$adsorption (Hoar).

- breakthrough due to electrostatic pressure (Sato).

- sulfide inclusions and other chemical and physical inhomogeneities of the metal, in the neighborhood of which the film has a distributed structure (S'mialowska).

In the same way, there is a lack of consensus as to how chloride ions pass through the film to the metal surface. Advocates of the penetration theories suggest either migration or gradual penetration of $\mathrm{Cl}^{-}$, causing pit nucleation as soon as the chloride ions reach the bare metal surface. On the other hand, mechanical models, assume that electrolyte reaches the uncovered metal through the break developed in the passive film as a result of the reasons mentioned above. Many researchers suppose that chloride anions cause dissolution of the passive film. With the help of Pourbiax (potential - $\mathrm{pH}$ ) diagram it has been demonstrated that the pitting potential (i.e. the potential at which pitting corrosion is initiated) decreased with increasing chloride concentration [78].

There are many theories regarding the interaction of halide with passive films on metal surfaces. Some are purely speculative, but many have been developed to explain certain experimental observations. However, none seem to be able to explain all the feature of film breakdown satisfactorily. Currently the most accepted views on the nature of the breakdown potential appears to be the following:

- that expressed by Videm [79] who claims the breakdown potential to be the potential above which the repassivation rate is lower than the dissolution rate.

- the assumption made by Hisamatsu et. al. [80], who believe that the critical potential of pit nucleation is the potential at which chloride ions become concentrated to such an extent that pit repassivation becomes impossible. 


\section{PROPAGATION OF PITS}

\subsection{General}

At the pit initiation sites large concentration of positively charged $\mathrm{Fe}^{2+}$ attracts negative anions, e.g., $\mathrm{Cl}^{-}$. Hydrolysis by

$$
\mathrm{Fe}^{2+}+2 \mathrm{H}_{2} \mathrm{O}+2 \mathrm{Cl}^{-} \longrightarrow \mathrm{Fe}(\mathrm{OH})_{2}+2 \mathrm{HCl}
$$

produces local $\mathrm{pH}$ reductions at the initiation sites. The result is a selfpropagating or autocatalytic mechanism of pit growth. The acid chloride solution further accelerates anodic dissolution, which in turn further concentrates chlorides in the pit. A soluble cap of $\mathrm{Fe}(\mathrm{OH})_{3}$ corrosion products collects at the pit mouth when $\mathrm{Fe}^{2+}$ diffuses out of the acid pit interior to the exterior, where it is oxidized to $F e^{3+}$ and precipitates in the neutral bulk solution. The cap impedes easy escape of $\mathrm{Fe}^{2+}$ but is sufficiently porous to permit migration of $\mathrm{Cl}^{-}$into the pit, thereby sustaining a high acid chloride concentration in the pit. Anodic polarization of the pit interior occurs by coupling to the exterior passive cathode surfaces. Cathodic reduction of a dissolved oxidizer such as oxygen consumes the electrons liberated by the anodic pit reaction.

The importance of the cathodic reaction to sustain pitting should be understood. Pit growth cannot continue without a cathodic reduction reaction to consume electrons liberated by (i.e., to polarize anodically) the pit anode reaction. Thus, pits are widely spaced in aerated salt solutions, because oxygen has limited solubility, and a large surrounding area is needed to provide enough reduction capability to support the central pit anode. Any pit initiating within the cathodic area of a larger pit is suppressed by cathodic protection. The greater solubility of $\mathrm{Fe}^{3+}$ yields greater reduction rates on a smaller surface area, and pits can survive much closer to one another in $\mathrm{FeCl}_{3}$ test solutions. Pits sustained above $E_{\text {pit }}$ by potentiostatic anodic polarization are also very closely spaced because of the neccessary anodic polarization, removing the cathodic reaction to the auxiliary or counter electrode.

In advanced stages, pits may become deep enough that reduction of $\mathrm{H}^{+}$on the pit walls near the outer surface is possible, while the pit bottom still sustains anodic dissolution. Thus, hydrogen bubbles emanating from pits have been observed.

A protection potential, $E_{\text {prot }}$, has been defined by a cyclic potentiostatic or potentiodynamic procedure. After some degree of anodic polarization above $E_{\text {pit }}$, the direction of polarization is reversed in a cyclic polarization test, and hysteresis is observed in which the return polarization curve follows an active 
path, compared to the initial anodic one. The crossover at the passive current density defines $E_{\text {pit }}$ below which established pits presumably cannot grow. By contrast, new pits initiate only above $E_{\text {pit }}$. Between $E_{\text {prot }}$ and $E_{\text {pit }}$, new pits cannot initiate, but old ones can still grow. An alloy that is resistant to pitting shows no hysteresis, whereas susceptible alloys show increasing hysteresis. The protection potential is dependent on the state of advance of the localized corrosion or, more precisely, on the $\mathrm{pH}$ value and on the composition of the solution inside the pit, and even if this composition varies in relation to time and to the external potential applied.

\subsection{Mechanisms}

\subsubsection{Pit Growth due to an Active Surface at the Base of the Pit and Chemically Inactive Walls}

The model of Pickering and Frankenthal gives a mechanistic understanding of the pit growth [81]. The model assumed that anodic dissolution of the active metal surface was the only chemical reaction occurring at the base of the pit in accordance with the equation:

$$
M \rightarrow M^{n+}+n e^{-}
$$

Frankenthal and Pickering [81] have measured the potential within pits during their growth and found that they were very active, well below the passive range of the metal and as much as one volt below the potential of the surface. They also found that hydrogen bubbles formed within the pits. This result strengthens the conclusion that the potential within the pit is very active and also raises the possibility that hydrogen induced cracking could result from a pit.

The model was significantly modified by Galvele [71] and includes the following hydrolysis reaction:

$$
\mathrm{M}^{n+}+\mathrm{H}_{2} \mathrm{O} \longrightarrow \mathrm{M}(\mathrm{OH})^{(n-1)+}+\mathrm{H}^{+}
$$

By including this effect, Galvele has shown that significant $\mathrm{pH}$ suppression can occur inside the pit. The pit envisioned in the model has an active metal surface at its base, insulated cylindrical walls, and a conductive planar cap at the base.

From Galvele's analysis, one can derive an expression that gives the change of the electrical potential inside the pit when the pitting potential is measured as a function of the salt concentration ( $\mathrm{NaCl}$, for example):

$$
\Phi-\Phi^{\prime}=\text { constant }-\frac{R T}{F} \ln (C)
$$


(a)
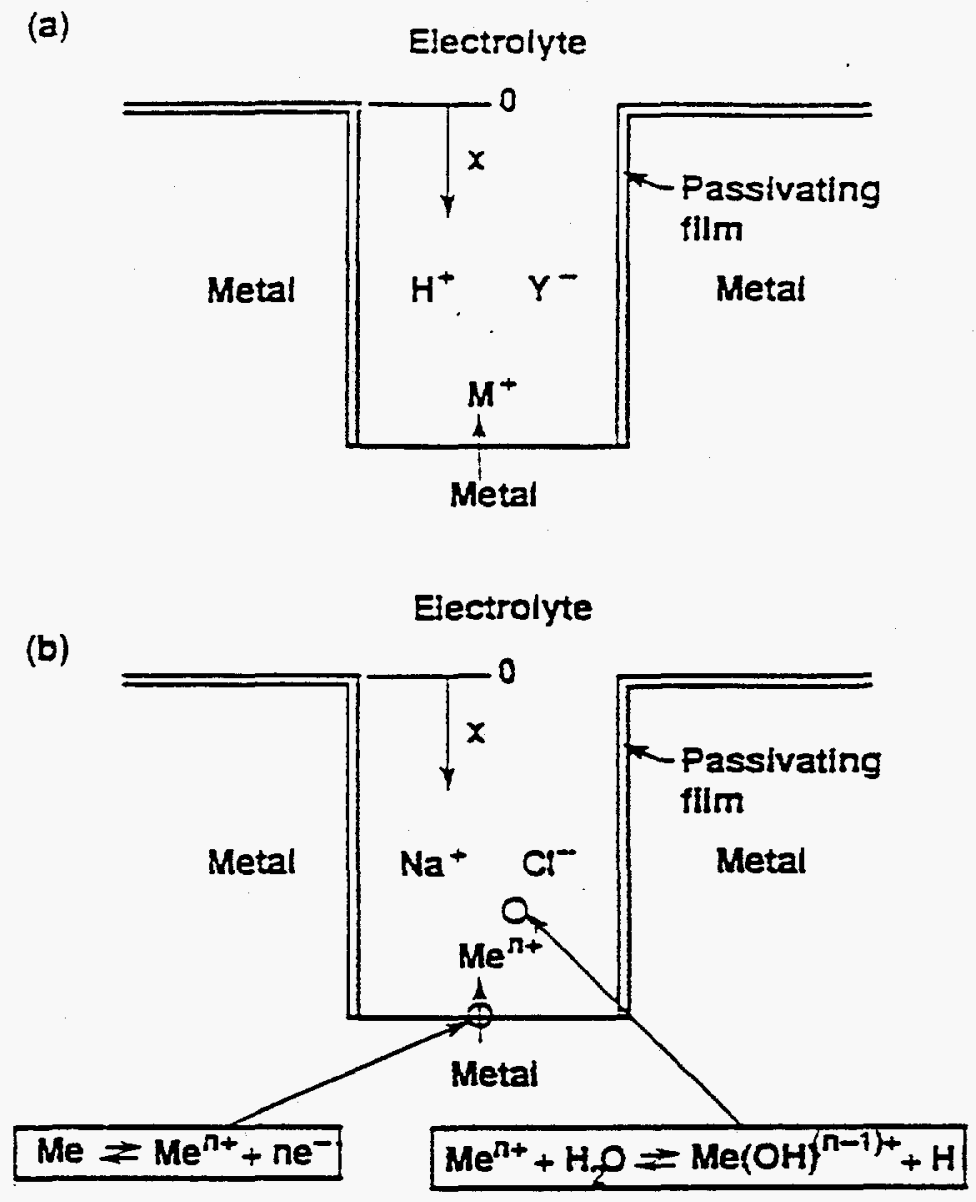

Figure 2: (a) The Pickering-Frankenthal model for propagation of a pit with an active metal base [81]. (b) The Galvele modification of the PickeringFrankenthal model takes into account hydrolysis and suppression of the $\mathrm{pH}$ [71]. Both models assume quasi-steady-state conditions.

where $C$ is the salt concentration, $\Phi$ is the corresponding electrical potential, and $\Phi^{\prime}$ is a reference potential. This electrical potential should be subtracted from the measured pitting potential value to get the real pitting potential. The parameter $\left[\Phi-\Phi^{\prime}\right]$ is analogous to the critical pitting potential, $E_{\text {pit }}$. Galvele [71] points out that the suppression of $\mathrm{pH}$ at the base of a pit to some critical level can prevent passivation. His arguments related to passive film stability are based on Pourbiax (potential-pH) diagrams.

The mathematical model of the one-dimensional plane pit developed by Galvele [71] under the assumption of the solution potential constancy within the pit attempted to explain all the main experimental facts concerning metal pitting in the presence of an indifferent electrolyte. He depicted the dependence 
of concentration of metal, hydrogen and hydrolysis ions upon pit depth and current density for a number of metals. Quasi-steady-state conditions were assumed. Though the model allows us to understand variations of ion concentration inside the growing pits, an explicit expression for the pit depth as a function of time is not derived. Consequently, such an approach to pit modeling for predicting the life of high-level radio-active waste tanks is of very little practical use.

\subsubsection{Pit Growth due to an Active Surface at the Base of the Pit and Chemically Active Pit Wall}

Models of electrochemical aspects of aqueous pitting corrosion are often based on crevice-like pitting geometry, the walls being regarded as chemically active or nonreactive. Metal dissolution from the base of the pit increases with time. The models due to Pickering and Frankenthal [81] and Galvele [71] are examples of pitting models based on chemically nonreactive walls. The pitting model due to Alkire and Siitari [82] is an example of models in which the the walls are taken to be chemically active. It also includes the effects of potential variation in the pit without including electromigration directly. The model [82] treats corrosion processes as heterogeneous coupled by mass and charge transport between different regions within the corrosion cell. Cathodic reaction (hydrogen reduction) on the side walls and external surface is predicted by assuming metal-ion hydrolysis and diffusion of hydrogen ions. The behavior of solute species is adequately described by dilute solution theory. Such cathodic reaction is favored for deep narrow regions in solutions of low hydrogen ion concentration. No experimental validation of the model was reported. Incidentally, hydrogen evolution within the pits reported by others in different metals like steel $[81,83]$, and aluminium [84] led to the development of the model [82]. It was suggested [78] however that more quantitative information could have been extracted and compared with experiment. For example, the $\mathrm{pH}$ in the crevice was predicted and also the rate of generation of hydrogen gas could have been calculated.

Another pitting model [85] has been developed for which the aqueous solution inside the pit was taken to be a binary electrolyte, that is, to contain just one cation (in case of dissolving metal) and one anion. Ionic transport within the solution was described using dilute-solution theory with transport occurring by both chemical diffusion and electromigration. The analysis models a relatively deep pit. It was found that pit propagation using current and potential measurements for reactive wall geometry are much lower than those observed for the nonreactive wall geometry for deep pits because of the absence of large net coupled currents. Deviation from this general behavior was observed for 
strongly passivating solution. In that solution, the walls of the pit were passivated, resulting in behavior that resembled that observed for the nonreactive wall geometry, i.e., high coupled currents and negligible current flow at the pit mouth. The model analysis of reactive and nonreactive wall pit is consistent with experimental results using AISI 1020 carbon steel in simulated ground water and brine solutions.

\subsubsection{Pit Growth Limited by Salt Film}

Vetter and Strehblow developed a pitting model $[67,86]$ in which these authors concluded from theoretical consideration that during the early stages of pit growth of an hemispherical pit the metal chloride concentration within the pit does not increase sufficiently for precipitation to occur. Experimental support for Vetter's and Strehblow's view of the stability of growing pits was obtained by Strehblow and Wenner [87].

Carbon steel containers are widely used in the disposal of low-level wastes in the United States [88]. The important factors that influence underground corrosion are:

1. Aeration factors that influence the amount of oxygen and moisture that reach the metal. The aeration properties of the soil depend primarily on the particle size and particle size distribution of the soil.

2. Electrolyte factors that deal with soil water chemistry (e.g. $\mathrm{pH}$, resistivity and occurrence of aggressive agents such as chlorides, sulfates and carbonates.

In alkaline soil environment, pitting corrosion of carbon steel containers has been confirmed [88]. Under conditions when corrosion products accumulate inside the pit, dissolution process can be controlled by diffusion of metal ions through these corrosion products and out of pit. The controlling mechanism for iron dissolution under alkaline conditions is the reaction:

$$
\mathrm{Fe}(\mathrm{OH})_{2}+2 \mathrm{H}^{+} \rightleftharpoons \mathrm{Fe}^{2+}+2 \mathrm{H}_{2} \mathrm{O}
$$

Equation 20 was used to compare different soils which were aerated to different extent using carbon and stainless steels. By applying the law of mass-action to the above reaction at equilibrium, a relation between $F^{2+}$ ion concentration and $\mathrm{pH}$ was derived at room temperature:

$$
\log \left[F e^{2+}\right]=10.23-2 p H
$$


Under alkaline condition an equation for the maximum pit depth, $h_{m}$, as a function of time, $t$ was obtained as:

$$
h_{m}=8.35 t^{0.45}
$$

The maximum pit depth, $h_{m}$, was a strong function of the soil $\mathrm{pH}$, exposure time $t[88]$.

\subsubsection{An Evaluation of Pit Propagation Mechanisms}

Chloride ions play a double role in pit growth. On the one hand, in acid solutions they increase the hydrogen ion activity, and thus enhance the corrosion. When sufficiently low $\mathrm{pH}$ is attained, chlorides cause a salt layer to form at the bottom of pits, which tends to hinder metal dissolution but prevents passivation. While studying the occurrence of pitting in the presence of an external potential, it is sufficient to restrict oneself to the reaction of metal dissolution occurring on the bare surface and hydrolysis reactions proceeding within the pit volume [71-73, 81, 83, 87]. Increasing the $\mathrm{pH}$ of the main solution as well as buffer anions of weak acids inhibit the process of pitting [71-73]. The value of the $\mathrm{pH}$ within the pit decreases as the pit grows, i.e., the solution due to hydrolysis of the metal is acidified as the pit grows [71-73].

While studying the corrosion pitting occurring in the absence of an external field, it is neccessary to take into account not only the anode reaction of dissolution at the pit bottom, but also the cathode reaction (e.g., discharge of $\mathrm{H}^{+}$) at the pit sides. Consequently, hydrogen evolution becomes important $[81,83]$. Sey et. al. [83] however conclude that hydrogen evolution is not an essential part of the pitting mechanism but that stress corrosion cracking commonly arises as a result of hydrogen gas formation within pits. This mechanism is similar to that of self-sustained growth of corrosion cracks due to electrochemical dissolution of the anodic metal at the crack root where the stress concentration is high, with the subsequent failure of the weakened material. The pit growth depends on the applied mechanical stress only to a small extent. However, at some critical depth, depending on the load and on the form and mutual position of the pits, mechanical fracture of the weakened layer takes place and a crack is originated.

\section{STRESS CORROSION CRACKING}

Stress corrosion cracking (SCC) is a brittle failure at relatively low constant tensile stress of an alloy exposed to a corrosive environment. The stress may be 
either externally applied or internally applied, or internally generated (residual), it may be steady or sustained, variable or cyclic, or any combination of these. The fracture may be either intergranular (IGSCC) or transgranular (TGSCC) and its process may either continuous or discontinuous. Environments in which SCC has been observed range from highly alkaline to highly acidic aqueous solutions. The specificity of alloy-environment combination exhibiting SCC often brackets the range in which the alloy also exhibits excellent resistance to general corrosion in the environment in the absence of any stress. Such a generic description, originally suggested by Staehle $[89,90]$ has gained general acceptance. That SCC failures continue to occur in many, if not all, major industrial applications for all alloys leading to increased costs, safety concerns, and reduced reliability of operation is also an accepted fact.

SCC was apparently first reported as the so-called season cracking of brass in ammonium-bearing environments in the early twentieth century and was a serious problem in the failure of cartridge cases for firearms during both world wars. Caustic cracking with resulting explosion of carbon-steel steam-engine boilers became a serious and dangerous problem in the 1920 s. In recent years, especially in the nuclear energy generation industry, SCC failures in a number of piping components, steam generator tubings, fuel claddings and turbine discs have resulted in considerable financial loss (in billions of dollars) and increased safety concerns. The leakage in high-level nuclear waste tanks both at Hanford and Savannah River Sites has also been a key safety issue in recent years and has received a considerable amount of attention.

\subsection{Conditions}

Historically, it has been thought that three conditions must be present simultaneously to produce SCC: a critical environment, a susceptible alloy, and some component of tensile stress as depicted by Figure 3. Not all environments cause cracking of any particular alloy, but new alloy-environment combinations resulting in SCC are being discovered on a regular basis. Thus, many researchers are of the opinion that a specific environment is not required for SCC. Nevertheless, the engineer should be familiar with those alloy-environment combinations which are known to produce SCC in order to avoid them in design. Although the three conditions in Figure 3 are not usually present together, time and service conditions may conspire to produce the necessary combinations that result in surprising and expensive failures. Boiling and evaporation can concentrate the critical solutes in very dilute and otherwise nonaggressive solutions. A factor of considerable importance for SCC is mechanical stress. The stresses required are small, usually below the yield stress, and are tensile in nature. The stresses can be externally applied but residual stresses often 


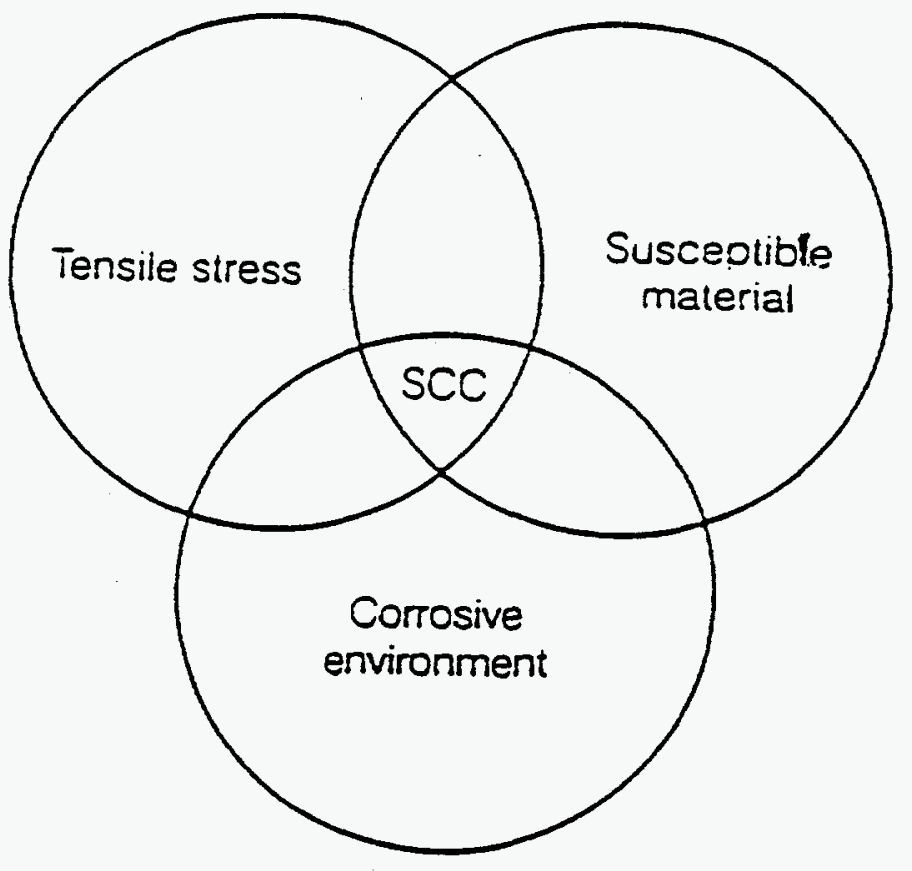

Figure 3: Simultaneous tensile stress, susceptible metallurgical condition, and critical corrosive solution required for stress corrosion cracking.

cause SCC failures.

A common misconception is that SCC is the result of stress concentration at corrosion-generated flaws (as quantified by the stress intensity factor $K$ ), and that when a critical stress intensity factor, $K_{\text {crit }}$, is reached, mechanical fracture results. Although stress concentration does occur at such flaws, it does not exceed the critical value required to cause mechanical fracture of the materials in an inert environment $\left(K_{I S C C}<K_{\text {crit }}\right)$. Uneven thermal expansion and contraction can produce residual tensile stress concentrations and heataffected zone after welding [76]. Pure metals are more resistant to SCC than alloys of the same base metal but are not immune. Virtually all alloys are susceptibility to some degree in the appropriate environments, and susceptibility increases with strength in any given class. Although SCC may be either transgranular or intergranular, the crack follows a general macroscopic path that is always normal to the tensile component of stress.

Carbon steels are susceptible to SCC in a number of corrosive environments. Perhaps the best known are nitrates, hydroxides and, carbonates. Similar failures occur in aqueous solutions and moist gases containing mixtures of 
carbon monoxide and carbon dioxide [92].

\subsection{Electrochemical Effects}

In 1967, only few environments were known to promote SCC of carbon steels [93], principally caustic and nitrate solutions and anhydrous ammonia. Parkins also carried out extensive research on SCC in coal gas liquors, mentioning $\mathrm{HCN}$ as a possible $\mathrm{SCC}$ agent; this was subsequently recognized as $\mathrm{CO}-\mathrm{CO}_{2}$ SCC [94]. Parkins later carried out extensive research on SCC in carbonatebicarbonate environments and identified SCC as the probable cause of cracking in natural gas transmission lines [95]. Other environments like acetates [96] and phosphates [97] caused cracking but probably are not of practical value. The correlation of SCC with steady state and transient electrochemistry has been a major theme of research, especially by researchers convinced of the primacy of anodic reactions in crack propagation. The recognition of interactions between local chemistry (established by localized corrosion) and the crack propagation mechanism has been the major achievement of the last two decades.

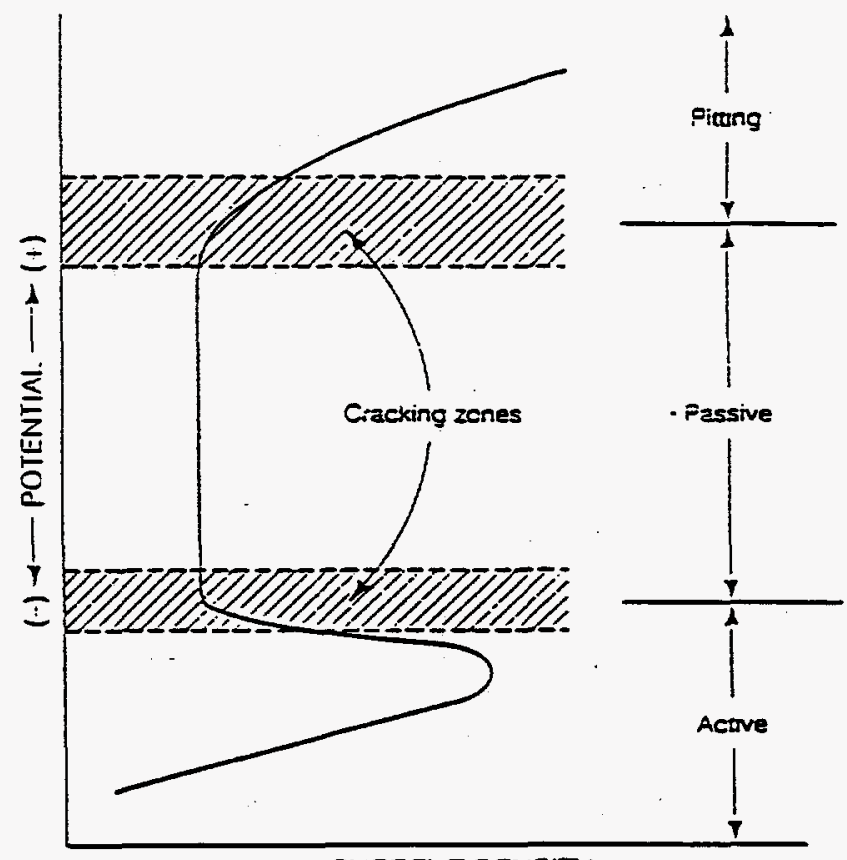

log CUAFENT DENSITY

Figure 4: Schematic anodic polarization curve showing zones of susceptibility to stress corrosion cracking.

Electrochemical potential has a critical effect on stress corrosion cracking(SCC). 
Figure 4 shows the schematic potentiodynamic anodic polarization curve for a typical active-passive corrosion-resistant alloy, with cross-hatched zones where SCC occurs in susceptible alloy-solution combinations $[98,99]$. The passive film is an apparent prerequisite for SCC, but the two zones of susceptibility appear at the potential boundary where the passive film is less stable. In zone 1, SCC and pitting are associated in adjacent or overlapping potential ranges. An example of zone-1 SCC is carbon steel in hot nitrates. SCC occurs in a narrow potential range $(-0.30$ to $+1.10 \mathrm{~V} \mathrm{SCE})$ as shown in Figure 5 , with pitting present at slightly noble potentials and passivity, with no cracking at slightly active potentials [100]. Incidentally, the potential range in which nitrate SCC occurs in high-level waste tanks using synthetic wastes was found to fall $[101,102,103]$, within the range in which SCC in nitrate solution was observed in laboratory studies [100]. Furthermore, it was also reiterated [101, 102] that electrochemical dissolution was indeed playing a major role in giving rise to intergranular failures both in laboratory and in-tank tests. Although stress corrosion cracks may initiate at pits due to stress intensification, they are not necessarily a prerequisite for SCC, even in zone 1. However, in some instances, potent solutions or oxides that are unstable on the exposed surface can accumulate within pits and initiate cracks. In the case of SCC of carbon steels exposed to nitrates, cracking initiates in pits where magnetite can accumulate.

In zone 2, far from the pitting potential range, SCC occurs where the passive film is relatively weak at active potentials barely adequate to form the film. SCC has been observed even in active as well as in zone $2(-0.90$ to -1.04 $\mathrm{V}$ SCE) for carbon steel in strong caustic solutions as shown in Figure 5 [100]. However, because anodic currents decrease with time, film formation and growth is probably present even in active potential ranges. Also, what may appear to be SCC in the active region may actually be occurring in Zone 2 because the potential of the active-peak current tends to become more active with time. That is, potential in the active potential range during short-term potentiodynamic polarization may actually be in Zone 2 during longer-term SCC exposures.

These are shown more clearly in Figure 5 from the work of Parkins [100]. Zone $2 \mathrm{SCC}$ is typified by carbon steel in hot carbonate/bicarbonate solutions $(-0.45$ to -0.625 V SCE range as shown in Figure 6) [104]. Intergranular SCC has been observed on the external surfaces of buried carbon and low-alloy steel linepipe used to transport petroleum and natural gas. The critical environment is a mixture of carbonate and bicarbonate at $75 \mathrm{C}$. These anions are found in the presence of mill scale at holiday and beneath paint coatings in the presence of cathodic protection. Parkins [104] found that cathodic protection puts the steel into a critical region (i.e., zone 2 in Figure 4), where the material is more 


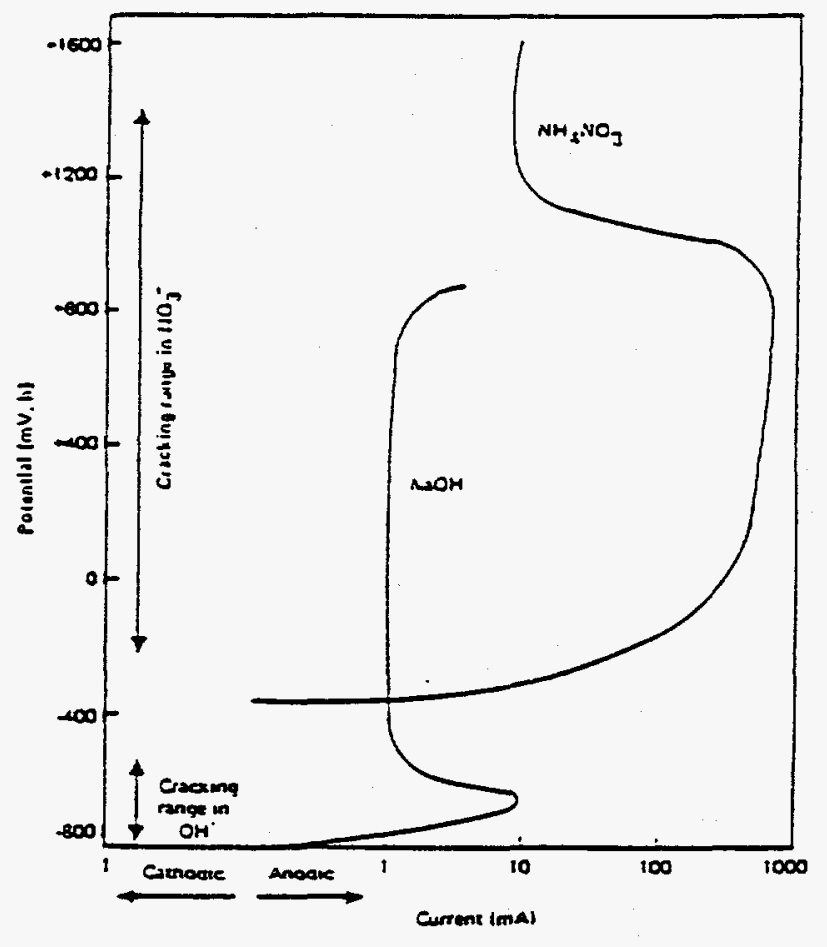

Figure 5: Anodic polarization curves on mild steel in boiling $8 \mathrm{~N} \mathrm{NaOH}$ and boiling $4 \mathrm{~N} \mathrm{NH}_{4} \mathrm{NO}_{3}$.

susceptible to SCC. Cracking is removed if the mill scale is removed before painting.

It was suggested [100] that the cracking of low carbon steels in nitrate occurs over a range of potentials where the soluble ferrous or ferric ions may exist. In hydroxide environments, the range of potentials over which cracking is observed agrees reasonably with the existence of soluble $\mathrm{HFeO}_{2}^{-}$in accordance with the reaction:

$$
\mathrm{Fe}+2 \mathrm{OH}^{-} \longrightarrow \mathrm{HFeO}-\mathrm{H}_{2}^{+}
$$

Thus stress corrosion cracking of low carbon steels in nitrates and hydroxides, which are very different types of environments may be explained in terms of the ability of these solutions to passivate exposed surfaces by the formation of $\mathrm{Fe}_{2} \mathrm{O}_{3}$ or $\mathrm{Fe}_{3} \mathrm{O}_{4}$ films while facilitating the formation of soluble $\mathrm{Fe}^{2+}, \mathrm{Fe}^{3+}$, or $\mathrm{HFeO}_{2}^{-}$at the bare metal exposed at the crack tip [100]. Even the mechanism of failure in carbonate/bicarbonate solution has been considered [100] similar to that for cracking in nitrates and hydroxides, whereby most of the exposed surfaces are rendered relatively inactive, but the formation of soluble species at the crack tip is permitted so that dissolution and hence crack propagation 


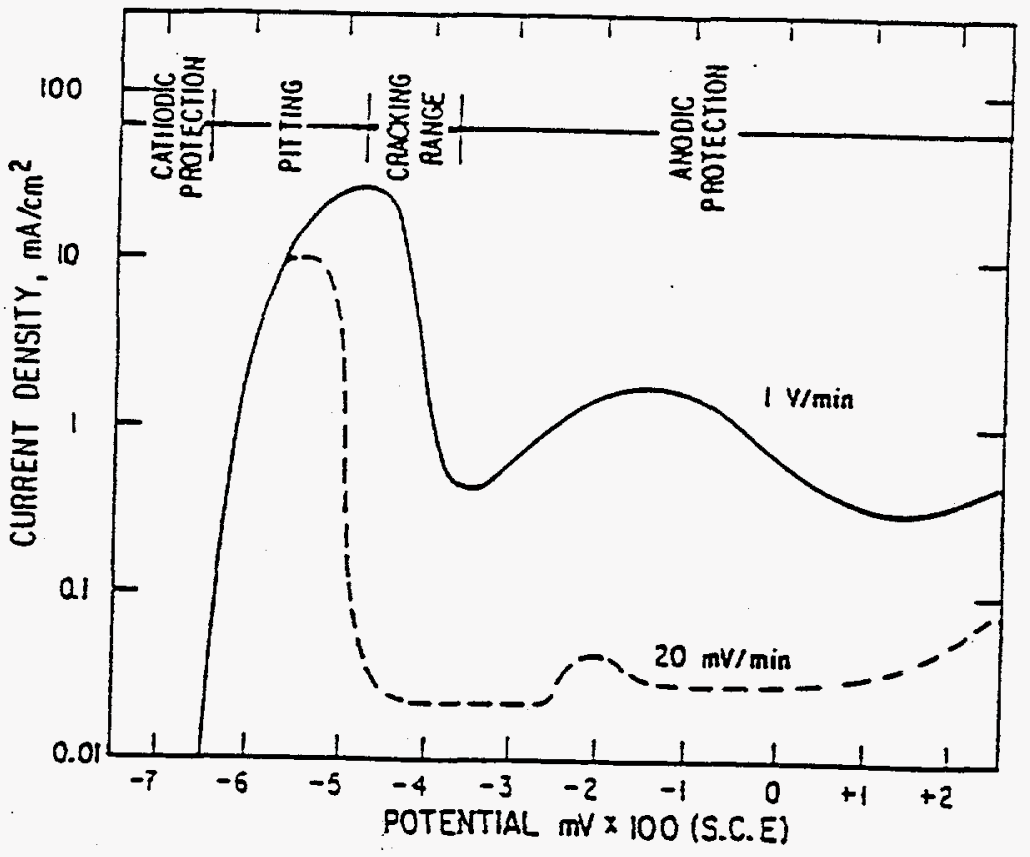

Figure 6: Anodic polarization curves at different potential sweep rates for mild steel in $\mathrm{Na}_{2} \mathrm{CO}_{3}+\mathrm{NaHCO}_{3}$ at $90 \mathrm{C}$ [104].

can occur.

From various studies [106] of mild steels in boiling nitrates with different cations, it appears that those solutions with acidic cations are the most potent, as is determined from the threshold stresses for the failure of $0.05 \%$ steel in various nitrates with concentration levels in the range $1-8 \mathrm{~N}$. This suggests that a nitrate solution that does not produce rapid or extensive cracking by itself within the $\mathrm{pH}$ range 3-7 can be made more aggressive by small additions of acid and this was found to be so [106]. However, additions of an inhibitor like nitrite reduced the propensity for stress corrosion cracking [107]. Movement of $\mathrm{pH}$ to higher values above $\mathrm{pH} 7$ by the addition of alkali causes a marked increase in resistance to cracking at values of $\mathrm{pH}$ above about 7 , a result confirmed by Szklarska-Smialowski [107]. Thus oxidizing additions like $\mathrm{KMnO}_{4}, \mathrm{MnSO}_{4}, \mathrm{NaNO}_{2}$ accelerate cracking while hydroxides and other salts, especially those forming insoluble iron products, such as $\mathrm{Na}_{2} \mathrm{CO}_{3}$ etc. retard or prevent failure. Substances which have been shown to inhibit caustic cracking when present in proper amounts include nitrite, sulfate, nitrate, and permanganate, carbonate. Nitrite ions have been found to inhibit stress corrosion cracking of 4340 carbon steel in nitrate solutions [108-113]. Impor- 
tantly, nitrite ion has a strong effect on the passivation potential only in an acid or weakly acid electrolyte. With the approach to neutral ( $\mathrm{pH} \sim 8$ ), the passivation potential is the same in many electrolytes and is oxidic [113]. However, with an increase in $\mathrm{pH}$, the adsorption of $O \mathrm{H}^{-}$ions increases, while the adsorption of other anions decreases.

A number of investigators have recognized that the conditions for caustic cracking are on the borderline between the formation of a passive oxide film and its dissolution [114]. Concentration cells of the type:

$\mathrm{Fe}($ crevice - or - crack) $\mid \mathrm{NaOH}$ (concentrated) $\| \mathrm{NaOH}$ (dilute) $\mid \mathrm{Fe}$ (metal - surface)

are set between concentrated caustic solutions (active areas) in crevices and dilute solutions (passive areas) at nearby exposed surfaces [115]. While low (passive) corrosion rates are independent of caustic concentrations in the range from 0.1 to $4 \% \mathrm{NaOH}$ (for a $0.12 \% \mathrm{C}, 0.47 \%$ steel) [116], a high rate of active corrosion attack is observed at concentrations exceeding about $50 \% \mathrm{NaOH}$. Between these two extremes the corrosion rate increases with $\mathrm{NaOH}$ concentration. It is in this concentration range ( 4 to $50 \% \mathrm{NaOH}$ ) that caustic cracking is observed for the above alloy [116]. Evidence seems to indicate that caustic cracking in pure $\mathrm{NaOH}$ solutions is associated with an intermediate range of $\mathrm{NaOH}$ concentrations in which mixed passive and active control of corrosion is operative.

It has been found [117-118] that caustic cracking in mild steels occurs within a narrow range of potentials $(-675$ to $725 \mathrm{mV})$ near the active peak of the potential-current curve. While mild steel is susceptible to caustic cracking over a range of $\mathrm{NaOH}$ concentrations, most investigations of caustic cracking have been conducted in 33 to $35 \% \mathrm{NaOH}$ since this concentration is believed to provide the most severe test [117-118]. The most negative condition for inducing caustic cracking coincides with the potential for initiating passivation in non-steady state current potential measurements [119-121].

\subsection{Mechanisms}

\subsubsection{Film Rupture/ Slip Dissolution Mechanism}

SCC occurs more readily in the potential range near the active-to-passive transition. At lower potentials, the sample will undergo general corrosion. If the sample is strongly passivated, SCC will be rapid. However, if the surface contains both active and passive regions (as can occur near the transition region), cathodic reactions can occur on the passive regions while corrosion is concentrated in the active regions. In the extreme, the areas in which anodic reaction will occur are very small, but penetration is relatively rapid. The coupling of 


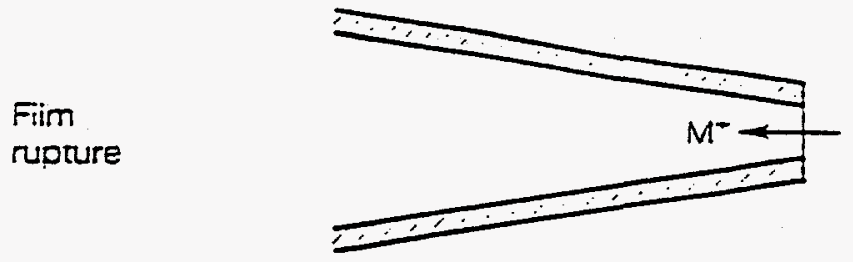

(2)

Hycrogen Emorittlement

Suriace mobiiity

Absorption incuced cleavage
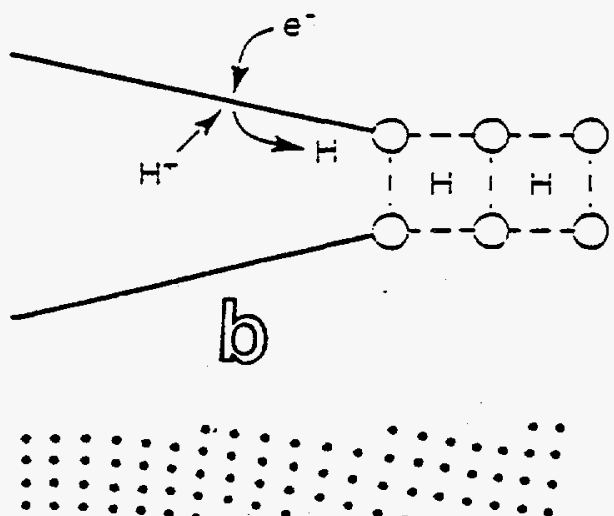

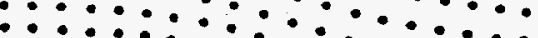
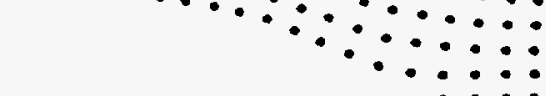

- $\bullet$

$0 \ldots$
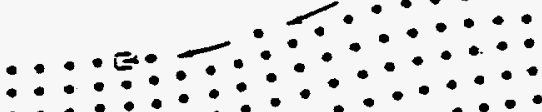

$\div: \div: \div: \div: \div \div$

(6)

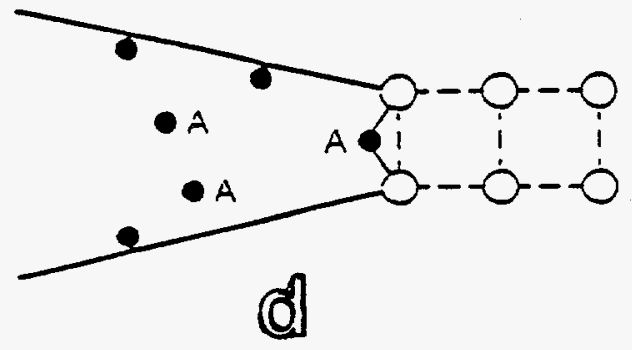

Crack grows by enocic dissolution at crack to where fiim is ruptures.

Dissoived H-aioms dilate lattice and ivestieri atomic bonds.

\section{Atoms migraie out oi crack tip.}

Adsorption of $\mathrm{A}$ weakens ciack ip toncs.

Figure 7: Schematic summary of proposed mechanisms of stress corrosion cracking. 
these electrochemical principles with consideration of the deformation process es near a crack tip leads to the film rupture/slip dissolution mechanism for SCC (Figure 7a).

The role of stress was not fully established in the sixties. Anodic processes were believed to propagate cracks by stress assisted intergranular corrosion in carbon steel [122]. The rupture of thin oxide films, as a key step in what was later known as the slip-dissolution model, was mentioned in passing by Vermilyea [123], who had earlier made precise electrochemical measurements on strained electrodes [124]. Thus the film rupture or slip-step dissolution was one of the first proposed stress corrosion cracking (SCC) mechanisms and still receives considerable support $[125,126]$.

When the stress is applied, the strain will be localized in specific regions such as at the crack tip or where the film is broken by scratch or by slip lines. All of the anodic current is focused in these regions. Under stress, the film continues to rupture at the crack tip, and fresh surfaces are exposed to corrosive solution which lead to crack extension by dissolution of the freshly exposed surface. During this process the sides of the progressing crack remain passive. Thus the corrosion is focused on a small anodic region at the crack tip, leading to rapid crack growth. In its general form, this model appears to be applicable to many cases of SCC.

A material in a passivating environment will be covered by a passive film. An important requirement for this mechanism is considered to be that the repassivation process should occur within a fairly narrow time interval. Such a thesis separates that general process of film rupture that can occur on any passive alloy from the particular process that produces susceptibility. Most investigators now agree that film rupture is essential to initiating cracking, but considerable controversy persists as to how a stress crack grows thereafter.

The slip-dissolution model was later associated with the names of Vermilyea, Scully, Staehle, Parkins, Ford, and Galvele the investigators who were the focus of most SCC research in the 1970s and 1980s. This history has been reviewed by Garud [127] and Ford [128]. It was in the beginning of the eighties after considerable amount of research by Parkins and others that the correlation of SCC with active-passive transitions and the delayed repassivation of fresh metal surfaces in these regions was demonstrated. It was then accepted that film rupture is the main role of stress in carbon steels. Once the protective film is ruptured under the influence of stress and the metal is in contact with the corrosive medium, propagation of the stress corrosion crack will take place.

There has been considerable controversy [129] regarding the mechanism of stress corrosion crack propagation in carbon steels once the protective film 
has been ruptured because two types of mechanisms can be operative either independently or together: (1) cracking by an active path corrosion process associated with anodic corrosion process and (2) cracking by hydrogen embrittlement mechanism due to hydrogen evolution.

Phelps [129] on the basis of the electrochemical polarization method described that when the anodic current is applied active path corrosion would occur. Active path corrosion would stop on the application of cathodic current. On the other hand, hydrogen generated by general corrosion is the cause of stress corrosion cracking. The application of cathodic current would generate more hydrogen and thus shorten the time to failure. The application of anodic current would generate less hydrogen and lengthen the time to failure.

Other evidences for the active path corrosion [130-132] and hydrogen embrittlement [133-135] mechanism have also been reported. It is also believed [136, 137] that the propagation of cracks is associated with the adsorption of specific electrolyte ions and with the decrease in the surface energy of the metal.

\subsubsection{Intergranular Stress Corrosion Cracking: Grain Boundary Cleanliness Is- sues}

An important feature of "active path" corrosion is that the crack tip moves through an anodic corrosion process and the cathodic process does not have any influence except to react with the electrons created in the anodic process [100].

Stress corrosion cracking of carbon steels in hydroxide, nitrate and carbonate solutions is considered to occur by anodic dissolution following rupture of the film by stress. The cracking phenomena in these solutions usually occurs along grain boundaries and morphologically similar defects. The film is composed of $\mathrm{Fe}_{2} \mathrm{O}_{3}$ and $\mathrm{Fe}_{3} \mathrm{O}_{4}$. At natural corrosion potential, the film may consist either of $\mathrm{Fe}_{2} \mathrm{O}_{3}$ alone or $\mathrm{Fe}_{2} \mathrm{O}_{3}$ dispersed with $\mathrm{Fe}_{3} \mathrm{O}_{4}$. The susceptibility is highest when there is a dense passive film of $\gamma-\mathrm{Fe}_{2} \mathrm{O}_{3}$ [138]. Contrary to another observation in a ferritic steel[139], it is stated that [140] the SCC resistance is low if the $\mathrm{C}$ content is high. This may be due to reduced grainboundary passivation arising from the $\mathrm{C}$ segregating relative to interior grain parts, which may allow cracks to propagate rapidly at the boundaries. The extent of stress corrosion cracking of mild steel in these solutions is dependent on the electrode potential of the steel and that a maximum in crack depth as a function of time is attained at approximately $-800 \mathrm{mV}$ (with respect to a mercury-mercuric oxide reference electrode [141-143].

Interestingly, Ondrejcin et. al. at Savannah Research Laboratory $[6,7]$ have 
measured open-circuit potential of high-level waste from 4 different single-shell tanks. The potentials falls within the range $(-0.30$ to $+1.10 \mathrm{~V})$ in $4 \mathrm{M} \mathrm{NaNO}$ but not in the range $(-0.90$ to $-1.04 \mathrm{~V})$ in $\mathrm{NaOH}$. Hence film-rupture seems to be a very relevant mechanism associated with the initial stages of $\mathrm{NO}_{3} \mathrm{SCC}$ in High-Level Nuclear Wastes tanks. All failures to-date, with respect to singleshell, and double-shell tanks are of intergranular type. These tanks were built during the late 1940s, 1950s and, 1960s.

A theory has been proposed to explain the intergranular SCC of mild steels in hydroxides and nitrate solutions [135]. The electrochemical mechanism involves SCC along pre-existing active paths such as segregates or precipitates along the grain boundaries. The active paths may result during processing or heat treatment. Dislocations resulting from applied stresses may accelerate diffusion and transport of impurity and alloy atoms to the grain boundaries causing localized segregation. Stresses may also play a role in facilitating the continual dissolution of the active path by promoting strains that prevent blockage of previously corroded paths. Evidence for this is that polished steel specimens suffer intergranular corrosion in nitrate solutions even without applied stresses. The range of potential over which SCC occurs is in agreement with the potential range over which high anodic activity is observed in straining electrode tests in such widely differing environments as nitrate and hydroxide.

Several authors have explained the stress corrosion cracking of iron and carbon steel in hydroxide, nitrate, and carbonate solutions through film rupture followed by purely anodic dissolution process $[105,109,118,120,122,130-132$, $135,136,144-149]$. However, concerns were raised as to whether the cracktip remains active during the cracking process [142, 143]. Parkins [150] had convincingly demonstrated a correlation between crack velocity and anodic current density on straining electrodes in several important systems, notably carbon steel in $\mathrm{NO}_{3}^{-}$, carbon steel in $\mathrm{OH}^{-}$, carbon steel in $\mathrm{CO}_{3}^{2-} / \mathrm{HCO}_{3}^{-}$, and carbon steel in $\mathrm{CO} / \mathrm{CO}_{2} / \mathrm{H}_{2} \mathrm{O}$. The proportionality demonstrated by Parkins in these systems [150] does not guarantee that the actual cracking process is electrochemical. Electrochemical (charge transfer) reactions may trigger a brittle mechanical cracking process that accounts for crack growth. Indeed, crack growth in some cases has been observed to proceed discontinuously in steps [151], and corresponding periodic crack arrest markings (striations) are frequently present on fracture surfaces [152], contrary to the expected smooth increase in crack length expected for electrochemical growth.

One of the main causes [153] for the occurrence of such catastrophic failures at the mild steel liner in the High-Level Waste tanks was the lack of removal of residual welding stresses. The corrosion cracks seen in the mild steel lin- 
ers of the tanks have indeed been associated with these stresses. The fact that stress corrosion cracking of carbon steel in nitrate solutions is always intergranular indicates that the composition and structure of the grain boundaries are dominant factors in stress corrosion cracking. A powerful technique [154] metallurgists have used to control the composition and structure of grain boundaries in steels in general and mild steel in particular is heat-treatment. The heat treatment of the mild steel liner of the leaked HLW tanks is not known. What is known is that the mild steel liners were not stress-relieved after welding to remove the residual stresses [153]. Not only does heat-treament relieve the mild steel from residual stresses and thus becomes helpful in reducing the propensity of SCC of the mild steel liner, it also controls segregation of impurities at the grain boundaries $[154,155]$. It is well known that [156] mild steel quenched from 900 to $950 \mathrm{C}$ (1650-1740F) is susceptible, but can be made resistant by tempering at $250 \mathrm{C}(480 \mathrm{~F})$ for one-half hour, or at $200 \mathrm{C}$ (390F) for 48 hours, even if the steel exposed to nitrates is highly stressed after heat treatment. However this resistant state, however, is temporary; on further heating (in the unstressed state) at $445 \mathrm{C}$ ( $830 \mathrm{~F}$ for 70 hours), or at $550 \mathrm{C}$ (1020F for 3 hours), and for correspondingly shorter times at higher temperatures, the steel becomes susceptible again and remains susceptible.

Low-temperature heating (i.e., $250 \mathrm{C}$ for one-half hour) randomly nucleates iron carbides (which rob the grain boundaries of carbon) accounting for increased resistance or immunity. Longer heating or heating to higher temperatures (e.g., 70 hours at 445C) allows slow-moving lattice imperfections within the grain to migrate to the grain boundaries, transporting carbon atoms with them. The carbon atoms along the grain boundaries of iron slow the movement of imperfections (and perhaps also alter the chemical affinity of the surface imperfections), favoring adsorption of damaging anions with the consequent disruption of metallic bonds and the steel again becomes susceptible to SCC.

According to the carbide (nitride) theory $[157,158]$, stress corrosion cracking of carbon steel in nitrate solutions is caused by dissolution of grain boundaries as a result of the precipitation of iron carbide precipitates. It has been found that [159] quenching of low carbon steel from $1173 \mathrm{~K}$ leads to fast cracking but heating above $1173 \mathrm{~K}$ leads to the dissolution of carbides and nitrides. The dissolution products include atoms that are present both in grains and on grain boundaries [159]. Therefore, fast cooling from such temperatures suppress the formation of carbides and nitrides. However, it is possible that precipitates of those compounds could be formed despite fast cooling.

Electron microscope studies of iron $(<0.0025 \% \mathrm{C})$ quenched from $1073 \mathrm{~K}$, have shown no cementite precipitates along grain boundaries [160]. On the other hand, heating of hardened, low-carbon steel above $473-523 \mathrm{~K}$ greatly 
decreases the susceptibility to stress corrosion cracking although heating leads to precipitation of carbides (nitrides) and consequently to a decrease in the concentration of carbon and nitrogen at grain boundaries. Electron microscope studies have confirmed that aging of hardened iron leads to precipitation of carbides [161]. In hot nitrate solutions, sites at which small amounts of such carbides are precipitated are not corroded faster than iron. The carbides act as efficient cathodes with the adjacent metal surface forming the anode of the electrochemical cell. This arrangement enhances anodic dissolution very close to the cathode leading to micropit or trench formation, the precursor of a crack $[118,135]$. But when large amounts of cementite are precipitated during high-temperature annealing, local corrosion is very rapid, but such precipitates cannot influence intergranular corrosion since their quantity along grain boundaries is very small.

Additionally, Bohnenkamp [118] studied the stress corrosion cracking of low carbon steel. He observed higher rates of dissolution of iron carbide in $\mathrm{NaOH}$ compared to iron and, a smaller rate of dissolution of iron carbide compared to iron, in calcium nitrate. On account of the similarity of intergranular stress corrosion cracking in sodium hydroxide and calcium nitrate it is cautioned that the preferred dissolution of carbide precipitates in sodium hydroxide plays a deciding part. Nevertheless, enrichment of dissolved carbon and nitrogen or submicroscopic precipitates at the grain boundaries must be deciding factors.

Yet in another study, the observation of localized corrosion attack of low-alloy steels in nitrate solutions through an electron microscope was a clear indication that the highest reactivity is located at high-angle grain boundaries where the interstitial elements such as $C$ and $N$ are segregated. In addition to $\mathrm{P}$ may segregate as a consequence of a galvanic effect caused by these interstitials [48]. Furthermore, it is contended [49] that, the grain boundaries next to large carbides are finally attacked anodically at the advancing edges in pearlitic phase transformation and segregated, leaving $F e_{3} C$ ferrite matrix interfaces and low-angle boundaries unattacked within a short time of exposure. Furthermore, fractography of stress corrosion cracking in carbon steels showed no carbide dissolution after tests were conducted in a variety of solutions like nitrates, hydroxides, and carbonates [160].

Poulson [162] reported that the carbide dissolution in nitrate, hydroxide, and carbonate solution was very limited supporting an earlier result [161]. However, it was suggested by Murata [49] that carbides are not attacked in nitrate solution, and the extension of one result from limited conditions to other similar conditions should be done with the utmost caution. On this basis, a considerable improvement in stress corrosion resistance was achieved by controlling grain boundary interstitials and P [48]. This is contrary to an earlier 
observation in relation to mild steel in the IGSCC in nitrates, hydroxides, and carbonates wherein selective attack was on the carbides [143]. Thus the filming characteristics are modified at the grain boundary where the segregants are present.

On the basis of electron microscopic observations, intergranular dissolution of metals, leading to stress corrosion cracking is not associated with the precipitation of carbides (nitrides) along grain boundaries, but with a critical concentration of carbon and nitrogen along the grain boundaries. While there are indications of the possible importance of $P$ in ferritic steels $[163,164]$ in promoting Intergranular Stress Corrosion Cracking (IGSCC), there are other data available $[157,159]$ indicating that $\mathrm{C}$ and $\mathrm{N}$ are important in such materials in relation to nitrate-induced cracking. Additionally, Slow Strain Rate Tests (SSRTs) on pure iron with exposure to carbonate-bicarbonate solution, and adding controlled amounts of $\mathrm{C}, \mathrm{N}$, or $\mathrm{P}$ by diffusion and homogenization confirmed that $\mathrm{P}$ segregation is not necessarily the origin of IGSCC of mild steels even in different corrosive environments [165]. Moreover, attempts to reproduce the Auger measurements [163] by propagating intergranular stress corrosion cracks through brittle fracture at liquid nitrogen temperature to produce intergranular facets on which spectroscopy could be conducted, were not successful on a range of ferritic steels [99] thus confirming the earlier observation [165].

However, the data of Okada et al [166] indicate that the mechanism of stress corrosion cracking of steels in boiling nitrate solutions may change from activepath dissolution (corrosion) to hydrogen embrittlement as the strength level of the steel increased, e.g., by heat-treatment.

In alkaline solution [167] cracking was explained on the basis of anodic dissolution of grain boundaries accelerated by stress. Stresses facilitate the dissolution of oxide and the formation of bare surfaces that are anodic with respect to the oxide film.

\subsubsection{Hydrogen Embrittlement: General}

Despite numerous investigations, there are conflicting views on the mechanism of stress corrosion cracking of carbon steels in alkaline media. Most investigators explain this phenomena on the basis of the electrochemical theory of stress corrosion cracking although they do not deny the possible influence of hydrogen embrittlement. Others, however, believe that stress corrosion cracking of steel in alkaline media is due mainly to hydrogen embrittlement wherein a serious deterioration in mechanical properties occurs due to hydrogen charging of the metal. A change from ductile failure in air to intergranular fracture 
in hydrogen is a common observation.

The most favorable conditions for hydrogen adsorption processes exist at the crack tip, on the small area of fresh metal surface not covered with the protective oxide film. It is generally assumed that hydrogen acts to weaken interatomic bonds in the plain strain region at the crack tip (Figure $7 \mathrm{~b}$ ). Another concept is that the adsorbed hydrogen reduces the surface energy of the metals, which should result in a decrease in energy required to cause the material to separate and should favor brittle propagation of the crack.Thus a reduced cohesion of the metal crack tip may also be a result of the hydrogen already present in the metal. The crack tip zone is believed to be specially preferred for hydrogen absorption. This occurs either as a result of increased electronegativity of the metal in the stressed state or due to high value of plastic strain built up near the crack tip which favors a local increase in hydrogen concentration.

That is why a hydrogen effect is significant in the process of subcritical crack growth; the incubation period depends, to a great extent, upon the state of the smooth specimen surface and (when there is a cut) upon the sharpness of the cut. Generally, the mechanism of hydrogen-embrittlement involves diffusion of hydrogen ions down the crack, reduction of these species to adsorbed hydrogen atoms at the crack-tip surface, surface diffusion of adsorbed atoms to a preferred surface site and adsorption of the atoms into the metal matrix followed by diffusion of hydrogen atoms to a position in front of the crackfront of the crack-tip. It is assumed that once a critical hydrogen content, $C_{\text {crit }}$, is achieved, the crack advances incrementally by mechanical failure in the affected zone, and the discontinuous cycle starts again.

Hydrogen is capable of chemisorption and diffusion in all the metals. Hydrogen is present in metals as protons. The hydrogen diffusivity in metals is greater than that of other gases and compounds. At the same time hydrogen is inferior to chlorine and, also, to oxygen in adsorption activity. Therefore, oxygen dissolved in water can serve as a good inhibitor of the subcritical crack growth, if the growth mechanism is associated with hydrogen adsorption. The effect of hydrogen on metals is due to the fact that protons, being intensively diffuse in dislocation cores, fill them and essentially increase the energy barrier for moving the dislocation. This effect and the the embrittlement promoted are peculiar both for hydrogen and for other impurity atoms (e.g., of nitrogen). However it is more significant for hydrogen because of its anomalously high diffusivity. Generally, the hydrogen-assisted crack velocity is proportional to $p_{B_{2}}^{\frac{b}{2}}$. This dependence is the essence of the well-known Sievert's Law.

Hydrogen can get to the bulk metal from the exterior if a suitably aggressive environment is present in the pit. At a slow rate of crack propagation during 
hydrogen charging, hydrogen enters the metal and causes its decohesion. At a fast cracking rate, on the other hand, the adsorption effect is to be expected. A reduced cohesion of the metal crack tip may also be a result of the hydrogen already present in the metal. The crack tip zone is believed to be specially preferred for hydrogen absorption and thus far for lattice decohesion, either as a result of increased electronegativity of the metal in the stressed state or due to high value of plastic strain build up near the crack tip which favors a local increase in hydrogen concentration.

A controlling factor in the "hydrogen embrittlement" mechanism is that the propagation of crack occurs by the absorption of atomic hydrogen into metal at cathode areas [100].

\subsubsection{Hydrogen Embrittlement: Carbon Steels}

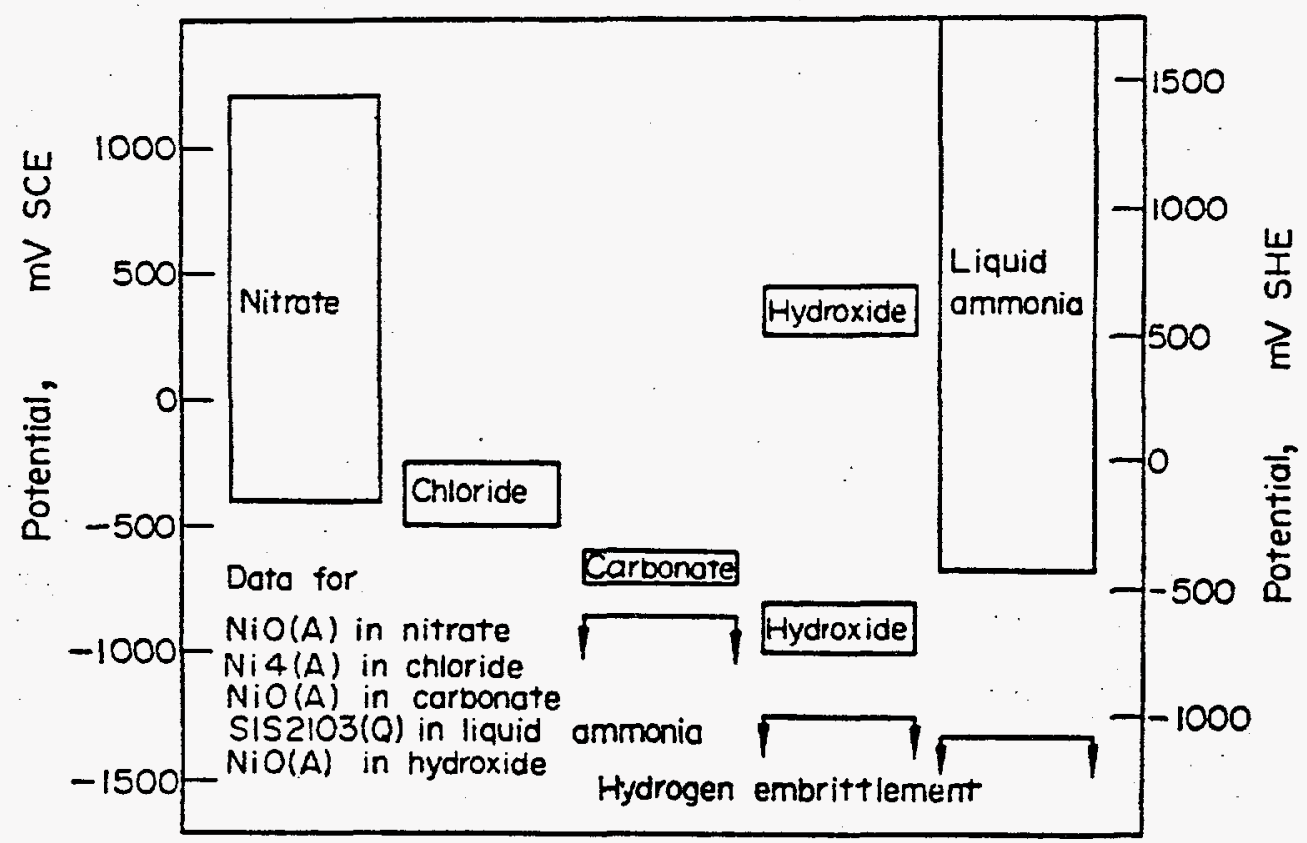

Figure 8: Schematic diagram showing potential ranges over which SCC of carbon steel occurs in various solutions [161].

It has been recently suggested that [9] the degradation of organic species in the High-Level Waste tanks under the influence of radiation produces nascent hydrogen without the compensating production of hydrogen peroxide that occurs during the radiolysis of water. This was expected to be true since slurries are 
present in the waste tanks in which the localized fraction of the organic phase increases, which in turn concentrates the radiocesium [9]. Besides, hydrogen can be liberated during chemical and electrochemical reactions, occurring on the metal surface (e.g., during the hydrogen discharge at the cathode). Consequently, hydrogen embrittlement of a liner made of carbon steel becomes an important degradation mode from the High-Level Waste tank perspective. Importantly, in the case of mild steel or iron of different purity, hydrogen ingress could cause the formation of brittle cracks which is thought to be chiefly due to hydrogen interaction with dislocations. Hydrogen can be supplied into the metal not only by physical adsorption of molecular hydrogen at the metal surface, but also by deposition of atomic hydrogen.

In the 1971 paper, Nielsen reported [168] that the concept of hydrogen embrittlement may be responsible for SCC of not only high strength steels but also lower strength steels. Thus it was suggested that the cracking of carbon steel in hydroxides [169], and nitrates [170] was due to hydrogen embrittlement. According to Diegle and Vermilyea [171] stress-enhanced corrosion of iron in $20-50 \%$ sodium hydroxide solutions at $85 \mathrm{C}$ resulted from repetitive rupture and repair of the protective surface film. A somewhat different view has been advanced by Bignold [172], according to whom stress corrosion cracking of steels in alkaline solution involves a combination of active dissolution at the crack tip and passivation near the mouth of the crack, while hydrogen evolution is not very localized and so is not very significant.

Zapfe [173] believes that brittle failure of steel in alkaline media is the result of temporary brittleness caused by diffusion of hydrogen, which is evolved in the reaction between the alkali solution and the metal. Podgorny [174], who investigated stress corrosion cracking of low-carbon steel in hot alkaline solutions, found that an increase in absorbed hydrogen reduced time to failure (under constant stress) and vice-versa. The corrosion of active iron in alkaline solutions has been described as [175]:

$$
\mathrm{Fe}+2 \mathrm{OH} \longrightarrow \mathrm{FeO}_{2}^{2-}+\mathrm{H}_{2}
$$

A shift in potential towards the passive region protects the metal against cracking.

While evidence for hydrogen embrittlement contribution to crack growth is substantial, the evidence is much less favorable for low strength alloys. As suggested by Poulson [161] there is no dispute to the contention that they can be made to fail by severe cathodic charging (see Figure 8). What is disputed is the relevance of these observations to conditions normally thought to exist during crack propagation. If hydrogen is involved in crack propagation it would appear reasonable to expect [161] that: 
(a) The fracture surface of an unambiguously hydrogen embrittled specimen and that produced during the SCC would at least be similar. However, Poulson [151] in his studies on SCC of carbon steels in nitrate, hydroxide and carbonate solutions did not find this to be so. The one exception being the varying amounts of cracking along prior austenitic grain boundaries which occurred in quenched steels either hydrogen embrittled or stress corroded [171].

(b) Although it has been shown by others [176] that hydrogen entry can occur at anodic potentials, a pre-requisite would seem to be the formation of pits in which the conditions for hydrogen evolution exist. This means that if hydrogen is responsible for cracking at anodic potentials, crack nucleation must be associated with pitting. Although some cracks were associated with pits this was not so. Transgranular cracks initiated at emergent slip steps while intergranular cracks started as grain boundary attack.

Furthermore, the suggestion that hydrogen aids martensite formation by lowering the stacking fault energy and the martensite subsequently rapidly dissolves [177] or fails in a brittle manner [178] would seem most unlikely. In annealed (ferritic) steels the formation of martensite during the conditions existing during a SCC test would appear most improbable, no matter how much hydrogen was adsorbed. For the quenched steels no brittle failure of the pre-existing martensite laths occurred, failure being by void coalescence in mechanical tests. Also localized dissolution of the martensite did not appear to occur either, suggesting such processes are unimportant in crack propagation.

Poulson [161] suggested that crack path in the oxide forming solutions is structurally preexisting, attack on unstressed specimens is structurally dependent and in nitrates intergranular corrosion can occur which is quantitatively related to susceptibility. Oxide forming solutions form thick corrosion products whose formation is structurally dependent [179]. That is they form last at grain boundaries which also dissolve more rapidly. Subsequently the oxide either never manages to format the crack or is continually ruptured.

It was reported earlier $[180,181]$ that:

- the dissolved corrosion products precipitate as oxides or hydroxides giving rise to acid solution in contact with oxide.

- hydrogen formed during the process easily dissolves in the metal, certainly when it is stressed.

- hydrogen is concentrated in stress zones around the cracks and pits. 
- in these hydrogen zones a contraction of stressed material occurs which gives rise to very high internal stresses at the H-zone/ductile metal.

- in this interface the crack is initiated and runs through the embrittled metal to the surface (in steps).

It follows $[180,181]$ that an electrochemical process is neccessary as a source for the local formation of hydrogen. With this thinking, Perdieus et. al. [182] studied the stress corrosion cracking of carbon steels in hot carbonate, nitrate and hydroxide solutions and came to a conclusion that the main cause of stress corrosion cracking was hydrogen embrittlement. This conclusion is reached on the basis of potential $\left(-0.46 \mathrm{~V}\right.$ and $\left.-0.75 V_{N H E}\right)$ and $\mathrm{pH}$ drop in the cracks. It was also expressed [183] that by increasing the potential, the amount of corrosion increases. The oxide formation will then lower the $\mathrm{pH}$ and form hydrogen. That is, when the potential is shifted to more noble values, extent of corrosion (e.g. at the grain boundaries) will increase. This increases the production of $\mathrm{H}^{+}$so that the formation and absorption of hydrogen becomes important with increasing potentials although Parkins [183] felt that on the basis of operating potential, electrochemical dissolution mechanism should be responsible for the intergranular failures. The susceptibility of ferritic steels to hydrogen embrittlement is now well known [184].

Frankenthal and Pickering [81] in their modeling studies of pit growth have found that hydrogen bubbles formed within the pits. This strengthened the conclusion that the potential within the pit is very active and also raises the possibility that hydrogen induced cracking could result from the pit. The model was modified by Galvele [71] who incorporated hydrolysis reaction. Such a reaction raised the $\mathrm{pH}$ within the growing pit. Furthermore, work at Naval Research Laboratory (NRL) has shown that in stress corrosion cracking of a number of high-strength steels, the tip of the crack becomes acidic [185]. Measurements showed the solutions at the crack tip to have a $\mathrm{pH}$ of 3.5 consistently. NRL concluded that the $\mathrm{pH}$ was controlled by the hydrolysis of the ferrous ion, i.e. the reaction

$$
\mathrm{Fe}^{2+}+\mathrm{HOH} \longrightarrow \mathrm{Fe}(\mathrm{OH})^{+}+\mathrm{H}^{+}
$$

was controlling. At the crack tip, the equation,

$$
p H=-\log \left[H^{+}\right]=3.5-0.5 \log \left[\mathrm{Fe}^{+2}\right]
$$

applies.

Turnbull and Thomas [186] developed an SCC model suited to problems of intergranular attack in the absence of stress. Crack propagation was controlled 
by ion transport and anodic dissolution. Turnbull and Thomas performed simulations of steel BS $436050 \mathrm{D}$ in $3.5 \% \mathrm{NaCl}$. Cathodic reduction was considered to take place both at the tip and on the walls of the crack. Hydrogen ion concentration and potential drop was found to vary little over the length of the crack, except at the crack tip.

In the case of iron, it is suggested [187] that the acidic character is attributable to hydrolysis of the dissolved metal ions formed as a primary product of corrosion. In the case of iron, dissolved metallic ions are formed in acidic solution during the initial phase until a limiting concentration is reached through reaction such as:

$$
\begin{aligned}
& \mathrm{Fe} \longrightarrow \mathrm{Fe}^{2+}+2 e^{-} \\
& 2 H^{+}+2 e^{-} \longrightarrow H_{2}
\end{aligned}
$$

or

$$
\frac{1}{2} \mathrm{O}_{2}+2 \mathrm{H}^{+}+2 e^{-} \longrightarrow \mathrm{H}_{2} \mathrm{O}
$$

or, if the initial medium is highly alkaline,

$$
\begin{gathered}
\mathrm{Fe}+2 \mathrm{H}_{2} \mathrm{O} \longrightarrow \mathrm{HFeO}_{2}^{-}+3 \mathrm{H}^{+}+2 e^{-} \\
2 \mathrm{H}^{+}+2 e^{-} \longrightarrow \mathrm{H}_{2}
\end{gathered}
$$

During this initial phase, originally neutral or acid solutions become slightly alkaline, and originally strong alkaline solutions become less alkaline. The process of acidification will cease as long as metallic ions thus formed are precipitated as oxides. Evolution of hydrogen becomes a strong possibility in the case of carbon steel under chemical and electrochemical conditions. Parkin [111] showed that in nitrate solutions, the severity of cracking increased according to the cation series $\mathrm{Na}^{+}<\mathrm{Ca}^{+}<\mathrm{NH}_{4}^{+}$. This series is also one of increasing acidity.

Hydrogen-induced cracking of pipe-line steels, which are essentially carbon steels, is associated with non-metallic inclusions $\left(\mathrm{Fe}_{3} \mathrm{C}\right)$ and the the accumulation of high-pressure hydrogen at these inclusions, particularly in alkaline solution [49]. Furthermore, segregation of $\mathrm{Mn}$ and $\mathrm{P}$ next to these inclusions accelerates the propagation of cracks. Thus controlling the size, shape and quantity of non-metallic inclusions, and reducing $\mathrm{Mn}$ and $\mathrm{P}$, have resulted in steels free from such cracking [188]. Recently, studies on A533B c 11, lowalloy steel has shown that the presence of $S$ did not affect the susceptibility to hydrogen assisted SCC of steel [189]. On the other hand, carbon steel showed different degrees of $\mathrm{SCC}$ in $35 \% \mathrm{NaOH}(10 \mathrm{M}), 1 \mathrm{~N} \mathrm{NaHCO}$ and, $1 \mathrm{~N} \mathrm{Na}_{2} \mathrm{CO}_{3}$ in the voltage range of -0.45 to $-0.76 \mathrm{~V}$ and that there is a relation between the hydrogen content of steel and degree of SCC [190]. It was shown [190] that 
the occurrence of intergranular cracking can often be related to the presence of other grain boundary impurities such as $\mathrm{P}, \mathrm{S}$ or, $\mathrm{Sn}$. The study on P- and $\mathrm{S}$ - doped $\mathrm{Fe}$ in $55 \% \mathrm{Ca}\left(\mathrm{NO}_{3}\right)_{2}$ solution at $60 \mathrm{C}$ and $+750 \mathrm{mV}$ provides additional experimental evidence. These elements segregate to the grain boundaries during tempering or ageing treatments and will themselves weaken the grain boundaries giving rise to an intergranular fracture mode. The amount of embrittlement observed in any situation is directly proportional to the impurity concentration at the grain boundary. [190]. The combination of these elements plus hydrogen can lead to greatly reduced threshold stress intensities in a hydrogen bearing environment. It has been suggested that the removal of impurities improves the resistance to hydrogen cracking [191].

\subsubsection{Surface Mobility}

According to Galvele [192], the available mechanisms based on dissolution are unable to predict new cases of environment-sensitive fracture. There has been a common observation by many that SCC, hydrogen embrittlement, and liquid metal embrittlement exhibit great similarities. Therefore, a single allembracing mechanism ought to explain all of these phenomena. With this premise, Galvele [192] has proposed a mechanism based on surface mobility (Figure 7c).

Galvele [192] has suggested that many forms of environmentally induced cracking grow by the capture of surface vacancies at the crack tip and countercurrent surface diffusion of atoms away from the crack tip. The mechanism predicts that stress corrosion cracking should be prevalent at temperatures below 0.5 times the melting point of the metal, $T_{m}$, and in the presence of low melting surface compounds, when surface mobility is maximized in preference to bulk diffusion in the metal crystal. The effect of critical environments to cause SCC is explained by low melting compounds which enhance surface mobility.

In this model the rate-determining step is the rate at which the excess atoms are transported by surface diffusion from the tip of the crack to new lattice sites. The model leads to an expression for crack growth rates in these various modes of failure on the basis of the surface diffusion of atoms. It is suggested [192] that the coefficient of surface diffusion is related to the temperature. The implication is that compounds having a melting point less than $1200 \mathrm{C}$ will promote stress corrosion cracking, whereas compounds with higher melting point are protective. Parkins [99] however, points out a difficulty in relation to cracking of carbon steels. While nitrates do promote cracking because the 
melting point of nitrates is low, it would predict that $\mathrm{Fe}_{3} \mathrm{O}_{4}$ should be a protective compound since its melting point is $1597 \mathrm{C}$. It is observed [99] that in many instances of SCC in carbon steels, the potential range of cracking is associated with $\mathrm{Fe}_{3} \mathrm{O}_{4}$ formation. Galvele [192] surmounts the problem by invoking arguments relating to the breakdown of the film, so that active $\Longrightarrow$ passive transitions and potential dependence are expected to be involved in SCC. Oriani [193] showed that the flow of surface atoms should be toward the crack tip rather than away from it in the presence of a stress field. Galvele [194] argued that surface atoms exist in the absence of a stress field. However, it is then debatable as to whether a driving force is available for surface vacancy formation and diffusion.

\subsubsection{Stress Sorption Mechanism}

Another theory that was brought to attention during the 1973 International Conference in France was the stress sorption mechanism [100]. This theory, originally advocated by Uhlig [195], does not involve chemical or electrochemical dissolution of metal at the crack tip but instead involves weakening of already strained metal atom bonds through adsorption at "mobile defect sites" of the crack tip (Figure 7d). The surface energy of the metal is said to be reduced, allowing the metal to part under tensile stress. The role of stress in this mechanism is somewhat different from the previous mechanism. The stress causes some plastic flow to precede and accompany crack formation. The interstitials, such as carbon and nitrogen, may play an important role in this mechanism by pinning or impeding movement of the imperfections, thus extending the life of the imperfection at the grain boundary surface sufficient for nitrate or hydroxyl ions to chemisorb [158, 196-198].

This mechanism has some appeal inasmuch as the described bond weakening is similar to the effect postulated for hydrogen during hydrogen embrittlement (HE). Adsorption in this mechanism [195] is assumed to be potential dependent, to account for cathodic suppression of stress corrosion cracking below a "critical potential". Effects of inhibitor species are explained by assuming competitive adsorption between aggressive and inhibiting anions. The effect of a specific dissolved species on stress corrosion cracking (SCC) of a particular alloy is explained by assuming specific adsorption of the species causes bond weakening at the crack tip. The passivation of carbon steel in hydroxide solutions in the presence of nitrite inhibitor has been explained on the basis of competition adsorption. With an increase in $\mathrm{pH}$, the adsorption of $\mathrm{OH}^{-}$ions increases, while the adsorption of other anions decreases [113].

An explanation of metallurgical effects on SCC requires the assumption of adsorption at mobile defect sites. The nature and character of such defects 
have not been specified. Pure metals are thought to be resistant because the defect sites move into and out of the surface areas at the root of a notch too rapidly for adsorption to succeed. No explanation is offered as to why such undefined defects should be more mobile in pure metals than in alloys nor why some adsorbed species inhibit, while others promote, SCC. Furthermore, there is no independent evidence of preferential adsorption sites. It has been argued that [199] adsorption is not specific at any particular potential but continually increases above the zero point of charge where positive and negative charges are neutralized on the surface. According to others [200] the model fails to explain measurable but limited plasticity ahead of an atomically sharp crack tip in a ductile metal and the discontinuous nature of crack propagation. Parkins [99] has summarized these and other arguments against the stress sorption mechanism.

The stress adsorption model is, as others have indicated, rather difficult to test. In particular it is difficult to design experiments which could lead to refutation. Although fractographic features in nitrates, carbonates and hydroxides could have possibly resulted from such a process, the available evidence is strongly in favor of a film rupture/dissolution model [196].

\section{PASSIVATION ISSUES}

\section{$10.1 \quad$ Steels}

Passivity is defined as a condition of corrosion resistance due to formation of thin surface films under oxidizing conditions with high anodic polarization. Some metals and alloys having simple barrier films with reduced corrosion at active potentials and little anodic polarization, are not considered to be passive by this definition. In this context Figures 1, 4-6 are relevant. The passive state is stable over a large potential, that is above the primary passive potential, which corresponds to maximum corrosion rate. Subsequently, the corrosion rate falls to very low values in the passive state (about $10^{6}$ times lower than the maximum in the active state corresponding to $C^{\prime}$ in Figure 1). However at the potential corresponding to $E_{\text {pit }}\left(E^{\prime}\right.$ in Figure 1) the passivity is lost and anodic current increases giving rise to a transpassive state. $E_{\text {pit }}$ is called the critical pitting potential.

Chromium alloys are noted for the formation of very stable, thin, resistant, surface films in less oxidizing conditions, especially when alloyed with iron and nickel. The Pourbiax diagram (plot of potential versus $\mathrm{pH}$ ) for iron superim- 


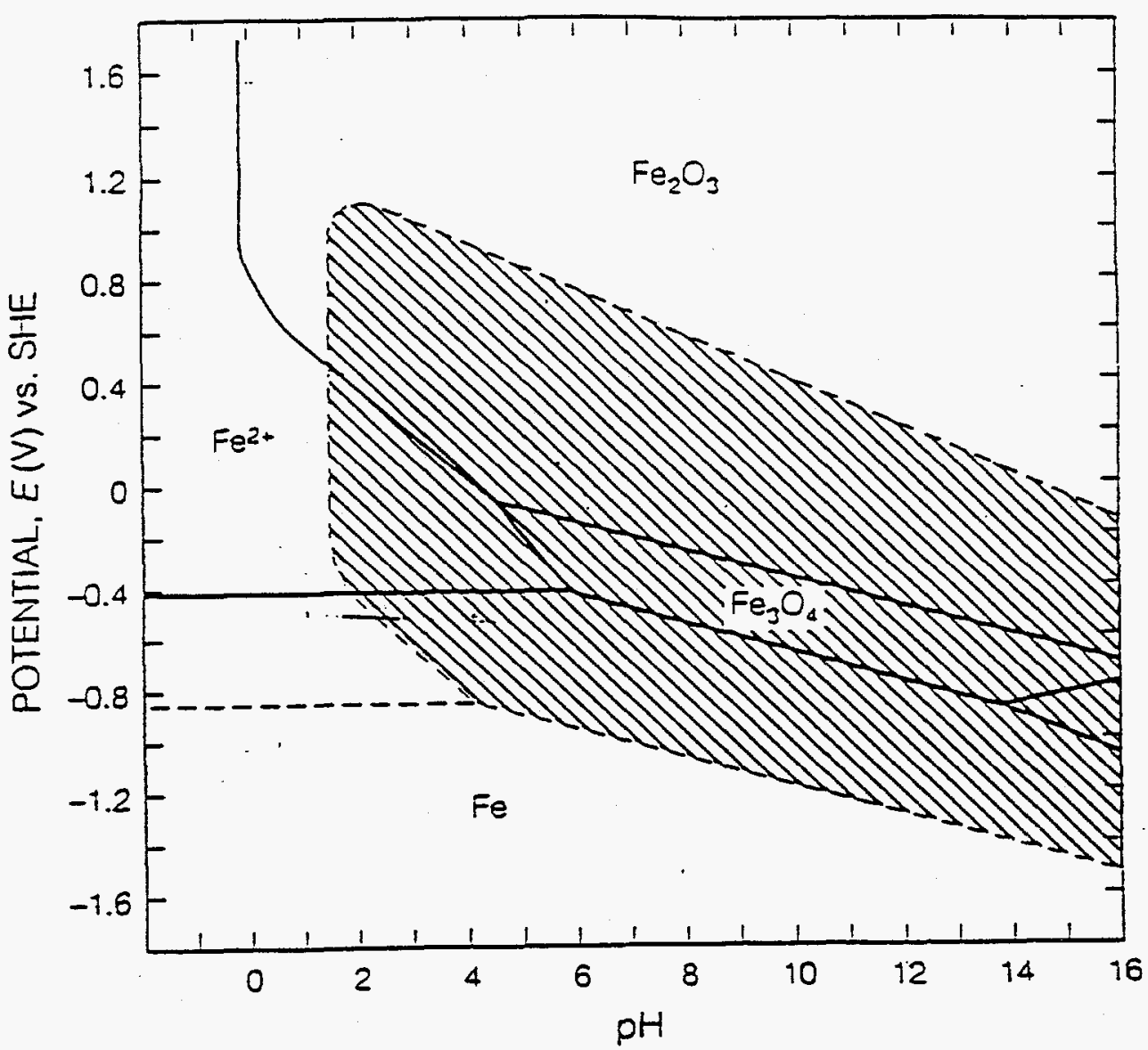

Figure 9: Pourbiax diagram for iron superimposed on the diagram for chromium designated by dashed lines. Shaded area indicates stability of $\mathrm{Cr}_{2} \mathrm{O}_{3}$ [201].

posed on the diagram for chromium, considered to form an oxide at much lower potentials, is indicated in Figure 9. Thus, chromium additions provide the basis for stainless steels and other corrosion resistant alloys. The structure of the film has eluded definition because it is so thin and fragile. Optical measurements indicate a compact, transparent film of 1 to $10 \mathrm{~nm}$ in thickness. Hydrogen has been detected in the film, indicating the presence of hydroxide, water or water of hydration. Although the most stable phases are usually the oxides, the Pourbiax diagram cannot rule out the formation of precursor condensed surface phases containing water and dissolved anions. Conflicting theories have suggested allotropic modifications of the bulk oxide or adsorbed anions as the source of passivity. Results from modern electron spectroscopic measurements are compromised by removal of water in the instrument vacuum systems, neccessarily altering the film structure and composition. Thus, conflicts in theory have been unresolved over the years.

Although thermodynamically iron should be oxidized at all $\mathrm{pH}$ values, in practice both the $\mathrm{Fe}(\mathrm{OH})_{2}$ and $\mathrm{Fe}_{3} \mathrm{O}_{4}$ corrosion products tend to accumulate on the metal surface producing partially protective layers which limit the rate of 
attack. The level of protection given by the protective layer varies with its morphology and the redox potential of the system. Under stagnant conditions and at ambient temperature it is reported that the corrosion rate remains low and roughly constant over the $\mathrm{pH}$ range 8-12. The constancy of the corrosion rate over this $\mathrm{pH}$ range is thought to arise because the electrolyte contacting the metal surface becomes saturated with $\mathrm{Fe}(\mathrm{OH})_{2}$ which buffers the $\mathrm{pH}$ at $\approx 9.5$. At the acidic limit of the $\mathrm{pH}$ range corrosion propagates more rapidly because of the increasing solubility of $\mathrm{Fe}^{2+}$ and because of the cathodic hydrogen ion reduction reaction (equation 1) can proceed rapidly. At the alkaline extreme of the $\mathrm{pH}$ range the corrosion rate shows a further fall because the higher $\mathrm{OH}^{-}$concentration causes the less thermodynamically stable $\mathrm{Fe}(\mathrm{OH})_{2}$ or the highly thermodynamically $\mathrm{Fe}_{3} \mathrm{O}_{4}$ surface films to become increasingly protective.

The presence of oxygen may accelerate the rate of general corrosion by depolarizing the cathodic reaction through reactions 2 and 3 . Sometimes oxygen may reduce the protection afforded by the corrosion layer because it oxidizes $\mathrm{Fe}^{2+}$ ions to $\mathrm{Fe}^{3+}$ which precipitates as dense and thermodynamically stable $\mathrm{Fe}(\mathrm{OH})_{3}$ away from the metal surface. Under these conditions the rate of metal dissolution is usually controlled by the rate of supply of oxygen to the metal surface.

In contrast to the above, oxygen may under some circumstances exert a beneficial effect on the corrosion of iron and steel by facilitating the formation of a truly passivating surface layer of $\mathrm{Fe}_{2} \mathrm{O}_{3}$ which is thermodynamically unstable. When this occurs the rate of general corrosion is reduced to typically $0.1-1 \mu \mathrm{m} / \mathrm{yr}$. This passivating effect is favored under conditions of high oxygen transport such as in flowing systems and also. when the environment contains ions which favor passivation such as carbonates. In general, oxygen will induce passivation in environments where the ratio of passivating to aggressive ions is favorable.

Passivity is a very desirable state for any metal in service because the corrosion rate is negligible. From a scientific viewpoint, it is not very well understood. There are two ways to provide corrosion protection: (1) by change in the corrosion medium (addition of corrosion-retarding substances or inhibitors) and (2) by change of electrode potential of the metal/corrosive medium (cathodic and anodic corrosion protection).

Inhibitors are substances that are added to the corrosive medium to lower the corrosion rate by retarding the anode process and/or the cathode process. An anodic inhibitor increases the anode polarization and hence moves the corrosion potential in the positive direction, whereas a cathodic inhibitor in 
the corresponding manner displaces the corrosion potential in the negative direction. With so-called mixed inhibitors, the potential change is smaller and its direction is determined by the relative size of the anodic and cathodic effects. With mixed inhibitors, the potential change is smaller and its direction is determined by the relative size of the anodic and cathodic effects [202].

Anodic inhibitors are typically anions which migrate to anode surfaces and which in favorable cases passivate the anode, often in conjunction with dissolved oxygen. In the class of anodic inhibitors we find a number of important inorganic inhibitors, such as orthophosphate, silicate, nitrite and chromate and also benzoate. Non-oxidizing inhibitors are effective only in conjunction with dissolved oxygen. Cathodic inhibitors are usually cations which migrate towards cathode surfaces where they are precipitated chemically or electrochemically and thus block (isolate) these surfaces. One example is afforded by retarding action of $\mathrm{As}^{3+}$ and $S b^{3+}$ on the dissolution of iron by acids. Simultaneous addition of two inhibitors may result in a considerably increased effect and may also reduce the risk of pitting which can be absorbed at low inhibitor concentrations.

It is well known that at the passivation potential the metal can be shifted back and forth between the active and passive states and that no macroscopic oxides are being nucleated. It is, however, generally well accepted that oxygen adsorption controls the passive film formation and that the initial step is either oxygen adsorption from the solution or adsorption of the oxygen end of the water molecules. Passivation is associated with the formation of an oxide layer through cathodic reaction depicted by equations 2-5. The thermodynamic equilibria for the above reactions are well documented by means of Pourbiax diagrams which are essentially potential-pH diagrams. These diagrams show clearly that $\mathrm{Fe}(\mathrm{OH})_{2}$ or $\mathrm{Fe}^{2+}$ form in the $\mathrm{pH}$ range 5 to $10 . \mathrm{Fe}_{3} \mathrm{O}_{4}$ has similar thermodynamic stability to $\mathrm{Fe}(\mathrm{OH})_{2}$, and may form preferentially to $\mathrm{Fe}(\mathrm{OH})_{2}$ particularly at temperatures above $60 \mathrm{C}$ which is similar to the temperature of the walls of the High-Level Waste Tanks.

The Pourbiax diagram (Electrode potential versus $\mathrm{pH}$ plots) is another way to show the propensity for cracking. Generally, it represents the reactions and reaction products that will be present when equilibrium has been attained, assuming all appropriate reactions have been included for given conditions of potential and $\mathrm{pH}$. Of special interest are the conditions in which a corrosion reaction is thermodynamically possible. The Pourbiax diagram however does not make predictions with respect to corrosion rates which may be a factor slower in liquid aqueous solutions.

According to the potential-pH diagram for iron in sulfate solutions as shown in 


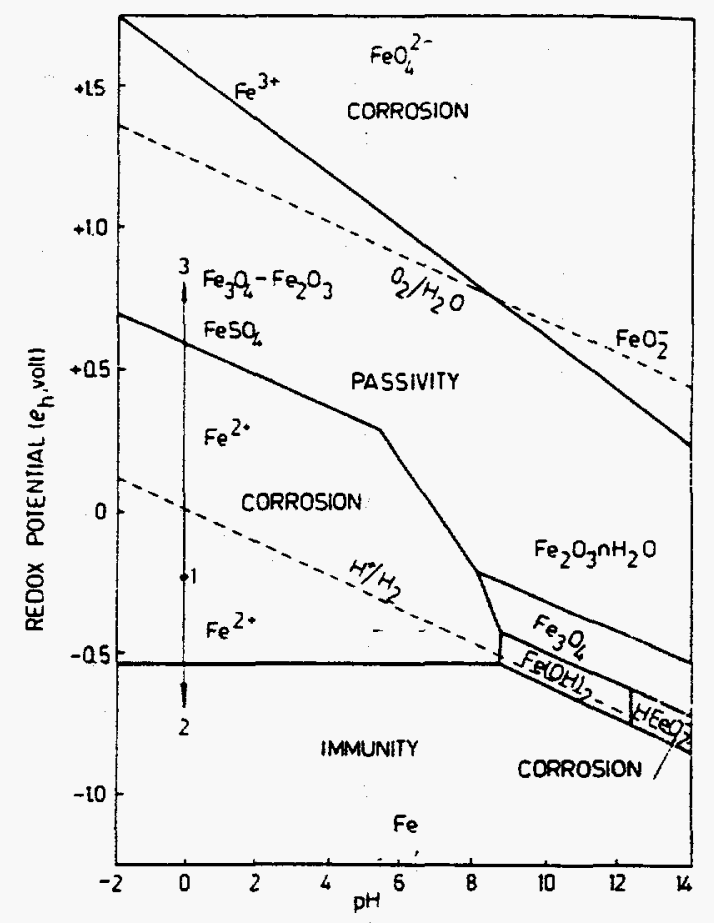

Figure 10: Potential-pH diagram for iron in sulfate solutions. Iron concentration $10^{-3}$ mole/liter, $25 \mathrm{C}$ [202]: (1) unprotected, corroding specimen; (2) cathodically protected specimen; (3) anodically protected specimen.

Figure 10, there are two ways to prevent corrosion by potential change. By applying a cathodic current, the potential of the steel specimen may be displaced down into the immunity range where the metal is in the thermodynamically stable range. It is also possible to stop corrosion by increasing the electrode potential of the specimen into the passivity range in which a higher oxide of iron is the stable phase. It is assumed that this oxide is obtained as a thin, dense and adhering film. The protective film is a semiconductor with small ionic conductivity and as soon as it has been formed, a very small current is needed to maintain the steel in the passive state.

\subsection{Carbon Steels}

In zone 1 (Figure 4), pitting and SCC occur in adjacent or overlapping potentials. For example, zone-1 SCC and pitting of carbon steel in hot nitrate occurs in a narrow potential range with pitting present at slightly noble potentials and passivity, with no cracking at slightly active potentials [48]. The usual corrosion conditions are not sufficiently oxidizing, in contrast to concentrated 
fuming nitric acid, which is considered to be the most highly oxidizing solutions available. In zone-2 SCC (Figure 4) is far from the pitting potential range. SCC occurs in this zone where the passive film is relatively weak at active potentials adequately to form a film. This has been observed for carbon steel in hot caustic solutions (Figure 5) as well as in carbonate-bicarbonate (Figure 6) solutions [49]. Anodic polarization curves for carbon steel in nitrate and hydroxide solutions are shown in Figure 4. Mild steel is susceptible to caustic cracking over a range of $\mathrm{NaOH}$ concentrations. Many of the laboratory investigations of caustic cracking have been conducted in 33 to $35 \% \mathrm{NaOH}$ since this concentration is believed to provide the most severe test [117-118].

Importantly, nonsusceptible alloy-environment combinations will not crack even if held in one of the potential zones described in Figure 4-6. Thus, temperature and solution composition (including $\mathrm{pH}$ and dissolved oxidizers, aggressive ions, and inhibitors or passivators) can modify the anodic polarization behavior to permit SCC as well as control corrosion potential in a critical region. Hence, one cannot predict susceptibility to SCC solely from the anodic polarization curve.

Achieving the critical potential range for caustic cracking in service may be a factor decided by the presence of solution impurities. For example, caustic cracking is promoted by a small amount of dissolved oxygen, but stopped at higher oxygen levels [116]. Similarly a small amount of $\mathrm{NaCl}$ accelerate caustic cracking while larger amounts tend to reduce this effect [116]. Other substances which have been reported to stimulate caustic cracking when present in critical concentration ranges include nitrate, permanganate and chromate. However when these same substances are present in the caustic solutions at relatively high concentrations, they act as inhibitors of caustic cracking by causing the potential to be more positive than the critical range for inducing cracking. There are strong oxidizing agents which passivate the entire surface of the steel to prevent caustic cracking [116]. Substances which have been shown to inhibit caustic cracking when present in proper amounts include nitrite, sulfate, nitrate, permanganate and carbonate.

All the leaking tanks have failed by $\mathrm{NO}_{3} \mathrm{SCC}$ both at Savannah and Hanford sites [153]. Consequently, the $\mathrm{pH}$ range in which these tanks were operating is presumed to be low at the corrosion sites. Low $\mathrm{pH}$ levels may be due to several reasons: (1) high levels of nitrate, (2), low levels of hydroxide, (3) low level of nitrite inhibitor [28, 153] (4) reduction in hydroxide level due to purging with air by carbon dioxide [24-26] consumption (5) increasing level of acidity due to release of oxidation products during the radiolysis of organic solvents [203] and, (6) release of hydrogen during the of radiolysis of organic solvents $[27,203]$ and burping $[27,204]$. Importantly, all the high-level waste (HLW) 
tanks at Hanford site are maintained at high $\mathrm{pH}$ levels (10-12) today. At the Hanford site, all the HLW tanks are protected internally by using an inhibitor [27]. Nitrite is added to the waste in these tanks and is the major inhibitor used in the protection of the mild steel liner from cracking.

\subsubsection{Corrosion Protection by Addition of Corrosion-retarding Substances (In- hibitors)}

Sodium nitrite is an effective inhibitor for iron and a number of other metals in a variety of liquids [205]. The amount needed increases with the chloride content. The concentration needed to protect mild steel in distilled water is only $50 \mathrm{ppm}$ but with a sodium chloride concentration of $500 \mathrm{ppm}$ the inhibitor concentration should be raised to $300 \mathrm{ppm}$ and with $3000 \mathrm{ppm}$ sodium chloride to $4000 \mathrm{ppm}$.

Below $\mathrm{pH} 6$ nitrite is relatively ineffective but its inhibitive properties improve with increase in $\mathrm{pH}$ value and reach a maximum in the range 9-10. Nitrite is an anodic inhibitor and passivator and acts by forming a stable film of ferric oxide which is continuously kept in a state of repair by an adequate concentration of inhibitor. Unlike many inhibitors, sodium nitrite is effective even when the metal is already rusted, a very desirable property in industrial systems [205].

Parkins [97] found that the severe cracking that is promoted by $8 \mathrm{M} \mathrm{KNO} \mathrm{K}_{3}$ can be inhibited by the open-circuit potential by the presence of only 2 or $3 \mathrm{~kg} / \mathrm{m}^{3}$ $(0.04 M)$. However, if the potential is raised above open-circuit value, cracking returns at potentials that increase as the concentration of $\mathrm{NaNO}_{2}$ is increased as is apparent in Figure 6 which shows the results from slow strain-rate tests involving solutions of different nitrite concentrations and various controlled potentials. The figure shows two plateaus, one at about $66 \% \mathrm{RA}$ and the other at about $20 \% \mathrm{RA}$, corresponding to ductile failure and severe stress corrosion fracture, respectively. It also is apparent that the ductile-fracture plateau extends to more positive potentials the higher the concentration, with cracking only obtained at $800 \mathrm{~kg} / \mathrm{m}^{3}(11.59 \mathrm{M}) \mathrm{NaNO}_{2}$ when the system was subjected to a potential above $\left(-0.4 V_{S C E}\right)$. Furthermore, in nitrite-free solutions Parkins [45] noticed a black film of $\mathrm{Fe}_{3} \mathrm{O}_{4}$ which formed over the exposed surfaces of the mild steel, but in solutions containing nitrite and for potentials at which cracking occurred, the surfaces remained unchanged, with a thin transparent film of $\mathrm{Fe}_{2} \mathrm{O}_{3}$, except for small discrete black spots from which the stress corrosion cracks propagated, the surfaces of which were covered with a film of $\mathrm{Fe}_{3} \mathrm{O}_{4}$. The implication is that the environmental conditions were locally changed from those of bulk environment to circumstances in which cracking occurred, which is suggested by the different corrosion products present on the fracture and outer surfaces of the specimens. This further implies that pitting 


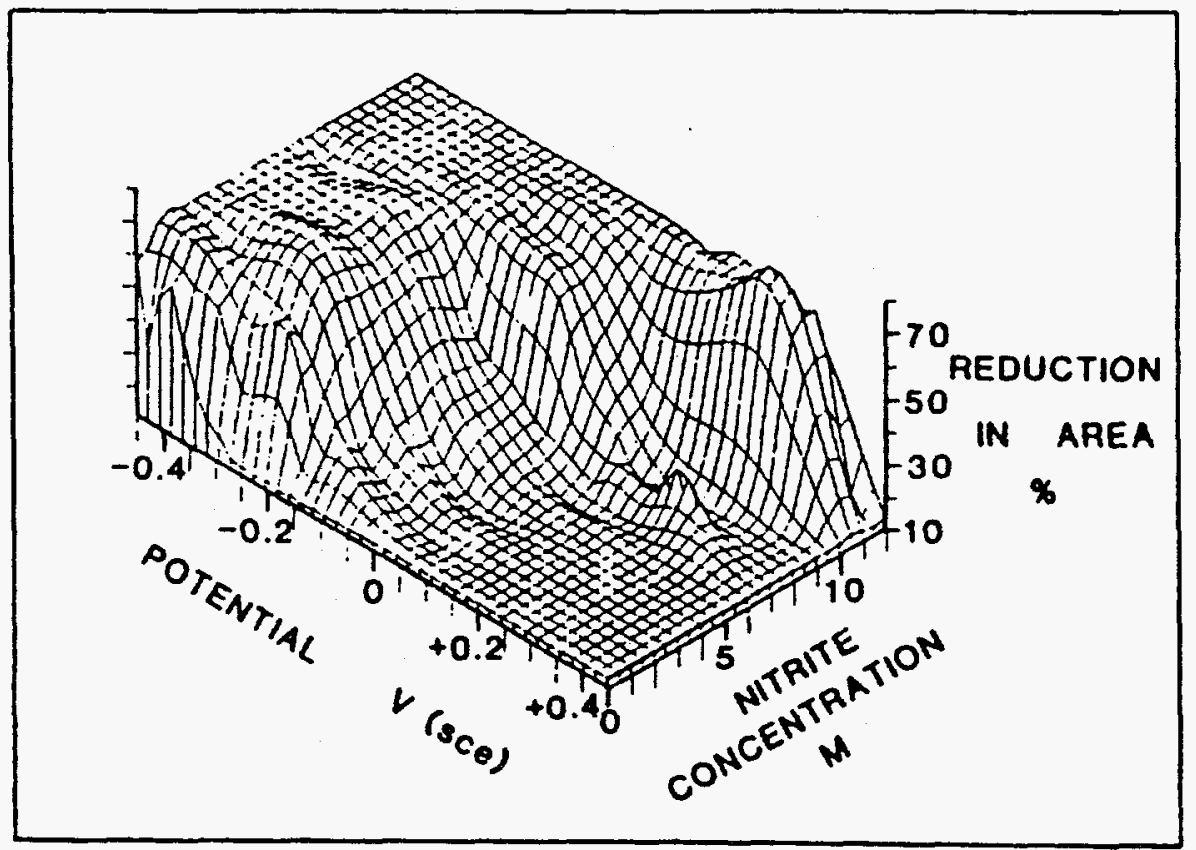

Figure 11: Effects of nitrite concentration and potential on the reduction in area to fracture $\mathrm{C}-\mathrm{Mn}$ mild steel specimens in boiling $8 \mathrm{M} \mathrm{KMnO}$ solution by slow strain rate testing [97].

occurs at defects in the film and the potentials at which cracking is initiated in the nitrite-containing solutions should correspond to the pitting potentials for the various nitrite concentrations.

It has been stated [109] that the decomposition of nitrate results in the formation of nitrite through the reaction:

$$
10 \mathrm{Fe}+6 \mathrm{NO}_{3}^{-}+3 \mathrm{H}_{2} \mathrm{O} \longrightarrow 5 \mathrm{Fe}_{2} \mathrm{O}_{3}+6 \mathrm{OH}^{-}+3 \mathrm{~N}_{2}
$$

assuming the passive layer to be $\mathrm{Fe}_{2} \mathrm{O}_{3}$. The $\mathrm{NO}_{2}^{-}$is assumed to be an oxidizing agent and its removal, by urea additions, would be expected to shift the potential of iron to less noble values and cause a decrease in the lifetime of specimens undergoing stress corrosion. This assumption has been supported by experimental results. However, this result appears to contradict some results due to Smialowski [110], who stated that in the absence of air, $\mathrm{NO}_{2}^{-}$is formed and this prevents cracking by acting as an inhibitor. Contrary to this observation, the addition of $1 \% \mathrm{NaNO}_{2}$ to $4 \mathrm{~N} \mathrm{NaNO}_{3}$ assisted cracking [111].

Smialowski [112] suggested the most probable cycle of reactions accompanying 
the initial stage of the corrosion process of mild steel in $\mathrm{NH}_{4} \mathrm{NO}_{3}$ at $100 \mathrm{C}$ as containing $98 \% \mathrm{~N}_{2}$ as:

$$
2 \mathrm{H}^{+}+\mathrm{Fe}+\mathrm{NO}_{3}^{-} \longrightarrow \mathrm{Fe}^{2+}+\mathrm{H}_{2} \mathrm{O}+\mathrm{NO}_{2}^{-}
$$

the production of the inhibiting $\mathrm{NO}_{2}^{-}$being increased by the oxidation of $\mathrm{Fe}^{2+}$ according to:

$$
2 \mathrm{Fe}^{2+}+\mathrm{NO}_{3}^{-}+\mathrm{H}_{2} \mathrm{O} \longrightarrow 2 \mathrm{Fe}^{3+}+\mathrm{NO}_{2}^{-}+2 \mathrm{OH}^{-}
$$

The precipitation of iron hydroxide in the above reaction leads to the formation of protective layers and passivation. Smialowski [112] analyzed the gas collected during prolonged corrosion of mild steel in ammonium nitrate solution. A possible reduction reaction occurring simultaneously as:

$$
2 \mathrm{NO}_{3}^{-}+6 \mathrm{H}_{2} \mathrm{O} \longrightarrow \mathrm{N}_{2}+12 \mathrm{OH}^{-}
$$

If such reactions are imagined to occur at the crack and the products are confined within the crack it is difficult to understand why cracking is not inhibited by the $\mathrm{NO}_{2}^{-}$, assuming this to be inhibitive as suggested but Smialowski [110] and neglecting any consideration of the effect of the $\mathrm{OH}^{-}$. It was also conceived that the $\mathrm{NO}_{2}^{-}$is formed by cathodic reaction according to [112]:

$$
\mathrm{NO}_{3}^{-}+\mathrm{H}_{2}+2 e \longrightarrow \mathrm{NO}_{2}^{-}+2 \mathrm{OH}^{-}
$$

which avoids the problem.

It has been recently suggested [113] that in acidic and weakly acidic electrolytes the reduction of nitrite ions is greatly facilitated by the formation of nitric acid, which in turn forms nitric oxide that is readily reduced on various metals:

$$
\begin{gathered}
3 \mathrm{HNO}_{2} \longrightarrow 2 \mathrm{NO}+\mathrm{NO}_{3}^{-}+\mathrm{H}^{+}+\mathrm{H}_{2} \mathrm{O} \\
\mathrm{NO}+5 e^{-}+6 \mathrm{H}^{+} \longrightarrow \mathrm{NH}_{4}^{+}+\mathrm{H}_{2} \mathrm{O}
\end{gathered}
$$

The appearance of a new cathodic depolarizer often leads to intensification of corrosion. Although the density of the cathode current increases, it does not become so great that the metal enters into the passive state. This explains the increase in the corrosion of cooling systems protected by sodium nitrite when accidental acidification of the medium occurs.

However, one interesting feature has been reported [113]. With the aid of sufficiently high concentrations of sodium nitrite, it has been found that steel can be passivated in an acid electrolyte in which the stability of phase films is low. Studies were conducted with the aid of potentiodynamic curves obtained 
in acid buffer electrolyte ( $\mathrm{pH}=2$ ), in which the sodium-nitrite concentration was varied continuously. It has been found that with an increase of the sodium-nitrite concentration in the buffer electrolye passivation is facilitated, the passivation potential shifts toward the negative, while the passivation currents decrease. For a $0.15 \mathrm{~N}$ concentration of sodium nitrite the passivation current drops from $20 \mathrm{ma} / \mathrm{cm}^{2}$ in a pure buffer electrolyte to $6 \mathrm{ma} / \mathrm{cm}^{2}$, while the passivation potential drops from +1.1 Volts to +0.05 Volt. However, if the sodium nitrite concentration is increased to $0.25 \mathrm{~N}$, steel enters into the passive state because of the steady-state potential $(+0.33$ Volt).

The effect of nitrite ions on passivation in the presence of sodium nitrite has been explained [113] by adsorption of these ions which reduces the free energy of the system and impedes the passage of ion-atoms from the lattice into the solution. It is not likely that the nitrite ions alter the nature of the passivating layer. Thus the potency of nitrate based solution depends upon its $\mathrm{pH}$ and the presence or otherwise of oxidizing additions or substances capable of forming insoluble iron salts.

Based on studies on corrosion of steels in the presence of nonoxidizing inhibitors, it has been emphasized [113] that hydroxyl ions play a special role in the passivation process. Their passivation properties manifest themselves, however, only when a certain potential has been reached, a potential more positive than for other anions like phosphate, borate, and silicate. However, hydroxyl ions do not themselves retard the kinetics of the anodic reaction until the potential reaches +0.2 Volts.

However, in caustic solution when inhibitors are present, it has been suggested that there is some critical ratio of inhibitor to $\mathrm{NaOH}$ concentration that has to be exceeded in order that the natural potential will fall outside of the susceptible range [113]. Such a behavior is undoubtedly associated with concurrent adsorption. Also, caustic cracking may be prevented by means of anodic protection (that is, by stabilizing the passive film) or by complete reduction of the passive film by cathodic protection currents. Today, all the High-Level Waste tanks are maintained at high $\mathrm{pH}$ levels (ie. 10-12 $\mathrm{pH}$ ).

Based on the above discussion and with reference to a waste tank environment, passivation by $\mathrm{NO}_{2}^{-}$would involve [113]:

- precipitation of $\mathrm{Fe}(\mathrm{OH})_{2}$ by competition in adsorption increases due to an increase in adsorption of $\mathrm{OH}^{-}$, while adsorption of other ions decreases.

- deposition of ferric oxide on the iron surface in the presence of $\mathrm{NO}_{2}^{-}$.

$$
9 \mathrm{Fe}(\mathrm{OH})_{2}+\mathrm{NO}_{2}^{-} \rightleftharpoons 3 \mathrm{Fe}_{3} \mathrm{O}_{4}+\mathrm{NH}_{4}^{+}+2 \mathrm{OH}^{-}+6 \mathrm{H}_{2} \mathrm{O}
$$


- $\mathrm{NH}_{4}^{+}$ions are oxidized by oxygen with the regeneration of $\mathrm{NO}_{2}^{-}$:

$$
\mathrm{NH}_{4}^{+}+4 \mathrm{H}_{2} \mathrm{O}+\frac{1}{2} \mathrm{O}_{2} \rightleftharpoons \mathrm{NO}_{3}^{-}+3 \mathrm{H}_{2} \mathrm{O}+2 \mathrm{H}^{+}
$$

Hence the role of the adsorbed $\mathrm{NO}_{2}^{-}$is [113]: (1) to oxidize divalent iron to trivalent iron by oxygen in order to facilitate film formation and (2) to regenerate $\mathrm{NO}_{2}^{-}$by oxidation of $\mathrm{NH}_{4}^{+}$.

10.2.2 Corrosion protection by electrochemical (cathodic and anodic) corrosion potential
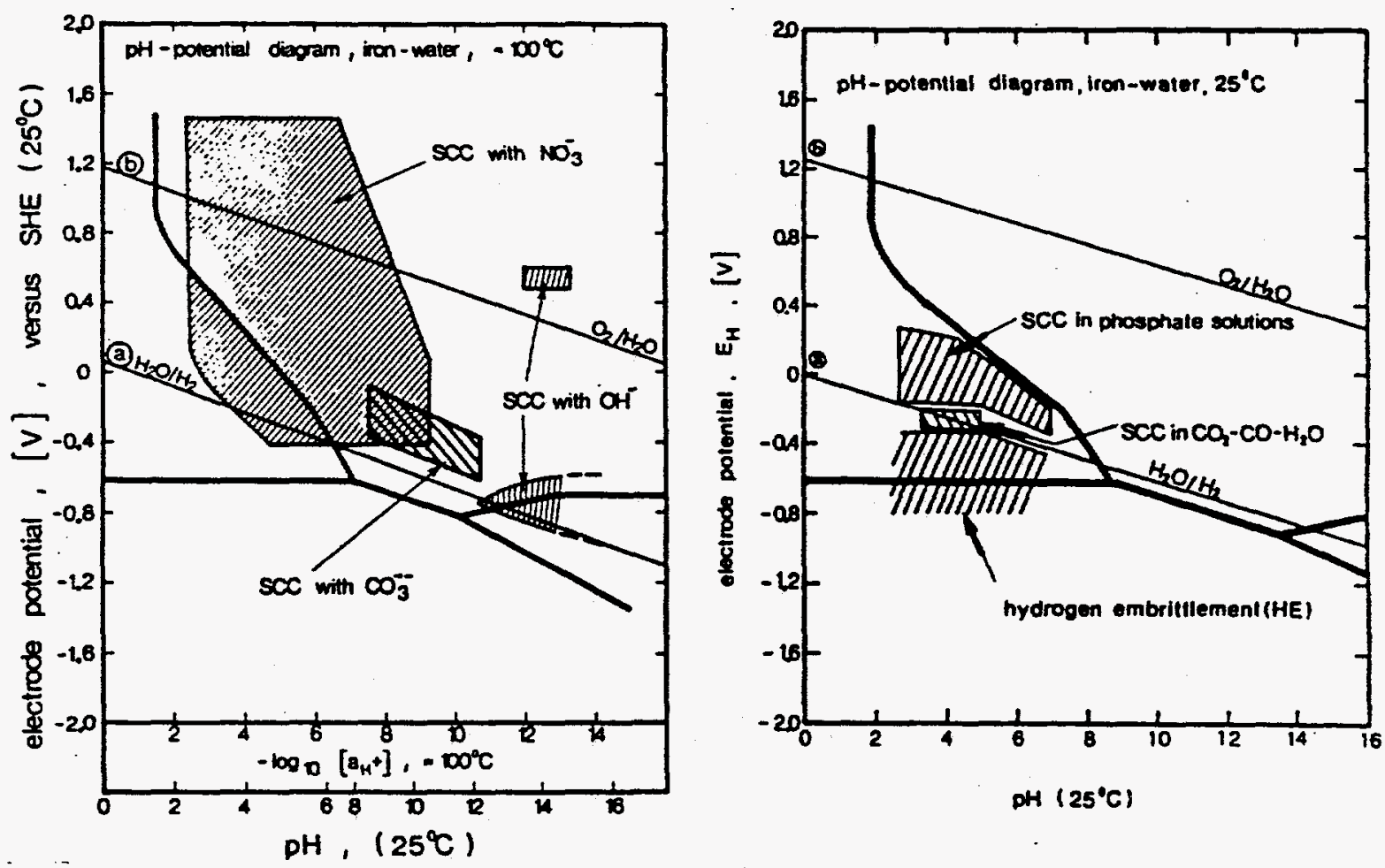

Figure 12: Ranges of $\mathrm{pH}$ and potential for bulk solutions in which stress corrosion cracking of carbon steels and low alloy steels with low to medium strengths is normally observed [206].

The restricted regimes of $\mathrm{pH}$ and potential in which stress corrosion cracking may occur in carbon and low alloy steels of low to medium strengths is summarized in Figure 11 [206]. It is a summary of literally hundreds of papers on SCC, and it points out the $\mathrm{pH}$-potential areas of safety and of danger from SCC. Each shaded area in Figure 11 encompasses environmental conditions 
which have resulted in dangerous and costly SCC-service failures of structures and machines built with carbon and low-alloy steels [201]. It is interesting to note that when the electrochemical data of Ondrejcin on synthetic waste solutions $[6,7,40-44]$ is considered, the $\mathrm{pH}$ range for $\mathrm{NO}_{3}^{-} \mathrm{SCC}$ with respect to the synthetic waste according to Figure 11 is $\approx 3$. This is indicative that $\mathrm{NO}_{3}^{-}$in waste tanks existed at low $\mathrm{pH}$ or highly acidic conditions.

At the Hanford site where connecting carbon steel pipes are cathodically protected [27] today with success, so far none of the High-Level Waste tanks have been cathodically protected.

\section{RADIATION EFFECTS}

\subsection{Background}

For many years it has been known that the interaction of aqueous solutions by gamma radiation produces ionic, free radical, and molecular products including $\mathrm{H} \cdot, \cdot \mathrm{OH}, e_{\mathrm{aq}}^{-}, \mathrm{H}_{3} \mathrm{O}^{+}, \mathrm{OH}^{-}, \mathrm{H}_{2}, \mathrm{H}_{2} \mathrm{O}_{2}, \mathrm{O}_{2}, \mathrm{O}_{2}^{-}$, and $\mathrm{HO}_{2}$ [153-154]. Species such as $e_{a q}^{-}, H$. and $H_{2}$ can act as reducing agents, while others such as $\mathrm{H}_{2} \mathrm{O}_{2}$, . $\mathrm{OH}, \mathrm{O}_{2}, \mathrm{O}_{2}^{-}$and $\mathrm{HO}_{2}$ can act as oxidizers. As a result of the production of such species under gamma irradiation, there may be alterations in the rates or mechanisms of corrosion attack. Particularly, in the case of reaction of water with gamma radiation because of the fast reactivity of ionic species, the "primary products" of water radiolysis are considered to be $\mathrm{H}^{+}, \mathrm{OH}^{-}$, $e_{a q}^{-}, \mathrm{HO}_{2}, \mathrm{H}_{2} \mathrm{O}_{2}$, and $\mathrm{H}_{2}$, where the first four are called the radical products, and the last two are the molecular products. The radical products are very chemically reactive, reacting with the molecular products or with dissolved solutes in the water. If oxygen is dissolved in the water, both $\mathrm{H}$ and $e_{a q}^{-}$react with it rapidly to form $\mathrm{HO}_{2}$ and $\mathrm{O}_{2}^{-}$, respectively. At $\mathrm{pH}$ near neutral, the $\mathrm{HO}_{2}$ ionizes rapidly to form $\mathrm{H}^{+}$and $\mathrm{O}_{2}^{-}$.

The result of all these reactions is that in irradiated oxygenated water, steadystate concentrations of the oxidizing species $\mathrm{OH}, \mathrm{O}_{2}^{-}$, and $\mathrm{H}_{2} \mathrm{O}_{2}$ are present. There is also a low steady-state concentration of $\mathrm{H}_{2}$. The obvious implication is that each of the models of localized corrosion must include equations for the mass transport, homogeneous reaction, and electrochemical reaction of each radiolytic species.

The composite of the reactions of all the reactive species in the solution is reflected by a corrosion potential $E_{\text {corr }}$ when an electrode of a particular material is immersed in such a solution. It has been found by several investigators $[155,156]$, that $E_{\text {corr }}$ of stainless steel shifts to more positive (noble) values 
in the presence of gamma radiation. The positive shift in $E_{\text {corr }}$ was composed of three parts [157]. The major part was found to persist after the irradiation was terminated, but most of it was replaced by a new solution. This part was attributed to hydrogen peroxide, $\mathrm{H}_{2} \mathrm{O}_{2}$. The part that remained after the solution was changed was attributed to permanent changes in the oxide layer on the steel. The third part was only present during irradiation and was attributed to the transient radical species.

\subsection{Carbon Steels}

Corrosion studies involving mild steels in irradiated solutions have been reported in a number of papers [158-161]. Marsh and his coworkers [159] have also reported studies on the influence of $\gamma$-irradiation on carbon steel corrosion in synthetic granite groundwater. Dose rates of $1-1.5 \times 10^{5}, 3.5 \times 10^{3}$ and $3 \times 10^{2}$ Rads/h were selected. Whereas unirradiated samples showed a general corrosion of less than $\approx 6 \mu \mathrm{m} / \mathrm{yr}$, the irradiated tests showed appreciable acceleration in the rate of corrosion with the weight loss measurements indicating corrosion rates exceeding $100 \mu \mathrm{m} / \mathrm{yr}$ in some tests at high dosage rates. It has been suggested that in high dose rate tests, there was a low yield of principal oxidizing products like $\mathrm{H}_{2} \mathrm{O}_{2}$ and $\mathrm{OH}$. However in low dose rate tests there is a higher yield of $\mathrm{H}_{2} \mathrm{O}_{2}$ and $\mathrm{OH}$ resulting in localized corrosion developed by differential oxygen cells which cause local acidity culminating in corrosion addition to that induced directly by the oxidizing radiolysis products. Furthermore, these oxidizing radiolysis products can cause a change in the morphology of the surface film produced on the specimens, thereby reducing the protective properties of the film and causing degradation of the tank wall. Such a mechanism was suggested in order to account for the detrimental effect of oxygen in a carbon steel tank filled with synthetic granite groundwater which was maintained oxygenated by passing $\mathrm{CO}_{2}$ free air through the gas space at the top of the tank at temperatures in the range 25-90C [159]. Similar trends (nonirradiated versus irradiated specimens) were observed on carbon steels recently [160] at $250 \mathrm{C}$ in moist air environment simulating the nuclear waste repository preclosure condition for tests conducted at 10,000 $\mathrm{Rad} / \mathrm{hr}, 1,000 \mathrm{Rad} / \mathrm{hr}$ and $100 \mathrm{Rad} / \mathrm{hr}$. Typically, the corrosion rates were lower at the lower dosage rates, but were significantly higher at $100 \mathrm{Rad} / \mathrm{hr}$ compared to the case without irradiation. However, no corrosion was observed at $150 \mathrm{C}$ in these steels possibly due to the formation of a corrosion product which is more resistant at this temperature. Recently, corrosion tests [158] on ASTM A-537 Class I and ASTM A-516 have not shown appreciable effects on corrosion rates performed with simulated wastes of the types DSS, Future Purex and HFW particularly at $\gamma$-radiation levels of $<1000 \mathrm{Rad} / \mathrm{hr}$ expected to be at tank walls at the Hanford Site. 
Intergranular corrosion (IGC) of mild steel has been observed only in the lowtemperature $(\approx 25 \mathrm{C})$, high-intensity $(0.3 \mathrm{MR} / \mathrm{hr})$ studies [162-163]. It is suggested [159] that apparently IGC of mild steel has been found to be significant when the concentration of one or more water-radiolysis products (eg. $\mathrm{H}_{2} \mathrm{O}_{2}$, $\mathrm{H}, \mathrm{OH}$ ) attains a critical value in the vicinity of the metal-solution interface. The rates at which the water-radiolysis primary products are formed are proportional to the radiation dose rate, but the rates at which these products recombine and interact with other radiolytic species are temperature-dependent; ie. they increase as the temperature increases. Thus, the critical concentration of the radiolytic species required to initiate significant IGC would be attained at high dose rates and low temperature.

The NACE Corrosion Data Survey [203] was examined for corrosion rates of carbon and stainless steels (SS) caused by tetraphenylborate (TBP) a solvent used to precipitate the radioactive cesium and nonradioactive potassium in the tanks located at the Savannah River Plant. It has been found that there is a general trend for organics to become more aggressive as they are further oxidized during radiolysis of TBP in the sequence: (1) hydrocarbon, (2) alcohol, (3) aldehyde, (4) and acetic acid (e.g., acetic, formic, or benzoic acids). Thus, increasing concentrations of oxidized products can result with time. Provided that a sufficient alkaline environment is maintained, the only organic salt from radiolysis of TBP which contributes directly to corrosion is sodium phenolate. However, the acidic nature of TPB decomposition products sometimes can result in acidic dissolution or activation of previously passivated steel. Stable passive films can be expected to be maintained on the carbon steel waste tanks provided that the $\mathrm{pH}$ remains moderately high and adequate nitrite is available to inhibit sulfate, chloride, and nitrate. This conclusion is supported by both laboratory and in-tank demonstration tests.

A Double-Shell Tank, Tank 241-SY-101 [204] at the Hanford site was filled with concentrated sodium nitrate and organic radioactive waste between 1977 and 1980. Organics present in this tank included hydroxy-ethylethylene diaminetriacetic acid (HEDTA), ethylene diamine triacetic acid (EDTA) and glycolate. These organics would also go through the same sequence of degradation as for the case of TBP giving rise to increasing concentrations of the oxidized products with time. If these products are acidic, then activation of the passivated steel can result. Hence it would be necessary to maintain the solutions in these tanks at high $\mathrm{pH}$ levels. Recently [27], it has been warned that several other tanks in the site contained the organics. Consequently, controlling the tanks at high $\mathrm{pH}$ levels is an inportant concern. 


\section{SUMMARY AND CONCLUSIONS}

1. Pitting corrosion is an important degradation mode both in the vapor phase and liquid phase in low carbon steels [5]. Although earlier studies [11-19] have reported pitting corrosion in High-Level Waste tanks, it has not been pursued vigorously.

2. Pitting corrosion occurs heterogenously at defects such as inclusions and grain-boundaries. None of the pit initiation model mechanisms with respect to steels take these defects into consideration. These defects reduce the driving force or free energy for pitting corrosion. This is important, as it influences the incubation time and critical pitting potential considerably.

3. The presence of $\mathrm{Cl}^{-}$is central to pit initiation and growth model mechanisms in low carbon steels. $\mathrm{Cl}^{-}$is an essential ingredient in the breakdown of the passive film. The presence of $\mathrm{Cl}^{-}$in the pits results in local acidification within the pits, resulting in low $\mathrm{pH}$.

4. Pit growth, according to the model mechanisms, is autocatalytic as a consequence of local reduction at low $\mathrm{pH}$. Studies at Savannah River Site have reported [20-26] the presence of $\mathrm{Cl}^{-}$in tank waste solutions.

5. Pit corrosion is a precursor to SCC. Once the pit reaches a critical size it becomes stable and stress corrosion cracking (SCC) takes over. Of all the SCC mechanisms known, the most relevant to high-level waste tank failure is the film rupture mechanism. This process involves breaking of the oxide film followed by anodic dissolution along weak grain-boundaries contaminated by segregants (importantly $\mathrm{C}$ and $\mathrm{N}$ due to improper heattreatments).

6. Since 1971, hydrogen embrittlement has been a well-recognized degradation mode in low carbon/mild/ferritic steels.

7. Several studies have strongly suggested that the $\mathrm{pH}$ within the growing pit as well as in the vicinity of the growing stress corrosion crack tip is highly acidic [185]. In acidic solutions, cathodic reduction reaction promote hydrogen-embrittlement in these steels.

8. Synergistic effects of grain-boundary segregation and hydrogen can lead to greatly reduced threshold stress intensities in a hydrogen bearing environment and can result in highly catastrophic failures in carbon steels. This is an important concern with respect to carbon steel liner in highlevel waste (HLW) tanks. The presence of radiation fields within the 
tanks can potentially accelerate hydrogen uptake through alterations in the character of the protective films.

9. Proper heat-treatment tends to homogenize the microstructure and reduce the propensity of catastrophic failures.

10. Corrosion involving pitting and stress corrosion cracking is a thermally activated process. Reducing the tank wall temperature can delay, if not prevent, the frequency of failure.

11. The presence of $\mathrm{NO}_{2}^{-}$in acid/alkaline solutions is very important. In acid solutions, $\mathrm{NO}_{2}^{-}$promotes the formation of thermodynamically unstable and porous, $\mathrm{Fe}_{2} \mathrm{O}_{3}$. In alkaline media, it catalyses $\mathrm{Fe}_{2} \mathrm{O}_{3}$ to form thermodynamically stable and dense, $\mathrm{Fe}_{3} \mathrm{O}_{4}$. in this environment, $\mathrm{NO}_{2}^{-}$ functions as an inhibiting agent.

12. According to the Pourbiax (potential versus $\mathrm{pH}$ ) diagrams for iron in different media, the formation of $\mathrm{Fe}_{3} \mathrm{O}_{4}$ is associated with the creation of passive surfaces and raising the potential of the mild steel into the passivity range.

\section{REFERENCES}

1. Progress Report, Separation Development Division, Metallurgical report, CN-1316, Clinton Laboratories, March 10, 1944.

2. Environmental Standards for the Management and Disposal of Spent Nuclear Fuel, High-Level and Transuranic Radioactive Wastes, 40 CFR Part 191, Environmental Protection Agency, Federal Register, Rules and Regulations, Volume 50, No. 192, page 38066 (1985).

3. R. M. Girder, Leaks in Radioactive Waste Tanks, Report, DP-990, E. I. DuPont de Nemours \& Co., Savannah River Labortory, Aiken, SC (1965).

4. J. C. Womack and D. J. Larkin, Investigation and Evaluation of 102Bx Tank Leak, Report, ARH-2035, Atlantic Richfield Hanford Company, Richfield, WA (1971).

5. D. C. Lini, Compilation of Hanford Corrosion Studies, Report, ARHST-111, Atlantic Richfield Hanford Company, Richland, WA (1975).

6. R. S. Ondrejcin, Stress Corrosion Cracking Test with Slow Strain Rate and Constant Current, ASTM STP 665, American Society for Testing and Materials, page 203 (1979). 
7. R. S. Ondrejcin, Prediction of Stress Corrosion of Carbon Steel by Nuclear Process Liquid Wastes, Report, DP-1478, E. I. DuPont de Nemours \& Co., Savannah Research Laboratory, Aiken, SC (1978).

8. J. A. Donovan, Materials Aspects of SRP Waste Storage - Corrosion and Mechanical Failure, Report, DP-1476, E. I. DuPont de Nemours \& Co., Savannah River Laboratory, Aiken, SC (1977).

9. Panel on Hanford Wastes, Radioactive Wastes at the Hanford Reservation - A Technical Review, National Academy of Sciences, Washington, D.C. (1978).

10. M. W. Wilding and B. E. Paige, Survey on Corrosion of Metals and Alloys in Solutions Containing Nitric Acid, Idaho Chemical Programs Report, ICP-1106, Allied Chemical Corp. (1976). Corp.

11. W. W. Koenig, Corrosion Rates of Mild and Stainless Steel, Report, HW-14923, General Electric Company, Richland, WA (1948).

12. W. W. Koenig and K. L. Sanborn, Corrosion Rate of Redox Waste Storage Tank Construction Material, Report, HW-18595, General Electric Company, Richland, WA (1950).

13. K. L. Sanborn, A Study of the Effect of $p H$ on First Cycle Bismuth Phosphate Waste on the Corrosion of Mild Steel, Report, HW-26202, General Electric Company, Richland, WA (1952).

14. N. D. Groves, Technical Activities Report - Corrosion and Welding Effect of Lowering the $p H$ in TBP Waste Solution, Report, HW-29183, General Electric Company, Richland, WA (1952).

15. E. C. Pitzer, Corrosion Test SAE 1010 Mild Steel in Synthetic Waste Solution, Report, HW-29183, General Electric Company, Richland, WA (1952).

16. R. E. Olson, Corrosion Tests SAE 1010 Mild Steel in Synthetic Nertralized Redox Wastes, Report, HW-26201, General Electric Company, Richland, WA (1954).

17. N. Endow and K. Sandorn, Laboratory Study of the Extent of Pitting and General Corrosion of SAE 1010 Steel in Simulated Neutralized Purex Waste Solution, Report, HW-32734, General Electric Company, Richland, WA (1954).

18. N. D. Groves, M. C. Fraser, and W. L. Walker, Field Corrosion Tests in Redox and Purex Underground Storage Tanks, Report, HW-37642, General Electric Company, Richland, WA (1953). 
19. K. L. Sanborn and W. R. Smith, Examination of Removal Tube Bundles for Redox, Report, HW-32642, General Electric Company, Richland, WA (1954).

20. A. F. Riechman, In Tank Precipitation Corrosion Results, Report, DPST83-925, Savannah Research Laboratory, Aiken, SC (1983).

21. A. F. Riechman, Integrated Program for Salt Decontamination - Prevention of Water Line Corrosion, Report, DPST-83-947, Savannah Research Laboratory, Aiken, SC, (1983).

22. A. F. Riechman and R. E. Eibling, In-Tank Processing: Program to Study Vapor Space Corrosion Above Solutions Containing Tetraphenylborate, Report, DPST-84-890, Savannah Research Laboratory, Aiken, SC (1984).

23. D. F. Bickford, Thermodynamic Model of Waste Tank Corrsion with Implications to Pitting During In-Tank Processing, Washing and Storage, Report, DPST-86-275, Savannah Research Laboratory, Aiken, SC (1986).

24. S. B. Oblath and J. W. Congdon, Inhibiting Localized Corrosion During Storage of Dilute Wastes, Waste Management 87, Tuscon, AZ (1987).

25. J. W. Congdon, Inhibition of Nuclear Waste Solutions Containing MuL tiple Aggressive Anions, Report, DP-MS-87-85 (1987).

26. J. W. Congdon, Inhibiting Localized Corrosion During Storage of Dilute SRP Wastes, Report, DP-MS-86-139 (1987).

27. Westinghouse Hanford Company Company Tank Waste Remediation System, High-Level Waste Tank Systems Structural Integrity Workshop, Richland, WA, Feb. 19-20 (1992).

28. R. S. Ondrejcin, Investigation of Cooling Coil Corrosion in Radioactive Waste Storage Tanks, Report, DP-1425, E. I. DuPont de Nemours \& Co., Savannah River Laboratory, Aiken, SC (1965).

29. M. G. Fontana and N. D. Green, Corrosion Engineering, McGraw-Hill Book Company, NY, NY, page 106, (1978).

30. H. H. Uhlig, Corrosion and Corrosion Control, 2nd Edition, John Wiley \& Sons, NY, NY (1971).

31. P. M. Aziz and H. P. Godard, Ind. Eng. Chem., Volume 44, page 1791 (1952). 
32. R. May, Journal Inst. Metals (London), Volume 32, page 65 (1956).

33. P. M. Aziz, Corrosion, Volume 12, No. 10, page 495t (1956).

34. N. D. Greene and M. G. Fontana, Corrosion, Volume 15, page 32t (1959).

35. M. A. Streicher, J. Electrochemical Soc., Volume 103, page 375 (1956).

36. W. Schwenk, Corrosion, Volume 20, page 129t (1964).

37. N. D. Stolica, Corrosion Sci., Volume 5, page 205 (1969).

38. K. E. Hausler and L. Fisher, Werkst. Korro., Volume 27, page 551 (1976).

39. M. Janik-Czachor, Werhst. Korro., Volume 30, page 255 (1979).

40. M. Janik-Czachor, J. Electrochem. Soc., Volume 128, page 513C (1981).

41. Z. Szklarska-Smialowska, Pitting Corrosion of Metals, NACE, Houston, page 377 (1986).

42. D. A. Jones, Corrosion Processes, R. N. Parkins, ed., Applied Science, Englewood, NJ, page 180 (1982).

43. B. E. Wilde, Passivity and Its Breakdown in Iron Base Alloys, NACE, Houston, page 129 (1976).

44. T. Nakama and K. Sasa, Corrosion, Vol. 35, page 43 (1979).

45. Z. Szklarska-Smialowski, Corrosion, Volume 28, page 288 (1972).

46. B. Baroux, Corrosion Sci., Volume 28, page 969 (1988).

47. D. A. Jones and A. J. P. Paul, Hydrometallurgical Reactor Design and Kinetics, R. G. Bautista, R. J. Wesley, G. W. Warren, eds., TMS-AIME, Warrendale, PA, page 293 (1987).

48. T. Murata, E. Sato and H. Kutsuwa, Iron and Steel Engineers, Volume 2, page $60(1980)$.

49. T. Murata, in Localized Corrosion, F. Hine, K. Komai, and F. Yamakawa, eds., Elsevier Science Publishing Co., page 17 (1988).

50. K. Ogura and T. Ohama, Corrosion, Volume 38, page 403 (1982).

51. A. C. Fraker, J. S. Harris, Corrosion Behavior of Mild Steel in High $p H$ Aqueous Media, Report, NISTIR 89/4173, National Technical Information Service, Springfield, VA (1989). 
52. N. Sato, J. Electrochemical Soc., Volume 123, page 1197 (1976).

53. T. Okada, Halide nuclei theory of pit initiation in passive metals, J. Electrochem. Soc., Volume 131, No. 2, page 241 (1971).

54. T. Okada, A Theory of Perturbation-initiated Pitting, Proc. Int. Symp. Honoring Prof. Marcel Pourbaix on his Eightieth Birthday: Equilibrium Diagrams and localized Corrosion, Robert P. Frankenthal and Jerome Kruger, eds., The Electrochemical Society, Pennington, NJ, Volume 849, page 402 (1984).

55. Ya. M. Kolotyrkin, J. Electrochem. Soc., Volume 108. page 209 (1961).

56. Ya. M. Kolotyrkin, Corrosion, Volume 19, page 261t (1963).

57. H. Bohni and H. H. Uhlig, J. Electrochem. Soc., Volume 116, page (1969).

58. H. P. Leckie and H. H. Uhlig, J. Electrochem. Soc., Volume 113, page 1262 (1966).

59. J. L. Rozenfeld and I. S. Danilov, Corrosion Sci., Volume 7, page 129 (1967).

60. J. L. Rozenfeld, Corrosion and Protection of Metals - Local Processes (in Russian), Metallurgia, Moskva (1970).

61. T. P. Hoar, R. B. Mears and G. P. Rothwell, Corrosion Sci, Vol 5, page 279 (1965).

62. M. A. Heine, D. S. Keir and M. J. Pryor, J. Electrochem. Soc., Volume 112, page 29 (1965).

63. M. J. Pryor, Proc. Inter. Conf. Localized Corrosion, Williamsburg 1971, R. W. Staehle, B. F. Brown, J. Kruger and A. Agrawal, eds., NACE, page 399 (1974).

64. C. L. McBee, J. Kruger, Proc. Inter. Confer. Localized Corrosion, Williamsburg 1971, R. W. Staehle, B. F. Brown, J. Kruger and A. Agrawal, eds., page 399 (1974).

65. K. J. Vetter, Ber. Bunsengel. Phys. Chem., Volume 69, page 589 (1965).

66. K. J. Vetter, Ber. Bunsengel. Phys. Chem., Volume 69, page 683 (1965).

67. K. J. Vetter, H. H. Strehblow, Ber. Bunsengel. Phys. Chem., Volume 74 , page 1024 (1970). 
68. T. P. Hoar, Corrosion Sci., Volume 7, page 355 (1967).

69. N. Sato, Electrochim. Acta, Volume 16, page 1683 (1971).

70. J. R. Ambrose and J. Kruger, Passivity and its Breakdown in Iron and Iron Base Alloys, USA-Japan Seminar, Honolulu 1975, R. W. Staehle and H. Okada, eds., NACE, page 91 (1976).

71. J. R. Galvele, J. Electrochem. Soc., Volume 123, page 464 (1976).

72. J. R. Galvele, J. B. Lumsden and R. W. Staehle, J. Electrochem. Soc., Volume 125, page 1204 (1978).

73. J. R. Galvele, Passivity of Metals, Corrosion Monograph Series, R. Frankenthal and J. Kruger, eds., Electrochemical Society, Pennington, New Jersey, page 285 (1977).

74. K. J. Vetter, H. H. Strehblow and H. H. Willgalis, Ber. Bunsengel. Phys. Chem., Volume 75, page 822 (1971).

75. Z. Szklarska-S'mialowska, Z. Corrosion, Volume 28, page 338 (1972).

76. K. F. Krysiak, Metals Handbook, Vol. 13, Corrosion, 9th ed., ASM International, Metals Park, OH, page 353 (1987).

77. L. I. Gailer and G. R. Wallwork, Proc. 6th. Intern. Congress on Metallic Corrosion, Sydney, Ext. Abstract 18.6 (1975).

78. S. M. Sharland, A Review of the Theoretical Modelling of Crevice and pitting Corrosion, Corrosion Sci., Volume 27, page 289 (1987).

79. K. Videm, Kjeller Report KR-149, Institutt for Atomenergi, Kjeller Norway (1974).

80. Y. Hisamatsu, T. Yoshii, and Y. Matsumura, Proc. Intern. Confer. Localized Corrosion, Williamburg 1971, R. W. Staehle, B. F. Brown, J. Kruger and A. Agrawal, eds., NACE, page 427 (1974).

81. H. W. Pickering and P. R. Frankenthal, On the mechanism of localized corrosion of iron and stainless steel - 1 - Electrochemical studies, J. Electrochem. Soc., Volume 119, page 1297 (1972).

82. R. Alkire and D. Siitari, J. Electrochem. Soc., Volume 126, page 15 (1979).

83. A. A. Seys, M. J. Brabers, and A. A. Van Haute, Corrosion, Volume 30, page 47 (1974). 
84. C. Edeleanu and U. R. Evans, Trans. Faraday Soc., Volume 47, page 1121 (1951).

85. J. A. Beavers, N. G. Thompson and A. J. Markworth, Advances in Localized Corrosion, H. Isaacs, U. Bertocci, J. Kruger, and S. Smialowska, eds., NACE-9, Houston, TX page (1990).

86. H. -H. Strehblow and J. Wenners, Z. Phys. Chem., Volume 98, page 199 (1975).

87. K. J. Vetter and H. H. Strehblow, in Localized Corrosion, R. W. Staehle, ed., NACE, Houston (1974).

88. S. F. Mughabghab and T. M. Sullivan, Waste Management, Volume 9, page 239 (1989).

89. R. W. Staehle, Comments on the History, Engineering and Science of Stress Corrosion Cracking, in Proc. Conf. on Fundamental Aspects of Stress Corrosion Cracking, R. W. Staehle, A. J. Forty, and D. Van Rooyen, eds., NACE-1, Houston, Texas, page 3 (1969).

90. R. W. Staehle, A Point of view concerning Mechanism of EnvironmentSensitive Cracking of Engineering Materials, in Proc. Intl. Conf. on Mechanisms of Environment Sensitive Cracking of Materials, P. R. Swann, F. P. Ford, and A. R. C. Westwood, eds., The Metals Society, London, page 574 (1979).

91. R. S. Ondrejcin, Investigation of cooling coil corrosion in radioactive waste storage tanks, Report, DP-1425, E. I. DuPont de Numours \& Co., Savannah River laboratory, Aiken, SC (1965).

92. G. Kobrin, in Metals Handbook, Volume 13, Corrosion, 9th ed., ASM International, Metals Park, OH, page 326 (1987).

93. W. K. Boyd, in Fundamentals Aspects of Stress-Corrosion Cracking, R. W. Staehle, A. J. Forty and D. Van Rooyen, eds., NACE, Houston, TX, page 593 (1969).

94. A. Brown, J. T. Harrison and R. Wilkins, in Stress Corrosion and Hydrogen Embrittlement of Iron Base Alloys, R. W. Staehle et. al., eds., NACE, Houston, TX, page 663 (1977).

95. R. N. Parkins, in Corrosion: Industrial Problems, Treatment and Control Techniques, V. Ashworth, ed., KFAS Proceedings Series, Pergamon Press, NY, Volume 2, page 54 (1987). 
96. N. J. H. Holroyd and R. N. Parkins, Corrosion Sci. Volume 20, page 707 (1980).

97 . R. N. Parkin, Materials Characterization, volume 26, page 303 (1991).

98. R. W. Staehle, in Stress Corrosion Cracking and Hydrogen Embrittlement of Iron Base Alloys, R. W. Staehle et. al., eds., NACE-5, NACE, Houston, TX, page 193 (1977).

99. R. N. Parkins, Environment-Induced Cracking of metals, R. P. Gangloff and M. B. Ives, eds., NACE, Houston, page 1 (1990).

100. C. S. Carter and M. V. Rideout, in Stress Corrosion Cracking and $B y$ drogen Embrittlement of Iron Base Alloys, R. W. Staehle, J. Hochmann, R. D. McCright, and J. E. Slater, eds., Unieux, France, page 524 (1973).

101. R. S. Ondrejcin, S. P. Rideout and J. A. Donovan, Control of stress corrosion cracking in storage tanks containing radioactive wastes, Nuclear Technology, Volume 44, page 247 (1979).

102. R. F. Maness, Stress corrosion cracking of mild steel in nitrate solutions, Report, HW-78168, General Electric Company (1968).

103. E. L. Moore, Stress corrosion cracking of A 515 Grade carbon steel, Atlantic Richfield Hanford company, Richland, WA (1971).

104. J. M. Suitclif, R. R. Fessler, W. K. Boyd, and R. N. Parkins, Corrosion, Volume 28, page 313 (1972).

105. R. N. Parkins, Proc. 5th Symposium on Line Pipe Research, Am. Gas Assoc., Arlington, VA, page U-1 (1974).

106. H. L. Logan, in The Stress Corrosion of Metals, John Wiley and Sons Inc., NY (1966).

107. Z. Szklarska-Smialowski, Corrosion, Volume 20, page 198t (1964).

108. H. Baker and C. Singleterry, Corrosion, Volume 28, page 385 (1973).

109. H. J. Engell and A. Baumel, in Physical Metallurgy of Stress Corrosion Fracture, T. N. Rhodin, ed., Interscience Publishers, NY, page 341 (1959).

110. M. Smialowski, First International Congress on Metallic Corrosion, Butterworths, page 295 (1961).

111. R. N. Parkins and R. Usher, First International Congress on Metallic Corrosion, Butterworths, page 289 (1961). 
112. M. Smialowski and Z. Szklarska-Smialowska, Corrosion, Volume 18, page 1t (1962).

113. I. L. Rozenfeld, in Corrosion Inhibitors, McGraw-Hill Inc., NY, (1981).

114. E. A. G. Liddiard, Corrosion Technology, Volume 10, page 95 (1963).

115. U. R. Evans, in Introduction to Metallic Corrosion, E. Arnold Ltd., London, page 110 (1960).

116. J. E. Reinoehl and W. E. Berry, Corrosion, Volume 28, page 151 (1972).

117. E. Herzog, M. Hugo, and J. Bellot, Corrosion-TPF, Volume 18, page 287 (1970).

118. K. Bohnenkamp, in Proc. Conf. Fundamental Aspects of Stress Corrosion Cracking, R. W. Staehle, ed., NACE, Houston, TX page 374 (1967).

119. G. Herbsleb and W. Schwenk, Stah u. Eisen, Volume 90, page 303 (1970).

120. H. Grafen, Corrosion Sci., Volume 7, page 177 (1967).

121. H. Grafen, Wertstoffe u. Korrosion, Volume 20, page 305 (1969).

122. R. N. Parkins, in Fundamental Aspects of Stress Corrosion Cracking, R. W. Staehle, A. J. Forty, and D. Van Rooyen, eds., NACE, Houston, TX, page 361 (1969).

123. D. Vermilyea, in Fundanetal Aspects of Stress corrosion Cracking, R. W. Staehle, A. J. Forty, and D. Van Rooyen, eds., NACE, Houston, TX, page 15 (1969).

124. S. F. Bubar and D. A. Vermilyea, J. Electrochem. Soc., Volume 113, page 892 (1966).

125. F. A. Champion, Symposium on Internal Stresses in Metal and Alloys, Inst. Metals, London, page 468 (1948).

126. H. L. Logan, J. Res. Natl. Bur. Stand., Vol. 48, page 99 (1952).

127. Y.S. Garud, in Predictive Capabilities in Environmentally Assisted Cracking, R. Rungta, ed., Am. Soc. of Mechanical Engineers, NY, page 91 (1985).

128. F. P. Ford, in Environment-Induced Cracking of Metals, R. P. Gangloff anf M. B. Ives, eds., NACE, Houston, TX, page 139 (1990). 
129. E. H. Phelp, in Fundamental Aspects of Stress Corrosion Cracking, R. W. Staehle, A. J. Forty, and D. Van Rooyen, eds., NACE, Houston, TX, page 398 (1969).

130. C. Tyzack, Corrosion, Volume 7, page 268 (1972).

131. J. Flis, Brit. Corrosion, Volume 8, page 57 (1973).

132. H. Okada, Y. Hosoi, and S. Abe, J. Japan Inst. Metals, Volume 36, page 464 (1972).

133. A. Troiano, in Hydrogen in Metals, International Congress, ChatenayMalabry, France, (1972).

134. P. Bastien, in Hydrogen in Metals, International Congress, ChatenayMalabry, France, (1972).

135. R. N. Parker, in Stress Corrosion Cracking of Low Strength Ferritic Steels, Conf. on The Theory of Stress Corrosion Cracking, J. C. Scully, ed., NATO Science Committee Research Evaluation Conference, Portugal, page 167 (1971).

136. C. D. Kim and B. E. Wilde, in Stress Corrosion Cracking - The Slow Strain Rate Technique, G. M. Ugiansky and J. H. Payer, eds., ASTM STP 665, American Society for Testing and Materials, Philadelphia, PA, page 97 (1979).

137. R. N. Parkins, Corrosion Sci., Volume 20, page 1 (1980).

138. R. N. Parkins, Corrosion Sci., Volume 29, page 1019 (1989).

139. J. Flis, Corrosion, Volume 29, page 37 (1973).

140. R. N. Parkins, Corrosion, Volume 46, page 178 (1990).

141. M. J. Humphries and R. N. Parkins, in Proc. of Fundamental Aspects of Stress Corrosion Cracking, R. W. Staehle, A. J. Forty and, D. Van Rooyen, eds., page 384 (1969).

142. W. France Jr., Corrosion, Volume 5, page 189 (1970).

143. T. Finley and V. Myers, Corrosion, Volume 4, page 150 (1970).

144. B. Wilde and C. Kim, Corrosion, Volume 28, page 350 (1972).

145. N. Nichols and R. Rostoker, Trans ASM, Volume 53, page 494 (1961). 
146. E. Coleman, R. Weinstein and R. Stacker, Acta Met., Volume 9, page 491 (1961).

147. D. Singbeil and D. Thomas, J. Electrochem. Soc., Volume 128, page 2065 (1981).

148. D. Singbeil and D. Thomas, J. Electrochem. Soc., Volume 129, page 2669 (1982).

149. M. J. Humphries and R. N. Parkins, Corrosion Science, Volume 9, page 747 (1967).

150. R. N. Parkins, British Corrosion J., Volume 14, page 5 (1979).

151. A. J. Forty and P. Humble, Philos. Mag., Volume 8, page 247 (1963).

152. E. N. Pugh, Corrosion, Volume 41, page 517 (1985).

153. M. L. Holzworth, R. M. Girder and L. P. Costas, How to prevent stress corrosion cracking of radioactive waste storage tanks, Materials Protection, Volume 7, page 26 (1968).

154. R. N. Parkins, Br. Welding J., Volume 2, page 495 (1957).

155. R. N. Parkins, Br. Welding J., Volume 8, page 24 (1961).

156. H. H. Uhlig and R. W. Revie, in Corrosion and Corrosion Control, Wiley and Sons, 3rd Edition, NY, NY, page 134 (1985).

157. G. V. Karpenkov and I. I. Vasilenko, Stress Corrosion Crackingof Steels, Trans Tech Publication, Aedermannsdorf, Swizerland, page 94 (1979).

158. R. N. Parkins, J. Iron Steel Inst., Volume 174, page 140 (1953).

159. H. Uhlig and J. Sava, Trans. ASM, Volume 56, page 361 (1963).

160. J. Flis and J. Scully, Corrosion Sci., Volume 8, page 235 (1968).

161. H. Keating, in Symp. on Internal Stresses in Metals and Alloys, page 311 (1948).

162. B. Poulson, Corrosion Sci., Volume 15, page 469 (1975).

163. C. Lea, E. D. Hondros, Proc. Roy. Soc., Volume 377, page 477 (1981).

164. C. Lea, Corrosion, Volume 40, page 337 (1984).

165. H. J. Krautschick, J. H. Grabke, W. Diekman, Corrosion Sci., Volume 28 , page 251 (1988). 
166. H. Okada, K. Yukawa and H. Tamura, Corrosion, Volume 32, page 201 (1976).

167. G. V. Karpenko and I. I. Vasilenko, in Stress Corrosion Cracking in Steels, Trans Tech publication, Aedermannsdorf, Switzerland, page 94 (1979).

168. N. A. Neilsen, Corrosion, Volume 27, page 173 (1971).

169. F. P. A. Robinson and L. G. Nel, in Proc. 2nd Inter. Congress on Metallic Corrosion, NACE, Houston, TX, page 171 (1969).

170. B. E. Wilde, Corrosion, Volume 27, page 326 (1971).

171. R. Deigle and D. Vermilyea, Corrosion, Volume 32, page 353 (1976).

172. G. Bignold, Corrosion, Volume 28, page 307 (1972).

173. C. Zapfe, Trans. AIME, Volume 2, page 81 (1944).

174. I. Podgornyi, Izv. VUZ Chernaya Metall., Volume 3 (1963).

175. G. V. Karpenko and I. I. Vasilenko, Stress Corrosion Cracking of Steels, page 93 (1979).

176. C. F. Barth, E. A. Stiegerwald and A. R. Troiano, Corrosion, Volume 25, page 353 (1969).

177. S. S. Birley and D. Tromans, Corrosion, Volume 27, page 63 (1971).

178. C. Edeleanu, JISl, Volume 143, page 140 (1953).

179. A. Brown, J. T. Harrison and R. Wilkens, in Stress Corrosion Cracking and Hydrogen Embrittlement of Iron Base Alloys, R. W. Staehle et. al. eds., NACE-5, NACE, Houston, TX, page 686 (1977).

180. M. Brabers, Welding Reports, Philips, Volume 9, page 150 (1973).

181. M. Brabers, Corrosion and Protection of Metals, CERN, Geneva (1976).

182. F. Perdieus, M. Brabers, and A. Van Haute, in Mechanisms of Environ ment Sensitive Cracking of Materials, P. R. Swann, F. P. Ford and, A. R. C. Westwood, eds., page 53 (1977).

183. R. N. Parkins, in Mechanisms of Environment Sensitive Cracking of Materials, P. R. Swann, F. P. Ford and A. R. C. Westwood, eds., page 62 (1977). 
184. A. W. Thompson, in Environment-Sensitive Fracture of Engineered Materials, Z. A. Foroulis, ed., The Metallurgical Society of AIME, Warrendale, PA, page 379 (1979).

185. G. Sandoz, C. T. Fujii, and B. F. Brown, Corrosion Sci., Volume 10, page 839 (1970).

186. A. Turnbull and J. G. N. Thomas, A model of crack electrochemistry for steels in the active state based on mass transport by diffusion and ion migration, J. Electrochem. Soc., Volume 129(7), page 1412 (1982).

187. A. Turnbull, in Corrosion Chemistry within Pits, Crevices and Cracks, A Turnbull, ed., Her Majesty's Stationary Office (London), page 1 (1987).

188. T. Murata, E. Sato and H. Hosio, Corrosion '77 - Technical paper, (1977).

189. H. Anzai, J. Kuniya and I. Masaoka, Metallurgical Trans., Volume 23A, page 1291 (1992).

190. C. J. McMahon, Jr., in Grain Boundaries in Engineering Materials, J. L. Walter et. al., eds., Claitors, Baton Rouge, page (1975).

191. C. L. Briant, in Metallurgical Aspects of Environmental Failures, Elsevier Publishers, NY, page 76 (1985).

192. J. R. Galvele, Corrosion Sci., Volume 27, page 1 (1987).

193. R. A. Oriani, Environment-Induced Cracking of Metals, R. P. Gangloff and M. B. Ives, eds., NACE, Houston, page 263 (1990).

194. J. R. Galvele, Environment-Induced Cracking of Metals, R. P. Gangloff and M. B. Ives, eds., NACE, Houston, page 264 (1990).

195. H. H. Uhlig, Fundamental Aspects of Stress Corrosion Cracking, R. W. Staehle, ed., NACE, Houston, TX, page 86 (1969).

196. R. N. Parkins, in Stress Corrosion Cracking and Hydrogen Embrittlement in Iron Base Alloys, R. W. Staehle et. al., eds., NACE-5, Houston, TX , page 601, (1977).

197. L. Long and H. Uhlig, J. Electrochem. Soc., Volume 56, page 964 (1965).

198. M. Engell, Corrosion Anticorr., Volume 13, page 308 (1965).

199. J. O'M. Bockris, Stress Corrosion Cracking and Hydrogen Embrittlement in Iron Base Alloys, R. W. Staehle et. al., eds., NACE-5, NACE, Houston, page 177 (1977). 
200. J. Kruger, Stress Corrosion Cracking and Hydrogen Embrittlement in Iron Base Alloys, R. W. Staehle et. al., eds., NACE-5, NACE, Houston, page 179 (1977).

201. D. A. Jones, in Principles and Prevention of Corrosion, Macmillan Publishing Co., NY, NY, page 116 (1992).

202. G. Wranglen, in An Introduction to Corrosion and protection of Metals, Chapman and Hall, NY, NY, page 174 (1985).

203. Corrosion Data Survey-Nonmetals Section, 5th edition, N. Hamner, Ed., NACE, Houston, TX (1975).

204. D. A. Reynolds, D. D. Siemer, D. M. Strachan and R. W. Wallace, $A$ survey of Avialable Information on Gas Generation in Tank 241-SY-101, Report, PNL-7520 (1991).

205. G. Butler and H. C. K. Ison, in Corrosion and Prevention in Waters, Reinhold Publishing Corp., NY, NY, page 165 (1966).

206. M. O. Speidel, in Advances in Fracture Research, Proc. 5th International Conference on Fracture (ICF5), Cannes, France, page 2685 (1981). 


\section{Failure Predictions-Rate Models in \\ Low Carbon Steels}

by

Rao K. Mahidhara

Thomas S. Elleman

K. Linga Murty

North Carolina State University

Raleigh NC 27695-7909

Report prepared for

Los Alamos National Laboratory

Contract No. 9-XQ-Y3122-1

December 15, 1992

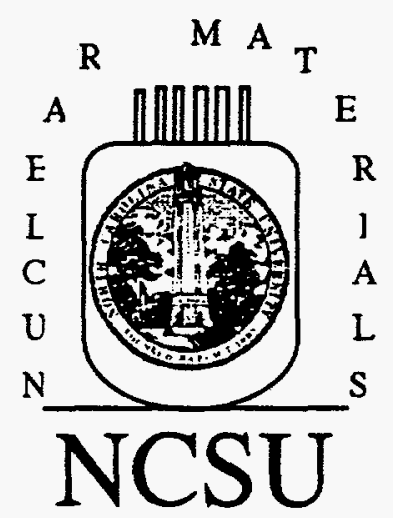




\begin{abstract}
The purpose of this review is to summarize failure models that predict the rate of corrosion of mild steel by the High-Level Wastes. Rate models for vapor-phase corrosion, liquid-phase pitting corrosion and stress corrosion crack propagation are considered. In the context of High-Level Waste tanks an important issue such as life-prediction is discussed. The failure predictions/rate models should help in the judicious selection of alloys for inner shell construction of future Double-Shell Tanks with the goal of delaying if not eliminating the chances of degradation by corrosion.
\end{abstract}




\section{Contents}

1 INTRODUCTION 1

1.1 Tank Liner Steels ................... 1

1.2 Composition of Radioactive Wastes ........... 2

2 FAILURE MODELS/CORROSION RATE PREDICTIONS IN LOW CARBON STEELS 4

2.1 Vapor-Phase Corrosion ................. 4

2.1.1 Wagner's Model for Diffusion-Controlled Scale Growth . . 5

2.1.2 Application of Wagner's Model . . . . . . . . . 6

2.2 LIQUID-PHASE CORROSION ........... 8

2.3 IIQUID PHASE PITTING CORROSION . . . . . . 8

2.3.1 Background .................... 8

2.3.2 Models on Pit Initiation .............. 9

2.3.3 Models on Propagation of Pits ............ 13

2.3.4 Initiation of Cracks at Pits with Critical Depths . . . . . . 15

2.4 PROPAGATION OF STRESS CORROSION CRACKS 16

2.4.1 Propagation Controlled by Ion Transport and Anodic Dissolution..................... 17

2.4.2 Model Relevant to High-Level Waste Tanks Involving Film Fracture at the Crack Tip ............. 18

2.4.3 Other Relevant Models Involving Film Fracture at Crack Tip 20

2.4.4 Life Prediction .................. 32

2.4.5 Hydrogen Embrittlement . . . . . . . . . . . . 34

2.4.6 Effect of Gamma Radiation ... . . . . . . . . 36

3 SUMMARY AND CONCLUSIONS 38 


\section{List of Figures}

1 Comparison of calculated and experimental parabolic rate constants for the oxidation of wustite, $\mathrm{Fe}_{x} \mathrm{O}$ to magnetite, $\mathrm{Fe}_{3} \mathrm{O}_{4}$ at $1000 \mathrm{C}$ in $\mathrm{CO} / \mathrm{CO}_{2}$ gas mixtures [20]. ..........

2 Application of Okada's model [24, 25] to evaluate the pitting potential of Type 316 stainless steel in cellulose bleach solutions at $50 \mathrm{C}[28] . \ldots \ldots \ldots \ldots \ldots$

3 Incubation time, $t$, for pitting of passive iron in borate buffer solution as a function of reciprocal of the potential difference, $\Delta V=V-V_{c}$ for various conditions indicated $\left(T=25^{\circ} \mathrm{C}\right)[31]$.

4 The Beck-Alkire model assumes that the surface of the hemispherical pit is covered by a resistive salt film [34]. This is a transient-mass-transport model. ...........

5 Evan's polarization diagram of the electrochemical reactions which occur within a crack. ..............

6 A schematic plot of the excess cathodic current generated on the crack sides and bare surface anodic dissolution current at the crack tip as functions of electrode potential at the tip. . .

7 Schematic polarization of the electrochemical reactions occurring at: (a) the crack tip and (b) the sample and crack surface.

8 Schematic illustration of the effect of time on SCC velocity of pipeline steel exposed to carbonate-bicarbonate solution [62]. .

9 Times required for stress corrosion cracks to reach a length of 6 $\mathrm{mm}$ for various lengthwise growth rates and number of cracks

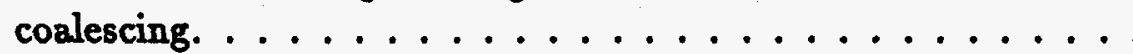




\section{INTRODUCTION}

\subsection{Tank Liner Steels}

The low carbon steel selected for the construction of the High-Level Waste tanks particularly, at Savannah River and Hanford Sites must perform well in the following categories:

- Mechanical strength and toughness.

- Fabricability and cost.

- Metallurgical phase stability

- Resistance to:

- Hydrogen embrittlement and hydrogen-induced degradation.

- Uniform oxidation and dissolution.

- Pitting.

- Stress corrosion cracking (SCC).

- Radiation-enhanced degradation.

- Microbiologically induced degradation.

Federal law requires that the high-level radioactive waste containers provide "substantially complete containment" for a period of 300 to 1000 years, with a very slow, controlled release of radionuclides allowed for 10,000 years [1,2]. High-level waste tanks both at the Savannah River Site at Aiken, SC and, Hanford Site at Hanford, WA had developed leaks at the walls of the primary vessel for tanks that were designed and built before 1960 at Savannah River [3] and Hanford [4]. The importance of preventing accidental leaks of stored waste to the ground had resulted in several corrosion studies on mild steel at Hanford in neutralized waste which were compiled by Lini [5]. Lini [5] has concluded that stress corrosion cracking (SCC) was the most serious threat to the integrity of the mild steel liners.

Nitrate stress corrosion cracking, in particular, was believed to be the cause of the leaks in the liner walls. Several studies in the review by Lini [5] have thus led to the stress annealing of all new tanks built at Hanford and the Savannah River Plant. Additionally, all tanks built since 1968 have been of double-wall construction with improved design and materials at both facilities with possible use of cathodic protection. 
From the data available in the literature, it was established that within the family of low carbon steels, ASTM A 516-70 (normalized) or A 537 Class I were far superior to the A 285 Grade B steel used for the early tanks $[6,7]$. This was because the ductile-to-brittle transition temperature (DBTT) for the A 285 Grade B was considerably higher than for the stress relieved A 516-70 [8]. Interestingly. Based upon elongation-electrochemical tension tests, it has been confirmed that under identical test conditions the resistance to cracking increased in the order A 285-B, A 516-70, and A 537 Class I [8]. The last two types have finer microstructure and smaller amount of ferrite along with improved fracture toughness compared to A 285-B steel and were specified for new tank construction beginning in 1976. Later tanks were built of the more stress corrosion resistant A 516-70. The most recent tanks have been built of A 516-70 normalized or A 537 Class I. These last two alloys were chosen to improve mechanical performance and are equivalent to A 516-70 (rolled) in stress corrosion resistance [9-15].

These steels have been studied from a corrosion standpoint in order to provide a technical basis for storage of radioactive wastes, to identify causes of materials deficiencies that were experienced at Savannah River Plant and suggest modifications in the construction of the tanks to increase the integrity of the tanks.

\subsection{Composition of Radioactive Wastes}

Both the high-level Redox wastes as well as the Purex wastes are essentially nitric acid wastes. High-level wastes from the various separation processes have been mixed, and therefore the composition has not been uniform from tank to tank. These wastes are initially acidic, containing essentially $\mathrm{HNO}_{3}$, but are neutralized prior to storage as liquid. In general high-level wastes in the storage tanks consist of sodium salts such as nitrate, nitrite, carbonate, aluminate, and small amounts of the hydrous oxides of iron and manganese. Approximately $90 \%$ of the waste is soluble salt, primarily sodium nitrate. The sodium nitrate results from neutralization of nitric acid processing solutions with sodium hydroxide. These salts are distributed between an aqueous supernatant liquid and a solid, ill-defined precipitate or sludge. The sludge which constitutes $10 \%$ of the waste is formed by the precipitation of iron, aluminium, transition metals, and transuranic hydroxides.

Today the high level wastes are maintained at relatively high $\mathrm{pH}(10-12)$ by the addition of high levels of hydroxide. Nitrite has been used to inhibit or reduce the occurrence of stress corrosion cracking (SCC). In addition, the high-level 
wastes contain fission-product radionuclides and actinide elements, such as uranium, plutonium and neptunium. Small quantities of organic matter, such as entrained extraction solvent, have occasionally been part of liquid wastes. It has been suggested [9] that such organic matter is rapidly and completely destroyed by radiolysis to give largely carbon-dioxide in the presence of intense radiation from high-level wastes, which combines with sodium hydroxide of the wastes, and water. Thus the organic content of the aged high-level wastes may be reduced below detectable limits.

Additionally, gamma radiolysis of salts can give rise to increasing levels of hydrogen ions thereby promoting stress corrosion cracking (SCC) in mild steels. A review has been published of the corrosion of metals and alloys in nitric acid and Purex waste covering the period 1947 through 1975 [10]. This review along with that of Lini [5] on corrosion of mild steel in neutralized waste are suggestive of the importance of pitting corrosion and stress corrosion cracking, in general and nitrate and alkaline SCC in particular.

In light of the background on failure processes, one can say that the overall corrosion model for waste tanks will consist of several integrated submodels.

In the case of tanks made of low carbon steel exposed to high-level liquid waste environments, information on the environment, properties of the materials, and mechanical forces acting on the waste containing tanks are input to models of mechanical failure, uniform oxidation, localized corrosion (LC), and stress corrosion cracking (SCC). In the context of tanks containing high-level nuclear wastes, models of pitting corrosion and SCC become relevant to provide a clearer picture of the mechanism of tank degradation.

Models of pitting corrosion and SCC can be categorized as initiating models or propagation models. Initiation models are more important than the propagation models on the time scale of interest to high-level waste tank designers. This is because the more one fully understands the initiation aspects of corrosion, the the easier would be to prolong the onset of the degradation process and hence the overall life of the High-Level Waste tanks. Additionally, important decisions related to materials selection with respect to the High-Level Waste composition it will contain, can be made. 


\section{FAILURE MODELS/CORROSION RATE PREDICTIONS IN LOW CARBON STEELS}

\subsection{Vapor-Phase Corrosion}

The rate of reaction in the later stages of oxidation depends upon whether the thick film or scale remains continuous and protective as it grows, or whether it contains cracks and pores and is relatively nonprotective. Because reactionproduct films are usually brittle and lack ductility, the initiation of cracks depends in some measure on whether the surface film is formed in tension favoring fracture or in compression favoring protection. This situation in turn depends upon whether the volume of reaction product is greater or less than the volume of metal from which the product forms [16]. If the ratio, $M d / n m D$, also known as the Pilling-Bedworth Ratio (PBR) is $>1$, a protective film forms. $M$ and $d$ are the atomic weight and density of the metal, and $n$ and $D$ are the number of metal atoms in a molecular formula and, density of the scale substance. When the ratio is less than unity, the scale is formed in tension and tends to be nonprotective.

Several models are used to predict corrosion rates in metals and alloys including carbon steel. These rate laws are categorized as linear (equation 1), parabolic (equation 2), cubic (equation 3), inverse log (equation 4), and direct $\log$ (equation 5).

$$
\begin{aligned}
m^{1}=k_{1} t \\
m^{2}=k_{2} t \\
m^{3}=k_{3} t \\
m^{-1}=k_{4} \log \left(\frac{t}{\tau_{1}+1}\right) \\
m^{+1}=k_{5} \log \left(\frac{t}{\tau_{2}+1}\right)
\end{aligned}
$$

$m=$ oxide thickness, $t=$ time, $\tau_{1} \& \tau_{2}=$ constants having units of time. The rate constants, $k_{i}$ have an Arrhenius dependence on temperature:

$$
k_{i}=A_{i} \exp -\left(\frac{E_{i}}{R T}\right)
$$

where $A_{i}=$ pre-exponential constant, $E_{i}=$ activation energy. Typically, oxide growth obeys a parabolic law if oxidation is limited by the diffusion of cations 
or anions through the oxide and if the oxide is completely adherent and protective corresponding to PBR $>1$. The oxide growth obeys a linear rate law if spalling of oxide occurs and PBR is usually greater than 1.

\subsubsection{Wagner's Model for Diffusion-Controlled Scale Growth}

In his derivation for an expression for the parabolic rate constant, Wagner [17-19] assumed that ions and electrons migrate independently in a growing scale; that is, the rate of transport of each component (cation, anion, or electron) is proportional to the gradient in the electrochemical potential for that component, but independent of the electrochemical potentials for the other components. The fluxes of the components have been expressed in the form typically employed in irreversible thermodynamics. The main assumptions of Wagner's model are:

1. The scale is a homogeneous diffusion barrier.

2. Only a single oxidation product forms.

3. The fluxes of ions and electrons are unidirectional and independent of distance for a thickness (quasi-steady-state scale growth).

4. Local equilibrium is maintained at the metal/scale and metal/gas interfaces and throughout the thickness of the scale.

It seems worthwhile to review the assumptions and to comment on their validity.

\section{Assumption No. 1}

The first assumption listed above is that the scale is a homogeneous diffusion barrier, which means that it is free of voids, pores, and fissures. The metal/scale and the scale/gas interfaces are essentially flat relative to the thickness of the scale and the scale is adherent to the metal. Loss of scale adherence does not mean that Wagner's model cannot be employed to describe the continued thickening of the scale as long as the scale remains intact and vapor-phase transport across the gap between the metal and the scale is rapid relative to the solid-state diffusion in the scale. Indeed, Wagner's model for diffusion-controlled scale growth can be altered to take into account the effects of defects.

\section{Assumption No. 2}

The second assumption of Wagner's model is that only a single oxidation product forms. During oxidation of iron, multiphase oxides are formed. The 
growth of multiphase oxide scales such as $\mathrm{FeO} / \mathrm{Fe}_{3} \mathrm{O}_{4}$ or $\mathrm{FeO} / \mathrm{Fe}_{3} \mathrm{O}_{4} / \mathrm{Fe}_{2} \mathrm{O}_{3}$ on iron has been modeled by a number of investigators [20,21].

\section{Assumption No. 3}

The third assumption in Wagner's model is that the cation flux is independent of distance for a given scale thickness. This assumption of quasi-steady-state scale growth is valid if there is a small deviation from stoichiometry in the metal oxide. Essentially all of the metal that enters the scale is used to extend the scale/gas interface. Very little is used to adjust the overall composition.

\section{Assumption No. 4}

The fourth assumption of the Wagner model is that equilibrium is maintained at the metal/scale and scale/gas interface and throughout the thickness of the scale. If local equilibrium is not achieved at the metal/scale or metal/gas interface, nonparabolic oxidation kinetics are observed. Wagner has in fact demonstrated that only small deviations from internal equilibrium typically occur in growing scales because the relaxation times for defect equilibration are normally much shorter that the reaction times for oxide layer formation on metals. The effect is more significant in compounds with lower defect concentrations. The expression for the parabolic rate constant, is $[17,18]$ :

$$
k=E n_{3}\left(n_{1}+n_{2}\right) \kappa
$$

where $E$ is the emf of the operating cell derived either from potential measurement or free-energy data, $n_{1}, n_{2}$, and $n_{3}$ are the mean cation, anion, and electron transference numbers, respectively, within the reaction-product film; $\kappa$ is the mean specific conductivity of film substrate. The constant $k$ appears in the relation:

$$
\frac{d w}{d t}=k \frac{A}{y}
$$

where $\frac{d w}{d t}$ is the rate of formation of film in equivalents/second, $A$ is the area, and $y$ is the thickness. The excellent agreement between theory and observation confirms the validity of the model suggested by Wagner for the oxidation process within the region for which the parabolic equation applies.

\subsubsection{Application of Wagner's Model}

Wagner's model for diffusion controlled oxidation of metals has been compared in the literature with experimentally determined parabolic rate constants for the oxidation of a large number of metals. The calculated rate-constants for the oxidation of $\mathrm{FeO}$ to form $\mathrm{Fe}_{3} \mathrm{O}_{4}$ was found to be in agreement with the 


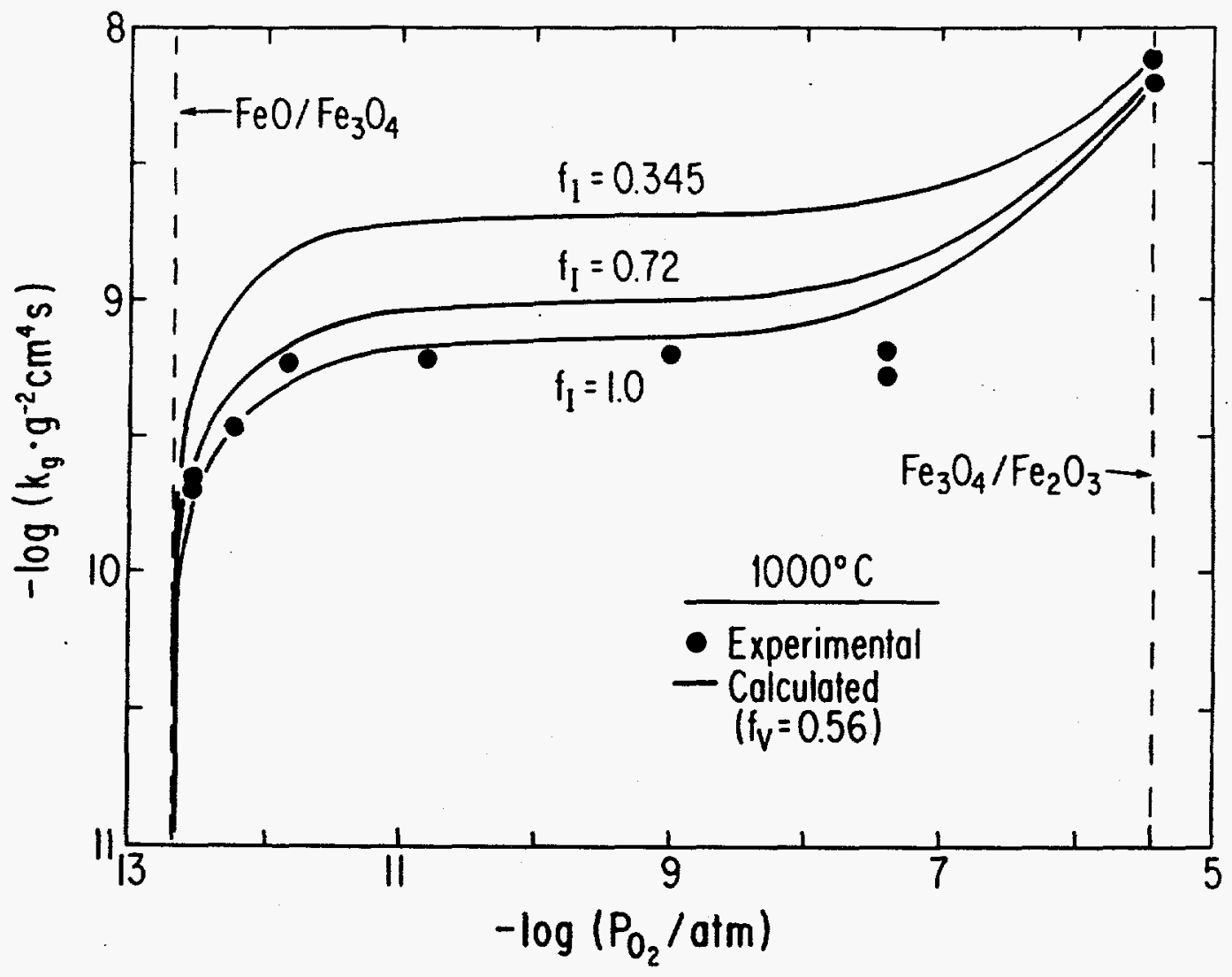

Figure 1: Comparision of calculated and experimental parabolic rate constants for the oxidation of wustite, $\mathrm{Fe}_{x} \mathrm{O}$ to magnetite, $\mathrm{Fe}_{3} \mathrm{O}_{4}$ at $1000 \mathrm{C}$ in $\mathrm{CO} / \mathrm{CO}_{2}$ gas mixtures [20]. 
experimental values (shown in Figure 1). Thus supporting the fact that the essential features of Wagner's model for the oxidation of a large number of metals are correct $[20]$.

\subsection{LIQUID-PHASE CORROSION}

Nitrate ions, carbonate ions, halides ions, organic species, oxygen alter considerably the rates of localized corrosion (LC). These ions are called promoters as they cause passive film breakdown and formation of pits. Stress corrosion cracking (SCC) initiates at pits by anodic dissolution at the base of the pit and crack tips. Generally, it has been found that SCC is caused by depolarizers like $\mathrm{O}_{2}, \mathrm{H}^{+}$, etc., under the influence of a mechanical stress. It has been experimentally observed that these rates are also typically orders of magnitude less than the pit propagation and stress corrosion cracking rates. Consequently, modeling of degradation under these circumstances should emphasize LC such as pitting in low carbon steels.

\subsection{LIQUID PHASE PITTING CORROSION}

\subsubsection{Background}

Penetration rates at local sites of corrosive attack are expected to be far more serious threats to the life of the High-Level Waste tank liner. Ionic and molecular species present in the wastes can serve as promoters, depolarizers, or inhibitors of localized corrosion (LC) and stress corrosion cracking (SCC) [22, 23].

Frequently, SCC initiates at pits. Anodic dissolution at the base of the pits and crack tips can be enhanced by a number of depolarizers, including $\mathrm{O}_{2}$ and, $H^{+}$. The cathodic reduction of the depolarizers on the surface outside of pits, and cracks can galvanically couple with anodic dissolution and oxidation processes that occur inside. In contrast to $\mathrm{NO}_{3}^{-}$, and $\mathrm{Cl}^{-}, \mathrm{NO}_{2}^{-}$and $\mathrm{OH}^{-}$ are well known inhibitors of low carbon steels in acidic and alkaline media. These inhibitors compete with halide and nitrate ions for adsorption sites on the metal oxide film and base metal.

A second factor required for SCC is mechanical stress. The stresses required are small, usually below the engineering yield stress, and are tensile in nature. The stresses can be externally applied. However, all failures with respect to High-Level Waste tanks to-date have been associated with lack of removal of residual stresses following welding [10]. In many corrosive environments, SCC is the result of stress concentration at corrosion-generated surface flaws 
(as quantified by the stress intensity factor $K$ ), and when a critical stress intensity factor, $K_{c r i t}$ is reached, mechanical fracture results.

\subsubsection{Models on Pit Initiation}

Mechanistic models and experimental observations are suggestive that pitting corrosion depends on chloride concentration, $\mathrm{pH}$, and temperature. Models related to pitting corrosion fall into two broad categories: initiation and propagation. Pit initiation models allow one to predict the effects of environment on quantities such as critical potential and induction time $[22,23]$.

\section{Halide Nuclei Theory}

Okada $[24,25]$ assumes that the pit initiation on a steel begins with the formation of a hemispherical halide nucleus on a passive oxide film. If the nucleus is stable and grows continuously, it can eventually breach the protective oxide. After dissolution of the metal halide, the underlying metal is exposed and undergoes rapid corrosive attack. Okada has used two independent approaches to derive the same expressions for the critical potential $E_{\text {pit }}$, the induction time $\tau$, and the critical size for the stable halide nucleus, $r^{*}$. For thin passive films, the critical potential is a linear function of the logarithm of the halide ion concentration, $\ln \left[X^{-}\right]$:

$$
E_{\text {pit }}=\text { constant }-\frac{R T}{\xi F} \ln \left[X^{-}\right]
$$

where $R$ is the universal gas constant, $T$ is the absolute temperature, $\xi$ is a constant, $F$ is Faraday's constant. The relationship between the critical pitting potential and halide ion concentration is consistent with the experimental results of several research findings [26-28]. A perfect agreement was obtained between chloride concentration, temperature, and $\mathrm{pH}$ for a Type 316 stainless steel in cellulose bleach solutions at $\mathbf{5 0 C}$ as shown in Figure 2 [28]. The pitting potential was calculated using the following equation:

$$
E_{c}=2570-5.81 T+0.07 T[p H]-0.49 T \log \left[\mathrm{Cl}^{-}\right]
$$

Pitting was determined to occur when the size of the halide nuclei exceeds a critical value $r^{*}$. The induction time, $\tau$ is the time required for the halide nuclei's radius to become larger than the critical size for stable nuclei, $r^{*}$ and is given by the equation:

$$
\ln \tau=\text { constant }-2 n \ln \left[X^{-}\right]-\frac{2 \xi F E}{R T}
$$




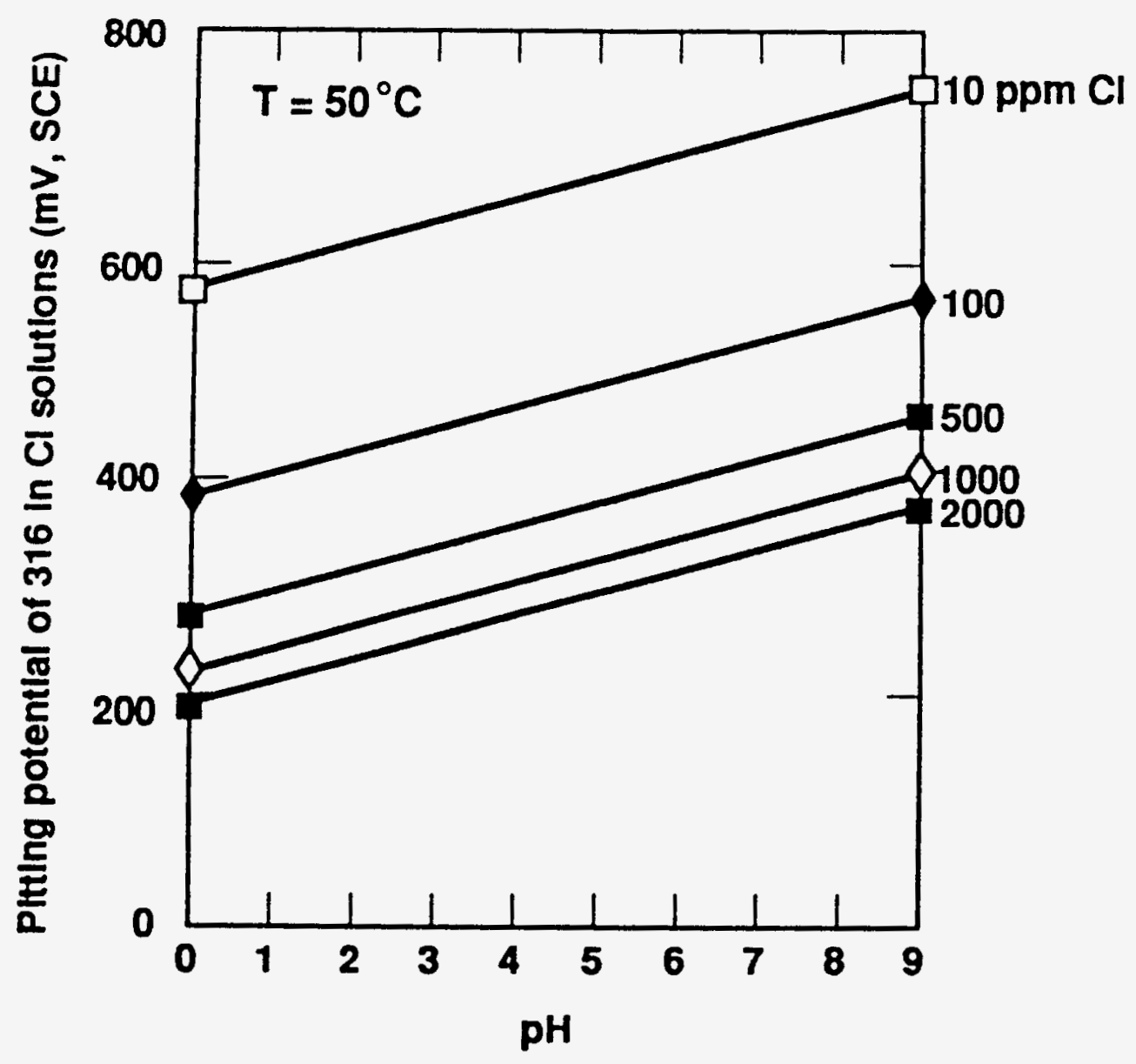

Figure 2: Application of Okada's model $[24,25]$ to evaluate the pitting potential of Type 316 stainless steel in cellulose bleach solutions at 50C [28]. 
where $n$ is the valency of the metal ion. Note that Equation 10 implies that the induction time increases exponentially as the chloride concentration decreases. Such correlations of induction time with potential, chloride, $\mathrm{pH}$ and temperature will be crucial in corrosion models that can be used to predict the life of High-Level Waste tanks.

\section{The Point Defect Model}

According to Lin et al.[29, 30], a passive film can be regarded as a crystalline material containing numerous point defects. It is assumed that during the film growth caused by the diffusion of anions from the film-solution interface, diffusion of the metal cations from metal-film to film-electrolyte interface occurs, producing metal vacancies at the metal-film interface. When the metal vacancy production rate is higher than the rate of vacancy disappearance, a void forms at the metal-film interface. After reaching a critical size, the passive film collapses. In the presence of halide anions, this process occurs more easily because these ions are incorporated into the outermost layer of the passive film by occupying anion vacancies in the film. The quantitative model for film breakdown provides a relationship between, breakdown overpotential,

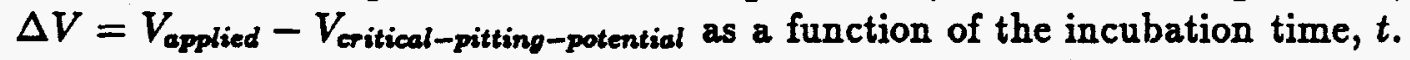
Mathematically, this is expressed as:

$$
t=\xi^{\prime}\left[\exp \left(\frac{\chi F \alpha \Delta V}{2 R T}\right)-1\right]^{-1}+\tau
$$

where

$$
\xi^{\prime}=\xi / J^{0} u^{-x / 2} \cdot a_{C l-} \exp \left(\frac{\chi F \alpha V_{c}}{2 R T}\right)
$$

In Equation 13, $\xi$ and $J^{0}$ are related to cation diffusion rate, $V_{c}$ is the critical pitting potential, $a_{C l}$ is the activity of chloride ion, $F$ is the Faraday's constant, $\xi$ is the charge of the cation, $\alpha$ is related to the potential drop at the film/solution interface and $\xi$ is the critical amount of metal holes accumulated.

Furthermore, when $\Delta V \geq 0.05 V$, $\exp (\xi F \alpha \Delta V / 2 R T)>>1$, so that Equation 13 is simplified to yield

$$
t=\xi^{\prime}\left[\exp \left(-\frac{\xi F \alpha \Delta V}{2 R T}\right)\right]+\tau
$$

The parameter $\tau$ is introduced to account for diffusion during the transient period and it is a measure of the time over which transient diffusion is significant compared to steady-state diffusion. For large values of $\Delta V$, the incubation time, $t$, is dominated by transient time, $\tau$. On the other hand, for small values of $\Delta V, t$ is proportional to $\exp (-\chi F \alpha \Delta V / 2 R T)$. 
Heusler and Fischer [31] obtained an empirical equation for the relationship between $t$ and $\Delta V$ of the form:

$$
\log t / t_{0}=V_{0} / \Delta V
$$

where $t_{0}$ and $V_{0}$ are constants. Figure 3 shows the experimental results of

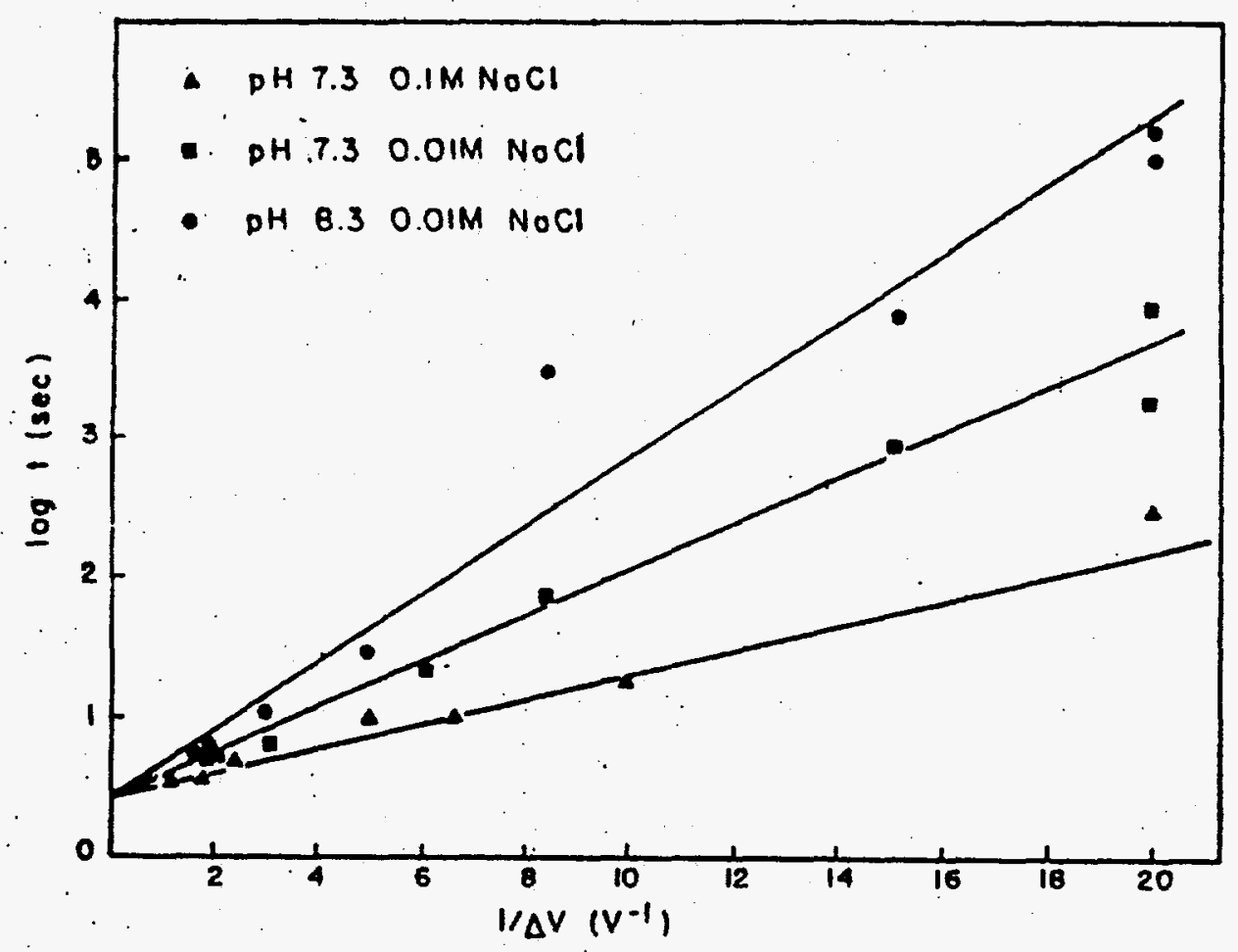

Figure 3: Incubation time, $t$, for pitting of passive iron in borate buffer solution as a function of reciprocal of the potential difference, $\Delta V=V-V_{c}$ for various conditions indicated $(T=25 \circ C)$ [31].

Heusler and Fischer plotted in accordance with Equation 15. Replotting the same data as $\log t$ vs $\Delta V$ showed that Equation 12 is valid. Log $t$ is inversely proportional to $\Delta V$ with a slope of -18.5 which is in excellent agreement with theoretical value of $-18.8 V^{-1}$. It can be seen that the experimental data are in excellent agreement with the theoretical prediction of the model $[29,30]$. 


\subsubsection{Models on Propagation of Pits}

Once a pit is initiated, it is necessary to calculate the rate of propagation (penetration). Using mass transport models, quantities such as $\mathrm{pH}$ inside a growing pit and growth rate can be computed. Stochastic probability theory was applied to describe the observed variances in critical potential [32]. The rate of pitting can be determined from logarithmic plots of survival probability as a function of time. Pit depths have been estimated using statistical methods [33].

A common aim of mathematical models of pit growth that have been developed is the prediction of the solution chemistry and electrochemistry within the restricted geometries of the cavities as a function of the many parameters on which these depend, e.g. crack dimensions, bulk solution composition, etc. Such information yields metal penetration rates. The complexity of various models seems largely dependent upon their required application. A distinction can be made between models which are based on large quantities of empirical data, and those which are constructed from more rigorous physical arguments and are generally more predictive. With respect to the former group, the engineering models are most commonly used to provide specific answers relating to some particular aspect of a corroding system, for example, defining environment limitations for use of a given alloy. Although the details vary greatly, the models are based on the same fundamental equations that govern the mass transport of aqueous chemical species in electrolytic solutions [34-36].

\section{Pit Growth Limited by Salt Film}

Beck and Alkire have developed a simple mass transport model for the growth of hemispherical pits which is depicted by Figure 4 [34]. They assumed that the initiation of pits on the surface of a passive metal occurs at flaws in the protective oxide film. Such a flaw could be either a halide nucleus generated by the mechanism proposed by Okada $[24,25]$ or a void generated by the point defect mechanism proposed by Lin, Chao, and Macdonald [29, 30]. These flaws have approximately the same dimension as the passive film thickness.

The pit growth rate, $d r / d t$, is proportional to the limiting current density, $i_{L}$. By integrating the expression for $d r / d t$, Beck and Alkire have obtained an expression for the pit radius, as a function of time and which is of the form :

$$
r=\sqrt{r_{1}^{2}+\frac{2 D C, M t}{\rho}}
$$

where $D$ is the diffusivity of the salt in the electrolyte, $C_{8}$ is the saturation concentration of metal salt in the electrolyte, $M$ is the atomic weight of the 


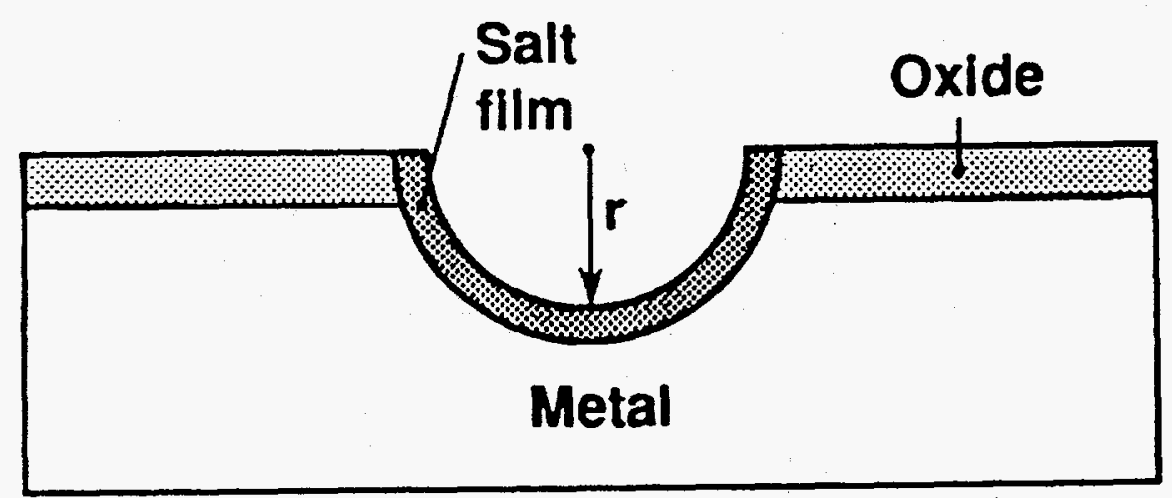

Figure 4: The Beck-Alkire model assumes that the surface of the hemispherical pit is covered by a resistive salt film [34]. This is a transient-mass-transport model.

metal, $t$ is the time, $r$ is the radius of the pit at any time $t, r_{1}$ is the initial radius of the pit and $\rho$ is the density of the metal undergoing dissolution.

The one-dimensional pitting of titanium in bromide occurs by growth of salt films on the surface which obey rate expressions based upon high-field conduction. The current density associated with growth of the salt film is given as:

$$
i_{f}=i_{0} \exp \left(\frac{\beta \eta_{f}}{t_{f}}\right)
$$

where $i_{0}$ is the corresponding exchange current density, $\beta$ is a constant, $\eta_{f}$ is the film overvoltage, and $t_{f}$ is the film thickness. The expression can be rearranged for calculation of the salt-film thickness:

$$
t_{f}=\frac{\beta \eta_{f}}{\ln \left(\frac{2 F D C_{l}}{i_{0} \tau}\right)}
$$

where $z$ is the valence of the metal involved in the salt, $D$ is the diffusivity of ions in the salt film, and $C$, is the saturation concentration of the salt in the bulk electrolyte. Beck and Alkire performed calculations that estimate 
$t_{f}$ to be approximately $77 \AA$ for a case where the pit radius $r$ is $1 \mu m$. It is important to note that this model, unlike those of Pickering and Frankenthal [35] and Galvele [36], gives an explicit expression for the pit size as a function of time and hence can be used to predict failure of the carbon steel waste tank liner due to pitting.

\subsubsection{Initiation of Cracks at Pits with Critical Depths}

Pits can serve as initiation for SCC. Buck and Ranjan [37] developed a model which describes crack initiation by the combined effects of a static stress and corrosion. This model makes use of the crack-tip-opening displacement and assumes that corrosion pits form and grow during the early stages of stresscorrosion cracking. The major role of the stress is to provide a plastic component to the displacement which develops by primary and secondary creep, depending on the application of the stress. Once a critical corrosion pit depth is achieved, the strain energy release rate is large enough to initiate a micro crack. The only adjustable parameter in the model is a threshold stress level below which cracks do not initiate. The predictions of the model in terms of the micro-crack incubation time under stress-corrosion conditions are found to be in reasonable agreement with all the experimental results obtained so far.

The expression for the time to initiate a stress corrosion crack, $t_{i}$ is [37]:

$$
t_{i}=\frac{\left(K_{I S C C}\right)^{2} e^{-V_{m} / V_{0}}}{\pi B\left(\sigma^{2}-\sigma_{0}^{2}\right)}
$$

where $K_{I S C C}$ is the stress intensity threshold for initiation of SCC, $\sigma$ is the applied stress, $\sigma_{0}$ is the stress needed to close the crack, $B$ is a constant, $-V_{m}$ is the electrochemical potential of the sample, and $V_{0}$ is the reversible potential.

This expression is based upon crack-tip-opening displacement (CTOD) model for crack initiation at a pit of critical depth. In this model, the micro-crack propagation rate, $\delta a_{m} / \delta t$, at the base of the pit is assumed to be linearly proportional to the opening displacement at the mouth of the pit, $\delta$. When $\delta$ exceeds a threshold value $\left(\delta_{c}+\delta_{0}\right)$ a crack is initiated at the base of the pit. The critical opening displacement for initiation of a SCC in the absence of "corrosion blunting" is $\delta_{c}$. Note that the quantity $\delta_{c}$ is proportional to $K_{I S C C}^{2} / \sigma_{\text {flaw }} E$, where $\sigma_{\text {flaw }}$ is the flow stress, and $E$ is Young's Modulus. The corrosion-pit opening displacement $\delta_{0}$ is that required to prevent blunting of the base of the pit by corrosion.

SCC can also begin in the absence of pitting by intergranular corrosion or slipdissolution processes. Intergranular-corrosion-initiated SCC requires that the local grain-boundary chemistry differ from the bulk chemistry. This condition 
occurs in stainless steels or with the segregation of impurities such as phosphorus, sulphur, or silicon in a variety of materials. Slip-dissolution-initiated SCC results from local corrosion at emerging slip planes and occurs primarily in materials with low stacking-fault energies. The processes of crack initiation and propagation by the slip-dissolution process are very similar.

\subsection{PROPAGATION OF STRESS CORROSION CRACKS}

Stress corrosion cracking is a phenomenon associated with a combination of static tensile stress, environment and in some systems, metallurgical condition, which leads to the initiation and propagation of high aspect ratio cracks. Cracking may be intergranular or transgranular and may propagate at rates with a wide range $10^{-10}$ to $10^{-2} \mathrm{~cm}^{-1}$. These cracks may lead to leaks in thin-section components employing relatively ductile alloys or they may lead to catastrophic failure in higher strength materials. The primary liner of the High-Level Waste tanks, which is made of mild steel, is under load emanating from the contents of the tanks. Under the influence of stress, cracks can propagate from pits which are considered to be the precursor to SCC.

Processes that are involved in the cracking phenomena are as follows:

1. Transport of the deleterious species to the crack tip.

2. Reactions of the electrolyte with newly produced crack surfaces to produce hydrogen or effect dissolution.

3. Hydrogen entry (or absorption).

4. Diffusion of hydrogen to the fracture (or embrittlement) site.

5. Partitioning of hydrogen among the various microstructural sites.

6. Hydrogen-metal interactions leading to embrittlement (that is, the embrittlement reaction).

Crack propagation models also can be categorized according to the state of passivity of the metal at the crack tip. In cases where the crack tip is not passivated and the strain rate is relatively low, propagation of SCC may be limited by the transport of ionic species along the length of the crack. Such transport models may be applicable to situations in which intergranular attack is encountered.

In carbon steels of interest as structural materials for High-Level Waste Tank construction, there is a presence of impurities such as $\mathbf{P}$ etc. Issues such as 
segregation of these impurities at the grain-boundaries cannot be discounted. These elements segregate to the boundaries during tempering or aging and will weaken the grain boundaries. The combination of these elements together with hydrogen can lead to a greatly reduced threshold stress intensities in a hydrogen bearing environment. Also, the susceptibility of a material to hydrogen susceptibility depends upon the alloy chemistry and particularly the grain boundary chemistry [38].

Hydrogen can be liberated during chemical and electrochemical reactions occurring on the metal surface (e.g., during the hydrogen discharge at the cathode). The most favorable conditions for hydrogen adsorption processes exist at the crack tip on a small area of the fresh metal surface not covered with the protective oxide film. That is why the hydrogen effect is significant in the process of subcritical crack growth; the incubation period depends, to a great extent, upon the state of the smooth specimen surface and (when there is a cut) upon the sharpness of the cut.

Other situations arise in which the crack tip is passivated. Under these conditions, the crack propagation is believed to occur by a mechanism which involves fracture of the passive film. Therefore, models adressing ion transport and anodic dissolution, brittle-film rupture and hydrogen-embrittlement become relevant in the context of High-Level Waste tank corrosion.

\subsubsection{Propagation Controlled by Ion Transport and Anodic Dissolution}

Turnbull and Thomas [39] have developed a model for the electrochemical conditions in a static crack for steel in the active state based upon the quasisteady-state mass transport of species by diffusion and ion migration. Though their model was developed for SCC, it is ideally suited to the problems of intergranular attack in the presence of stress and crevice corrosion. The main reactions considered were anodic dissolution of the metal, hydrolysis of ferrous ions, and cathodic reduction of hydrogen ions and water. The reactions were assumed to take place both at the tip and on the walls of the crack. The reduction of oxygen in the crack was not included since it was demonstrated to be insignificant in a static crack at steady state.

Turnbull and Thomas also considered the buffering effect of $\mathrm{CO}_{2}$ in seawater:

$$
\begin{aligned}
\mathrm{H}_{2} \mathrm{CO}_{3} \Leftrightarrow \mathrm{H}^{+}+\mathrm{HCO}_{3}^{-} \\
\mathrm{HCO}_{3}^{-} \Leftrightarrow \mathrm{H}^{+}+\mathrm{CO}_{3}^{2-}
\end{aligned}
$$

Recent studies by Congdon [9] have emphasized the importance of such reaction in the context of High-Level Radioactive Waste tanks. Such reactions 
normally occur during ventilation of the tanks with air. The absorbed $\mathrm{CO}_{2}$ alter the $\mathrm{pH}$ of the highly alkaline nuclear waste.

The general equation for the conservation of species in the crack, based upon dilute solution theory, is:

$$
\frac{\partial C_{i}}{\partial t}+\nu \nabla C_{i}=D_{i} \nabla^{2} C_{i}+z_{i}\left(\frac{F}{R T}\right) D_{i} \nabla\left(C_{i} \Phi\right)+R_{i}
$$

where the second term on the left-hand side of the equation represents convective transport. The three terms on the right-hand side represent diffusion, electron migration, and generation or consumption of the species. Since there is a term for electromigration effects, rigorous solution requires that Laplace's equation must also be solved $[40,41]$. The authors assumed that the crack propagation rate was so slow that convective transport in the crack could be neglected. Furthermore, they assumed quasi-steady state, which eliminated the time derivative and reduced Equation 22 to an ordinary differential equation.

A numerical solution to Equation 22 was obtained by application of a variant of the Newton-Raphson iterative technique. This involved converting the system of ordinary differential equations to nonlinear integral equations. The boundary conditions at the crack opening were the ion concentrations in the bulk electrolyte outside of the crack. The boundary conditions at the crack tip and along the walls of the crack were derived from the current density due to the anodic dissolution of the metal at the crack tip, and the current density for the rates of reduction of hydrogen ions and water.

Turnbull and Thomas performed simulations of steel BS 4360 50D in 3.5\% $\mathrm{NaCl}$. The model predicted that the concentration of ferrous ions near the crack would be slightly higher than the equilibrium value. The hydrogen ion concentration varied very little over the length of the crack, except at the crack opening. It was found that the potential drop changed slowly with distance from the crack tip. It was found that the potential drop changed slowly with distance from the crack tip, except at the crack opening. The validity of the model was checked experimentally by measuring the $\mathrm{pH}$ in an artificial crevice at various potentials. No rate equations were developed using this model.

\subsubsection{Model Relevant to High-Level Waste Tanks Involving Film Fracture at the Crack Tip}

Although some corrosion work has been done since the mid-1940s when waste storage began, the changes in the processes and waste types have outpaced the development of new data pertinent to the new double shell tanks. As a 
consequence, Pacific Northwest Laboratory (PNL) began to development of corrosion data on a broad base of waste compositions in 1980 .

Devine and his co-workers [42-45] developed corrosion data on tank construction materials such as ASTM A 537 carbon steel (used in double-shell tanks) and A 516 carbon steel (used in earlier single-shell tanks) in an expanded double-shell slurry (DSS) composition range. The also considered other waste compositions with temperatures up to the tank design temperature, $350 \mathrm{~F}$ $(177 \mathrm{C})$ at which temperature corrosion rates were not expected to exceed one mil per year.

The available data were selected from the literature. The survey included data from the Savannah River and Hanford experiments which were found inadequate to describe the behavior of the waste proposed for storage in the new tanks. Therefore, additional corrosion rate data have been generated through experiments using weight loss (to determine the corrosion rate) and U-bend specimens (to determine the fracture behavior). The corrosion data were necessary to allow safe operation of the waste tanks in which a wide range of simulated waste fluids up to tank design temperature, $350 \mathrm{~F}$ (177 C).

Initially corrosion work was carried out on double shell slurry (DSS) waste, using fluid compositions expected to be generated and at temperatures at or below $100 \mathrm{C}$. The mechanism of the protection of Fe was considered to be due to the production of a protective $\mathrm{Fe}_{3} \mathrm{O}_{4}$ film. The corrosion data were analyzed and have been used to generate prediction equations. Both linear and nonlinear equations were used to produce prediction equations for interpolating, the expected corrosion behavior of the storage tanks to new combinations of storage conditions. The experiment was designed so that the data would accommodate fitting a 300 parameter polynomial model for each alloy which expressed corrosion rate as a function of exposure time in hours, temperature, and the levels of the nine anions in a chemical solution.

The 300 parameter model includes the intercept and 299 terms which are the 299 predictors, multiplied by a coefficient. The intercept and the 299 coefficients are unknown parameters in the model. These are estimated by fitting the model to the experimental data. Statistical tests on the estimates were then performed to decide which of the unknown coefficients are not zero. Stepwise regression analysis was then used to select an adequate subset of predictors in each model corresponding to each alloy type. The models were statistical in nature with no attempt to describe the physical interaction [43, 44].

Predictor equations have been developed for A 537 (which has 55 predictors in the model and $R^{2}=0.89$ where $R^{2}$ is the percent of the variability in the 
observed corrosion rates accounted for the fitted model) and A 516-70 (which has 74 predictors in the model and $R^{2}=0.87$ ) in a range of synthetic DSS waste compositions expected to be stored in the double-shell tanks. Both linear and non-linear equations were used to produce predictor expressions. These equations have been used to predict the corrosion rate as a function of temperature, alloy and time within the ranges of experiment. The predicted corrosion rates in mils per year (mpy) obtained for each alloy type ( $0.350 \mathrm{mpy}$ for A-537 and $0.359 \mathrm{mpy}$ ) in the DSS environment is in reasonable agreement with the mean experimental value ( 0.360 mpy for A-537 and 0.359 mpy for A-516).

It was concluded that the DSS specified in the environmental impact statement (EIS) could be put into the new tanks made of A-537 mild steel provided the temperatures were kept close to or below the proposed operating values $(100 \mathrm{C})$. However, it was not possible to conclude from the prediction equation whether the presence or absence of a component was significant. Later, these models were extended to model separately different compositions and ranges of compositions, to simulate Double Shell Slurry waste and Future PUREX waste at temperatures between 40 and $180 \mathrm{C}$ as well as, Hanford Facilities waste at temperatures of 25 and $50 \mathrm{C}$.

A fourth comprehensive model has also been developed using the combined corrosion data collected for each of the above waste types [44, 45]. It was found that the corrosion rates were well below the design limit of $1 \mathrm{mpy}(0.001$ inch/yr) and usually less than 0.5 mpy. Excessive corrosion rates ( $>1 \mathrm{mpy}$ ) were only found in dilute waste compositions or in concentrated caustic compositions at temperatures above $140 \mathrm{C}$. Localized and stress corrosion cracking were only observed under similar conditions. Indeed, though U-bend tests are considered to be a severe test [46], less SCC was observed than expected from the previous work [13-14]. Normal operating conditions for the wastes tested [45] do not lead to significant corrosion rates.

\subsubsection{Other Relevant Models Involving Film Fracture at Crack Tip}

A model involving stress corrosion crack growth by anodic dissolution has been developed by Doig and Flewitt [47]. The distribution of electrochemical reactions and electrode potential within the crack which grows by anodic dissolution is evaluated analytically. It predicts that the electrode potential at the tip of the stress corrosion crack is lower than the experimentally measured bulk potential. Bare surface dissolution models for stress corrosion crack growth allow calculation of a maximum theoretical crack growth rate which is related to the maximum anodic current from the oxide ruptured bare surface. However, these predicted growth rates are often several orders of magnitude 
greater than those measured experimentally or experienced in service components $[48,49]$. Consequently, a variety of rate controlling parameters, other than maximum bare surface dissolution current, have been introduced in order to reduce the maximum theoretical crack growth rate to more realistic values. These parameters include oxide repassivation rate, micro-creep, solution renewal and critical charge concepts [48, 50-52].

In general, bare surface anodic dissolution characteristics have been measured under laboratory conditions using smooth, bulk specimen subject to potentiostatic control. The measured potential dependence has been analyzed in an attempt to evaluate the contribution of the various parameters to stress corrosion crack growth rates measured at the same potential. Implicit in such a correlation is the assumption that the electrode potential which is determined for the bulk stress corrosion specimen, is the potential prevailing at the crack tip. Figure 5 shows a schematic Evan's polarization diagram of the electrochemical reactions which occur within the crack for a parallel sided stress corrosion crack of width $w$ in the $Z$ direction which is infinite in the $X Y$ plane for $\mathbf{x} \geq \mathbf{0}$.

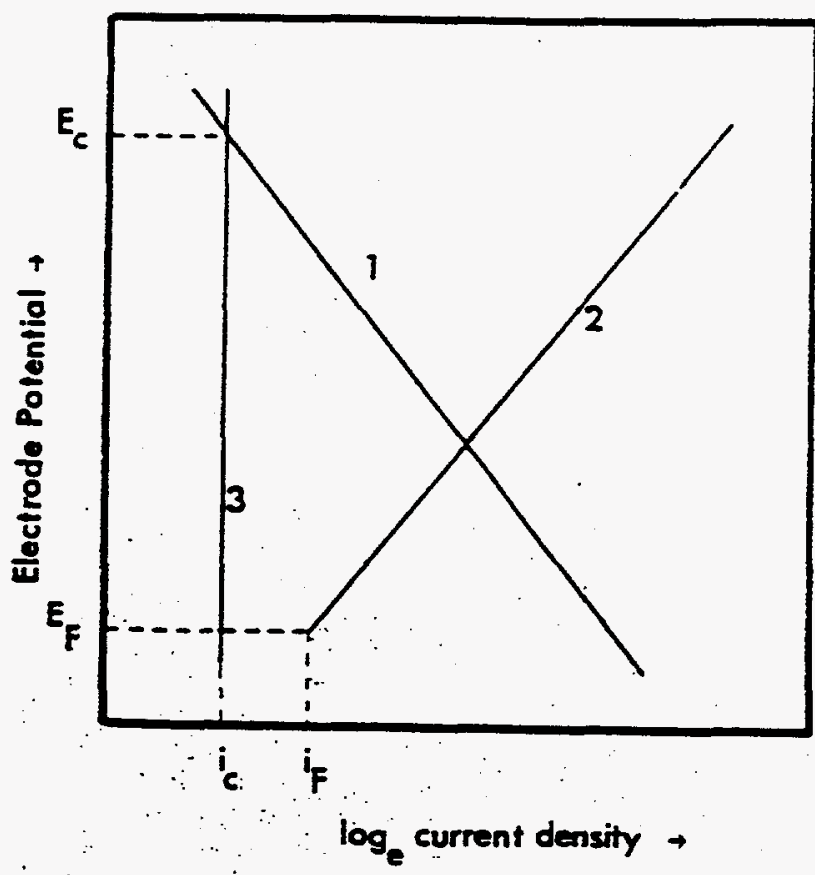

Figure 5: Evan's polarization diagram of the electrochemical reactions which occur within a crack. 
The cathodic reaction occurs on the crack surfaces with the current density versus electrode potential relationship described by line 1 . The bare surface anodic dissolution reaction occurs at the crack tip with a current density versus electrode potential behavior described by line 2 , and the anodic dissolution reaction on the oxide covered passive crack surfaces occurs at an almost constant current density, line 3 . It was assumed that :

1. the rate of this last reaction is independent of electrode potential, i.e. the slope of line 3 is infinite.

2. the bare surface anodic dissolution reaction, line 2, and the cathodic reaction, line 1, obey Tafel kinetics.

Thus, for the cathodic reaction:

$$
i_{\text {cathode }}=i_{c} \exp \left(\frac{E_{c}-E_{x}}{\beta}\right)
$$

where $i_{\text {cathode }}$ is the cathodic current density at potential $E_{x}, i_{c}$ is the corrosion current density, $E_{c}$ is the equilibrium bulk corrosion potential, $E_{x}$ is some potential removed from $E_{c}$, and $\beta$ is the Tafel slope (slope of potential vs. $\log$ (current) plot at a region where the experimental curve superimposes upon the true polarization curve of the reaction. Similarly for the bare surface anodic dissolution reaction:

$$
i_{\text {anodic }}=i_{F} \exp \left(\frac{E_{z}-E_{F}}{\alpha}\right)
$$

where $i_{\text {anodic }}$ is the bare surface anodic current density at potential $E_{x}, i_{F}$ is the exchange bare surface anodic current density at the reversible electrode potential $E_{F}$ and $\alpha$ is the Tafel slope of the reaction.

Assuming mechanical rupture of the oxide film at the crack tip, an anodic current, wianodic, flows from the region of the tip. As a consequence of the finite conductance of the solution within the crack, this current flow is accompanied by a change in the electrode potential, $E_{x}$, down the crack which is given by Fick's law of diffusion:

$$
i_{x}=w C\left[\frac{d E_{x}}{d x}\right]
$$

where $i_{z}$ is the anodic current flow in the crack at the electrode potential $E_{x}$ and $C$ is the specific conductance of the solution within the crack. A complementary cathodic reduction reaction occurs on the crack surfaces which reduces the anodic current flow, $i_{x}$, along the crack by an amount given by:

$$
\frac{d i_{x}}{d x}=-2\left(i_{\text {cathode }}-i_{c}\right)
$$


This leads to an excess cathodic current which increases with a decreasing value of $E_{x}=0$ at the crack tip and is given by:

$$
i_{x=0}=w C\left(\frac{4 i_{c}}{w C}\right)^{\frac{1}{2}} \cdot f\left(E_{x=0}\right)
$$

The various current versus potential relationships are shown schematically

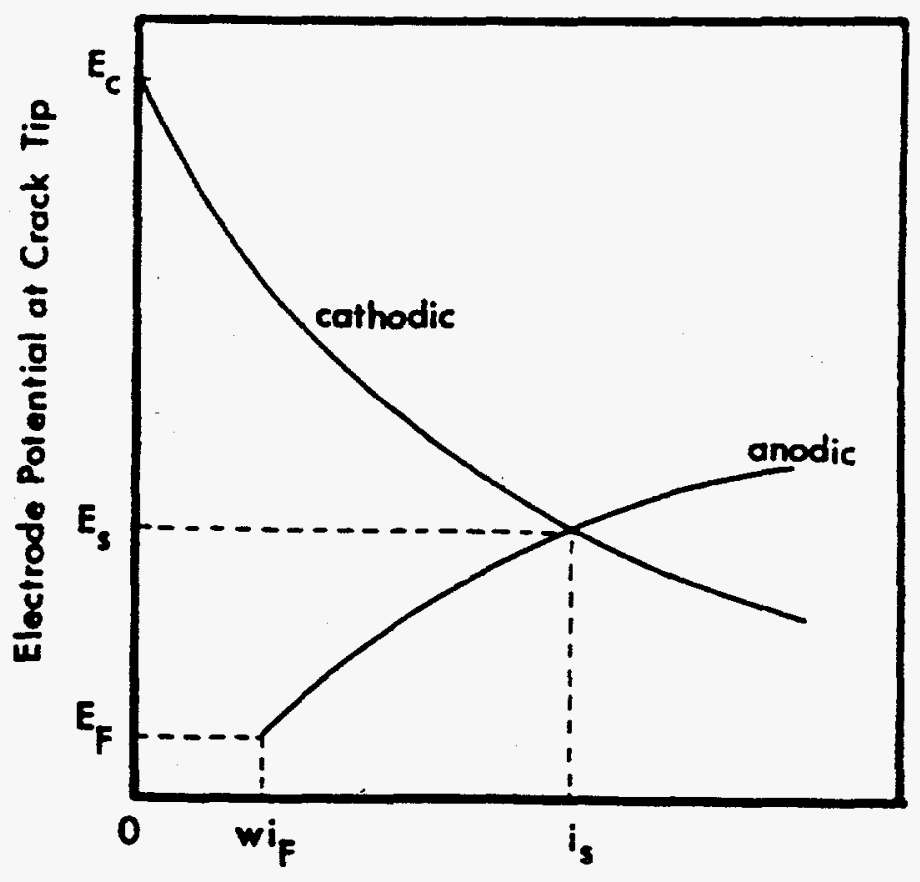

Figure 6: A schematic plot of the excess cathodic current generated on the crack sides and bare surface anodic dissolution current at the crack tip as functions of electrode potential at the tip.

in Figure 6 where the value of the current $i$, at potential $E$, defines the equilibrium bare surface anodic dissolution current and complementary excess cathodic current generated on the crack surfaces. By substitution from Equations 24 and 27, we have Equation 28:

$$
w i_{F} \exp \left(\frac{E_{x=0}-E_{F}}{\alpha}\right)=\left(4 i_{c} w C\right)^{\frac{1}{2}} \cdot f\left(E_{x=0}\right)
$$

Therefore, the electrode potential, $E_{s}$, which can exist at the tip of a growing stress corrosion crack, is always less than the bulk equilibrium potential, $E_{c}$. Clearly, the major part of the cathodic current is generated within the region local to the tip, the magnitude of which is described by the condition:

$$
x\left[\frac{4 i_{c}}{w C}\right]^{\frac{1}{2}} \approx 0.5
$$


Equation 29 shows that the present analysis is accurate for crack lengths $\geq$ $0.25 \mathrm{~cm}$. The above model has been used to predict the stress corrosion crack growth rates in ferritic iron-nickel alloys in terms of bulk electrochemical parameters: $E_{c}, i_{c}, E_{F}, i_{F}, \alpha, \beta$, and $C$ in a $5 \mathrm{M}$ sodium hydroxide solution. Since the electrode potential determines the anodic dissolution at the crack tip, the maximum theoretical crack growth rate predicted by this model is given as:

$$
v=\frac{i_{\text {anodic }} M}{\rho F n}
$$

where $M$ is the molecular weight of the cation at the crack tip, $n$ is the charge/mole of the dissolving cation, $F$ is the Faraday constant which is the amount of electricity associated with one mole of electrochemical reaction (96, $500 \mathrm{cal} . / \mathrm{mole}$ ). The theoretical crack growth rate according to the analysis is lower than that more usually evaluated, assuming bulk corrosion potential $E_{c}$. This is true particularly in high concentration solutions. The analysis allows maximum theoretical stress corrosion crack growth rates to be predicted more accurately from the measured equilibrium electrochemical properties in the iron-nickel alloys. Also, changes in the solution composition within the stress corrosion crack resulting from corrosion reactions have been estimated and measured, so that appropriate environments for electrochemical measurements could be selected.

The analysis does not consider the contribution of the oxide film which forms on the surfaces of the growing crack. Such film formation follows a logarithmic growth law and therefore the oxide thickness tends towards a limiting value, $t$. The presence of the oxide reduces the crack width and lowers the conductance of the solution within the crack. If the net crack width is $w$, the reduced cathodic current, i(net), from Equation 28 given by:

$$
i(n e t)=\left[4 i_{c}(w-2 t)\right]^{\frac{1}{2}} \cdot f\left(E_{z=0}\right)
$$

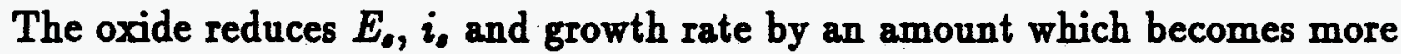
significant as the value of $w$ is decreased, i.e. at lower stress intensities. For $t$ $=0.2 \mu \mathrm{m}$, the growth rate at $\mathrm{K}=20 \mathrm{MNm^{- \frac {3 } { 2 } }}$ is reduced by $\approx 50 \%$, and for $2 t \geq w$ the growth rate is zero, thereby providing a criterion for a threshold stress intensity. The above value for $t$ gives $K_{T H}=12 \mathrm{MNm}^{\frac{3}{2}}$, which is in reasonable agreement with measured vales for low alloy steels.

Thus, the analysis strongly emphasizes the importance of both the anodic dissolution and cathodic reduction reactions in controlling the stress corrosion crack growth rate. Further, it is the cathodic polarization behavior of the crack surface close to the tip which is critical. The electrode potential at the tip of a stress corrosion crack is controlled by a dynamic balance between the bare 
surface anodic dissolution kinetics of the crack tip, the cathodic polarization behavior on the crack surfaces and the conductance of the solution.

Since the anodic and cathodic behavior are strongly dependent upon material composition, it is neccessary to have a knowledge of the local composition along the stress corrosion path.

Environmental enhancement of crack growth under either static or dynamic loads includes a direct interaction of the environment with the straining metal at the tip of the advancing crack. Therefore, any analysis of the crack advance process must include a description of this crack tip region, both in acqueous solution and the in the strained metal. To date, much effort in establishing these mechanisms has been devoted to correlating the cracking behavior with external environmental conditions including the bulk solution chemistry and electrochemical potential. These studies have been useful when considering overall environmental conditions which lead to cracking, but they are of little value for describing either the growth kinetics or the effect of small changes in the external environment on susceptibility.

The magnitude of the difference between crack tip and bulk solutions environments has been the subject of some discussion [52]. The difficulties associated with direct experimental measurement has left the evaluation of chemical composition to either inference for indirect experiments or simplified analytical models. The weakness of the former approach lies in the difficulty of extrapolating to other experimental conditions or identifying critical parameters that control overall cracking susceptibility. Analytical approaches, however, offer the advantage of providing a predictive capability, a direct method of identifying critical parameters which may subsequently be tested experimentally and a basis for the extrapolation of laboratory data to the in-service waste tank operating conditions.

Recently, an electrochemical model was put forward [53]. In this model, the ion flux, $\theta_{A}$, within a conducting electrolyte is dependent upon both chemical and electrochemical gradients and is described by the general equation:

$$
\theta_{A}=-D_{A}\{\operatorname{grad}([A])-[A] n F / R T \operatorname{grad}(E)\}
$$

for each ion species $A$ where [] represents molar concentration, $D_{A}$ is the ion diffusion coefficient, $n$ is the charge (positive), $F$ is the Faraday, $R$ is the gas constant, $T$ is the absolute temperature and $E$ is the electrode potential. For a bulk solution in equilibrium where the local ion concentrations are constant:

$$
\operatorname{div}\left(\theta_{A}\right)=0
$$

such that:

$$
\nabla^{2}[A]-(n F / R T) \nabla([A] \nabla E)=0
$$


These equations define the distribution of electrode potential and ion concentration of species $A$ with similar equations applying for each of the ions species present. Thus a concentration gradient of charged species [A] will be in local equilibrium with an electrode potential gradient $\nabla E$ and conversely, where an ion flux exists, there will be an associated electrode potential gradient.

Within the growing crack, local corrosion reactions consume and generate ions and concentration gradients are developed which result in an associated electrode potential gradient. Solution of the general Equation 34 defines the equilibrium distribution of both electrode potential and electrolyte composition within the crack subject to the boundary conditions defined by Equation 32. The complex potential dependence of the electrode reaction rates within the crack usually requires these equations to be solved numerically using experimentally determined constants and electrode reaction rates. The crack tip is assumed to be anodically active as a result of the crack advance process generating a continuous dynamic plastic strain that exposes a film-free, bare metal surface to the local environment.

Metal ions, $M e^{n+}$, are produced at a rate governed by the local electrochemical conditions and diffuse from the crack tip. The unstressed crack surfaces are covered by a passive oxide corrosion product on which the dominant electrode reaction is the net cathodic reduction of the environment to produce hydroxyl ions. Under conditions where hydrogen evolution accompanies the cathodic process, there exists the possibility of either gas bubble formation intermittently disrupting the ion current flow and thereby the crack advance process or diffusion of hydrogen atoms into the hydrostatically stress volume adjacent to the crack providing the conditions for hydrogen assisted growth.

Under these circumstances, the crack advance rate is related to the hydrogen production rate which is also controlled by the local electrochemical potential. For long narrow cracks where current flow is predominantly along the crack length in the direction $x$, the Equation 34 may be reduced to this single variable. For a small element of the crack, $\Delta x$, at a distance $x$ from the tip the steady flux of $M e^{n+}$ metal ions at $x$ is $i(x)$. Equation 34 reduces to an electrochemical equivalent:

$$
d i(x) / d x=2 i(O H) / w
$$

or:

$$
d^{2} E / d x^{2}=2 i(O H) / w C(x)
$$

where $i(O H)$ is negative, $w$ is equal to the crack width and $C(x)$ is equal to the local conductivity. Solution of this equation requires the boundary conditions to be defined at the crack tip. Continuous anodic dissolution of the 
crack tip over the width of the plastically deforming region was assumed and approximated to the total width $w$. Thus at $x=0$ and $E=E_{0}$ :

$$
d E / d x=i(x) / C(x)
$$

where $i(x)$ is the net anodic current density at the crack tip potential $E_{o}$, given from the measured polarization behaviour. For concentrated solutions the term $C(x)$ is approximated by a constant of magnitude equal to the conductivity of the relevant bulk environment, $C$. Solution of Equation 36 is achieved when the electrode potential at the mouth of the crack, $E_{1}$, equals the bulk corrosion potential, $E_{2}$. With this constraint, there exists a unique electrode potential which can exist at the crack tip, $E_{t}$, for any particular polarization behavior, solution conductivity, $C$, crack length, $l$, crack width $w$, and surface or bulk corrosion potential, $E_{2}$. It is this electrode potential, $E_{t}$, which controls the electrochemical processes at the crack tip including both the anodic dissolution rate and together with $p H$, the cathodic production of hydrogen which may contribute to any hydrogen embrittlement processes.

The solution to Equations 36 and 37 establishes a description of the electrode potential within a crack and boundary conditions are considered typical for low alloy ferritic steels in hydroxide solutions. In order to provide the basis for investigating the influence of systematic changes in the various electrode reaction kinetics, it was assumed that the kinetics for all reactions is approximated by a Tafel type relationship wherein activation polarization (the polarization caused by a slow electrode reaction) of any kind increases with current density, Figure 7, such that on the crack surface:

$$
i_{x}=i_{2}\left[\exp \left(\left(E_{x}-E_{2}\right) / \alpha_{2}\right)-\exp \left(\left(E_{x}-E_{2}\right) /-\beta_{2}\right)\right]
$$

and at the crack tip:

$$
i_{t}=i_{1}\left[\exp \left(\left(E_{t}-E_{1}\right) / \alpha_{1}\right)-\exp \left(\left(E_{t}-E_{1}\right) /-\beta_{1}\right)\right]
$$

where $E_{t}$ is the electrode potential at the crack tip $(x=0)$ and $i_{n}, E_{n}$, and $\beta_{n}$ are the corrosion current density, the equilibrium corrosion potential, the anodic and cathodic Tafel parameters, respectively, for the crack surface $(n=2)$ and crack tip $(n=1)$ electrode reactions. The electrode potential at the crack tip determines the rate of anodic dissolution and thereby the crack velocity, $V$, from the relation:

$$
V=i_{1}\left[\exp \left(\left(E_{t} E_{1}\right) / \alpha_{1}\right)\right] \cdot\left[M / \rho F n^{*}\right]
$$

where $M$ is the molar mass, $\rho$ is the density, $F$ is the Faraday, and $n^{*}$ is the charge number of the anodic reaction. The crack width, $w$, may be equated to the crack opening displacement, $\delta$, given by [54]:

$$
\delta=0.5 K^{2} /\left(\sigma_{y} E_{y}\right)
$$




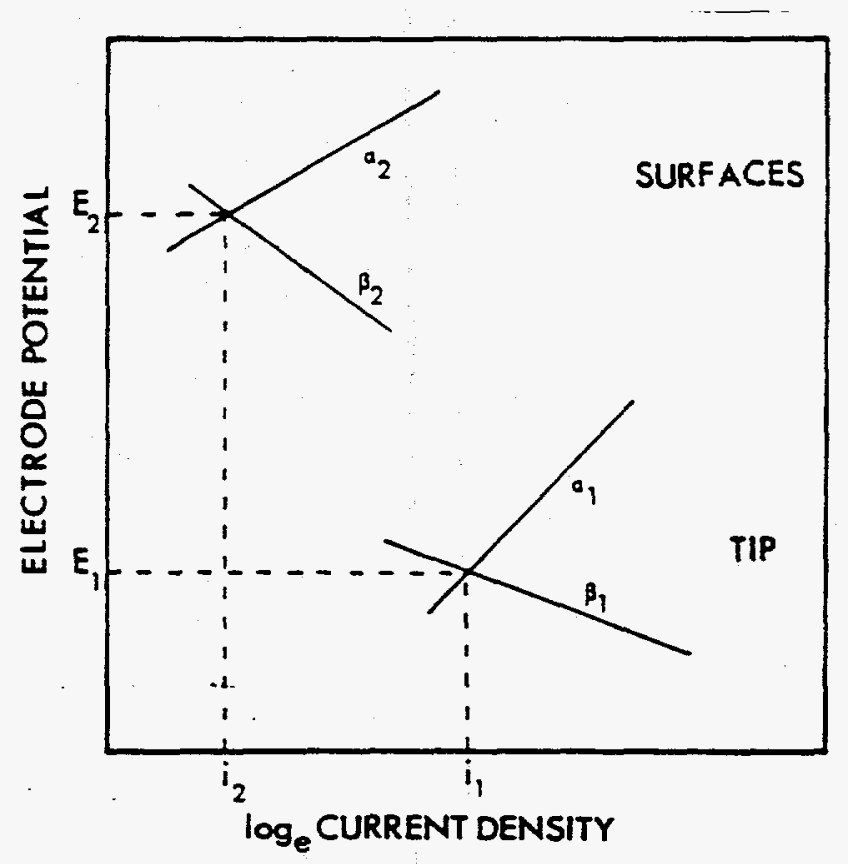

Figure 7: Schematic polarization of the electrochemical reactions occurring at: (a) the crack tip and (b) the sample and crack surface.

where $K$ is the applied stress intensity, $\sigma_{y}$ is the material yield strength and $E_{y}$ is the Young's modulus of elasticity. Thus there is a minimum strain condition of the tip region which defines a threshold value for cracking which may be expressed in terms of a critical crack opening displacement, $\delta^{*}$. This represents the distribution of strain ahead of the crack tip which is just sufficient to provide a strain rate to effect continued anodic dissolution and thereby crack growth.

The models developed by Andresen and Ford $[55,56]$ assume that the propagation of SCC is due to the fracture of the passive film at the crack tip. Their model is essentially a slip dissolution model in which slip emergence at the crack tip causes structural damage of the passive film with consequent oxidation of the underlying matrix and subsequent film repair. These oxidation kinetics are related to the crack advance:

$$
\dot{a}=\frac{M Q_{f}}{z \rho F} \cdot \dot{\epsilon_{c t} \cdot} \frac{1}{\epsilon_{f}}
$$

where $Q_{f}$ is the oxidation charge density between rupture events, $M$ is the atomic weight, $\rho$ is the density, $F$ is the Faraday's constant, $z$ is the oxidation 
state of the metal involved in the film, $\epsilon_{f}$ is the oxide fracture strain and $\epsilon_{e t}$ is the crack tip strain rate. The model can be isolated into three primary conceptual and predictive elements:

- the rate of film rupture (proportional to the crack tip strain rate).

- the solution chemistry at the crack tip.

- the resultant kinetics of oxidation/re-passivation in this environment following film rupture event.

The effects of water and material chemistry on $\dot{a}$ can be represented by a single parameter $n$. The crack tip strain rate, $\dot{\epsilon}_{e t}$, formulations developed by Ford $[57,58]$ then permit the calculation of the frequency of film rupture events. This in turn, is useful to predict the environmental crack growth rate, $\dot{a}$. The effects of water and material chemistry on $\dot{a}$ can be represented by a single parameter $n$ as:

$$
\dot{a}=f(n) \cdot\left(\dot{\epsilon}_{\mathrm{et}}^{\cdot}\right)^{n}
$$

The relationship between $\dot{a}$ and $\dot{\epsilon}_{c t}$ shown in the equation was derived from the power-law relationship that was found to exist between time and anodic current density immediately following fracture of the film. The transient is simply represented as:

$$
i_{a}=a t^{-n}
$$

The primary objective of Andresen and Ford has been to establish a scientific basis for determining $n$ as a function of corrosion potential, solution conductivity, and alloy composition (sulphur content, etc.).

Several cathodic reactions occur outside of the crack and are galvanically coupled with the anodic repassivation (and dissolution) of the crack tip. These include the reduction of oxygen and hydrogen ion [59-61]:

$$
\begin{aligned}
\mathrm{O}_{2}+\mathrm{H}_{2}+2 e^{-} & \rightarrow 2 \mathrm{OH}^{-}, \\
\mathrm{O}_{2}+4 H^{+}+4 e^{-} & \rightarrow 2 \mathrm{H}_{2} \mathrm{O}, \\
2 \mathrm{H}^{+}+2 e^{-} & \rightarrow \mathrm{H}_{2}
\end{aligned}
$$

Clearly, a specific relationship between $\dot{a}$ and $\dot{\epsilon}_{\text {ct }}$ is needed. Unfortunately a thorough review of the literature on SCC of the carbon steels has not revealed correlations relevant to the High-Level Waste tanks.

The dissolution process has been applied by Parkins [62] to intergranular cracking phenomena observed in carbon steel pipelines. The crack velocity is reasonably represented by writing Faraday's second law as a penetration rate 
(Equation 30). Indeed, according to Equation 30 stress corrosion cracks would penetrate an 8-mm wall thickness of a pipeline in 100 days, which is much shorter than the average failure time of 15 years for those relatively few joints of pipeline that have failed by the dissolution mechanism. Thus Equation 30 remains an upper bound velocity as long as the crack tip remains unfilmed. If filming occurs to the extent that dissolution ceases, the local crack growth rate will remain at zero until the rupture of such films reactivates dissolution. Thus, the processes of metal dissolution, film formation and film rupture collectively determine the average crack growth rate which can be anywhere between the upper bound given by Equation 30 and zero depending on the relative contribution of the three processes mentioned. Then the crack-tip strain rate enters into such considerations because it determines the time interval between film rupture events, in the extreme creating bare metal at a rate that exceeds the film growth rate to permit the upper-bound growth rate to be achieved.

Therefore, the anodic current density needs to be replaced by the appropriately integrated current transients that are obtained between rupture events, so that Equation 30 is modified as:

$$
v=\frac{Q}{\dot{\epsilon}} \cdot \dot{\epsilon}_{\mathrm{ct}} \cdot \frac{M}{\rho F n}
$$

where $Q=$ the charge density passed, $\dot{\epsilon}=$ the strain to rupture the film, $\dot{\epsilon}_{\text {ct }}=$ crack-tip strain rate. $Q$ is readily measured from the current response when bare metal is exposed to the environment concerned and is subsequently allowed to film while, $\epsilon$ can be estimated from the strain that needs to be applied to a filmed surface in order to evoke a sudden increase in current when bare metal is created. There are expressions for calculating the cracktip strain-rate for single cracks involving static, monotonically increasing or cyclic loading conditions [62-64] or for multiple cracks, as generated by slow strain-rate testing (SSRT). For the latter case,

$$
\dot{\epsilon}=\frac{75}{n} \cdot \epsilon_{a p p}^{\cdot}+\frac{C V}{5} \cdot \ln \left(\frac{1000}{n}\right)
$$

where $n=$ number of cracks along the gage length, $\epsilon_{a p p}^{\cdot}=$ applied strain rate. The constants in Equation 49 will depend on the materials and test specimen size. Parkins has applied Equation 49 to pipeline steel specimens having a 12.5-mm-long, 2.5-mm-diameter gage length. For the cyclic loading of singlecrack specimens:

$$
\dot{\epsilon}_{c t}=\frac{1}{2 T} \cdot \frac{\Delta K^{2}}{G \sigma_{y}} k
$$

where $T=$ loading time, $G=$ shear modulus, $\Delta K=$ stress intensity factor range, $\sigma_{y}=$ yield stress, and $k=a$ constant that reflects the size of the 
plastic zone associated with the single crack. Equation 50 gives a reasonable correlation with experimental observations if the plastic zone is taken to be the specimen thickness for pipeline steel specimens [65]. The agreement between experimentally determined and predicted crack velocities are in reasonable agreement [65].

The initiation of SCC requires the disruption of surface films, just as does their continued growth. The time dependence of plastic strain therefore implies that crack nucleation will be time dependent. While the average crack growth rate diminishes with time, the number of cracks shows the reverse trend. Also, once a SCC is initiated, it alone does not propagate to produce failure. Profiles of SCC in pipelines exposed to carbonate-bicarbonate solutions at both microscopic and macroscopic levels suggest that crack coalescence occurs, since the crack fronts are undulating in ways indicative of separately nucleated cracks have merged. While most cracks do not grow continuously, some dormant cracks may be reactivated because of nucleation of new cracks in appropriate proximity to the dormant cracks. The various stages through which the SCC

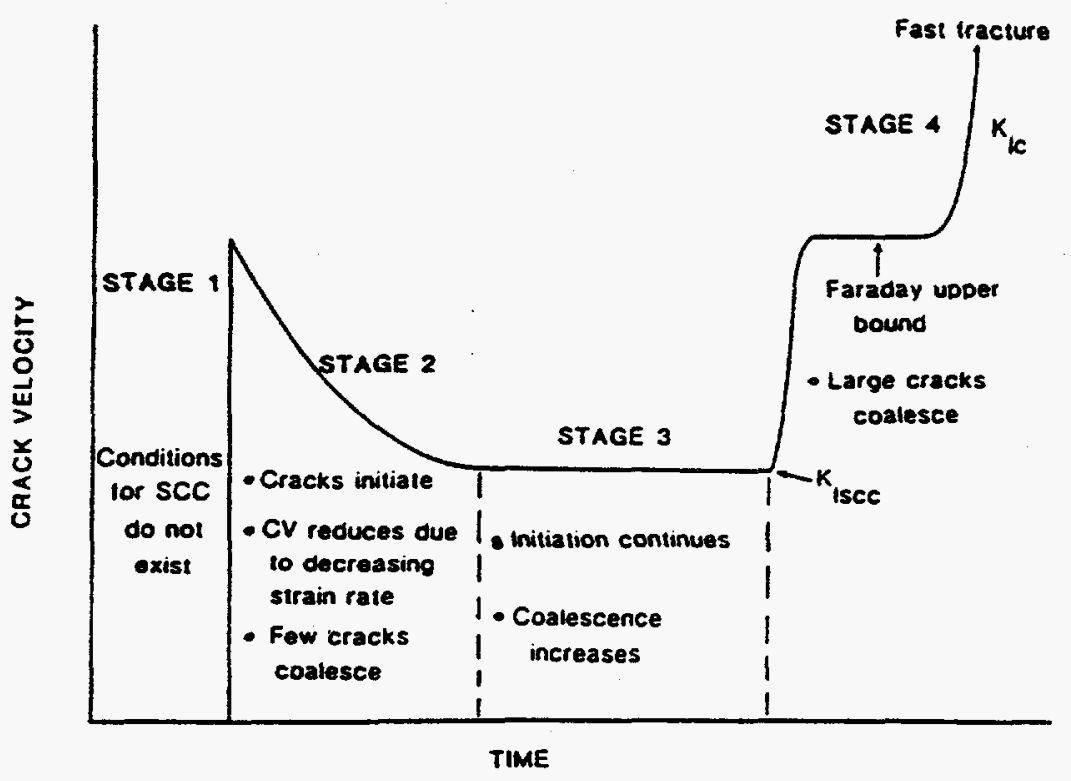

Figure 8: Schematic illustration of the effect of time on SCC velocity of pipeline steel exposed to carbonate-bicarbonate solution [62].

velocity for an operating pipeline passes as a function of time are illustrated schematically in Figure 8. In stage 1 the conditions for SCC do not exist, al- 
though those prerequisites of cracking (coating deterioration, cracking solution generation and establishment of a cracking potential) are eventually met. So far, time to the end of Stage 1 has not been predicted. However, it is suggested [54] that probabilistic approach offers the best hope.

In stage 2 cracks are initiated once the environmental requirements for cracking are met, assuming a susceptible steel and appropriate stressing conditions. The growth rate of the cracks diminishes with time. New cracks continue to be nucleated with the passage of time and their coalescence with dormant small cracks occurs eventually to sustain the average growth rate at a level (stage 9 ) that is, some two orders of magnitude or more below the upper bound given by Equation 30. Coalescence eventually produces cracks (probably some $10 \mathrm{~mm}$ or so long) that result in $K_{I S C C}$ being exceeded, so that the crack velocity increases to the upper bound values. If single cracks grow under those conditions, a leak will eventually occur, but if a number of such larger cracks coalesce, $K_{I C}$ is reached and fast fracture results.

\subsubsection{Life Prediction}

While an expression such as Equation 48 is capable of providing good agreement with laboratory results [64], it has been suggested [62] that the use of Equation 48 is more likely to be fruitful in relation to mechanistic aspects of cracking than in predicting the remaining life of cracked structures. This is so because neither the precise composition of the environment at the pipe surface nor the potential are not known, both of which influence charge density. This then gives rise to difficulties in applying approaches based on Equation 48 to problems such as remaining-life predictions for cracked structures. Thus, if cracks are discovered, there will inevitably be questions related to how long the structure may be operated safely if slow SCC continues. According to Parkins [54], many pipelines have approximated to a linear dependency between time and crack velocity. Also, crack coalescence is important and needs to be incorporated into life prediction calculations. However, in stage 2 work hardening dominates with relatively few crack coalescences. In pipeline steel Parkins found [65] that significant coalescence occured in more than $3 \times 10^{4}$ hours in carbonate-bicarbonate solutions, by which time cracks are about 0.46 $\mathrm{mm}$ long and $0.12 \mathrm{~mm}$ deep. This is regarded as the end of stage 2 after which crack coalescence becomes the dominant factor.

In stage 3 cracks grow until they reach the size whereby $K_{I S C C}$ is exceeded and the time in that stage will be determined by the number of cracks that coalescence $\left(n_{s}\right)$ and the average lengthwise crack velocity $\left(V_{3}\right)$ as well as the 
crack length required to achieve $K_{I S C C}\left(I_{K_{I S C C}}\right)$. Assuming that each crack grows from both of its ends at the surface:

$$
\text { Time }- \text { in }- \text { stage }-3=\frac{I_{K_{I S C C}}-\left(0.46 n_{0}\right)}{n_{8} .2 . V_{3}}
$$

Calculation of times in Stage 3 for various crack velocities and the number of small cracks coalescing is shown in Figure 9.

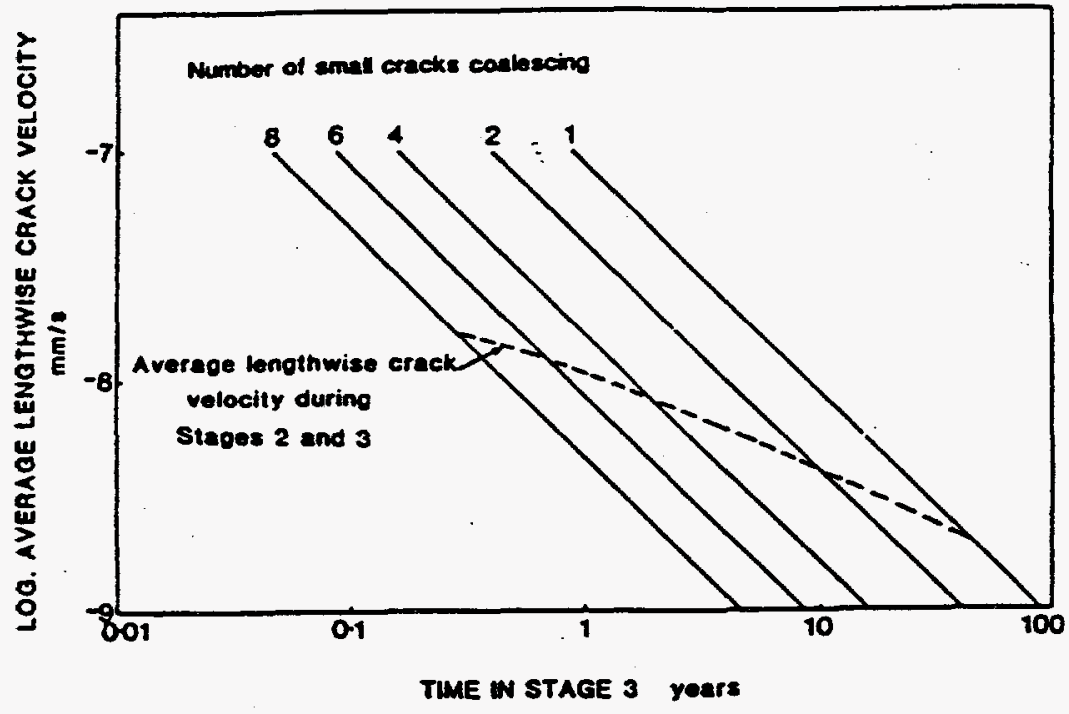

Figure 9: Times required for stress corrosion cracks to reach a length of $6 \mathrm{~mm}$ for various lengthwise growth rates and number of cracks coalescing.

The Figure 9 is indicative that the depth-wise crack velocity in the region of $10^{-\theta} \mathrm{mm} / \mathrm{s}$ at about $3 \times 10^{4} \mathrm{~h}$, the lengthwise growth rate being twice that in the depth direction. Figure 9 also indicates that the time required for a crack to reach $6 \mathrm{~mm}$ length without coalescence is $\mathbf{4 0}$ years. Since joints that have failed have done so from about 6 to 25 years, it appears unlikely that Stage 3 could progress without crack coalescence in such cases. Crack coalescence has been observed in experimental studies which means [54] that such coalescence would reduce the time in Stage 3 by about an order of magnitude, compared a to single crack achieving a length of $6 \mathrm{~mm}$. 
When $K_{I S C C}$ is achieved the crack velocity will increase to the upper bound given by Equation 30 because the crack tip strain rate increases to the point where the crack tip is maintained bare and dissolution can occur continuously. Growth in Stage 4 will occur until the pipe wall is penetrated and a leak occurs, or, if macroscopic crack coalescence occurs, until the critical crack size corresponding to $K_{I C}$ is reached and fast fracture results. The time in Stage 4 can be written as:

$$
\text { Time - in - stage }-4=\frac{I_{K_{I C}}-6 . n_{L}}{n_{L} \cdot 2 . V_{4}}
$$

where $n_{L}$ is the number of large cracks coalescing, $I_{K_{I C}}$ is the crack length for fast fracture and $V_{4}$ is the crack velocity in Stage 4. It has been found [62] that an observed crack length-to-depth ratio of 4 , the wall of the pipe $(8 \mathrm{~mm})$ is penetrated and a leak occurs before the SCC reaches the critical length (140 $\mathrm{mm}$ ) for fast fracture. Also, unless more than about four cracks coalesce, a leak is more likely than fracture and service failures often show about eight relatively large cracks as having coalesced on the fracture surface. As with the coalescence of relatively small cracks in Stage 3, the time in Stage 4 reduces as the number of merged cracks increases.

Thus simple approaches have been used to define the times spent in the various stages of $\mathrm{SCC}$ growth in a pipeline in $\mathrm{Na}_{2} \mathrm{CO}_{3} / \mathrm{NaHCO}$ solution at $75 \mathrm{C}$ and can be extended to $S C C$ of carbon steel due to High Level Wastes. This information should help, not only to predict the life of carbon steel in such an environment but it also can be used for the judicious selection of new steel for the primary liner of future High Level Waste tanks.

However, no adequate approach to assessing the time spent in Stage 1 exists. Clearly, it is Stage 3, with the critical role for the number of cracks coalescing, that determines whether the time to a leak or rupture is long or short. Stage 4 , with its relatively high crack velocity, will usually be of a short duration, even for markedly differing number of cracks coalescing in that stage. Crack coalescence is important and is mechanics related i.e. related to the rate of coalescence [62] and more studies need to be done to obtain conditions under which crack coalescence will or will not occur. With such studies, engineering design will be more stress-related and more realistic approaches to crack growth rate measurements will be used for remaining-life predictions.

\subsubsection{Hydrogen Embrittlement}

The hydrogen embrittlement of carbon steels is a very important mode of SCC [66-69]. Parkins [54] has emphasized that in many systems including carbon steels in nitrate, hydroxide and carbonate/bicarbonate, the crack growth 
mechanism involves dissolution and film rupture. However, when hydrogen related phenomena occur the resulting disruption of films allows hydrogen entry into the metal and transportation of hydrogen into the metal lattice. Furthermore, hydrogen embrittlement of carbon steels is a common phenomenon. Modeling work culminating in corrosion-rate and life-prediction assessments of High-Level Waste tanks must incorporate this important mode of failure.

To formalize and quantify the understanding of environment-assisted crack growth, modeling of crack growth under sustained loading has been developed [70-73]. The models are based upon the premise that crack growth results from embrittlement by hydrogen and that this embrittlement is rapid relative to the preceding processes of hydrogen absorption. The rate of crack growth is dependent, therefore, either on the rate of hydrogen production at the newly created crack surfaces, or upon the rate of diffusion of hydrogen to the embrittlement region. Processes that inhibit hydrogen production at the crack surfaces are expected to reduce embrittlement susceptibility. The models predict the pressure and temperature dependence for crack growth, and provide upper bound estimates of crack growth rates. Because they do not explicitly contain any metallurgical parameters, they cannot provide estimates of absolute growth rates for a given alloy.

Because of the high rates of surface reaction, the newly created crack surfaces act as an effective 'sink' and can significantly reduce pressure at the crack tip (ie., as much as four orders of magnitude) [70,71]. At sufficiently low pressures, the net rate of reaction depends on the rate of transport of gases to the crack tip. Using molecular or Knudsen flow to model gas phase transport [150], the upper bound for the rate of crack growth can be obtained simply from a balance between the rate of supply (transport) and the rate of consumption (surface reaction) for the aggressive environment. Crack growth rate, according to this model, is proportional to the external pressure, and inversely proportional to the square-root of the absolute temperature; namely,

$$
\left(\frac{d a}{d t}\right)_{I I} \propto p_{0} / \sqrt{T}
$$

where $p_{0}$ and $T$ are the external pressure and temperature, respectively. The model has been able to adequately describe the crack growth rate for AISI 4340 steel tested in hydrogen sulfide at $0.133 \mathrm{kPa}$ at the room temperature [70].

At higher pressures, both gas phase transport and surface reactions are sufficiently fast to maintain an adequate supply of hydrogen; crack growth rate then is determined by the rate of hydrogen diffusion into a region ahead of the crack tip. On the basis of a model for hydrogen diffusion into a small region at the crack tip, which itself is contained within the crack-tip plastic zone, crack 
growth has been shown to be proportional to the square root of diffusivity (D) and pressure [151] as:

$$
\left(\frac{d a}{d t}\right)_{I I} \propto \sqrt{p_{0} D}=\sqrt{p_{0} D_{0}} \exp \left(-\frac{E_{D}}{2 R T}\right)
$$

The apparent activation energy for crack growth, therefore, would be equal to one-half that for diffusion $\left(E_{D}\right)$. Comparison between the activation energy for crack growth in $\mathrm{H}_{2} S$ at $2.66 \mathrm{kPa}$ with that for more reliable diffusion data shows the expected relationship.

When the surface reactions are relatively slow, the pressure at the crack tip is essentially equal to the external pressure [72]. Since the rate of crack growth is proportional to the rate of production of hydrogen at the crack surfaces, for a first order reaction the growth rate would be proportional to pressure and to the reaction rate constant. The Stage II growth rates would exhibit a temperature dependence (with an activation energy) identical to that of the surface reaction process $[72,73]$.

$$
\left(\frac{d a}{d t}\right)_{I I} \propto p_{0} k_{c} \propto p_{0} \exp \left(-\frac{E s}{R T}\right)
$$

where $k_{c}$ and $E$, are the reaction rate constant and activation energy for the appropriate surface reaction, respectively. Correlation of activation energies for crack growth and for surface reactions, for water and hydrogen, is based on this consideration $[72,73]$.

\subsubsection{Effect of Gamma Radiation}

For many years it has been known that the interaction of aqueous solutions by gamma radiation produces ionic, free radical, and molecular products including $\mathrm{H} \cdot, \mathrm{OH}, \mathrm{e}_{\mathrm{aq}}^{-}, \mathrm{H}_{3} \mathrm{O}^{+}, \mathrm{OH}^{-}, \mathrm{H}_{2}, \mathrm{H}_{2} \mathrm{O}_{2}, \mathrm{O}_{2}, \mathrm{O}_{2}^{-}$, and $\mathrm{HO}_{2}[74,75]$. Species such as $e_{a q}^{-}, \vec{H} \cdot$ and $\mathrm{H}_{2}$ can act as reducing agents, while others such as $\mathrm{H}_{2} \mathrm{O}_{2}$, . $\mathrm{OH}, \mathrm{O}_{2}, \mathrm{O}_{2}^{-}$and $\mathrm{HO}_{2}$ can act as oxidizers. As a result of the production of such species under gamma irradiation, there may be alterations in the rates or mechanisms of corrosion attack modes. Particularly, in the case of reaction of water with gamma radiation the "primary products" of water radiolysis are considered to be $\mathrm{H}^{+}, \mathrm{OH}^{-}, e_{a q}^{-}, \mathrm{HO}_{2}, \mathrm{H}_{2} \mathrm{O}_{2}$, and $\mathrm{H}_{2}$, where the first four are called the radical products, and the last two are the molecular products. The radical products are very chemically reactive, reacting with the molecular products or with dissolved solutes in the water, if present. If oxygen is dissolved in the water, both $\mathrm{H}$ and $e_{a q}^{-}$react with it rapidly to form $\mathrm{HO}_{2}$ and $\mathrm{O}_{2}^{-}$, respectively. At a $\mathrm{pH}$ near neutral, the $\mathrm{HO}_{2}$ ionizes rapidly to form $\mathrm{H}^{+}$and

$\mathrm{O}_{2}^{-}$. The result of all these reactions is that in irradiated oxygenated water, 
steady-state concentrations of the oxidizing species $\mathrm{OH}, \mathrm{O}_{2}^{-}$, and $\mathrm{H}_{2} \mathrm{O}_{2}$ are present. There is also a low steady-state concentration of $\mathrm{H}_{2}$.

Corrosion studies involving mild steels in irradiated solutions have been reported in a number of papers [79-82]. Marsh and his coworkers [79] have reported studies on the influence of $\gamma$-irradiation on carbon steel corrosion in synthetic granite groundwater. Dose rates of $1-1.5 \times 10^{5}, 3.5 \times 10_{3}$ and $3 \times 10^{2}$ Rads/h were selected. Whereas unirradiated samples showed a general corrosion less than $\approx 6 \mu \mathrm{m} / \mathrm{yr}$, the irradiated tests showed appreciable acceleration in the rate of corrosion with the weight loss measurements indicating corrosion rates exceeding $100 \mu \mathrm{m} / \mathrm{yr}$ in some tests at high dosage rates.

It has been suggested that in high dose rate tests, there was a low yield of principal oxidizing products like $\mathrm{H}_{2} \mathrm{O}_{2}$ and $\mathrm{OH}$. However in low dose rate tests there is a higher yield of $\mathrm{H}_{2} \mathrm{O}_{2}$ and $\mathrm{OH}$ resulting in localized corrosion developed by differential oxygen cells which cause local acidity and corrosion in addition to that induced directly by the oxidizing radiolysis products. Furthermore, these oxidizing radiolysis products can cause a change in the morphology of the surface film on the specimens thereby reducing the protective properties of the film and causing degradation of the tank wall. Such a mechanism was suggested in order to account for the detrimental effect of oxygen in carbon steel tanks filled with synthetic granite groundwater which was maintained oxygenated by passing $\mathrm{CO}_{2}$-free air through the gas space at the top of the tank at temperatures in the range 25-90C [79]. Similar trends (nonirradiated versus irradiated specimens) were observed on carbon steels recently [80] particularly at $250 \mathrm{C}$ in a moist air environment that simulated the repository preclosure condition. For tests conducted at $10,000 \mathrm{Rad} / \mathrm{hr}, 1,000 \mathrm{Rad} / \mathrm{hr}$ and, $100 \mathrm{Rad} / \mathrm{hr}$, the corrosion rates were lower at the lower dosage rates, but were significantly higher at $100 \mathrm{Rad} / \mathrm{hr}$ compared to the case without irradiation. However, no corrosion was observed at $150 \mathrm{C}$ for the irradiated steels possibly due to the formation of corrosion product which is more resistant at this temperature.

Intergranular corrosion (IGC) of mild steel has been observed only in the low-temperature $(\approx 25 \mathrm{C})$, high-intensity $(0.3 \mathrm{MR} / \mathrm{hr})$ studies $[83,84]$. It is suggested that [84], IGC of mild steel has been found to be significant when the concentration of one or more water-radiolysis products (eg. $\mathrm{H}_{2} \mathrm{O}_{2}, \mathrm{H}, \mathrm{OH}$ ) attains a critical value in the vicinity of the metal-solution interface. The rates at which the water-radiolysis primary products are formed are proportional to the radiation dose rate, but the rates at which these products recombine and interact with other radiolytic species are temperature-dependent; ie. they increase as the temperature increases. Thus, the critical concentration of the radiolytic species required to initiate significant IGC would be attained at high 
dose rates and low temperature. A hypothesis consistent with previous results [79-83] was suggested. Such a hypothesis based on water-radiolysis products is consistent with results reported earlier [79-82].

The obvious implication is that each of the models of localized corrosion must include equations for the mass transport, homogeneous reaction, and electrochemical reaction of each radiolytic species when considering the influence of radiolysis. However, corrosion tests [81] on ASTM A-537 Class I and ASTM A-516 have not shown appreciable effects on corrosion rates performed with simulated wastes of the types DSS, Future Purex and, HFW particularly at $\gamma$-radiation levels of $<1000 \mathrm{Rad} / \mathrm{hr}$ similar to the levels expected to be at tank walls at the Hanford Site.

\section{SUMMARY AND CONCLUSIONS}

1. The literature related to models for predicting failure rates of High Level Waste tanks from corrosion data has been reviewed.

2. Models that predict some aspects of corrosion rate, temperature dependence or rate dependence upon solution composition have been developed for the following phenomena:

(a) Vapor phase corrosion.

(b) Liquid phase corrosion.

(c) Localized corrosion.

(d) Stress corrosion cracking.

(e) Hydrogen embrittlement.

3. The models described are simple and relate to the following phenomena:

(a) Vapor Phase Corrosion: A model by Wagner [17-19] relates the corrosion rate to the $\mathrm{pH}$ and concentration of gas phase constituents. The model is the most applied and has the best verification of experimental data for the vapor phase corrosion of a large number of alloy systems including steels.

(b) Liquid Phase Pitting Corrosion: The following general analytical models have been proposed for pit initiation:

* Halide Nuclei Theory $[25,26]$.

* Point Defect Model [29, 30]. 
The model that explains the pit formation by chloride in terms of pitting potential, temperature and chloride concentration at defects is the Halide Nuclei Theory $[25,26]$. It has found application in several systems.

The following general analytical models have been proposed:

* Pit Growth Limited by Salt Film [34].

(c) Propagation of Stress Corrosion Cracks: The following models have been proposed for propagation of stress corrosion cracks:

* Propagation Controlled by Ion Transport And Anodic Dissolution [39].

* Film Fracture at the Crack Tip [42-45, 47, 53, 55, 56, 62].

Models based on film fracture at the crack tip are undoubtedly the most popular and have been successfully applied to several systems.

4. The following models appear to have some potential applicability to the corrosion of carbon steel waste tanks:

(a) Halide Nuclei Theory for Pit Initiation: Given input data on $\mathrm{pH}$, chloride concentration, and temperature, this model can be used to predict pitting rates in carbon steel.

(b) Pit Growth by Salt Film: Given input data on diffusivity and saturation concentration of the oxide $\left(\mathrm{Fe}_{3} \mathrm{O}_{4}\right)$ in the electrolyte, initial radius of the pit, atomic weight and density of the metal undergoing dissolution, this one-dimensional model can be used in to predict the pit growth rates in carbon steel.

(c) Stress Corrosion Cracking by Film Fracture at Crack Tip: The mechanism has been used to model the nitrate stress corrosion cracking in High Level waste tanks. Initial studies were made on A 285 B, A 516-70 and A 537 Class I type ferritic steels [42-45] with reasonable success. Lately, models developed by Andresen and Ford [55, 56] relating crack growth rate to the crack tip strain rate have been succesfully applied to Light Water Reactor (LWR) environments. The model can be used also to model the crack growth rates in carbon steels due to High Level Waste tanks. Given the oxide film fracture strain, oxidation charge density between rupture events, density and oxidation state of the metal involved in the film, and crack tip strain rate, it is possible to obtain the value for crack growth rate.

4. The following general deficiencies can be identified for a majority of the models: 
(a) They are primarily designed to be used in laboratory corrosion studies where precise identification of input parameters can be made. These parameters are not generally well established in field studies.

(b) Electrical potential gradients must be known which are rarely available in field corrosion measurements.

(c) Hydrogen embrittlement, an important corrosion process, is generally ignored in most of the corrosion models.

(d) The concentrations of radiolysis products should be known.

(e) Parameters in corrosion models need to be quantified where needed.

(f) Statistical techniques should be introduced into models.

5. The above analytical models, including a model for hydrogen embrittlement, should be taken into consideration to predict accurately the remaining life of the High Level Waste tanks.

\section{REFERENCES}

1. Progress Report, Separation Development Division, Metallurgical report, CN-1316, Clinton Laboratories, March 10, 1944.

2. Environmental Standards for the Management and Disposal of Spent Nuclear Fuel, High-Level and Transuranic Radioactive Wastes, 40 CFR Part 191, Environmental Protection Agency, Federal Register, Rules and Regulations, Volume 50, No. 192, page 38066 (1985)

3. R. M. Girder, Leaks in Radioactive Waste Tanks, Report, DP-990, E. I. DuPont de Nemours \& Co., Savannah River Laboratory, Aiken, SC (1965).

4. J. C. Womack and D. J. Larkin, Investigation and Evaluation of 102-BX Tank Leak, Report, ARH-2035, Atlantic Richfield Hanford Company, Richland, WA (1971).

5. D. C. Lini, Compilation of Hanford Corrosion Studies, Report, ARHST-111, Atlantic Richfield Hanford Company, WA (1975).

6. R. F. Maness, Stress corrosion cracking of mild steel in nitrate solutions, Report, HW-78168, General Electric Company (1968).

7. E. L. Moore, Stress corrosion cracking of A 515 Grade carbon steel, Atlantic Richfield Hanford Company, Richland, WA (1971). 
8. R. S. Ondrejcin, Investigation of cooling coil corrosion in radioactive waste storage tanks, Report, DP-1425, E. I. DuPont de Nemours \& Co., Savannah River Laboratory, Aiken, SC (1965).

9. J. W. Congdon, Inhibition of nuclear waste solutions containing multiple aggressive anions, Report, DP-MS-87-85 (1987).

10. R. S. Ondrejcin, S. P. Rideout and J. A. Donovan, Control of stress corrosion cracking in storage tanks containing radioactive wastes, Nuclear Technology, Vol. 44, page 247 (1979).

11. M. L. Holzworth, R. M. Girder and L. P. Costas, How to prevent stress corrosion cracking of radioactive waste tanks, Materials Protection, Vol. 7 , page 26 (1968).

12. R. S. Ondrejcin, Stress corrosion cracking test with slow strain rate and constant current, ASTM STP 665, American Society for Testing and Materials, page 203 (1979).

13. R. S. Ondrejcin, Prediction of stress corrosion of carbon steel by nuclear process liquid wastes, Report, DP-1478, E. I. DuPont de Nemours \& Co., Savannah Research Laboratory, Aiken, SC (1978).

14. J. A. Donovan, Materials aspects of SRP waste storage - corrosion and mechanical failure, Report, DP-1476, E. I. DuPont de Nemours \& Co., Savannah River Laboratory, Aiken, SC (1977).

15. R. S. Ondrejcin, Prevention of stress-corrosion cracking in nuclear waste storage tanks, Report, DP-MS-83-79, Savannah River Laboratory, Aiken, SC (1984).

16. N. Pilling and R. Bedworth, J. Inst. Metals., Vol.29, page 534 (1923).

17. C. Wagner, Z. Phys. Chem., Vol. B21, page 25 (1933).

18. C. Wagner, in Atom Movements, American Society for Metals, Metals Park, Ohio, page 153 (1951).

19. C. Wagner, Prog. Solid-State Chem., Vol 10, page 3 (1975).

20. G. J. Yurek, J. P. Hirth, and R. A. Rapp, in Corrosion Mecharisms, ed. F. Mansfeld, Marcel Decker Inc., New York, NY, page 397 (1987).

21. S. R. Shatynski, R. A. Rapp, and J. P. Hirth , Acta Met., Vol. 24, page 1071 (1976). 
22. M. G. Fontana and N. D. Green, Corrosion Engineering, McGraw-Hill Book Company, New York, NY (1978).

23. H. H. Uhlig and R. W. Revie, Corrosion and Corrosion Control, John Wiley \& Sons, New York, NY (1985).

24. T. Okada, J. Electrochem. Soc., Vol. 131 (2), page 124 (1984).

25. T. Okada, Proc. International Symposium honoring Prof. Marcel Pourbiax on his 80th Birthday: equilibrium diagrams and localized corrosion, editors R. P. Frankenthal and J. Kruger, Vol.84-9, page 402 (1984).

26. H. J. Engell and N. D. Stolica, Z. Phys. Chem., Vol. 20, page 113 (1959).

27. M. Janik-Czachor, J. Electrochem. Soc., Vol. 128(12), page 513C-519C, page (1981).

28. G. Matamala, Corrosion, Vol. 43(2), page 97 (1987).

29. C. Y. Chao, L. F. Lin, and D. D. Macdonald, J. Electrochem. Soc., Vol. 128, page 1187 (1981).

30. L. F. Lin, C. Y. Chao, D. D. Macdonald, J. Electrochem. Soc., Vol. 128, page 1194 (1981).

31. K. E. Heusler and L. Fischer, Werkst. Korros., Vol. 27, page 551 (1976).

32. T. Shibata and T. Takeyama, Corrosion, Vol. 33 (7), page 243 (1977).

33. G. P. Marsh, K. J. Taylor and Z. Sooi, The kinetics of pitting corrosion of carbon steel, Swedish Nuclear Fuel and Waste Management Company, Box 5864, S-102 48 Stokholm, Sweden, SKB Technical Report, 88-09 (1988).

34. T. R. Beck and R. C. Aikire, J. Electrochem. Soc., Vol. 126, page 1662 (1979).

35. H. W. Pickering and P. R. Frankenthal, J. Electrochem. Soc., Vol. 119, page 1297 (1972).

36. J. R. Galvele, J. Electrochem. Soc., Vol. 123, page 464 (1976).

37. O. Buck and R. Ranjan, in Modeling environmental Effects on Crack Growth Processes, eds. R. H. Jones and W. W. Gerberich (The Metallurgical Society), page 209 (1986). 
38. C. J. McMahon, Jr., in Hydrogen Effects in Metals, Eds. I. M. Bernstein and A. W. Thompson, The Metallurgical Society of AIME, Warrendale, PA, page 219 (1981).

39. A. Turnbull and J. G. N. Thomas, J. Electrochem. Soc., Vol. 129, page 1412 (1982).

40. R. H. Jones, M. J. Danielson and C. A. Oster, Modeling of environmental effects on crack growth, Symp. Proc., Metallurgical Society, Warrendale, PA, page 41 (1986).

41. J. S. Newman, Transport in infinitely dilute solutions, in: Electrochemical Systems (Prentice-Hall, Englewood, Cliffs, NJ), page 217 (1973).

42. J. R. Devine, W. M. Bowen, S. A. McPartland, R. P. Elmore and, D. W. Engel, Double-Shell-Slurry Low-Temperature Corrosion Tests, Report, PNL-427, Pacific Northwest Laboratory, Richland, WA (1983).

43. J. R. Devine and W. M. Bowen, Corrosion of Carbon Steel in Oxidizing Caustic Solutions, Report, PNL-SA-11667, Pacific Northwest Laboratory, Richland, WA (1983).

44. D. B. Mackey and J. R. Devine, User's Guide for Waste Tank Corrosion Data Model Code, Report, PNL-5766, Pacific Northwest Laboratory, Richland, WA (1986).

45. J. R. Devine, W. M. Bowen, D. B. Mackey, D. J. Bates and, K. H. Pool, Prediction Equations for Corrosion Rates of A 537 and a 516 Steels in Double Shell Slurry, Future Pyrex and, Hanford Facilities Wastes, Report, PNL-5488, Pacific Northwest Laboratory, Richland WA (1985).

46. W. H. Ailor, Handbook of Corrosion Testing, John Wiley \& Sons, New York, NY, page 250 (1971).

47. P. Doig and P. E. J. Flewitt, in Embrittlement by the Localized Crack Environment, Ed. R. P. Gangloff, The Metallurgical Society of AIME, Warrendale, PA, page 305 (1985).

48. F.P. Ford, in Understanding Micromechanisms of Fracture, Gordon Conference, New Hampshire, USA (1975).

49. T. P. Hoar and R. W. Jones, Corrosion Science, Volume 13, page 725 (1973).

50. J. C. Scully, Corrosion Science, Volume 15, page 207 (1975). 
51. J. R. Ambrose and J. Kruger, J. Electrochem. Soc., Volume 120, page 59(1974).

52. J. C. Scully, Stress Corrosion Cracking, in Treatise on Materials Science and Technology, Academic Press, NY, page 103 (1983).

53. P. Doig and P. E. J. Flewitt, An Analytical Description of Stress Crack Growth by Anodic Dissolution, in Embrittlement and Localized Crack Environment, ed., R. P. Gangloff, page 305 (1984).

54. J. F. Knott, Fundamentals of Fracture Mechanics, Butterworths, London, page 89 (1973).

55. P. L. Andresen, Modeling of water and material chemistry effects on crack tip and resulting crack growth kinetics, in 3rd Int. Conf. Degradation of Materials in Nuclear power Industry, Traverse City, MI, August 31-September 4 (1987).

56. F. P. Ford, Current understanding of mechanisms of stress corrosion and corrosion fatigue, Symp. Environment-Sensitive Fracture: Evaluation and Comparision of Test Methods, Gaithesburg, MD, April 26-28, 1982, eds. S. W. Dean, E. N. Pugh, G. M. Ugiansky, Am. Soc. Test. \& Mater., ASTM STP 821, Philadelphia, PA, page 32-51 (1982) .

57. F. P. Ford, D. F. Taylor, P. L. Andresen, and R. G. Ballinger, Environmentally Controlled Cracking of Stainless and Low Alloy Steels in Light Water Reactor Environments, EPRI NP -5064M (RP2006-6) (1987).

58. F. P. Ford and P. L. Andresen, Development and Use of Predictive Model of Crack propagation in 304/316L, A593B/A508, and Inconel 600/182 Alloysin 288C Water, Proc., Third Inter. Symposium on "Environmental Degradation of Materials in Nuclear power Systems - Water Reactors", Traverse City, MI, Aug 1987, TMS-AIME, 1988.

59. R. W. Staehle, Stress Corrosion Cracking and Hydrogen Embrittlement of Iron Base Alloys, R. W. Staehle et. al. eds., NACE-5, NACE, Houston, page 193 (1970).

60. H. H. Uhlig, Physical Metallurgy of Stress Corrosion Fracture, T. N. Rhodin ed., Interscience, page 1 (1959).

61. J. O'M. Bockris, Stress Corrosion Cracking and Hydrogen Embrittlement in Iron Base Alloys, R. W. Staehle et. al. eds., NACE-5, NACE, Houston, TX page 177 (1977).

62. R. N. Parkins, Corrosion, Vol. 46, page 178 (1990). 
63. R. N. Parkins, G. P. Marsh, and J. T. Evans, in Predictive Methods for Assessing Corrosion Damage to BWR Piping and PWR Steam Generators, eds. H. Okada and R. W. Staehle, NACE, Houston, TX, page 249 (1982).

64. D. P. G. Lidbury, in Embrittlement by the Localized Crack environment, Ed. R. P. Gangloff, AIME, New York, NY, page 149 (1983).

65. R. N. Parkins, Corrosion, Vol. 43, page 130 (1987).

66. C. S. Carter and M. V. Rideout, in Stress Corrosion Cracking and Bydrogen Embrittlement of Iron Base Alloys, eds. R. W. Staehle, J. Hochmann, R. D. McCright, and J. E. Slater, Unieux, France, page 524 (1973).

67. B. Poulson, Corrosion Sci., Vol. 15, page 469 (1975).

68. M. O. Speidel, in Advances in Fracture Research, Proc. 5th International Conference on Fracture (ICF5), Cannes, France, page 2685 (1981).

69. A. W. Thompson, in Environment-Sensitive Fracture of Engineered Materials, Z. A. Foroulis, ed. The Metallurgical Society of AIME, Warrendale, PA, page 379 (1979).

70. N. H. Chan, K. Klier, and R. P. Wei, Scripta Met., Vol. 12, page 1043 (1978).

71. M. Lu, P. S. Pao, T. W. Weir, G. W. Simmons, and R. P. Wei, Met. Trans., Vol. 12A, page 805 (1981).

72. T. W. Weir, G. W. Weir, R. G. Hart, and R. P. Wei, Scripta Met., Vol. 14, page 357 (1980).

73. M. Lu, P. S. Pao, N. H. Chan, K. Klier, and R. P. Wei, in Hydrogen in Metals, Suppl. to Trans. Japan Inst. Metals, Vol. 21, page 449 (1980).

74. A. O. Allen, The radiation of Water and aqueous Solutions, D. Van Nostrand and Co., Princeton, N. J. (1961).

75. J. W. T. Spinks and R. J. Woods, An Introduction to Radiation Chemistry, 2nd edition, John Wiley, New York (1976).

76. G. P. Marsh, K. J. Taylor, G. Bryan and S. E. Worthington, The influence of radiation on the corrosion of stainless steel, Corros. Sci. Vol. 26, page 971(1986). 
77. Y. J. Kim and R. A. Oriani, Brine radiolysis and its effect on the corrosion of grade-12 titanium, Corrosion, Vol. 43, page 92 (1987).

78. R. S. Glass, R. A. Van Konynenburg and G. E. Overturf, Corrosion processes of austenitic stainless steels and copper-based materials in gammairradiated aqueous environments, CORROSION/86, Paper No. 258, NACE, Houston, TX (1986).

79. G. P. Marsh, I. D. Bland, K. J. Taylor, S. Sharland and P. Tasker, An assessment of carbon steel overpacks for radioactive waste disposal, Report EUR 10437EN, (1986).

80. R. P. Anantatmula and R. P. Colburn, Irradiation corrosion of waste package container materials in air/steam environment, Report DE-AC0687RL10930, Westinghouse Hanford Company (1991).

81. R. P. Anantatmula and R. P. Colburn, CORROSION/92, Paper No. 72, NACE, Houston, TX (1992).

82. M. A. Molecke, J. A. Ruppen and R. B. Diegle, Materials for High-Level Waste Cannister/Overpacks in salt formations, Nuclear Technology, Vol. 63, page 476 (1983).

83. R. J. Reda, S. Akers and, J. L. Kelly, Trans. ANS, Vol. 53, page 224 (1986).

84. R. J. Reda, S. L. A. Hana and, J. L. Kelly, Corrosion, Vol. 44, page 632 (1988). 